\title{
Versuche zur Strukturaufklärung bakterieller Thiouridin Synthetasen
}

\author{
Dissertation \\ zur Erlangung des Doktorgrades \\ der Mathematisch-Naturwissenschaftlichen Fakultäten \\ der Georg-August-Universität zu Göttingen
}

vorgelegt von

Peter-Thomas Naumann

aus Trier

Göttingen 2005 
D7

Referent:

Prof. Dr. Ralf Ficner

Korreferent:

PD. Dr. Michael Hoppert

Tag der mündlichen Prüfung:

18.01.2006 
Meinen Eltern 
"Und wenn du noch so oft an ihre Türen klopfst, die Natur wird nie erschöpfend Auskunft geben."

Iwan S. Turgenjew, Aufzeichnungen eines Jägers 


\section{Inhaltsverzeichnis}

1. Einleitung 1

1.1 RNA 1

1.2 Katalytische RNA (Ribozyme) 2

1.3 RNA Welt 3

1.4 Formen von RNA 4

1.5 Struktur von tRNA 4

$\begin{array}{lll}1.6 & \text { Modifikationen von tRNA }\end{array}$

1.7 Thionukleoside 8

1.7.1 2-Thiouridin 8

$\begin{array}{lll}1.7 .2 & \text { 4-Thiouridin } & 10\end{array}$

1.8 Thil - Biosynthese von Thiamin 12

1.9 Thermophile Proteine 14

1.10 Thermotoga maritima 15

$\begin{array}{lll}1.11 & \text { Zielsetzung } & 16\end{array}$

2. Material und Methoden 17

2.1 Organismen, Plasmide und Primer 17

$2.2 \quad$ Nährmedien und Zellanzucht 19

2.2.1 Zellanzucht von E. coli 19

2.2.2 Stammkulturen 20

2.2.3 Reinheitskontrolle 20

$\begin{array}{lll}2.2 .4 & \text { Bestimmung von Wachstumsparameter } & 20\end{array}$

2.3 Standardtechniken für die Arbeit mit Nukleinsäuren 21

2.3.1 Behandlung von Geräten und Lösungen 21

2.3.2 Reinheitskontrolle und Konzentrationsbest.

von Nukleinsäuren 21

2.3.3 Fällung und Konzentrierung von Nukleinsäuren 21

$2.4 \quad$ Polymerasekettenreaktion, PCR 22

2.4.1 Isolierung von Genom-DNA aus Thermotoga maritima 23

2.4.2 Reinigung von PCR-Fragmenten 24

$2.5 \quad$ Analytische Plasmidisolierung (MiniPrep) 24 
2.6 Präparative Plasmidisolierung (MidiPrep) 25

2.7 Gelelektrophorese von Nukleinsäuren 26

2.7.1 Standard Agarose-Gelelektrophorese 26

2.7.2 Färbung und Dokumentation von Agarosegelen 26

2.7.3 Größenstandards für Nukleinsäuren 27

$\begin{array}{lll}2.7 .4 & \text { Isolierung von DNA-Fragmenten aus Agarosegelen } 27\end{array}$

$2.8 \quad$ Restriktionsspaltung von DNA 27

2.9 Ligation von DNA-Fragmenten 28

2.10 DNA-Sequenzierungen 28

2.10.1 Analyse von Sequenzdaten 28

2.11 Transformation und Selektion rekombinanter Klone 29

2.11.1 Präparation kompetenter Zellen 29

2.11.2 Transformation durch Hitzeschock 29

2.11.3 Selektion von Transformanten 30

$\begin{array}{lll}2.12 & \mathbf{3 0}\end{array}$

2.12.1.1 Expression im analytischen Maßstab 30

2.12.1.2 Expression im präparativen Maßstab 31

2.12.1.3 Expression von Selenomethionin-enthaltenen

2.12.1.4 Zellaufschluss 32

2.13 Diskontinuierliche SDS-Polyacrylamidgelektrophorese nach Laemmli (1970) 33

2.13.1 Färbung von SDS-Gelen 34

2.13.1.1 Färbung von Proteingelen 34

2.13.1.2 Färbung von Protein-RNA-Komplexgelen (STAINS ALL) 35

2.13.2 Größenstandards für SDS-Gele 36

2.13.3 Proteinbestimmung nach Bradford (1976) 36

$\begin{array}{lll}2.13 .4 & \text { Proteinsequenzierung } & 37\end{array}$

$\begin{array}{lll}2.14 & \text { Proteinaufreinigung } & 37\end{array}$

$\begin{array}{lll}\text { 2.14.1 Aufreinigung durch Hitzeschock } & 37\end{array}$

$\begin{array}{lll}2.14 .2 & \text { Anionenaustauschchromatographie } & 37\end{array}$

2.14.3 Gelfiltrationschromatographie 38

2.14.4 Hydrophobe Interaktionschromatographie (HIC) 39

$\begin{array}{lll}2.14 .5 & \text { Affinitätschromatographie }\end{array}$ 
2.14.6 Spaltung mit PreScission ${ }^{\mathrm{TM}}$-Protease 41

$\begin{array}{lll}\text { 2.14.7 Konzentrierung von Proteinen } & 41\end{array}$

2.14.8 Spektrum zur Kontrolle auf unspezifische Aggregation 42

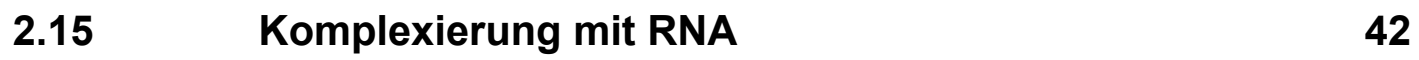

$2.16 \quad$ Kristallisation von Proteinen 43

2.16.1 Kristallisation im sitting drop Verfahren 43

2.16.2 Cryopuffer 44

$\begin{array}{lll}2.17 & \text { Phasenproblem } & 44\end{array}$

2.17.1 Selenomethionin 45

2.17.2 Schwermetallsoaks 45

$2.18 \quad$ Free Mounting System 46

2.19 Datensammlung 47

2.19.1 Montieren der Proben 47

$\begin{array}{lll}2.19 .2 & \text { Datensammlung Drehanode } & 47\end{array}$

2.19.3 Datensammlung Synchrotron 48

$2.20 \quad$ Datenprozessierung 48

2.21 Chemikalien, Biochemikalien und Enzyme 49

3. Ergebnisse $\quad 50$

3.1 Expression und Aufreinigung von Thil und MnmA aus Escherichia coli $\quad 50$

3.1.1.1 Expression und Aufreinigung von Thil aus

E. coli durch Anionenaustauschchromatographie 50

3.1.1.2 Weitere Anreicherung von Thil aus E. coli durch Hydrophobe Interaktionschromatographie (HIC) 54

3.1.1.3 Letzter Reinigungschritt von Thil aus E. coli durch Gelfiltration 56

3.1.2.1 Expression und Aufreinigung von MnmA aus E. coli durch Anionenaustauschchromatographie 58

3.1.2.2 Weitere Anreicherung von MnmA aus E. coli durch Hydrophobe Interaktions Chromatographie (HIC) 63

3.1.2.3 Letzter Reinigungsschritt von MnmA durch Gelfiltration 65

3.1.3 Kristallisationsversuche von Thil und MnmA aus E. coli 67 
3.2.1.1 Expression von Thil aus T. maritima

3.2.1.2 Reinigung von Thil aus T. maritima durch Hitzeschock

3.2.1.3 Reinigung von Thil aus T. maritima durch Anionenaustauschchromatographie (DEAE)

3.2.1.4 Gelfiltration von Thil aus T. maritima 76

3.2.1.5 Untersuchung des Thil auf unspezifische Aggregation 79 Alternative Aufreinigung von Selenomethionin enthaltendem Thil ohne Hitzeschock

3.2.2.1 Induktion und Anionenaustauschchromatographie von Se-Thil

3.2.2.2 Weitere Reinigung des Se-Thil durch

Hydrophobe Interaktionschromatographie (HIC)

3.2.2.3 Letzter Reinigungsschritt von Se-Thil durch Gelfiltration 86

3.2.2.4 Kontrolle der Insertion von Selenomethionin

durch MALDI-TOF

3.2.3 Expression und Reinigung von MnmA aus T. maritima

3.2.4 Expression und Reinigung von Thil und MnmA als MBP-Fusionsproteine

3.2.4.1 Expression und Reinigung von Thil aus

T. maritima als MBP-Fusionsprotein

3.2.4.2 Reinigung des MBP-Thil im „batch“-Verfahren 94

3.2.4.3 Spaltung von MBP-Thil mittels PreScission ${ }^{\mathrm{TM}}$ _Protease 96

Expression und Reinigung von MnmA aus T. maritima

3.3 Kristallisationsversuche von Thil und MnmA aus

T. maritima

3.4 Komplexierung von Thil aus T. maritima mit einer artifiziellen verkürzten tRNA

Gelfiltration von freiem Thil aus T. maritima 
3.7 Röntgenkristallographische Untersuchungen am Thil-RNA-Komplex 117

$\begin{array}{lll}3.7 .1 & 122\end{array}$

$\begin{array}{lll}\text { 3.7.2 Phasierung mit Hilfe von Selenomethionin } & 126\end{array}$

$\begin{array}{lll}3.7 .3 & 129\end{array}$

$\begin{array}{lll}\text { 3.7.4 Phasierung mit Hilfe von Schwermetallsoaks } & 131\end{array}$

$\begin{array}{lll}3.8 & \text { Free Mounting System (FMS) } & 138\end{array}$

$\begin{array}{lll}3.9 & \text { Strukturbestimmung durch Molekularen Ersatz } & 151\end{array}$

4. Diskussion 152

4.1 Thil und MnmA aus E. coli 152

4.2 Thil und MnmA aus T. maritima 155

4.2.1. Klonierung und Reinigung von Thil und MnmA aus

T. maritima als MBP-Fusionsproteine 157

4.2.2 Klonierung und Reinigung von Thil und MnmA ohne „tag“ (pET-System) 157

4.3 Kristallographische Untersuchungen am Thil-RNA-Komplex 158

$\begin{array}{lll}\text { 4.3.1 Kristallographie } & 158\end{array}$

4.3.2 Röntgenkristallographische Untersuchungen und FMS 162

4.3.3 Phasenbestimmung von Thil-RNA-Komplex Kristallen 163

4.3.3.1 Phasierung mit Selenomethionin 163

$\begin{array}{lll}\text { 4.3.3.2 } & \text { Phasierung durch Schwermetallsoaks }\end{array}$

$\begin{array}{lll}4.4 & \text { Ausblick } & 165\end{array}$

$\begin{array}{ll}\text { 5. } & 167\end{array}$

$\begin{array}{ll}\text { 6. Zusammenfassung } & 174\end{array}$

$\begin{array}{ll}\text { 7. Literaturverzeichnis } & 175\end{array}$

8. $\quad 192$ 


\section{Abkürzungsverzeichnis}

\begin{tabular}{|c|c|}
\hline Abb. & Abbildung \\
\hline ad & bis \\
\hline Amp. & Ampicillin \\
\hline APS & Ammoniumpersulfat \\
\hline Aufl. & Auflage \\
\hline $\mathrm{Bp}$ & Basenpaare \\
\hline bzw. & beziehungsweise \\
\hline${ }^{\circ} \mathrm{C}$ & Grad Celsius \\
\hline ca. & circa \\
\hline Cam. & Chloramphenicol \\
\hline $\mathrm{cm}$ & Zentimeter \\
\hline C-terminal & carboxyterminal \\
\hline $\mathrm{Da}$ & Dalton \\
\hline d.h. & das heisst \\
\hline DNA & Desoxyribonukleinsäure \\
\hline DNAse & Desoxyribonuklease \\
\hline dNTP & Desoxyribonukleotid-5'-triphosphat \\
\hline ds & doppelsträngig \\
\hline DTT & Dithiothreitol \\
\hline E. coli & Escherichia coli \\
\hline EDTA & Ethylendiamintetraessigsäure \\
\hline et al. & et alteri \\
\hline Fa. & Firma \\
\hline g & Erdbeschleunigung $(9.81 \mathrm{~m} / \mathrm{s})$; Gramm \\
\hline $\mathrm{h}$ & Stunde \\
\hline Hrsg. & Herausgeber \\
\hline i.A. & im Allgemeinen \\
\hline IPTG & Isopropyl- $\beta-D-$ thiogalactopyranosid \\
\hline $\mathrm{k}$ & kilo \\
\hline Kan. & Kanamycin \\
\hline | & Liter \\
\hline
\end{tabular}




\begin{tabular}{|c|c|}
\hline LB & Luria Bertani \\
\hline $\log$ & dekadischer Logarithmus \\
\hline $\mathrm{m}$ & Meter, milli \\
\hline M & Molar, Molekulargewicht \\
\hline$\mu$ & mikro \\
\hline MAD & multi wavelength anomalous diffraction \\
\hline MALDI & Matrix Assisted Laser Desorption Ionization \\
\hline $\max$ & maximal \\
\hline MCS & Multiple Cloning Site \\
\hline $\min$. & Minute, mindestens \\
\hline MIR & multiple isomorphous replacement \\
\hline mod. & modifiziert \\
\hline mRNA & messenger Ribonukleinsäure \\
\hline mol & Stoffmenge $\left(6,023 \times 10^{23}\right)$ \\
\hline $\mathrm{n}$ & nano \\
\hline N-terminal & aminoterminal \\
\hline o.a. & oben angegeben \\
\hline $\mathrm{OD}_{\mathrm{x}}$ & Optische Dichte bei der Wellenlänge $x$ \\
\hline $\mathrm{OH}$ & Hydroxy- \\
\hline PAGE & Polyacrylamid-Gelelektrophorese \\
\hline PCR & Polymerase-Kettenreaktion \\
\hline $\mathrm{pH}$ & $\begin{array}{l}\text { negativer dekadischer Logarithmus der Protonen- } \\
\text { konzentration }\end{array}$ \\
\hline RNA & Ribonukleinsäure \\
\hline RNAse & Ribonuklease \\
\hline RT & Raumtemperatur \\
\hline s & siehe, Sekunde \\
\hline SAD & single wavelength anomalous dispersion \\
\hline SDS & Natriumdodecylsulfat \\
\hline spez. & spezifisch \\
\hline $\mathrm{t}$ & Zeit \\
\hline $\mathrm{T}$ & Temperatur \\
\hline T. maritima & Thermotoga maritima \\
\hline Tab. & Tabelle \\
\hline
\end{tabular}




$\begin{array}{ll}\text { TBE } & \text { Tris-Borat-EDTA } \\ \text { TEMED } & \text { N,N,N'N'- Tetramethylethyldiamin } \\ T_{m} & \text { mittlere Schmelztemperatur } \\ \text { Tris } & \text { Tris-(hydroxymethyl)-aminomethan } \\ \text { tRNA } & \text { transfer-Ribonukleinsäure } \\ \text { U } & \text { Unit, } \mu \text { mol/min } \\ \text { u.a. } & \text { unter anderem } \\ \text { Upm } & \text { Umdrehungen pro Minute } \\ \text { UV } x x x & \text { Ultraviolette Strahlung der Wellenlänge xxx nm } \\ \text { V } & \text { Volt, Volumen } \\ \text { Vol. } & \text { Volumen } \\ \text { v/v } & \text { Volumen pro Volumen } \\ \text { w/v } & \text { Masse pro Volumen } \\ \text { z.B. } & \text { zum Beispiel } \\ \text { z.T. } & \text { zum Teil }\end{array}$

Einbuchstabencode für Aminosäuren

$\begin{array}{llllll}\text { A } & \text { Alanin } & \text { C } & \text { Cystein } & \text { D } & \text { Asparaginsäure } \\ \text { E } & \text { Glutaminsäure } & \text { F } & \text { Phenylalanin } & \text { G } & \text { Glycin } \\ \text { H } & \text { Histidin } & \text { I } & \text { Isoleucin } & \text { K } & \text { Lysin } \\ \text { L } & \text { Leucin } & \text { M } & \text { Methionin } & \text { N } & \text { Asparagin } \\ \text { P } & \text { Prolin } & \text { Q } & \text { Glutamin } & \text { R } & \text { Arginin } \\ \text { S } & \text { Serin } & \text { T } & \text { Threonin } & \text { V } & \text { Valin } \\ \text { W } & \text { Tryptophan } & \text { Y } & \text { Tyrosin } & & \end{array}$

Einbuchstabencode für Nukleotide
A Arginin
C Cytosin
G Guanin
T Thymin
U Uridin 


\section{Einleitung}

\section{$1.1 \quad$ RNA}

Die Ribonukleinsäuren (RNA) sind eine Gruppe von biologisch relevanten Makromolekülen. Alle bisher bekannten natürlichen RNA-Formen sind entweder in RNA-Prozessierungen oder in die Proteinbiosynthese involviert (Winkler et al., 2004). In diesen Bereichen werden von RNAs diverse Aufgaben z.B. als Informationsträger (mRNA), Adapter (tRNA), Gerüstmoleküle und Katalysatoren (rRNA) übernommen (Henrich, 2004). Im Allgemeinen kann man RNAs als Polymere aus Nukleosid-Phosphaten bezeichnen, die durch Phosphodiesterbindungen verknüpft sind. Die hieran beteiligten Basen sind in erster Linie Adenin, Cytosin, Guanin und Uracil (anstelle des in der DNA verwendeten Thymins). Daneben sind noch verschiedene, z.T. sehr seltene Basen in RNA enthalten, die durch Modifikation der kanonischen Basen generiert werden. Bis heute wurden ca. 100 Basenmodifikationen gefunden (Garcia und Kittendorf, 2005). Deren Synthese erfolgt durch eine Vielzahl unterschiedlicher Reaktionen. Dabei reicht das Spektrum von einfachen chemischen Reaktionen, wie z.B. Methylierung und Thiolierung, bis zu komplexen Reaktionen, in denen, auch durch die Aktivität mehrerer Enzyme, zusätzliche funktionelle Gruppen wie z.B. Dimethylamin (vgl. MnmA, 1.7.1) eingefügt werden.

Während zur Sekundärstrukturbildung der DNA lediglich eine Bindung zwischen je einer Purinbase mit je einer Pyrimidinbase erfolgt (Adenin und Thymin, Cytosin und Guanin), sind zur Ausbildung der Sekundärstruktur in RNAs auch diverse andere Bindungen möglich. Hierzu zählen neben den oben beschriebenen Watson-Crick-Paarungen noch die Wobble-Paarungen zwischen Guanosin und Uridin, Guanosin und Thymidin und Adenosin und Cytosin, reverse Watson-Crick-Paarungen, Hoogsteen-Paarungen und reverse Hoogsteen-Paarungen. Bei diesen „Nicht"-Watson-Crick-Paarungen werden statt - oder zusätzlich zu - den Watson-Crick-Paarungen Wasserstoffbrückenbindungen, ausgebildet. In Folge dessen ist z.B. auch die Bindung von drei Basen untereinander möglich (Basentripel). Zusätzlich 
werden in RNAs vielfach Nukleotide in Schleifen (Loops) angeordnet, wenn so die Möglichkeit besteht, dass die übrigen gegenüberstehenden Nukleotide komplementäre Paare bilden können.

\section{$1.2 \quad$ Katalytische RNA (Ribozyme)}

Mit der Entdeckung der katalytischen Aktivität der Ribonuklease P (GuerrierTakada et al., 1983) wurde eine völlig neue Klasse der Biokatalysatoren entdeckt. Zwar besteht die Ribonuklease $\mathrm{P}$ aus einem Protein- und einem RNA-Anteil, es konnte jedoch gezeigt werden, dass die Katalyse nur durch den RNA-Bestandteil durchgeführt wird (Buck et al., 2005).

RNAs, die eine enzymatische Aktivität besitzen, werden allgemein als Ribozyme bezeichnet. Es konnte nachgewiesen werden, dass die katalytische Aktivität der Ribonuklease $\mathrm{P}$ nicht nur, wie ursprünglich gezeigt, unter hohen $\mathrm{Mg}^{2+}-$ Konzentrationen vorkommt, sondern auch in vitro unter physiologischen $\mathrm{Mg}^{2+}-$ Konzentrationen (Tanaka et al., 2005). Dabei prozessiert die Ribonuklease $P$ Primärtranskripte zu tRNA. Ribozyme wurden in Pro- und Eukaryonten gefunden. $\mathrm{Zu}$ ihnen zählen z.B. die selbstspleißenden Introns, die sich selbstständig aus einem RNAVorläufermolekül herausschneiden (Brock, 2001). Dabei erzeugen sie, wie die Ribonuklease $\mathrm{P}$, durch Hydrolyse ein $3^{`}-\mathrm{OH}-E$ nde und ein $5^{`}-\mathrm{PO}_{4}$-Ende. Andere Beispiele für Ribozyme sind das etwa 40 Nukleotide große „hammerhead“ Ribozym, das Hepatitis $\delta$ Ribozym und das Neurospora VS Ribozym. Diese kleinen Ribozyme erzeugen bei der RNA-Spaltungen eine 5 `-Hydroxy- und eine 2 '3`-Cyclophosphat-Gruppe (Heckman et al., 2005).

Auch die ribozymale Aktivität des erst kürzlich entdeckten bakteriellen Ribozyms glmS katalysiert diese Reaktion. Dieses Ribozym wurde in der 5`non-coding Region des Transkripts des glmS Gens gefunden. Die Aktivität des Ribozyms wird durch Glucosamin-6-Phosphat reguliert, dem Produkt des Enzyms GlmS (Glucosamin-6-Phosphat-Synthase). Es handelt sich also um einen sog. Riboswitch, d.h. diese RNA reguliert ihre Tätigkeit selbstständig durch die Bindung an ein Zielmolekül (Winkler et al., 2004). Ob so ein Einfluss auf die Expression der Glucosamin-6-Phosphat-Synthase besteht, wird diskutiert (Wilkinson und Been, 2005). 
Es können aber auch andere chemische Reaktionen katalysiert werden, wie das Beispiel eines artifiziellen Diels-Alder-Ribozyms zeigt. Dieses katalysiert die Bildung von kovalenten C-C-Bindungen zwischen Anthracen und Maleimid-Derivaten durch eine Diels-Alder Reaktion (Helm et al., 2005).

Sogar das häufigste RNA-Molekül in der Zelle - die rRNA - ist ein Ribozym. Obwohl sie erst durch die Interaktion mit vielen Proteinen zum aktiven Ribosom wird, konnte gezeigt werden, dass bei der Proteinbiosynthese die Bildung der Peptidbindung zwischen den Aminosäuren durch den RNA-Anteil katalysiert wird (Rodnina et al., 2005).

\section{$1.3 \quad$ RNA-Welt}

Die unter 1.2 beschriebenen Eigenschaften der Ribozyme zeigen die Möglichkeit einer Welt auf, in der biologische Prozesse ohne Beteiligung von Enzymen ablaufen. Diese Vision wird als RNA-Welt-Hypothese bezeichnet (Gilbert, 1986) und beschreibt eine Möglichkeit der Genese des Lebens auf der Erde. Da dieses Urmodell noch kein Leben im heutigen Sinne enthält, bezeichnet man es auch als Chemische Evolution (Kawamura et al., 2005). Es geht davon aus, dass sich durch UV-Strahlung und elektrische Entladungen die ersten organischen Moleküle gebildet haben könnten und so auch die RNA entstand. Die Tatsache, dass Ribozyme eigenständig Nukleotide aus Zucker und Stickstoffbasen synthetisieren können (Brock, 2001), zeigt die Möglichkeit auf, dass sich die RNA Moleküle selbst replizierten. Da die RNA selbst einen komplexen Aufbau besitzt, wird die Peptid-Nukleinsäure (PNA) wiederum als Vorläufer der RNA diskutiert (Bohler et al., 1995), zumal gezeigt wurde, dass sich die Bestandteile der PNA leicht aus den Komponenten der angenommenen präbiotischen Welt bilden lassen (Nelson et al., 2000). In der PNA werden die vier kanonischen Basen im Gegensatz zur RNA nicht durch ein Zucker-, sondern durch ein Peptidrückgrat verbunden. Nach dem Wechsel zur RNA erfolgte dann ein spontaner Einschluss in Lipoproteinvesikel, der zur Entstehung der ersten selbstreplizierenden Organismen führte. Da das Spektrum an Katalysen, die von Ribozymen durchgeführt werden, nicht sehr breit ist, wäre der Schritt zur Proteinwelt dann damit zu erklären, dass die Evolution bei Auftreten von komplexeren Organismen die in dieser Hinsicht wesentlich vielseitigeren 
Proteine bevorzugte. Die erforderliche höhere Zuverlässigkeit der Speicherung der genetischen Information lieferte dann die reverse Transkription der RNA in die wesentlich stabilere DNA (Stryer, 1999).

\subsection{Formen von RNA}

RNA kommt in allen rezenten Lebewesen vor, was als ein Hinweis auf ihre Vergangenheit gewertet werden könnte (siehe 1.3). Dabei unterscheidet man mehrere Formen von RNA. Die häufigsten in der Reihenfolge ihres Anteils in der Zelle sind rRNA, tRNA, mRNA und snRNA.

Die ribosomale-RNA (rRNA) stellt in Escherichia coli (E. coli) mit ca $80 \%$ der zelleigenen RNA den größten Anteil (Röhm, 1998). Sie bildet mit mehreren Proteinen die Ribosomen, an denen die Translation von mRNA in ein Protein erfolgt.

Die transfer-RNA (tRNA) ist mit einem Anteil von 10-20\% an der gesamten Zell-RNA die zweithäufigste RNA-Form (Röhm, 1998). Ihre Aufgabe ist der Transport von Aminosäuren zum Ribosom (siehe auch 1.5).

Die dritthäufigste RNA-Form ist mit ca. 5\% die messenger-RNA (mRNA) (Röhm, 1998). Sie übernimmt die Übertragung der genetischen Information zwischen ihrer Lagerstätte, der DNA, und dem Ort der Translation zu Proteinen, den Ribosomen.

Der Anteil der small-nuclear-RNA (snRNA) liegt nur noch bei $<1 \%$. Sie prozessieren in Eukaryoten die mRNA. Dies geschieht im sog. Spleißosom, einem Komplex aus RNAs und zahlreichen Proteinen.

Es existieren zwar noch diverse weitere RNA-Formen (z.B. micro-RNA) aber auf diese soll hier nicht weiter eingegangen werden.

\subsection{Struktur von tRNA}

tRNA besteht meist aus 73-94 Nukleotiden. Als einzige RNA-Form enthält sie neben dem in RNAs üblichen Uridin die Base Thymin. Durch die Präsenz von ungewöhnlichen Nukleotidinteraktionen ist die Struktur von tRNAs weit vielfältiger als z.B. bei DNA (vgl. 1.1). Die tRNA entsteht durch Prozessierung aus Vorstufen-tRNA (precursor-tRNA). Im Falle von E. coli wurde z.B. ein Primärtranskript gefunden, das sieben tRNAs enthält. Dieses wird am 5'Ende vor jeder reifen tRNA durch die schon erwähnte Endonuklease 
Ribonuklease P gespalten, wobei Hinweise gefunden wurden, dass die 5'CCA-3`-Basenfolge neben der Struktur als Erkennungssignal zur Spaltung dient (Tanaka et al., 2005). Das $3^{`}$-Ende wird dann im Folgenden durch die Exonuklease Ribonuklease $D$ so lange verkürzt, bis ein $5^{`}-\mathrm{CCA}-3^{`}$-Ende (Bindestelle für ein Aminosäuremolekül) erreicht ist. Sollte dieser Abbau zu weit gelaufen sein, wird ein neuer $5^{\prime}$-CCA-3'-Rest durch eine CCANucleotidyl-Transferase angeheftet.

Die Sekundärstruktur der so entstandenen tRNA ähnelt der Form eines Kleeblatts (Abb.1).

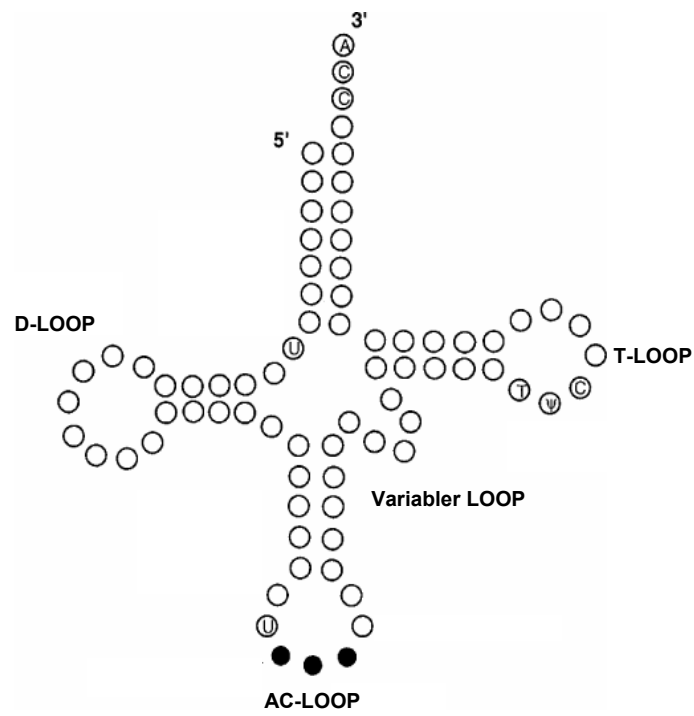

\section{Abb.1) Kleeblattstruktur/2D-Struktur von tRNA (modif. Lauhon, 2002)}

Dabei lässt sich diese Struktur in Bereiche von gepaarten (duplex) Nukleotiden (stem-Bereiche) und ungepaarten Nukleotiden (Loops) unterteilen. Das Akzeptor-Ende (3`-Ende) weist in allen tRNAs die Basenfolge $5^{`}-\mathrm{CCA}-3^{`}-\mathrm{OH}$ auf. Hier wird die Carboxylgruppe der zu transportierenden Aminosäure mit der $3^{\prime}-\mathrm{OH}$ oder $2^{\prime}-\mathrm{OH}$ Gruppe des endständigen Adenosins durch die Aktivität einer für jede Aminosäure spezifischen Aminoacyl-tRNA-Synthetase verestert. Dabei findet während der Proteinsynthese möglicherweise ein Wechsel zwischen der $3^{`}-\mathrm{OH}$ - und der 2`-OH-Gruppe statt (Stryer, 2001). 
Verfolgt man die Struktur des Moleküls weiter in Richtung 5'-Ende, so erreicht man den T-Loop. Dieser besteht aus sieben Nukleotiden, die immer die Basenfolge 5`-T- $\Psi-C-G-3 `$ enthalten ( $\psi=$ Pseudouridin). Dem T-Loop folgt der sog. variable-Loop. Seine Größe zeigt in Abhängigkeit von der jeweiligen tRNA eine große Variabilität auf, wobei er in die Bildung der 3DStruktur (s.u.) involviert ist (Ishitani, et al., 2003). Essentiell neben dem 5 CCA-3'-Ende ist der nun folgende Anticodon-Loop (AC-Loop). Er enthält das Anticodon, das mit der mRNA in Kontakt tritt. Der D-Loop enthält charakteristischerweise Dihydroxy-Uracil und ist mit dem variablen-Loop an der Bildung der 3D-Struktur beteiligt (s.u.). Die Tertiärstruktur der tRNA wurde durch röntgenkristallographische Untersuchung der tRNA ${ }^{\text {Phe }}$ aus Hefe bestimmt (Kim et al., 1974). Dabei konnte festgestellt werden, dass eine Lförmige (oder hammerförmige) 3D-Struktur vorliegt (siehe Abb. 2).

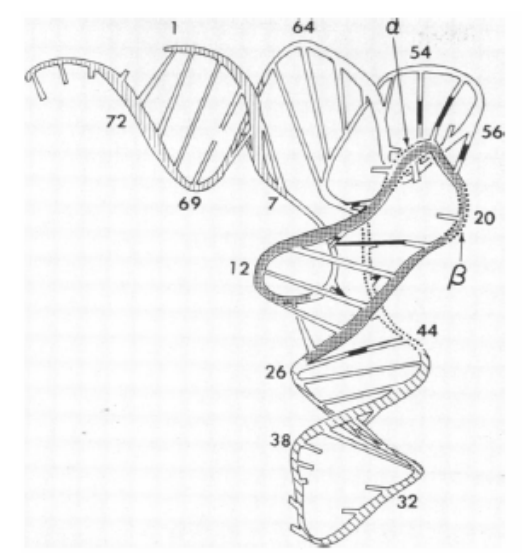

Abb. 2) 3D-Struktur von tRNA Molekülen am Beispiel von tRNA ${ }^{\text {Phe }}$ (Kim et al., 1974)

Bei dieser L-Struktur der tRNA ist zu erkennen, dass ihrer Aufgabe entsprechend das $5^{`}$-CCA-3`-Ende und der Anticodon-Loop im Vergleich zum übrigen Molekül exponiert liegen. Zur Bildung der L-Struktur erfolgt eine Interaktion von D-Loop und variablem-Loop, die v.a. durch tertiäre Interaktionen stattfindet (Kim et al., 1973). In diesem sog. Kernbereich der tRNA findet man viele modifizierte Nukleotide wie $s^{4} U 8, m^{1} G 9, m^{2} G 10, \psi 13$, $m^{1} A 22, m^{22} G 26, m^{7} G 46$ und $m^{5} \mathrm{C} 48$ (Ishitani et al., 2003). Zur weiteren Stabilisierung der L-Form erfolgt noch eine Interaktion zwischen D- und TLoop. Auch hier sind mehrere modifizierte Nukleotide (Gm18 und 455 ) enthalten (Ishitani et al., 2003). 


\section{$1.6 \quad$ Modifikationen von tRNA}

In allen Organismen wird die tRNA posttranskriptional modifiziert. Bisher hat man in tRNAs über 80 modifizierte Nukleotide gefunden (Waas et al., 2005). Von diesen gibt es nur acht, die in allen drei Reichen (Archaea, Bacteria und Eukarya) an der identischen Position der jeweiligen tRNA auftreten (Björk et al., 2001). Ein Beispiel hierzu ist 1-Methylguanosin, $m^{1} G 37$. Diese modifizierte Base kommt nicht nur an Position 37 (AC-Loop) der tRNAs für Leucin, Prolin und Arginin vor (3 Ausnahmen bei über 500 bekannten tRNAs), sondern auch in der entsprechenden tRNA-Position in Mitochondrien und Chloroplasten (Björk et al., 2001). Diese konservierte Modifikation könnte deshalb als ein Rudiment der RNA-Welt (1.3) gewertet werden, da es Vermutungen gibt, dass der ursprüngliche Zweck der Basenmodifikation eine Variation der chemischen und strukturellen Eigenschaften des jeweiligen RNA-Moleküls war (Waas, et al., 2005). Als Aufgabe dieser Modifikation in rezenten Lebewesen wurde die Unterdrückung von Leserasterverschiebungen (frameshifts) festgestellt (Björk et al., 1989, Hagervall et al., 1993).

Man kennt aber noch andere Funktionen der Basenmodifikationen. Speziell im AC-Loop gibt es Modifikationen, die eine Unterdrückung des WobbleProblems bewirken (näheres siehe 1.7.1). Weiterhin wurde ein Einfluss von Modifikationen auf die Bindung der tRNA an das Ribosom (Ashraf et al., 1999; Yarian et al., 2000), auf die Fehlerrate von Basenfehlpaarungen (Hagervall et al., 1998) und die Translationsgeschwindigkeit (Kruger et al., 1998) gefunden. Zusätzlich sind Modifikationen im restlichen tRNA-Molekül bekannt, die im T- und D-Loop die Stabilität der 3D-Struktur der RNA erhöhen (Romby et al., 1987). Auch Umwelteinflüsse wie die Temperatur ziehen spezifische tRNA Modifikationen nach sich. Bei einem Vergleich der Anzahl von tRNA Modifikationen in psychrophilen, mesophilen und thermophilen Organismen, konnte sogar festgestellt werden, dass mit Ausnahme des Dihydrouridins, die Gesamtzahl von tRNA-Modifikationen mit der Umgebungstemperatur ansteigt (Dalluge et al.,1997).

Allgemein kann man anhand der aufgezählten Beispiele erkennen, dass eine große Vielfalt in der Art der Modifikationen auftritt, in denen die zahlenmäßig größte Gruppe die methylierten Nukleotide sind (Röhm, 1998). Hier wird durch Methyltransferasen eine Methylgruppe auf die jeweilige Base 
übertragen. Aber auch andere Alkylierungen, sowie Isomerisierungen und Transglycosylierungen (Synthese von Queuosin, Garcia und Kittendorf, 2005) wurden gefunden. Auch Elemente wie Schwefel (s. 1.7) oder Selen werden zur Modifikation von tRNA-Basen (z.B. 5-Methylaminomethyl-2Selenouridine (Mihara, 2002)) eingesetzt.

\section{$1.7 \quad$ Thionukleoside}

Wird während der Modifikation Schwefel in ein Nukleosid inseriert, bezeichnet man die resultierende Base allgemein als Thionukleosid. Bisher sind vier Thionukleoside in $E$. coli beschrieben worden, die alle in der tRNA gefunden wurden (Lauhon, 2002). Es handelt sich hierbei um 4-Thiouridin (siehe 1.7.1), 5-Methylaminomethyl-2-Thiouridine (siehe 1.7.2), 2-Thiocytidine und 6-N-Dimethylallyl-2-Methylthioadenosin.

Es wurde gezeigt, dass das Vorkommen von 6-N-Dimethylallyl-2Methylthioadenosin an die Verfügbarkeit von gelösten Eisenionen gekoppelt ist. Fehlen Eisenionen z.B. in kranken Tieren, kann in Bakterien, die aus diesen Tieren isoliert wurden, kein 6-N-Dimethylallyl-2-Methylthioadenosin in der tRNA nachgewiesen werden (Griffiths et al., 1978).

Die Modifikation zu 2-Thiocytosin führt an Position 32 der tRNA zu einer Änderung der Anticodon-Loop-Struktur (Baumann et al., 1985).

\subsubsection{2-Thiouridin}

Die Bildung von 2-Thiouridin (Abb. 3) wird durch das Enzym MnmA katalysiert. Dabei substituiert MmmA Sauerstoff an Position 2 von Uridin durch Schwefel (siehe Pfeil, Abb. 3). 


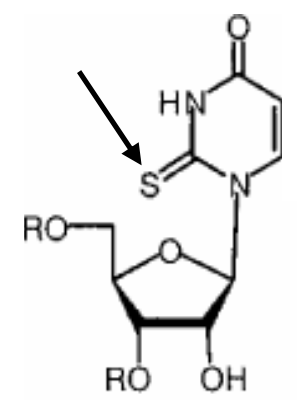

$$
s^{2} U
$$

\section{Abb. 3) Abbildung von 2-Thiouridin}

Als Reaktionsmechanismus (auch in Bezug zum aufgeklärten Reaktionsmechanismus zur Synthese von 4-Thiouridin) wird angenommen, dass Schwefel aus der Aminosäure Cystein unter Verwendung von Pyridoxylphosphat auf das Enzym IscS übertragen wird, wobei ein intramolekularer Sulfan-Schwefel gebildet wird. Dieses Persulfid wird auf MnmA übertragen, das eines der Schwefelatome auf das zuvor an Position 2 durch ATP und $\mathrm{Mg}^{2+}$ aktivierte Uridin überträgt. Anschließend erfolgt die Spaltung der resultierenden internen Disulfidbindung im MnmA (Kambampati und Lauhon, 2000) (Abb. 4).

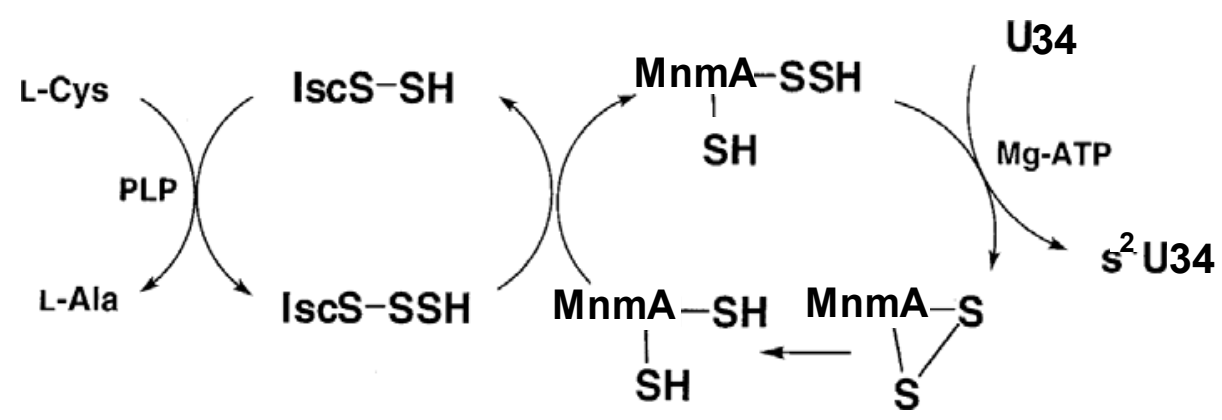

Abb. 4) Syntheseweg von 2-Thiouridin durch MnmA (modif. nach Kambampati und Lauhon, 2000)

Die weitere Reaktion in der durch die Enzyme MnmE und MnmC eine Bindung eines Dimethylaminrests an das $\mathrm{C}_{5}$ des Uridinrings erfolgt, führt zu dem biologisch relevanten 5-Methylaminomethyl-2-Thiouridin. Diese Modifikation kann in allen drei Reichen des Lebens gefunden werden und tritt an Position 34 der tRNAs von Glutamin, Lysin und Glutamat auf. Diese Position wird auch als Wobble-Position bezeichnet. Während im genetischen Code die ersten zwei Basen die jeweilige Aminosäure festlegen, kann durch eine Variation der Base in der letzten Position des Tripletts die Insertion einer 
anderen Aminosäure erfolgen. Um dieses Problem zu umgehen, wird wie hier am Beispiel der tRNA der Aminosäuren Glutamin, Lysin und Glutamat gezeigt, die Base an Position 34 (Wobble-Position) der tRNA modifiziert, so dass durch die Wechselwirkung des modifizierten Restes mit der entsprechenden Base in der mRNA die Auswahl an möglichen BasenPaarungen festgelegt wird.

\subsubsection{4-Thiouridin}

Eine sehr ähnliche, ebenfalls Schwefel enthaltene Modifikation der tRNA, ist das durch die Aktivität von Thil gebildete 4-Thiouridin. Hier wird der Sauerstoff an Position 4 des Uridins durch Schwefel substituiert (siehe Abb. 5, Pfeil).
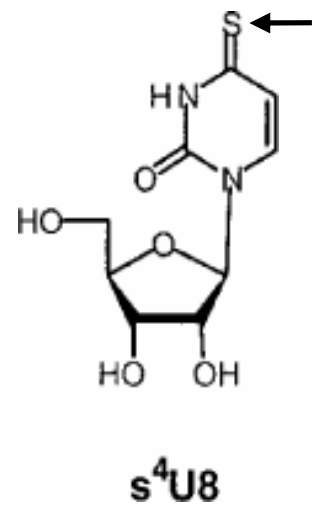

Abb. 5) Abbildung von 4-Thiouridin

Hier wurde der zur Synthese von 2-Thiouridin durch MnmA vorgeschlagene Reaktionsmechanismus nachgewiesen (vgl. Abb. 4). Schwefel wird also über die Bildung eines Persulfides übertragen (Abb. 6).

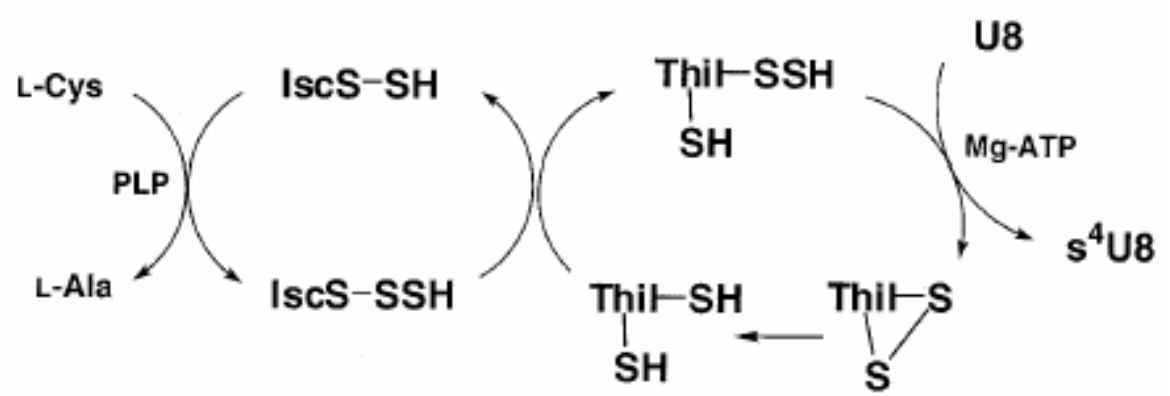

Abb. 6) Syntheseweg von 4-Thiouridin durch Thil (Lauhon, 2002) 
Im Gegensatz zu MnmA sind hier mehr Details bekannt (Abb. 7). Nachdem zunächst das Cystein 456 durch die Übertragung von Schwefel aus Cystein über IscS zu einem Persulfid reagiert, erfolgt ein nukleophiler Angriff des endständigen Schwefels aus diesem Persulfid auf das an Position $\mathrm{C}_{4}$ durch ATP aktivierte Uridin. Im weiteren Reaktionsverlauf erfolgt eine Freisetzung von AMP und die Bindung des Schwefels an das Uridin. Das so gebildete 4-Thiouridin wird freigesetzt und Cystein 456 und 344 des Thil bilden in der Folge eine Disulfidbrücke aus. Diese wird durch eine Reduktion (in vitro durch DTT) wieder in den Ausgangszustand versetzt und steht für eine erneute Persulfidbildung durch IscS zur Verfügung.

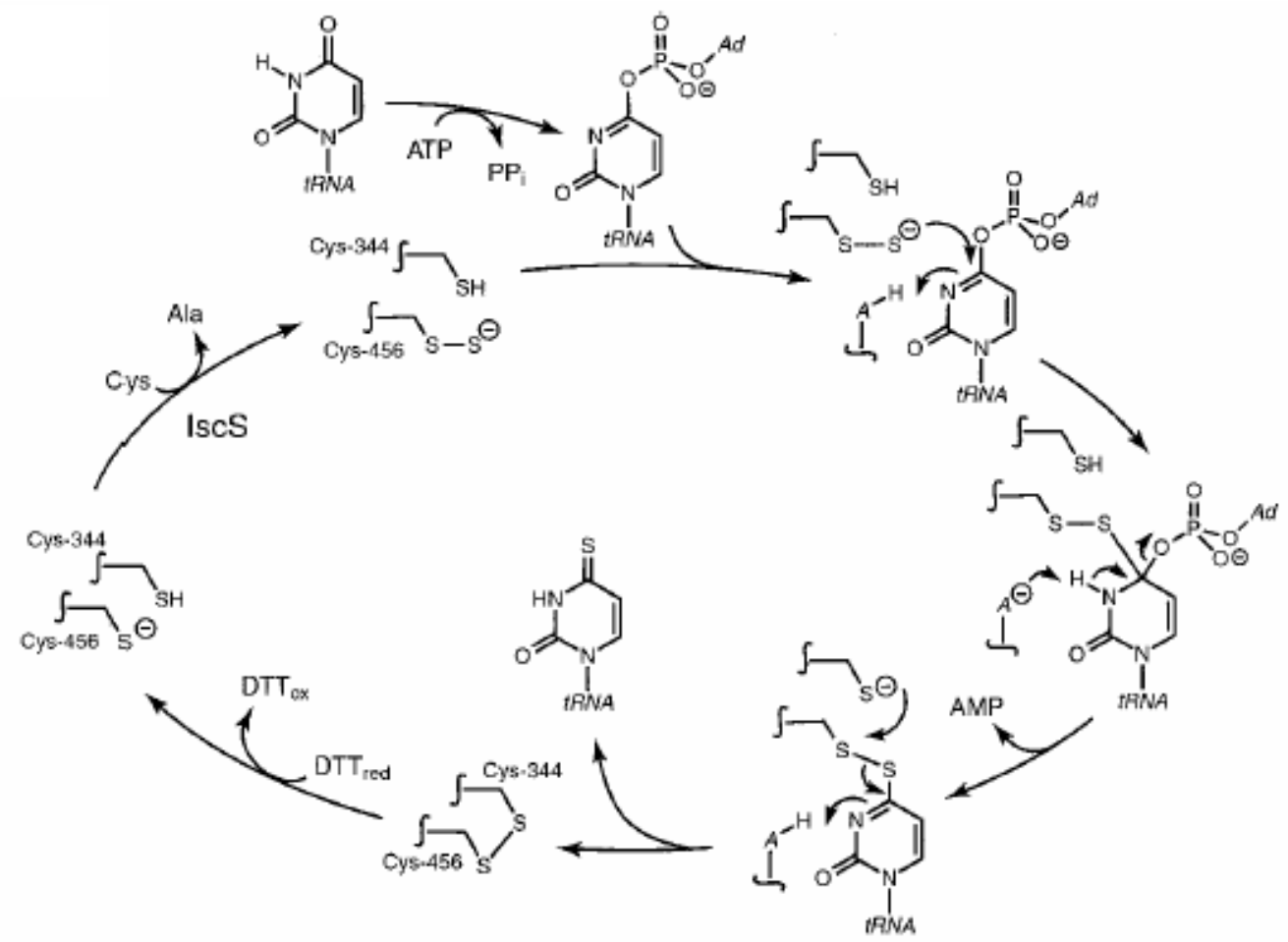

Abb. 7) Reaktionsmechanismus zur Synthese von 4-Thiouridin (Mueller et al., 2002)

Es konnte gezeigt werden, dass diese Modifikation in Abhängigkeit vom Wachstum an Position 8 fast jeder tRNA aus E. coli auftritt (Lauhon et al., 2004).

Die Anwesenheit von 4-Thiouridin in einem tRNA Molekül bewirkt zweierlei: Im unmodifizierten Molekül bildet das 2'-Hydroxyl des Uridin an Position 8 der tRNA eine reverse Hoogsteen-Base mit Adenosin an tRNA-Position 14 (im D-Loop) aus (Griffey et al., 1986). Diese ist nach der Modifikation zu 
4-Thiouridin nicht mehr möglich. Allerdings ist die modifizierte Base nun Bestandteil eines bisher in Salmonella enterica serovar typhimurium und E. coli nachgewiesenen UV-Schutzmechanismus.

Dieser UV-Schutz beruht auf der Bildung einer kovalenten Bindung von 4-Thiouridin mit Cytidin an Position 13 der tRNA, wenn eine Exposition mit UV-Licht erfolgt. Hierbei tritt zunächst eine photochemisch induzierte 2+2 Cycloaddition auf, die durch mehrere Eliminationsreaktionen in eine kovalente C-C-Bindung übergeht (Favre et al., 1971). Die so veränderte tRNA kann aus sterischen Gründen nicht mehr durch die zugehörige Aminoacyl-tRNA-Transferase mit der korrespondierenden Aminosäure beladen werden (Carre et al., 1974). Die Bindung der ungeladenen tRNA an das Ribosom bewirkt die Bildung des Signalmoleküls ppGpp (TetraphosphatGuanosin), welches die Reaktionskaskade des Stringent-Response startet. Daraufhin stoppen die Proteinbiosynthese und das Zellwachstum (Ramabhadran und Jagger, 1976). Eventuell können die Zellen die so eingesparte Energie für Reparaturen der UV-Strahlenschäden im Erbgut verwenden.

\section{$1.8 \quad$ Thil - Biosynthese von Thiamin}

Neben der Modifikation von tRNA wurde auch eine Beteiligung des Enzyms Thil an der Biosynthese von Thiaminmonophosphat entdeckt (Taylor et al, 1998). Thiaminmonophosphat ist der Vorläufer von Thiaminpyrophosphat (Vitamin $\mathrm{B}_{1}$ ), einem essentiellen Co-Faktor für viele zelluläre Prozesse, und wird durch die Fusion der Produkte zweier Reaktionswege synthetisiert. Diese Produkte sind zum einen 5-Methyl-4-( $\beta$-Hydroxyethyl)Thiazolphosphat und zum anderen 4-Amino-5-Hydroxymethyl-2-Methylpyrimidinpyrophosphat. Das dabei entstehende Thiaminmonophosphat wird entweder durch Phosphorylierung (Enterobakterien) oder durch Dephosphorylierung und anschließende Pyrophosphorylierung (aerobe Bakterien und Hefe) gewonnen (Leonardi und Roach, 2004). In E. coli wird der Pyrimidinanteil aus 5-Aminoimidazol-Ribotid durch die Katalyse der Enzyme ThiC und ThiD synthetisiert (Vander Horn et al., 1993). Der Thiazolanteil entsteht aus Tyrosin, Cystein und 1-Deoxy-D-Xylulose unter der Beteiligung der Enzyme ThiFSGH (Vander Horn et al., 1993 und Begley et al., 1999), Thil (Webb et 
al., 1997 und Palenchar et al., 2000) und IscS (Lauhon und Kambampati, 1999). Dabei konnte in vitro gezeigt werden, dass Glycin am C-Terminus des Enzyms ThiS durch die Aktivität des Enzyms ThiF zu ThiS-COAMP adenyliert wird und durch IscS unter Verbrauch von Pyridoxalphosphat und Schwefel aus Cystein zu dem Thiocarboxylat ThiS-COSH umgewandelt wird (Xi et al., 2001). Da jedoch thir-Mutanten keine Thiaminsynthese aufzeigen (Webb et al., 1997), wurde gefolgert, dass Thil in vivo wahrscheinlich zusammen mit IscS die Transformation von ThiS-COOH zu ThiS-COSH katalysiert (Mihara und Esaki, 2002). Inzwischen konnte der Transfer von Cystein-Schwefel über IscS und Thil auf ThiS-COOH nachgewiesen werden (Leonardi und Roach, 2004). Nachdem im weiteren Biosyntheseverlauf durch die Aktivität der Enzyme ThiG und ThiH aus Tyrosin und ThiS-COSH Thiazol synthetisiert wurde, erfolgt die Vereinigung der beiden Vorstufen zu Thiaminmonophosphat (Begley et al., 1999) (siehe Abb. 8).

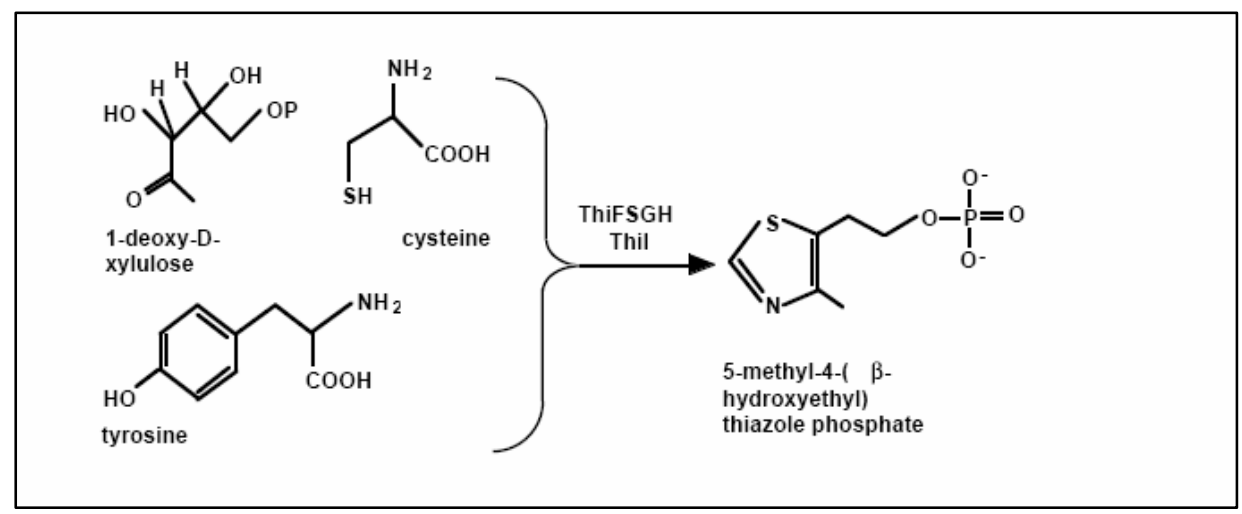

Abb. 8) Beteiligung von Thil an der Synthese von Thiazolphosphat (Leonardi und Roach, 2004) 


\section{$1.9 \quad$ Thermophile Proteine}

Die Erforschung von thermophilen Proteinen ist in den letzten Jahren zusehends ins Interesse der Forschung gerückt. Hier wird daran gearbeitet v.a. Katalysen, deren Reproduktion durch den Menschen einen hohen chemischen und pekuniären Aufwand erfordern, wirtschaftlich zu nutzen. So werden heute thermophile Proteine in der Nahrungsmittelindustrie, in der Papiergewinnung, Detergenzproduktion, Arzneimittelherstellung und zur Behandlung von toxischen Abwässern eingesetzt (Haki und Rakshit, 2003). Die Thermophilie von Enzymen, also die Resistenz gegenüber Temperaturen über $45^{\circ} \mathrm{C}$ beruht auf mehreren Effekten. So konnte gezeigt werden, dass in thermophilen Proteinen stärkere van-der-Waals-Kräfte herrschen (Berezovsky et al., 1997). Bei der Analyse der Aminosäuren im Proteininneren wurde im Vergleich zu mesophilen Proteinen von einer höheren Hydrophibizität berichtet (Schumann et al., 1993). Auch die Ausbildung von zusätzlichen Wasserstoffbrückenbindungen (Jaenicke und Bohm, 1998) und eine höhere ionischen Interaktion (Vetriani et al., 1998) zwischen den Proteinresten durch Variation der „verwendeten“ Aminosäuren konnte gezeigt werden. Ein hieraus resultierender zusätzlicher Effekt ist die dichtere Packung der Proteinkette per se (Hurley et al., 1992). Auch eine Verkürzung von an der Oberfläche des Proteins liegenden „Loop“-Bereichen kann eine höhere Thermostabilität zur Folge haben (Thompson und Eisenberg, 1999). Es tritt also kein „Patentrezept“ zur Ausbildung von thermophilen Verhalten auf, vielmehr kann man zwischen strukturell bedingten (meist in Archaea) und sequenzabhängigen Ursachen (Bakterien) der Thermophilie eines Proteins unterscheiden (Berezovsky und Shakhnovich, 2005). 


\section{$1.10 \quad$ Thermotoga maritima}

Die im Laufe dieser Arbeit erhaltenen Kristalle stammen von Thil aus Thermotoga maritima. T. maritima ist ein hyperthermophiles, stäbchenförmiges Eubakterium aus der Gruppe der Thermotogales. Es besitzt sein Temperaturoptimum bei $80{ }^{\circ} \mathrm{C}$ und konnte aus geothermalen Tiefseesedimenten bei Vulcano, Italien isoliert werden (Nelson et al., 1999).

Den Namen „Thermotoga“ erhielt dieses Bakterium aufgrund seiner großen periplasmatischen Räume an den Zellpolen (siehe Abb. 9).

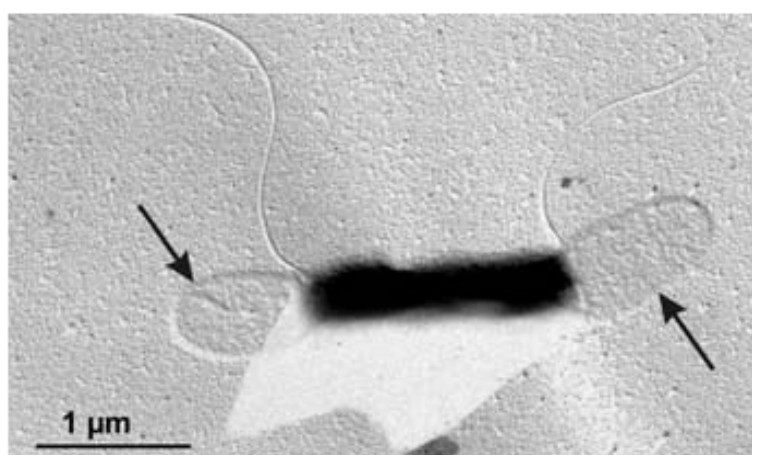

Abb. 9) EM-Aufnahme von Thermotoga maritima (Stetter, O.K., Rachel, R., Universität Regensburg)

Die großen periplasmatischen Räume an den Zellpolen sind deutlich erkennbar (Pfeile).

T. maritima gehört zu den organotrophen Bakterien und kann ein weites Spektrum an einfachen und komplexen Kohlenhydraten zum Wachstum verwenden. Zu diesen zählen z.B. Glucose, Maltose, Stärke, Zellulose, Laminarin, Xylan (Huber et al., 1986 und Chhabra et al., 2002) oder auch Pektin (Kluskens et al., 2003). Die Analyse der rRNA der kleinen Untereinheit der Ribosomen zeigte, dass T. maritima weit unten im Stammbaum des Lebens abzweigt (Thoma et al., 1998).

Das Genom von T. maritima umfasst 1,8 Mbp mit einem GC Gehalt von $46 \%$ (Nelson et al., 1999). 


\section{$1.11 \quad$ Zielsetzung}

Im Laufe dieser Arbeit sollten die Enzyme Thil und MnmA aus E. coli exprimiert und aufgereinigt werden. Anschließend sollten durch Kristallisationsversuche röntgenkristallographisch verwertbare Kristalle generiert werden.

Zusätzlich sollten die Orthologen von Thil und MnmA aus T. maritima kloniert und ein Expressions- und Aufreinigungsprotokoll etabliert werden. Im Anschluss sollten auch mit den orthologen Proteinen Proteinkristalle generiert werden. 


\section{Material und Methoden}

\subsection{Organismen, Plasmide und Primer}

Folgende E. coli Stämme wurden in der vorliegenden Arbeit verwendet. Die Beschreibung der Genotypen erfolgt in Tab.1:

Klonierungen: - Escherichia coli $\mathrm{DH} 5 \alpha$

- Escherichia coli XL1blue

Expressionen: - Escherichia coli BL21 (DE3)

- Escherichia coli BL21 (DE3) pLysS

- Escherichia coli ER2508

- Escherichia coli B834 (DE3)

Tab. 1) Genotypen der verwendeten E. coli Stämme

\begin{tabular}{|c|c|c|}
\hline Stamm & Genotyp & Referenz/Quelle \\
\hline DH5a & 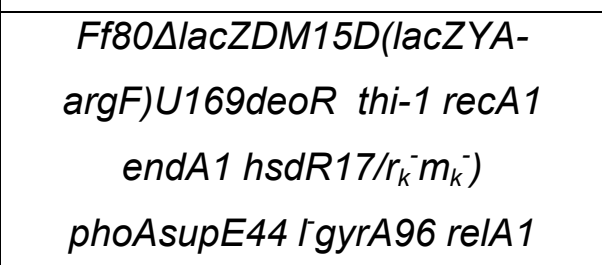 & $\begin{array}{l}\text { Invitrogen, } \\
\text { Karlsruhe }\end{array}$ \\
\hline XL1 blue & 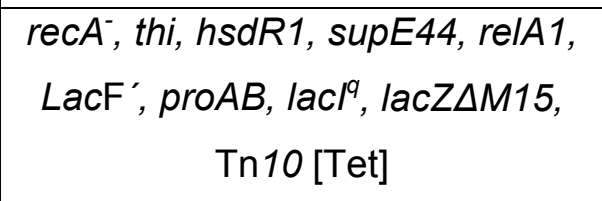 & $\begin{array}{l}\text { Stratagene, } \\
\text { La Jolla, USA }\end{array}$ \\
\hline BL21 (DE3) & $\begin{array}{l}F \text {, ompT, hsdSB (rB-mB; } \text {; ein } \\
\text { E.coli B-Stamm) mit DE3, ein a- } \\
\text { Prophage, der das T7-RNA- } \\
\text { Polymerasegen trägt }\end{array}$ & $\begin{array}{l}\text { Novagene, } \\
\text { Bad Soden }\end{array}$ \\
\hline $\begin{array}{l}\text { BL21 (DE3) } \\
\text { pLysS }\end{array}$ & $\begin{array}{l}\text { Identisch zu BL21 (DE3), trägt } \\
\text { jedoch zusätzlich noch das } \\
\text { pLysS Plasmid, dessen Produkt } \\
\text { T7-Lysozym die T7-RNA-Poly- } \\
\text { merase inhibiert. }\end{array}$ & $\begin{array}{l}\text { Novagene, } \\
\text { Bad Soden }\end{array}$ \\
\hline
\end{tabular}




\begin{tabular}{|c|c|c|}
\hline Stamm & Genotyp & \begin{tabular}{|l} 
Referenz/Quelle \\
\end{tabular} \\
\hline ER2508 & 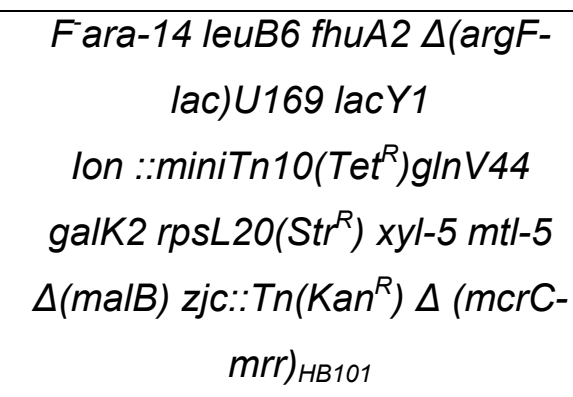 & $\begin{array}{l}\text { New England Biolabs, } \\
\text { Frankfurt a. M. }\end{array}$ \\
\hline B834 (DE3) & $\begin{array}{c}F^{-}, \text {ompT[Ion], hsdSB (rB-mB-), } \\
\text { gal, dcm, met (DE3) }\end{array}$ & $\begin{array}{l}\text { Novagene, } \\
\text { Bad Soden }\end{array}$ \\
\hline
\end{tabular}

Außerdem wurden folgende Plasmide verwendet:

Tab.2) Verwendete Plasmide

\begin{tabular}{|l|l|l|}
\hline Plasmid & Referenz/Quelle & Resistenz \\
\hline pET21b & Novagene, Bad Soden & Ampicillin \\
\hline pET21c & Novagene, Bad Soden & Ampicillin \\
\hline pET28a & Novagene, Bad Soden & Kanamycin \\
\hline pMAL-c2XP & $\begin{array}{l}\text { New England Biolabs, } \\
\text { Frankfurt a. M. (modif. } \\
\text { Gouloudis) }\end{array}$ & Ampicillin \\
\hline
\end{tabular}

Um die gewünschten Gensequenzen zu amplifizieren, wurden für die PCR folgende Oligonukleotide (Primer) (MWG Biotech, Ebersberg) eingesetzt:

\section{a.) Zur Klonierung von thil aus T. maritima in pET28a}

Thilfor: $\quad 5$-CCCCATGGAAGAGTTGAGAGTTTACATA

Thilrev: $\quad 5$-CCAAGCTTTCACTCTATCACCTCGACTTTTCT

Thilfor enthielt eine Ncol- und Thilrev eine HindIII- Schnittstelle

b.) Zur Klonierung von mnmA aus T. maritima in pET28a

TrmUfor: 5`-CCCCATGGAAGTAGGGGTAGCACTCAGTGGA

TrmUrev: $\quad$ 5-CCAAGCTTTCATCGAATTCCCTCCTTTATAAT

TrmUfor enthielt eine Ncol- und TrmUrev eine HindIII- Schnittstelle. 
c.) Zur KIonierung von thil aus T. maritima in pMALc2XP

Thilfor: $\quad 5$-CCGGATCCAAAGAGTTGAGAGTTTACATAGTGA

Thilrev: $\quad$ 5'-CCCCAAGCTTTCACTCTATCACCTCGACTTTTC

Thilfor enthielt eine Ncol- und Thilrev eine HindlII- Schnittstelle.

d.) Zur Klonierung von mnmA aus T. maritima in pMALc2XP

TrmUfor: $\quad$ 5'-CCGGATCCAAAGTAGGGGTAGCACTCACTG

TrmUrev: 5'-CCCCAAGCTTTCATCGAATTCCCTCCTTTATA

TrmUfor enthielt eine Ncol- und TrmUrev eine HindIII- Schnittstelle.

\section{$2.2 \quad$ Nährmedien und Zellanzucht}

\subsubsection{Zellanzucht von E. coli}

Die Zellanzuchten der benötigten E. coli-Stämme wurden in LB-Medium in zuvor sterilisierten Eppendorf-Reaktionsgefäßen oder Erlenmeyerkolben durchgeführt. Dabei betrug das Kulturvolumen in EppendorfReaktionsgefäßen bis zu $70 \%$ und in Erlenmeyerkolben bis zu $50 \%$ des jeweiligen Fassungsvermögens. Die Kulturen wurden bei $37{ }^{\circ} \mathrm{C}$ und 200 Upm auf Rotationsschüttlern inkubiert.

\begin{tabular}{|c|c|}
\hline Trypton & 10 \\
\hline Hefeextrakt & 5 \\
\hline $\mathrm{NaCl}$ & 10 \\
\hline $\mathrm{H}_{2} \mathrm{O}_{\text {bidest. }}$ & ad $1000 \mathrm{ml}$ \\
\hline \multicolumn{2}{|c|}{$\begin{array}{l}\text { Eine Einstellung des } \mathrm{pH} \text {-Wertes war nicht erforderlich. } \\
\text { Zur Herstellung von Festmedien wurden } 1,5 \% \text { (w/v) Aga }\end{array}$} \\
\hline
\end{tabular}


Für die Anzucht plasmidtragender E. coli-Kulturen wurden folgende Medienzusätze verwendet:

Tab.3) Verwendete Medienzusätze und ihre Konzentrationen

\begin{tabular}{|c|c|c|}
\hline Antibiotikum/Induktor & Stammlösung & Endkonzentration \\
\hline Ampicillin & $100 \mathrm{mg} / \mathrm{ml}$ & $100 \mu \mathrm{g} / \mathrm{ml}$ \\
\hline Chloramphenicol & $20 \mathrm{mg} / \mathrm{ml}$ & $20 \mu \mathrm{g} / \mathrm{ml}$ \\
\hline Kanamycin & $50 \mathrm{mg} / \mathrm{ml}$ & $50 \mu \mathrm{g} / \mathrm{ml}$ \\
\hline \hline IPTG & $1 \mathrm{M}$ & $0,5 \mathrm{mM}$ \\
\hline
\end{tabular}

\subsubsection{Stammkulturen}

Für die Herstellung von Stammkulturen wurden die Zellen bis zur exponentiellen Phase in LB-Medium kultiviert. Anschließend wurden $500 \mu \mathrm{l}$ Zellsuspension entnommen, mit $500 \mu$ sterilem Glycerin (87 \%, w/v) vermischt und bei $-80{ }^{\circ} \mathrm{C}$ gelagert.

\subsubsection{Reinheitskontrolle}

Die Reinheit der Kultur wurde von Zeit zu Zeit unter dem Phasenkontrastmikroskop (Axioskop40, Zeiss, Jena) überprüft. Außerdem wurde durch Vereinzelungsausstriche die Koloniemorphologie zu Vergleichszwecken herangezogen.

\subsubsection{Bestimmung von Wachstumsparametern}

Das Wachstum der einzelnen Kulturen wurde durch Trübungsmessung bei einer Wellenlänge von 600 nm mit Hilfe eines Photometers (BioPhotometer, Eppendorf, Hamburg) verfolgt. Dazu wurde die Trübung von $1 \mathrm{ml}$ Kultur in Einwegkunststoffküvetten von $1 \mathrm{~cm}$ Schichtdicke (Sartorius, Göttingen) gegen steriles LB-Medium bestimmt. Bei einer $\mathrm{OD}_{600}$ größer als 1 wurden die zu bestimmenden Proben mit sterilem LB-Medium verdünnt. 
Um eventuell vorhandene Nukleasen zu entfernen, wurden alle verwendeten Geräte und hitzestabilen Lösungen bei $121{ }^{\circ} \mathrm{C}$ für $20 \mathrm{~min}$ sterilisiert. Metallgegenstände wurden mit 70 \%-igem Ethanol gespült und anschließend abgeflammt. Hitzelabile Lösungen wurden sterilfiltriert $(0,2 \mu \mathrm{m}$ Sterilfilter, Sartorius, Göttingen).

\subsubsection{Reinheitskontrolle und Konzentrationsbestimmung von Nukleinsäuren}

Da organische Verunreinigungen wie Phenole und aromatische Verbindungen Licht einer Wellenlänge von $280 \mathrm{~nm}$ absorbieren, kann die Reinheit einer DNA-Lösung anhand des Verhältnisses von $\mathrm{OD}_{260} \mathrm{zu} \mathrm{OD}_{280}$ bestimmt werden. Dabei sollte das Verhältnis ungefähr 1,8 betragen. (Sambrook et al., 1989).

Die Konzentration von doppelsträngiger DNA oder einzelsträngiger RNA in

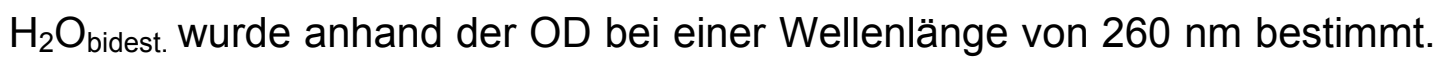
Hierbei gilt, dass eine $O D_{260}$ von 1 einer Konzentration an Doppelstrang-DNA von $50 \mu \mathrm{g} / \mathrm{ml}$ bzw. einer Konzentration an Einzelstrang-RNA von $40 \mu \mathrm{g} / \mathrm{ml}$ entspricht (Davis et al., 1980).

Alle Bestimmungen wurden photometrisch in UV-durchlässigen Kunststoffküvetten (Uvetten, Brand, Wertheim) durchgeführt.

\subsubsection{Fällung und Konzentrierung von Nukleinsäuren}

Um Nukleinsäurelösungen anzukonzentrieren, wurde die DNA-Lösung mit 1/10 Vol. 7 M Ammoniumacetat und 2 Vol. eiskaltem Ethanol (96 \% (v/v)) versetzt. Nach Durchmischung wurde die Lösung für $30 \mathrm{~min}$ bei $-20{ }^{\circ} \mathrm{C}$ inkubiert. Anschließend wurde die DNA bei $16000 \mathrm{~g}$ für $30 \mathrm{~min}$ bei $4{ }^{\circ} \mathrm{C}$ abzentrifugiert (Eppendorf centrifuge 5417R, Eppendorf, Hamburg). Nach 
dem Dekantieren des Überstandes wurde das resultierende Pellet getrocknet und anschließend in $\mathrm{H}_{2} \mathrm{O}_{\text {bidest. }}$ resuspendiert.

Der Vorteil der Verwendung von Ammoniumacetat liegt darin, dass es sich bei Trocknung des DNA-Pellets verflüchtigt und folglich die Salzkonzentration der DNA-Lösung nach Wiederaufnahme des Pellets in $\mathrm{H}_{2} \mathrm{O}_{\text {bidest. sehr gering }}$ ist.

\section{$2.4 \quad$ Polymerasekettenreaktion (PCR)}

Die Polymerasekettenreaktion ist ein adäquates Mittel zur in vitro Amplifikation von DNA. Hierbei wird die DNA durch Erhitzen auf $95{ }^{\circ} \mathrm{C}$ zum Schmelzen gebracht, d.h. sie zerfällt in zwei Einzelstränge. Wird die Temperatur auf oder unter die Schmelztemperatur von zwei chemisch synthetisierten Oligonukleotiden gebracht, können diese als sog. Primer an die Einzelstrang-DNA hybridisieren. Hierbei wird die Sequenz der Primer so gewählt, dass sie zum $5^{`}$ oder $3^{`}$ Ende der zu synthetisierenden DNA komplementär sind.

An diese Bereiche kann nun eine DNA-Polymerase binden und verlängert bei Anwesenheit von dNTPs unter geeigneten Temperaturbedingungen (z.B. Taq-Polymerase: $72{ }^{\circ} \mathrm{C}$ ) die Primer, bis diese dann als Matrix für den jeweils anderen Primer dienen können. Wiederholungen diese Zyklusses führen zur Anreicherung (Amplifikation) des erwünschten DNA Abschnitts.

Um z.B. die kodierende Gensequenz von thil aus T. maritima zu amplifizieren, wurde folgender Reaktionsansatz verwendet:

\section{PCR-Reaktionsansatz}

$\begin{array}{lr}\text { Taq-Polymerase } & 1 \mu \mathrm{l} \\ \text { PCR-Puffer (10x) } & 5 \mu \mathrm{l} \\ \text { dNTP-Mix } & 1 \mu \mathrm{l} \\ \text { DNA-Susp. } & 2 \mu \mathrm{l} \\ \mathrm{H}_{2} \mathrm{O}_{\text {bidest. }} & \text { ad } 50 \mu \mathrm{l}\end{array}$


Nach dem Zusammenfügen der oben aufgeführten Komponenten auf Eis, wurde der PCR-Reaktionsansatz in einem PCR-Automaten (Tpersonal, Biometra, Göttingen) nach folgendem Temperaturprofil behandelt:

\begin{tabular}{|c|c|c|}
\hline \multicolumn{2}{|c|}{$1 \times\{300 \mathrm{~s}$} & $\left.94^{\circ} \mathrm{C}\right\}$ \\
\hline $5 x$ & $20 \mathrm{~s}$ & $94^{\circ} \mathrm{C}$ \\
\hline & $60 \mathrm{~s}$ & $40^{\circ} \mathrm{C}$ \\
\hline & $60 \mathrm{~s}$ & $72^{\circ} \mathrm{C}$ \\
\hline $25 x$ & $30 \mathrm{~s}$ & $94^{\circ} \mathrm{C}$ \\
\hline & $45 \mathrm{~s}$ & $60^{\circ} \mathrm{C}$ \\
\hline & $60 \mathrm{~s}$ & $72{ }^{\circ} \mathrm{C}$ \\
\hline & $600 \mathrm{~s}$ & $\left.72^{\circ} \mathrm{C}\right\}$ \\
\hline
\end{tabular}

\subsubsection{Isolierung von Genom-DNA aus Thermotoga maritima}

Die Tatsache, dass Thermotoga maritima sehr große periplasmatische Räume besitzt, macht die Zellmembran empfindlich gegen alternierendes Tieffrieren und Auftauen (Armknecht, pers. Mitt.).

Um die Genom-DNA von Thermotoga maritima zu isolieren, wurden deshalb ca. 0,3 g Zellmaterial sechsmal in Folge jeweils bei RT aufgetaut und anschließend wieder bei $-20^{\circ} \mathrm{C}$ eingefroren. Anschließend wurde das Zellmaterial in 0,5 ml DEP-Puffer (DNA-Extraktions-Puffer) resuspendiert und die Zellen mit einem Sonifier (Branson Sonifier 250, Danbury, USA) aufgeschlossen. Dazu wurden die auf Eis inkubierten Zellen so lange mit zweiminütigen Stössen einer Amplitude von $100 \%$ (gerätespezifische Einheit) und eine daran anschließende dreiminütige Abkühlphase behandelt, bis die Lösung im Gegenlicht klar erschien.

Nach 3-maliger Phenol-Chloroform-Extraktion (Zugabe von 1 Vol. Chloroform-Phenol-Gemisch, Vortexen für $1 \mathrm{~min}$, Zentrifugation $1 \mathrm{~min}$, $16000 \mathrm{~g}, 4^{\circ} \mathrm{C}$, Eppendorf centrifuge 5417R, Eppendorf, Hamburg), wurde die DNA durch Zugabe von 2 Vol. eiskalten Ethanols $(96 \%(\mathrm{v} / \mathrm{v}))$ und Inkubation bei $-20^{\circ} \mathrm{C}$ gefällt. Nach $30 \mathrm{~min}$ Zentrifugation bei $16000 \mathrm{~g}$ und $4{ }^{\circ} \mathrm{C}$ (Eppendorf centrifuge 5417R, Eppendorf, Hamburg) wurde das Pellet 
mit $70 \%$ Ethanol (v/v) gespült, getrocknet und in $\mathrm{H}_{2} \mathrm{O}_{\text {bidest. }}$ resuspendiert. Die so erhaltene DNA-Lösung wurde nach 2.4 weiterbehandelt.

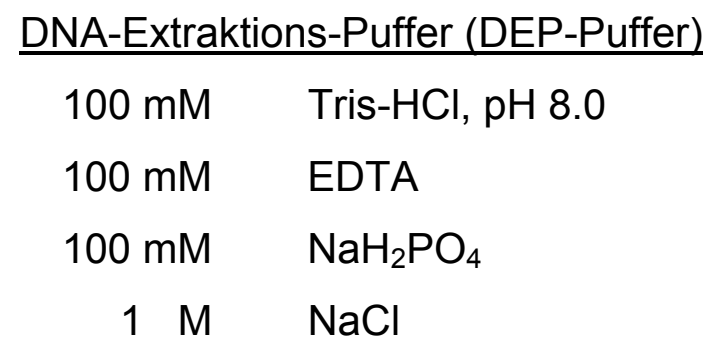

\subsubsection{Reinigung von PCR-Fragmenten}

Die Reinigung von PCR-Produkten erfolgte wahlweise mit Hilfe käuflicher Kits (Qiagen, Hilden) oder durch Agarosegelelektrophorese mit anschließender Gelextraktion (2.7.4).

Bei Reinigung über ein Kit wurde das Qiaquick PCR Purification Kit (Qiagen, Hilden) verwendet. Der Einsatz der Komponenten erfolgte dabei strikt nach Angaben des Herstellers.

\subsection{Analytische Plasmidisolierung (MiniPrep)}

Die nach unten gewonnene DNA war sehr rein und konnte ohne weitere Behandlung für Transformation (2.11) und Sequenzierung (2.10) eingesetzt werden.

Es wurden $E$. coli Zellen in 1-5 ml großen Übernachtkulturen in LB-Medium angezogen und durch Zentrifugation für $10 \mathrm{~min}$ bei $4{ }^{\circ} \mathrm{C}$ und $4000 \times \mathrm{g}$ (Allegra 2IR, Beckman Coulter, Krefeld) geerntet. Anschließend erfolgte die Isolierung der Plasmid-DNA mit Hilfe eines Qiaprep Spin Miniprep Kits (Qiagen, Hilden). Resuspendieren des Pellets, Lyse, Proteinfällung, Bindung der DNA an die Säulenmatrix und Elution erfolgten entsprechend den Angaben des Herstellers mit den mitgelieferten Lösungen. Es handelt sich hierbei um das Prinzip der Plasmidanreicherung nach Birnboim und Doly (1979). Dabei adsorbiert DNA unter Hochsalzbedingung an eine Silica-Matrix und wird im Anschluss unter Niedrigsalzbedingung $\left(\mathrm{H}_{2} \mathrm{O}_{\text {bidest. }}\right)$ eluiert. 


\subsection{Präparative Plasmidisolierung (MidiPrep)}

Die nach unten gewonnene DNA war sehr rein und konnte ohne weitere Behandlung für Transformationen (2.11) und Sequenzierungen (2.10) eingesetzt werden.

Die benötigten $E$. coli-Zellen wurden in $50 \mathrm{ml}$ LB-Medium über Nacht angezogen und durch Zentrifugation für $10 \mathrm{~min}$ bei $4^{\circ} \mathrm{C}$ und $3500 \times \mathrm{g}$ (Avanti J20 XPI, Beckman Coulter, Krefeld) geerntet. Anschließend erfolgte die Isolierung der Plasmid-DNA mit Hilfe eines Qiagen Plasmid Midi-Kits (Qiagen, Hilden). Das für Plasmid-DNA selektive Aufreinigungsprinzip beruht hier auf einer alkalischen SDS-Lyse der Zellen mit nachfolgender Anionenaustauschchromatographie.

Resuspendieren des Pellets, Lyse, Proteinfällung, Bindung der DNA an die Säulenmatrix und Elution erfolgten entsprechend den Angaben des Herstellers mit den mitgelieferten Lösungen.

Die eluierte Plasmid-DNA wurde mit 0,7 Vol. eiskaltem Isopropanol versetzt und zur Fällung der DNA für $1 \mathrm{~h}$ bei $-20^{\circ} \mathrm{C}$ inkubiert. Anschließend wurde die DNA durch Zentrifugation für 30 min bei $4^{\circ} \mathrm{C}$ und 20000 x g (Avanti J20 XPI Beckman Coulter, Krefeld) pelletiert. Das erhaltene Plasmid-DNA-Pellet wurde mit eiskaltem Ethanol (70 \% Ethanol (v/v)) gewaschen, anschließend

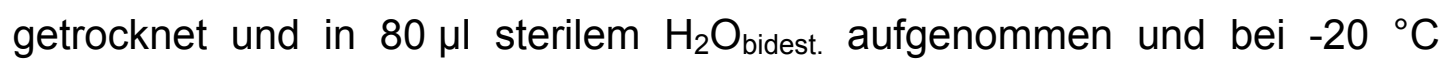
gelagert. 


\section{Gelelektrophorese von Nukleinsäuren}

\subsubsection{Standard Agarose-Gelelektrophorese}

Um die gewonnene DNA zu analysieren, wurde eine AgaroseGelelektrophorese in horizontalen Gelelektrophoresekammern durchgeführt. Das Gelvolumen betrug für analytische Zwecke zwischen 20 und $30 \mathrm{ml}$ und für präparative Zwecke $150-200 \mathrm{ml}$, mit einer Konzentration von $1 \%$ Agarose (w/v) in TBE-Puffer. Vor dem Auftragen wurden die Proben mit 1/6 Volumen Schwerelösung versetzt. Die Elektrophorese wurde bei $100 \mathrm{~V}$ (Powerpack P24, Biometra, Göttingen) in 1 x TBE-Puffer durchgeführt.

\section{$\underline{\text { TBE-Puffer }}$}

$\begin{array}{ll}\text { Tris- } \mathrm{HCl}(\mathrm{pH} 8,0) & 89 \mathrm{mM} \\ \text { EDTA } & 20 \mathrm{mM} \\ \text { Borsäure } & 89 \mathrm{mM}\end{array}$

\subsubsection{Färbung und Dokumentation von Agarosegelen}

Nach dem Ende der Agarosegelelektrophorese wurde das Gel für 30 min in einer Ethidiumbromid-Färbelösung $(2 \mu \mathrm{g} / \mathrm{ml}$ Ethidiumbromid in $1 \times \mathrm{TBE}$ ) angefärbt. Während der Bestrahlung mit UV-Licht $(\lambda=254 \mathrm{~nm})$ wurden die fluoreszierenden DNA-Banden mit einem Geldoc 2000 System (Biorad, München) dokumentiert. 


\subsubsection{Größenstandards für Nukleinsäuren}

Für die Größenbestimmung der DNA wurden folgende Größenstandards verwendet:
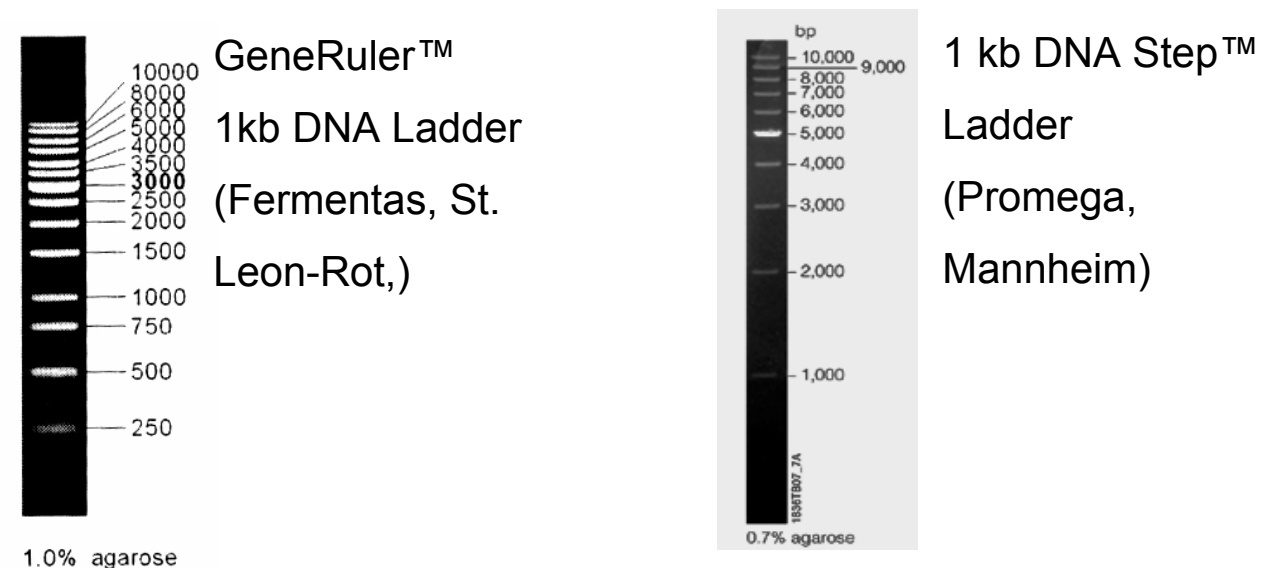

\subsubsection{Isolierung von DNA-Fragmenten aus Agarosegelen}

Die Isolierung von DNA-Fragmenten aus Agarosegelen (Gelextraktion) erfolgte mit Hilfe eines QIAquick Gel Extraction-Kits (Qiagen, Hilden). Hier wird die Tatsache genutzt, dass DNA unter Hochsalzbedingungen an eine Silicamatrix bindet, von der sie durch Zugabe von $\mathrm{H}_{2} \mathrm{O}_{\text {bidest. wieder eluiert }}$ werden kann.

Die gewünschten DNA-Fragmente wurden nach Anfärbung durch Ethidiumbromid (2.7.2) mit einer Skalpellklinge unter UV-Licht ausgeschnitten. Die Lyse der Agarosematrix, Bindung der DNA an die Säulenmatrix, Reinigung und Elution mit $\mathrm{H}_{2} \mathrm{O}_{\text {bidest. }}$ erfolgten entsprechend den Angaben des Herstellers mit den mitgelieferten Lösungen.

\section{8}

\section{Restriktionsspaltung von DNA}

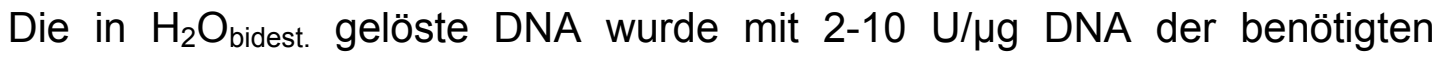
Restriktionsenzyme in dem vom jeweiligen Enzymhersteller empfohlenen Puffersystem für $1-3 \mathrm{~h}$ bei $37^{\circ} \mathrm{C}$ inkubiert. 
Restriktionsspaltungen mit mehreren Enzymen erfolgten prinzipiell nacheinander, wobei der Erfolg der vorangegangenen Spaltung erst auf einem analytischen Agarosegel überprüft wurde. Anschließend erfolgte eine präparative Aufreinigung des gesamten Ansatzes über ein Agarosegel mit anschließender Gelextraktion, bevor mit der nächsten Restriktionsspaltung begonnen wurde.

\section{$2.9 \quad$ Ligation von DNA-Fragmenten}

Ligationen erfolgten im vom Hersteller gelieferten Puffersystem (NEB, Frankfurt a. M.). Die gereinigte DNA wurde in einem dreifachen molaren Überschuss von Insert zu Plasmid in 1x Ligationspuffer gegeben, mit $1 \mathrm{U}$ Ligase/10 $\mu \mathrm{g}$ DNA versetzt und bei $16{ }^{\circ} \mathrm{C}$ über Nacht inkubiert. Ligationen erfolgten meist in Reaktionsansätzen mit einem Volumen von $20 \mu \mathrm{l}$. Anschließend wurde der Ansatz ohne weitere Behandlung zur Transformation (2.11.2) eingesetzt.

Sequenzierungen von DNA erfolgten nach dem Sanger-Verfahren (Sanger, 1977). Hierbei werden fluoreszenzmarkierte Nukleotide, die zugleich als Terminatoren dienen verwendet.

Durchgeführt wurden die Sequenzierung von doppelsträngiger Plasmid-DNA im Göttinger Genomics Laboratory, G2L (Institut für Mikrobiologie und Genetik der Universität Göttingen) am ABIPRISM 337 DNA-Sequencer.

\subsubsection{Analyse von Sequenzdaten}

Die aus 2.10 erhaltenen Sequenzen wurden mit Hilfe des Programms Chromas Version 1.45 (McCarthy, Southport, Australien) geöffnet. Dann wurde die Sequenz mit Hilfe des online zur Verfügung stehenden Programms ClustalW (www.expasy.ch) mit der „Original“-Sequenz aus der Datenbank verglichen. 


\section{$2.11 \quad$ Transformation und Selektion rekombinanter KIone}

Kompetente $E$. coli-Zellen können mit rekombinanter Plasmid-DNA transformiert werden (Cohen et al., 1973).

\subsubsection{Präparation kompetenter Zellen}

Zur Herstellung von kompetenten Zellen wurden 0,5 I LB-Medium mit einer Übernachtkultur des gewünschten Stamms angeimpft. Dabei musste die Menge des Inokulums so gewählt werden, dass die ${ } D_{600}$ nach dem Animpfen unter 0,1 lag. Nach Inkubation bei $37{ }^{\circ} \mathrm{C}$ auf dem Rotationsschüttler wurde die Kultur bei einer $\mathrm{OD}_{600}$ von $0,5-0,6$ für 30 min auf Eis inkubiert.

Es folgte eine Zentrifugation bei $4500 \mathrm{~g}$ (Avanti J20 XPI, Beckman Coulter, Krefeld). Das resultierende Pellet wurde in $125 \mathrm{ml}$ eiskalter $0,1 \mathrm{M} \mathrm{MgCl}_{2}$ Lösung resuspendiert und für 20 min auf Eis inkubiert. Anschließend wurden die Zellen bei $2500 \mathrm{~g}$ abzentrifugiert und in $250 \mathrm{ml}$ eiskalter $0,1 \mathrm{M} \mathrm{CaCl}_{2}$ Lösung resuspendiert. Nach erneuter Inkubation für 10 min wurde wiederum bei $2500 \mathrm{~g}$ abzentrifugiert und das erhaltene Pellet in $5 \mathrm{ml}$ eines eiskalten Gemisches aus $0,1 \mathrm{M} \mathrm{CaCl}_{2}$ und $15 \%$ Glycerin aufgenommen. Diese Suspension wurde in $200 \mu \mathrm{l}$ Aliquots aufgeteilt und bis zur weiteren Verwendung bei $-80^{\circ} \mathrm{C}$ gelagert.

\subsubsection{Transformation durch Hitzeschock}

Es wurden je $200 \mu \mathrm{l}$ kompetente Zellen (siehe 2.11.1) auf Eis aufgetaut und mit ca. 50 ng Plasmid-DNA versetzt. Nach 5 min erschütterungsfreier Inkubation auf Eis erfolgte ein 30 sekündiger Hitzeschock bei $42{ }^{\circ} \mathrm{C}$. Es erfolgte nun auf Eis die Zugabe von $800 \mu$ LB-Medium und eine einstündige Inkubation bei $37{ }^{\circ} \mathrm{C}$ zur Ausprägung der Plasmid-codierten Antibiotikaresistenz. Im Anschluss wurde der gesamte Ansatz auf je zwei Selektivagarplatten ausplattiert. 


\subsubsection{Selektion von Transformanten}

Nach Inkubation über Nacht bei $37^{\circ} \mathrm{C}$ wurden die erhaltenen Kolonien auf die Anwesenheit von rekombinanter DNA untersucht. Dazu wurden sie einmal auf neue Selektivagarplatten (Masterplatte) ausgestrichen (gepickt) und zusätzlich wurde Zellmaterial für Colony-PCRs eingesetzt.

Dazu wurde Zellmaterial in $50 \mu \mathrm{l}$ vorgemischte PCR Ansätze gegeben. In diesen befanden sich neben den üblichen PCR-Komponenten (2.4) ein Insertprimer und ein Vektorprimer. Nach erfolgreicher PCR wurde die entsprechende Kolonie auf der Masterplatte in LB angezogen, die DNA isoliert und nochmal mittels Restriktionsspaltung auf Vorhandensein des Inserts untersucht. Bei einem positiven Ergebnis wurde der entsprechende Klon für weiterführende Experimente eingesetzt.

\subsection{Arbeiten mit Proteinen}

\subsubsection{Expression im analytischen Maßstab}

Nachdem durch Colony-PCR (2.11.3) und anschließenden Restriktionsverdau (2.8) gezeigt worden war, dass die Klonierung erfolgreich verlaufen war, wurde kontrolliert, ob der betreffende Klon das erwünschte Enzym exprimierte. Hierzu wurde, ausgehend von einer Einzelkolonie auf Festmedium, eine Übernachtkultur im $5 \mathrm{ml}$ Maßstab angeimpft und bei $37^{\circ} \mathrm{C}$ inkubiert. Mit dieser wurde am folgenden Tag eine $50 \mathrm{ml}$ LB-Kultur angeimpft, mit den entsprechenden Selektivmedien versetzt und bis zum Erreichen einer $\mathrm{OD}_{600}$ von 0.5 inkubiert. Die Expression des Inserts erfolgte durch Zugabe von 0,5 mM IPTG. Anschließend wurden nach 1h, $2 \mathrm{~h}, 4 \mathrm{~h}$, 6 h, 10 h und nach einer Inkubation über Nacht (ÜN) Proben gezogen. Dazu wurde der Kultur ein Volumen entnommen, das bei einer Verdünnung auf $1 \mathrm{ml}$ einer $\mathrm{OD}_{600}$ von 0.5 entsprochen hätte. Dieses wurde scharf abzentrifugiert (Eppendorf centrifuge 5417R, Eppendorf, Hamburg) und in $40 \mu \mathrm{l}$ Laemmli-Puffer resuspendiert. Anschließend erfolgte eine SDS-PAGEAnalyse (2.13). Durch diese „Eichung“ aller Proben auf einen Fixwert, war es 
möglich, den Erfolg der Expression zu dokumentieren und zu verfolgen, ob diese auch über den gesamten beobachteten Zeitraum stabil blieb.

\subsubsection{Expression im präparativen Maßstab}

Konnte nach 2.12.1.1 gezeigt werden, dass die Induktion der Genexpression erfolgreich war, erfolgte die Expression im präparativen Maßstab. Hierzu wurde, ausgehend von einer Einzelkolonie auf Festmedium, eine Übernachtkultur in 100 ml LB-Medium, das mit den entsprechenden Selektivmedien versetzt worden war, angeimpft und bei $37^{\circ} \mathrm{C}$ ÜN inkubiert. Am folgenden Tag wurden $2 \times 1$ । Kultur mit je 30 ml Übernachtkultur angeimpft und bei $37^{\circ} \mathrm{C}$ inkubiert. Nach Erreichen einer $\mathrm{OD}_{600}$ von 0.5 wurde die Genexpression durch Zugabe von 0.5 mM IPTG gestartet. Nach $4 \mathrm{~h}$ Expression wurden die Kulturen bei $4500 \mathrm{~g}$ und $24{ }^{\circ} \mathrm{C}$ für $10 \mathrm{~min}$ abzentrifugiert (AvantiJ20 XPI, Beckman Coultur, USA) und die Pellets bis zur weiteren Verwendung bei $-20^{\circ} \mathrm{C}$ aufbewahrt. Um den Erfolg der Expression zu dokumentieren, wurden auch hier Proben analog zu 2.12.1.1 gezogen und aufgearbeitet.

\subsubsection{Expression von Selenomethionin-enthaltenen E. coli-Zellen (modif. Reuter, 1999)}

Selenomethionin enthaltendes Thil wurde durch die Verwendung von methioninauxotrophen E. coli B834(DE3) Zellen hergestellt.

Hierzu wurde das Plasmid pET28a-thil in kompetente E. coli B834(DE3)Zellen durch Hitzeschock transformiert (2.11.2). Ausgehend von einer Einzelkolonie auf Festmedium wurde eine Übernachtkultur bei $37^{\circ} \mathrm{C}$ in Minimalmedium herangezogen. Zum Wachstum der auxotrophen $E$. coli B834(DE3) wurden dem Minimalmedium neben den benötigten Antibiotika noch Glucose, Thiamin, Biotin und L-Methionin zugegeben. Mit je $30 \mathrm{ml}$ der ÜN-Kultur wurden $2 \times 1$ I Expressionskultur angeimpft und bei $37^{\circ} \mathrm{C}$ auf einem Schüttler inkubiert. Nach Erreichen einer ${ } D_{600}$ von 0,6 wurden die Zellen durch Zentrifugation (AvantiJ20 XPI, Beckman Coultur, USA) sedimentiert und in je $1 \mathrm{I}$ des oben beschriebenen Minimalmediums ohne Methionin resuspendiert. Es erfolgte eine einstündige Inkubation bei $37^{\circ} \mathrm{C}$ 
auf dem Schüttler. Nun wurden $50 \mathrm{mg} / \mathrm{l}$ DL-Selenomethionin zugegeben. Nach weiteren 30 min wurde die Genexpression durch Zugabe von 0,5 mM IPTG induziert. $4 \mathrm{~h}$ später wurden die Zellen durch Zentrifugation abgeerntet (AvantiJ20 XPI, Beckman Coultur, USA) und bis zur weiteren Verwendung bei $-20{ }^{\circ} \mathrm{C}$ gelagert.

Minimalmedium

$\begin{array}{rl}750,0 \mathrm{ml} & \mathrm{H}_{2} \mathrm{O}_{\text {bidest. }} \\ 200,0 \mathrm{ml} & \mathrm{M} 9 \text { Salts } \\ 2,0 \mathrm{ml} & 1 \mathrm{M} \mathrm{MgSO}_{4} \\ 0,1 \mathrm{ml} & 1 \mathrm{M} \mathrm{CaCl}_{2}\end{array}$

M9 Salts

$\begin{array}{rl}240 \mathrm{mM} & \mathrm{Na}_{2} \mathrm{HPO}_{4} \times 7 \mathrm{H}_{2} \mathrm{O} \\ 110 \mathrm{mM} & \mathrm{KH}_{2} \mathrm{PO}_{4} \\ 40 \mathrm{mM} & \mathrm{NaCl} \\ 100 \mathrm{mM} & \mathrm{NH}_{4} \mathrm{Cl} \\ \text { ad } 1000 \mathrm{ml} & \mathrm{H}_{2} \mathrm{O}_{\text {bidest. }}\end{array}$

Zusätzlich wurden pro 1000 ml noch folgende Zusätze zugegeben:

\author{
4 g Glucose \\ $50 \mathrm{mg}$ L-Methionine (oder DL-Selenomethionin) \\ $2 \mathrm{mg}$ Biotin \\ $2 \mathrm{mg}$ Thiamin
}

\title{
2.12.1.4 Zellaufschluss
}

Um die Zellen aufzuschließen, wurden die Pellets von je 2 I Kulturvolumen aus 2.12.1.2 $15 \mathrm{~min}$ auf Eis inkubiert. In diesem Zeitraum startete die Lyse der Zellen durch das enthaltene T7-Lysozym. Anschließend wurden die Zellen in $30 \mathrm{ml}$ Puffer A, der mit 2 mM EDTA, 2 mM DTT und einer Complete Protease Inhibitor Tablette (Roche, Mannheim) versetzt worden war, resuspendiert. Der Zellaufschluss erfolgte mit Hilfe eines Sonifiers (Branson Sonifier 250, Danbury, USA). Die Suspension wurde auf Eis mit zweiminütigen Stössen einer Amplitude von $100 \%$ (gerätespezifische Einheit) und einer daran anschließenden dreiminütigen Abkühlphase so lange behandelt, bis die Suspension im Gegenlicht klar erschien. Anschließend erfolgte eine $5 \mathrm{~min}$ Zentrifugation bei $30000 \mathrm{~g}$ und $4{ }^{\circ} \mathrm{C}$ (Avanti 
J20 XPI, Beckman Coultur, USA). Der resultierende Überstand wurde zur Aufreinigung mittels Hitzeschock (2.14.1) verwendet.

\section{Puffer A}

$50 \mathrm{mM}$ Tris- $\mathrm{HCl}, \mathrm{pH} 7.5$

$50 \mathrm{mM} \mathrm{NH}_{4} \mathrm{Cl}$

\subsection{Diskontinuierliche SDS-Polyacrylamidgelektrophorese nach Laemmli (1970)}

Es wurden SDS-Gele mit $12,5 \%$ und 17,5\% Acrylamidkonzentration verwendet. Die einzelnen Lösungen wurden gemäß Anleitung zusammenpipettiert und in eine Gelapparatur eingefüllt. Während der Polymerisation des Trenngels war dieses mit $\mathrm{H}_{2} \mathrm{O}_{\text {bidest. }}$ überschichtet, um eine regelmäßige Grenze zwischen Trenn- und Sammelgel zu erhalten. Nach der Polymerisation des Trenngels wurde das Wasser abgegossen und die Sammelgellösung über das Trenngel geschichtet. Anschließend wurde der Kamm eingesetzt. Komplett durchpolymerisierte SDS-Gele wurden bis zur Verwendung bei $4{ }^{\circ} \mathrm{C}$ gelagert.

Die SDS-PAGE fanden in einer Gelapparatur (Biorad, München) statt. Folgende Rezepturen kamen zur Anwendung:

\section{a.) Trenngellösungen (6 ml pro Gel)}

\section{Acrylamidkonzentration [\%]}

$30 \%$ Acrylamid, $0.8 \%$ Bis-

acrylamid Stammlösung [ml]

$2,5 \quad 3,5$

$1,88 \mathrm{M}$ Tris- $\mathrm{HCl}, \mathrm{pH} 8.8[\mathrm{ml}]$

$0,5 \%$ SDS [ml]

$\mathrm{H}_{2} \mathrm{O}_{\text {bidest. }}$ [ml]

TEMED [ $\mu \mathrm{l}]$ 
b.) Sammelgellösung (5\%ig, $2 \mathrm{ml}$ pro Gel)

$\begin{array}{rl}0,33 \mathrm{ml} & 30 \% \text { Acrylamid, } 0.8 \% \text { Bisacrylamid Stammlösung } \\ 0,40 \mathrm{ml} & 0,635 \mathrm{M} \text { Tris- } \mathrm{HCl}, \mathrm{pH} 6.8 \\ 0,40 \mathrm{ml} & 0,5 \% \text { SDS } \\ 0,87 \mathrm{ml} & \mathrm{H}_{2} \mathrm{O}_{\text {bidest. }} \\ 2,00 \mu \mathrm{l} & \text { TEMED } \\ 10,00 \mu \mathrm{l} & \text { APS }\end{array}$

c.) Laufpuffer, $\mathrm{pH} 8,3$

3,02 g Tris-Base

$14,40 \mathrm{~g}$ Glycin

$1,00 \mathrm{~g}$ SDS

ad $1000 \mathrm{ml} \quad \mathrm{H}_{2} \mathrm{O}_{\text {bidest. }}$

d.) Laemmli-Puffer (Proben-Puffer)

$2,0 \mathrm{ml} \quad 0,625 \mathrm{M}$ Tris- $\mathrm{HCl}, \mathrm{pH} 6.8$

$0,2 \mathrm{~g} \quad \mathrm{SDS}$

$5,0 \mathrm{ml} \quad$ Glycerin

$0,5 \mathrm{ml} \quad \beta$-Mercaptoethanol

$0,1 \mathrm{ml} \quad$ Bromphenolblau (1\%ige Lösung in Ethanol)

$2,4 \mathrm{ml} \quad \mathrm{H}_{2} \mathrm{O}_{\text {bidest. }}$

2.13.1 Färbung von SDS-Gelen

\subsubsection{Färbung von Proteingelen}

Nach Ende der SDS-PAGE wurden die SDS-Gele der Apparatur entnommen und für 10 min in Coomassie-Färbelösung unter leichtem Schütteln inkubiert. Anschließend wurde das gefärbte SDS-Gel in Wasser überführt und in diesem so lange inkubiert, bis der Hintergrund entfärbt war. Danach erfolgte 
die Analyse der SDS-Gele auf einem Leuchtschirm. Zur Dokumentation wurden die SDS-Gele mit einem Geldoc 2000 System (Biorad, München) gescannt.

\section{Coomassie Färbelösung}

$\begin{aligned} 2,0 \mathrm{~g} & \text { Coomassie Brillant Blau R250 } \\ 0,5 \mathrm{~g} & \text { Coomassie Brillant Blau G250 } \\ 425 \mathrm{ml} & \text { Ethanol } \\ 50 \mathrm{ml} & \text { Methanol } \\ 100 \mathrm{ml} & \text { Essigsäure } \\ 425 \mathrm{ml} & \mathrm{H}_{2} \mathrm{O}_{\text {bidest. }}\end{aligned}$

\subsubsection{Färbung von Protein-RNA-Komplexgelen (STAINS ALL)}

SDS-Gele, in denen RNA und Protein angefärbt werden sollten, wurden mit dem Farbstoff STAINS ALL (Sigma, Taufkirchen) angefärbt. Dazu wurde das betreffende SDS-Gel nach erfolgreicher SDS-PAGE für 30 min in Fixierer inkubiert. Anschließend erfolgte eine einstündige Färbung in STAINS ALL Färbelösung. Um den Hintergrund aufzuhellen und die Banden sichtbar zu machen, erfolgte einen Inkubation in STAINS ALL Entfärber. Nach dieser Behandlung erschienen Proteinbanden unter Tageslicht rot und RNA Banden violett.

Um die Färbung weiter zu intensivieren, erfolgte im Anschluss noch eine "gewöhnliche“ Coomassie Färbung nach 2.13.1.1, wodurch unter Tageslicht Proteine als dunkelblaue Banden und RNA als tiefschwarze Banden zu erkennen waren. Die SDS-Gele wurden dann mit einem Geldoc 2000 System (Biorad, München) gescannt.

\begin{tabular}{|c|c|c|c|}
\hline Fixierer & & \multicolumn{2}{|c|}{ STAINS ALL Färbelösung } \\
\hline $25 \%$ & Methanol & $50 \%$ & Formamid \\
\hline $10 \%$ & Eisessig & $50 \%$ & $\mathrm{H}_{2} \mathrm{O}_{\text {bidest. }}$ \\
\hline $00 \%$ & $\mathrm{H}_{2} \mathrm{O}_{\text {bidest. }}$ & $0,5 \%$ & STAIN \\
\hline
\end{tabular}




\section{STAINS ALL Entfärbelösung}

$50 \%$ Formamid

$50 \% \mathrm{H}_{2} \mathrm{O}_{\text {bidest. }}$

\subsubsection{Größenstandards für SDS-Gele}

Zur Größenbestimmung der Proteine wurden für die SDS-PAGE folgende Marker verwendet:
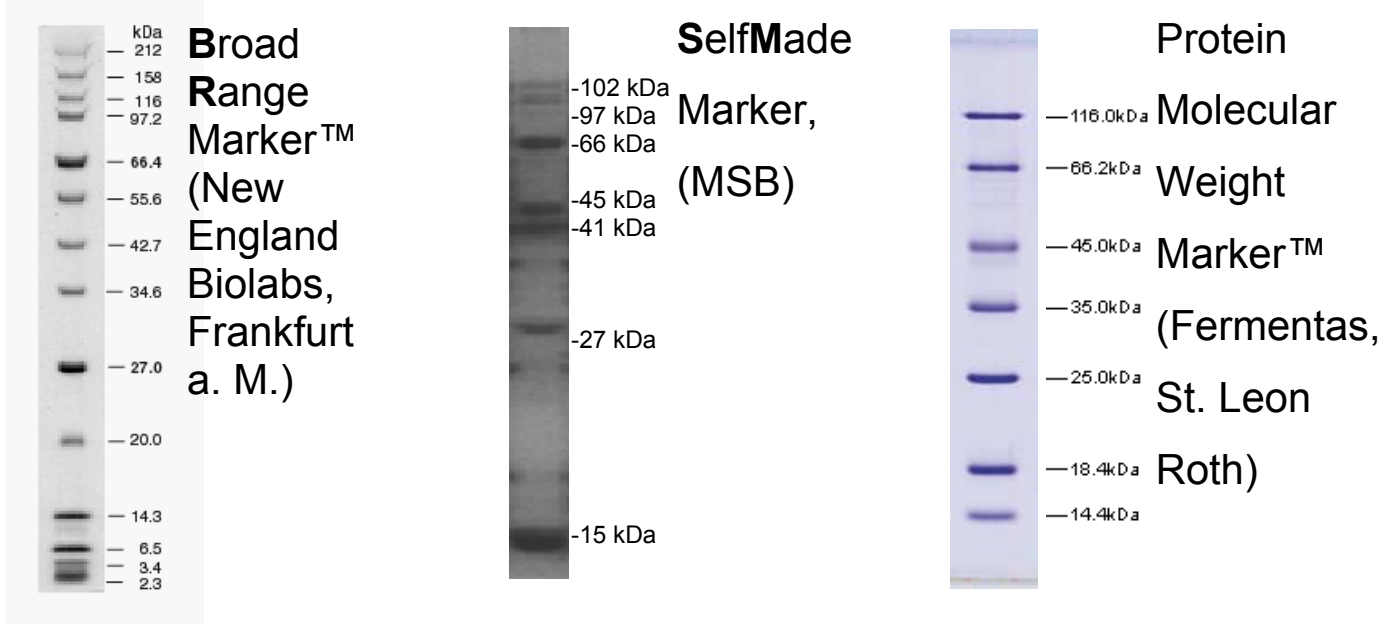

\subsubsection{Proteinbestimmung nach Bradford (1976)}

Die Quantifizierung von Proteinen erfolgte mit Hilfe des Bradford Assays. Dazu wurden $10 \mu$ l Proteinsuspension zu $990 \mu$ l gebrauchsfertig verdünntem Bradford Testreagenz (Biorad, München) gegeben und sorgfältig gemischt. Nach 5 minütiger Inkubation bei RT wurde die Extinktion der Probe in Einwegkunststoffküvetten in einem Photometer (Biophotometer, Eppendorf, Hamburg) bei einer Wellenlänge von $595 \mathrm{~nm}$ bestimmt. Da das Photometer auf diese Methode geeicht worden war, entsprach das Produkt aus abgelesener Extinktion und dem Korrektur-Faktor 2 unmittelbar der Proteinkonzentration in $\mathrm{mg} / \mathrm{ml}$ der Probe. Grundlage dieser Methode ist das Lambert-Beersche Gesetz $(E=\varepsilon \times c \times d)$, das das Verhältnis von Extinktion (E) zu Proteinkonzentration (c), spezifischem Extinktionskoeffizienten $(\varepsilon)$ und der Schichtdicke der durchstrahlten Probe (d) beschreibt. 


\subsubsection{Proteinsequenzierung}

Proteinsequenzierungen erfolgten am Institut für Biochemie II der Universität Göttingen unter der Leitung von Dr. K. Neifer. Um die Identität eines aufgereinigten Proteins $\mathrm{zu}$ identifizieren, erfolgte eine $\mathrm{N}$-terminale Sequenzierung der ersten zehn Aminosäuren.

\section{$2.14 \quad$ Proteinaufreinigung}

\subsubsection{Aufreinigung durch Hitzeschock}

Die Aufreinigung von Thil aus dem thermophilen Organismus Thermotoga maritima startete mit einem Hitzeschock. Während des Hitzeschocks denaturierte ein Großteil der E. coli-Proteine und konnte anschließend durch Zentrifugation abgetrennt werden.

Da in Vorversuchen gezeigt werden konnte, dass Plastikgefäße wie z.B. Falcon-tubes den Belastungen nicht standhielten, wurde der Überstand aus 2.12.1.4 in ein Glasgefäß überführt und für $10 \mathrm{~min}$ bei $80^{\circ} \mathrm{C}$ inkubiert. Dabei wurde die Probe zur optimalen Temperaturverteilung in 1 minütigem Abstand umgeschwenkt. Diese Vorgehensweise hatte sich in Vorversuchen als die effektivste für Thil erwiesen. Nach einer kurzen Abkühlphase im Eisbad wurde die Probe bei $30000 \mathrm{~g}$ und $24{ }^{\circ} \mathrm{C}$ für $10 \mathrm{~min}$ abzentrifugiert (Avanti J20 XPI, Beckman Coulter, Krefeld), der Überstand abgenommen, sterilfiltriert und für die nachfolgenden Reinigungen bei RT eingesetzt.

\subsubsection{Anionenaustauschchromatographie}

Die Anionenaustauschchromatographie beruht auf elektrostatischen Wechselwirkungen zwischen der positiv geladenen Säulenmatrix und negativen Bereichen des Proteins. Diese können durch eine steigende lonenkonzentration im Puffer aufgehoben werden, d.h. das Protein kann so wieder von der Säule eluiert werden. 
In diesem Fall wurde eine Diethylaminoethylmatrix (DEAE) verwendet. Der nach 2.12.1.4 (E. coli-Proteine) oder 2.14.1 ( $T$. maritima) erhaltene Rohextrakt wurde sterilfiltriert $(0,2 \mu \mathrm{m}$, Sartorius, Göttingen) und mit Hilfe eines Superloops, der an einem Äkta prime System (Amersham Bioscience, Freiburg) angeschlossen war, mit einer Flussgeschwindigkeit von $2 \mathrm{ml} / \mathrm{min}$ auf eine DEAE-Sepharose-Säule geladen. Nachdem ungebundene Proteine durch Spülen der Säule mit Puffer A heruntergewaschen worden waren (3 $\mathrm{ml} / \mathrm{min}$ ), wurde ein Gradient von 0-100 \% Puffer B angelegt (2 ml/min).

Der Verlauf der Aufreinigung wurde graphisch mit Hilfe eines Computers aufgezeichnet, und der gesamte Lauf mit einem Fraktionssammler fraktioniert.

Nach Erreichen von 100 \% Puffer B wurde darauf geachtet, dass die Leitfähigkeit stabil blieb, um sicherzustellen, dass die gesamte Säule in Puffer B war. Anschließend wurden Proben gezogen, indem je $20 \mu \mathrm{l}$ von Fraktionen in denen Extinktion bei $280 \mathrm{~nm}$ verzeichnet worden war, mit $20 \mu \mathrm{l}$ Laemmli-Puffer versetzt wurden. Diese wurden dann durch SDS-PAGE analysiert (2.13).

\section{$\underline{\text { Puffer A }}$}

$\begin{aligned} 50 \mathrm{mM} & \mathrm{NH}_{4} \mathrm{Cl} \\ 50 \mathrm{mM} & \text { Tris-HCl, pH } 7.5 \\ 2 \mathrm{mM} & \text { DTT }\end{aligned}$

$\underline{\text { Puffer B }}$

\begin{tabular}{|c|c|}
\hline $50 \mathrm{mM}$ & $\mathrm{NH}_{4} \mathrm{Cl}$ \\
\hline $50 \mathrm{mM}$ & Tris-HCl, $\mathrm{pH} 7.5$ \\
\hline $1 M$ & $\mathrm{NH}_{4}\left(\mathrm{SO}_{4}\right)_{2}$ \\
\hline $\mathrm{mM}$ & DTT \\
\hline
\end{tabular}

\subsubsection{Gelfiltrationschromatographie}

Mit Hilfe der Gelfiltration kann man Proteine in Abhängigkeit von ihrem Stokes-Radius trennen. Die Gelpartikel bestehen aus einem inerten stark hydratisierten Material von sehr poröser Struktur. Aufgrund der unterschiedlichen Porengröße können Proteine mehr oder weniger tief in die Säulenmatrix eindringen, was wiederum zu der Geschwindigkeit, mit der sie im Anschluss von der Säule eluiert werden, in proportionalem Verhältnis steht. 
Nach der Anionenaustauschchromatographie und der folgenden SDS-PAGE wurden die Fraktionen, von denen gezeigt werden konnte, dass sie Thil (MnmA) enthielten, gepoolt und mittels eines VIVAspin Konzentrators (cut-off $30000 \mathrm{Da}$ ) auf ca. $10 \mathrm{ml}$ ankonzentriert. Die Reinigung erfolgte über eine 26/60 S75 Superdexsäule. Die ankonzentrierte Probe wurde sterilfiltriert und mit einem Superloop auf die Säule gebracht $(1,5 \mathrm{ml} / \mathrm{min})$. Anschließend wurde der Fluss auf $0.5 \mathrm{ml} / \mathrm{min}$ reduziert, der Säulenlauf mit Hilfe eines Fraktionssammlers gesammelt und der Verlauf anhand der Extinktion bei $280 \mathrm{~nm}$ auf einem angeschlossenen Computer dokumentiert. Von den entsprechenden Fraktionen wurden Proben gezogen $(20 \mu \mathrm{l}$ Probe $+20 \mu \mathrm{l}$ Laemmli), die mittels SDS-PAGE analysiert wurden. Diejenigen, welche Thil (bzw. MnmA) enthielten, wurden zur weiteren Verwendung ankonzentriert (2.14.7).

\begin{tabular}{cl}
\multicolumn{2}{c}{ S75 Laufpuffer } \\
$150 \mathrm{mM}$ & $\mathrm{NH}_{4}\left(\mathrm{SO}_{4}\right)_{2}$ \\
$20 \mathrm{mM}$ & Tris- $\mathrm{HCl}, \mathrm{pH} 7.5$
\end{tabular}

\subsubsection{Hydrophobe Interaktions Chromatographie (HIC)}

Im Falle des Thil (bzw. MnmA) aus E. coli erfolgte zwischen Anionenaustauschchromatographie und Gelfiltration noch ein Reinigungsschritt mit Hydrophober Interaktions Chromatographie (HIC). Bei dieser Reinigungsmethode werden die hydrophoben Bereiche des Proteins durch eine Erhöhung der Salzkonzentration exponiert. Dadurch können diese an die hydrophobe Säulenmatrix binden. Da dieser Prozess reversible ist, können durch eine Reduzierung der Salzkonzentration die Proteine in Anhängigkeit von ihrer Hydrophobizität wieder von der Säule eluiert werden.

Die Fraktionen aus 2.14.3, von denen gezeigt werden konnte, dass sie Thil (bzw. MnmA) enthielten, wurden gepoolt und mit der Menge an Ammoniumsulfat versetzt, die dazu nötig war, die Endkonzentration auf $1 \mathrm{M}$ Ammoniumsulfat anzuheben. Die Probe wurde sterilfiltriert (0,2 $\mu \mathrm{m}$, Sartorius, Göttingen) und mit Hilfe eines Superloops, der an ein ÄKTAPurifier-System angeschlossen worden war, auf eine Phenylsepharosesäule 
gebracht. Nach dem Auswaschen von ungebundenen Proteinen wurde ein Gradient von 1-0 M Ammoniumsulfat angelegt. Der Verlauf der Aufreinigung wurde anhand der Extinktion bei $280 \mathrm{~nm}$ mit Hilfe eines angeschlossenen Computersystems aufgezeichnet und mittels eines Fraktionssammlers fraktioniert.

Im Anschluss wurden die Fraktionen durch SDS-PAGE analysiert (siehe auch 2.13)

\begin{tabular}{|c|c|c|c|}
\hline \multicolumn{2}{|c|}{ Puffer A } & \multicolumn{2}{|c|}{ Puffer B } \\
\hline $20 \mathrm{mM}$ & $\mathrm{NH}_{4} \mathrm{Cl}$ & $20 \mathrm{mM}$ & $\mathrm{NH}_{4} \mathrm{Cl}$ \\
\hline $50 \mathrm{mM}$ & Tris-HCl, $\mathrm{pH} 7.5$ & $50 \mathrm{mM}$ & Tris-HCl, $\mathrm{pH} 7.5$ \\
\hline $1 \mathrm{M}$ & $\mathrm{NH}_{4}\left(\mathrm{SO}_{4}\right)_{2}$ & $2 \mathrm{mM}$ & DTT \\
\hline $2 \mathrm{mM}$ & DTT & & \\
\hline
\end{tabular}

\subsubsection{Affinitätschromatographie}

Im Falle der als MBP-Fusionsproteine (Maltose-Binding-Protein) exprimierten Proteine wurde der Rohextrakt (siehe 2.12.1.4) im ersten Reinigungsschritt über die Affinität von MBP zu Amylose aufgereinigt.

Dazu wurden die mit pMAL-c2XP-thil oder -mnmA transformierten $E$. coli ER2508 Zellen nach 2.12.1.2 mit 0,5 mM IPTG induziert. Um die Expression der Enzyme amyA (a-Amylase) und malE (MBP) aus E. coli zu inhibieren, erfolgte die Zellanzucht in LB-Medium unter Zusatz von $1 \%$ Glucose.

Nach der Ernte wurden die Zellen analog zu 2.12.1.4 resuspendiert und aufgeschlossen. Die Aufreinigung fand im batch-Verfahren statt. Amylosebeads (NEB, Frankfurt a.M.) wurden in eine kommerziell erhältliche Leersäule (Poly-Prep Chromatography Columns, Biorad, München) gegeben und mit Lysis-Wasch-Puffer äquilibriert. Danach erfolgte der Auftrag der Probe. Nach dem Auswaschen von ungebundenen Proteinen durch LysisWasch-Puffer (Kontrolle des Durchflusses mittels Bradford-Bestimmung) erfolgte die Elution des MBP-Fusionsproteins mit Elutionspuffer. Das Eluat wurde dabei aufgefangen. Mittels Bradford-Bestimmung wurde analysiert, in welchen Fraktionen sich Protein befand. Eine anschließende SDS-PAGE 
(Siehe 2.13) dieser Proben zeigte den Verlauf der Affinitätschromatographie auf.

\begin{tabular}{|c|c|c|c|}
\hline \multicolumn{2}{|c|}{ Lysis-Wasch-Puffer } & \multicolumn{2}{|c|}{ Elutionspuffer } \\
\hline $50 \mathrm{mM}$ & Tris-HCl, pH 7.5 & $50 \mathrm{mM}$ & Tris-HCl, $\mathrm{pH} 7.5$ \\
\hline $300 \mathrm{mM}$ & $\mathrm{NaCl}$ & $300 \mathrm{mM}$ & $\mathrm{NaCl}$ \\
\hline $1 \mathrm{mM}$ & EDTA & $1 \mathrm{mM}$ & EDTA \\
\hline $2 \mathrm{mM}$ & DTT & $10 \mathrm{mM}$ & Maltose \\
\hline & & $2 \mathrm{mM}$ & DTT \\
\hline
\end{tabular}

Regeneration des Säulenmaterials:

- 2 Säulenvolumen $\mathrm{H}_{2} \mathrm{O}_{\text {bidest. }}$

- 2 Säulenvolumen 0,1\% SDS

- 3 Säulenvolumen $\mathrm{H}_{2} \mathrm{O}_{\text {bidest. }}$

anschließend wurde die Säulenmatrix in $20 \%$ Ethanol überführt.

\subsubsection{Spaltung mit PreScission ${ }^{\mathrm{TM}}$-Protease}

Im Vektor pMAL-c2XP war zwischen den Gensequenzen, die für MBP und das Zielprotein kodieren, eine PreScission ${ }^{\mathrm{TM}}$-Protease Erkennungssequenz inseriert worden (Gouloudis, 2005). Diese ermöglichte es, MBP durch die hochspezifische PreScission ${ }^{\mathrm{TM}}$-Protease (Erkennungssequenz: LEVLFQGP) vom Zielprotein abzutrennen.

Dazu wurde die Proteinkonzentration der aus 2.14.5 erhaltenen Suspension mittels Bradford bestimmt. Zu $1 \mathrm{mg} \mathrm{MBP-Fusionprotein} \mathrm{wurden} 20 \mu \mathrm{l}$ PreScission ${ }^{\mathrm{TM}}$-Protease $(\mathrm{c}=0,3 \mathrm{mg} / \mathrm{ml})$ zugegeben. Die Inkubation erfolgte unter stetigem Umschwenken bei $4{ }^{\circ} \mathrm{C}$ über Nacht.

\subsubsection{Konzentrierung von Proteinen}

Um die Konzentration von Proteinsuspensionen z.B. für Kristallisationsansätze zu erhöhen, oder auch das Volumen einer Proteinsuspension vor einem Säulenlauf zu verringern, wurden VIVAspin Konzentratorröhrchen (Vivascience, Hannover) verwendet. Bei diesen wird die Proteinsuspension 
dadurch ankonzentriert, dass die Suspension durch Zentrifugation (Fliehkräfte) gegen eine Membran mit definierter Ausschlussgrenze (cut-off) gedrückt wird. Hierbei können alle Moleküle, deren Größe unterhalb des cutoffs liegt, die Membran passieren. Für Thil-Suspensionen wurden Konzentratoren mit cut-offs von $30 \mathrm{kDa}$ verwendet, für die Konzentrierung des Komplexes wurden $10 \mathrm{kDa}$ cut-offs verwendet, da die verwendete RNA eine Größe von $13 \mathrm{kDa}$ aufwies. Die Zentrifugationen erfolgten bei $15{ }^{\circ} \mathrm{C}$ und 3000 g (Allegra 2IR centrifuge, Beckman Coulter, Krefeld). Um eventuelle Präzipitate zu entfernen, wurde das Konzentrat im Anschluss, in Anhängigkeit vom verbliebenen Volumen, sterilfiltriert, oder scharf abzentrifugiert (Eppendorf centrifuge 5417R, Eppendorf, Hamburg).

\subsubsection{Spektrum zur Kontrolle auf unspezifische Aggregation}

Um sicher zu stellen, dass im Zuge der Aufreinigung keine unspezifischen Aggregate in der Proteinsuspension aufgetreten waren, die eine Kristallisation schon im Vorfeld stark erschwert hätten, wurde mit einem Photometer (Ultrospec 2100pro, Pharmacia, Cambridge, England) ein Spektrum von $200 \mathrm{~nm}$ bis $900 \mathrm{~nm}$ aufgenommen. Anhand des charakteristischen Kurvenverlaufs kann hierbei festgestellt werden, ob bei dem vorliegenden Protein eine unspezifische Aggregation vorliegt.

Die Messungen erfolgten in UV durchlässigen $1 \mathrm{ml}$ Quarzküvetten.

\subsection{Komplexierung mit RNA}

Nach erfolgreicher Aufreinigung von Thil, wurde dieses mit einem RNAFragment, von dem zuvor gezeigt worden war, dass es sich um das Minimalsubstrat zur erfolgreichen Enzymkatalyse handelt (Lauhon, 2004) komplexiert.

Dazu wurden nach der S75 Gelfiltration (2.14.3) die Fraktionen, die auf dem SDS-Gel Thil enthielten, vereinigt und auf eine Proteinkonzentration zwischen 5 und $10 \mathrm{mg} / \mathrm{ml}$ gebracht (2.14.7). Anschließend wurde diejenige Menge an RNA zugegeben, die benötigt wurde, um ein molares Verhältnis 
von Protein zu RNA von 1: 1,5 einzustellen. Dieser Ansatz wurde dann bei $4{ }^{\circ} \mathrm{C}$ unter stetiger Bewegung auf einem Rollenmischer für $1 \mathrm{~h}$ inkubiert.

Anschließend wurde der komplette Ansatz über eine S75-Säule (10/30) gegeben, um überschüssige RNA abzutrennen (2.14.3).

Nach Beendigung des Laufes wurden Proben gezogen $(10 \mu \mathrm{l}$ Probe $+10 \mu \mathrm{l}$ Laemmli), die einer SDS-PAGE unterzogen wurden. Diese wurden mit STAINS ALL angefärbt (2.13.1.2). Komplex enthaltene Fraktionen wurden ankonzentriert (siehe 2.14.7) und für Kristallisationssversuche verwendet.

\subsection{Kristallisation von Proteinen}

\subsubsection{Kristallisation im sitting drop Verfahren}

Kristallisationen wurden im "Sitzenden Tropfen“ in Fertigplattensystemen (Cryschem Plate, Hampton Research, USA) durchgeführt. Dazu wurden zu $1 \mu \mathrm{l}$ Proteinsuspension (oder Komplexsuspension) mit einer Konzentration zwischen $5 \mathrm{mg} / \mathrm{ml}$ und $15 \mathrm{mg} / \mathrm{ml}$ je $1 \mu \mathrm{l}$ Reservoirlösung pipettiert. Zur Suche nach unbekannten Kristallisationsbedingungen wurden die kommerziell erhältlichen Screens der Firmen Hampton Research (Crystal Screen 1 und 2, Crystal Screen Lite, Crystal Screen Cryo, PEG/ION-Screen), Jena Bioscience (JBScreen 1-10), Biogenova (Magic Screen) und Molecular Dimensions (Footprint Screen 1-3, Structure Screen) verwendet. Die Platten wurden mit einer klaren, lösungsmittelbeständigen Klebefolie versiegelt und unter stetiger Kontrolle mit einem Binokular (MZ125-Stereo, Leica) bei $20^{\circ} \mathrm{C}$ inkubiert.

Erfolg versprechende Ansätze (kleine Kristalle, Mikrokristalle oder Spheruliten) wurden unter Variation der einzelnen Screen-Bestandteile reproduziert und feingescreent.

Kristalle von Thil aus T. maritima konnten so nach drei Tagen erhalten werden. Ihre Größe nahm aber über einen Zeitraum von ca. 3 Monaten stetig zu. Die Dokumentation von Kristallen erfolgte mit einer Digitalkamera (Nikon Coolpix 4500). 


\subsubsection{Cryopuffer}

Um während der Datenaufnahme die molekularen Eigenbewegungen und Strahlungsschäden in den Kristallen möglichst gering zu halten, werden Messungen meist bei $100 \mathrm{~K}$ im steten Stickstoffstrom durchgeführt. Um zu verhindern, dass beim dazu nötigen Tieffrieren der Kristalle Eiskristalle entstehen, die die geordnete Struktur im Inneren der Kristalle zerstören würden, muss ein geeignetes Cryoprotektans gefunden werden. Dieses sorgt dafür, dass das Wasser der Mutterlauge zu einem glasartigen Aggregatzustand gefriert. Weiterhin sollte dieses Cryoprotektans keinen Effekt auf die Kristalle haben.

Für die hier verwendeten Thil-RNA-Komplexkristalle hatte sich die Zugabe von $30 \%$ Glycerin zum Kristallisationspuffer (100 mM Natriumcitratpuffer, pH 4.6 und 2 M Natriumformiat) als effektivster Cryopuffer erwiesen.

\subsection{Phasenproblem}

Während der Datenaufnahme werden nur die Intensitäten $I_{\mathrm{hkl}}$ der Reflexe gemessen. Um die Elektronendichte berechnen zu können, werden jedoch die Strukturfaktoren $F_{h k l}$ benötigt. Für diese gilt:

$F_{h k l}=\mid F_{h k l} l \exp \left(i \varphi_{h k l}\right)$

Wobei:

$\left|f_{h k l}\right|=\sqrt{ }\left|F_{h k \mid}\right|$

Die Phaseninformation $\varphi_{\mathrm{hkl}}$ geht jedoch während des Messvorganges komplett verloren.

Um diese Phaseninformation $\varphi_{\mathrm{hkl}} \mathrm{zu}$ erhalten, werden Schwermetallionen in die Einheitszelle eingebaut, woraus sich ergibt: 
$F_{\text {hklderiv. }}=F_{\text {hklnat }}+f_{\text {hkl }}$

Es repräsentiert hierbei $F_{\text {hklderiv. }}$ die Strukturfaktoren des mit Schwermetallionen dotierten Kristalls, $F_{\text {hklnat }}$ die Strukturfaktoren des nativen Kristalls und $f_{\text {hkl }}$ die Strukturfaktoren des Schwermetalls.

Die Strukturfaktoren des Schwermetalls $f_{h k l}$ lassen sich anhand der Strukturgleichung aus der Atomzahl des verwendeten Schwermetalls und seinen Positionen in der Einheitszelle errechnen. Da $F_{h k l}$ schon aus den Datensätzen bekannt ist, erfährt Gleichung [1] eine Lösung.

Um die Position(en) des Schwermetalls in der Einheitszelle zu bestimmen, bedient man sich der Patterson Methode.

\subsubsection{Selenomethionin}

Eine Möglichkeit zur Lösung des Phasenproblem ist die Insertion von Selen und die Durchführung eines MAD (multi wavelength anomalous diffraction) Experimentes, in dem Datensätze von Selen-enthaltenden Kristallen bei drei verschiedenen Wellenlängen (peak, inflection und remote) aufgenommen werden.

Um diese Methode zu nutzen, wurde Selen durch Transformation in den Methionin-auxotrophen Stamm E. coli B834 (DE3) und einer anschließenden Expression unter Zugabe von Selenomethionin (siehe 2.12.1.3) inseriert. Die Aufreinigung erfolgte analog zu der des nativen Thil (siehe 2.12).

Die Insertion von Selenomethionin konnte von Herrn Dr. Bernhard Schmitt (MPI für experimentelle Medizin, Göttingen) durch MALDI-TOF nachgewiesen werden.

\subsubsection{Schwermetallsoaks}

Da die Selenomethionindatensätze zu keinem aussagekräftigem Ergebnis führten, wurde versucht Kristalle mit Schwermetallen zu dotieren, um MIR (multiple isomorphous replacement) Experimente durchführen zu können.

Dazu wurden Kristalle in eine Lösung bestehend aus Muttertropfen und diversen Schwermetalllösungen (v.a. Hg, Pt) einer Konzentration von $5 \mathrm{mM}$ 
für 20 min inkubiert. Anschließend wurde der Kristall mit einem Loop gefischt und schnell durch das Cryoprotektans gezogen, bevor er zur Datenaufnahme montiert wurde (siehe 2.19.1).

\section{$2.18 \quad$ Free Mounting System (FMS)}

Da es nach längerer Experimentierphase nicht gelungen war, die Qualität der Kristalle durch Variation des Cryopuffers und/oder der Kristallisationsbedingung zu verbessern, wurden die Kristalle der Methode des „Free Mounting Systems“ (FMS) unterzogen. Diese Versuche fanden bei der Fa. Proteros in München unter der freundlichen Mithilfe von Herrn Dr. Reiner Kiefersauer statt.

Beim FMS wird ein Kristall ohne Mutterlösung in einem Gasstrom bestimmter Humidität montiert. Eine kontrollierte Reduktion der Humidität des Gasstroms und somit auch der Humidität im Kristall hat in der Vergangenheit schon öfter zu einer Steigerung der Datenqualität geführt (Kiefersauer et al., 2000).

Um die geeignete Bedingung für die hier verwendeten Thil-Kristalle zu bestimmen, wurde zuerst die Mutterlösung in einem Loop in der FMSApparatur eingespannt. Nun wurde die Start-Humidität des Gasstroms bestimmt, indem überprüft wurde bei welcher Humidität der Tropfen keine Änderung seines Volumens zeigt (Überwachung und Auswertung durch ein computergestütztes Videosystem). Anschließend wurden Kristalle bei diesem Humiditätswert eingespannt. Nachdem die restliche Mutterlösung mit einem Filterpapierstreifen aus dem Loop entfernt wurde, begann das kontrollierte Austrocknen des Kristalls. Hierbei wurde kontinuierlich die Qualität der Röntgenstrahlenstreuung gemessen. Nachdem der Punkt gefunden worden war, an dem die Streuung des Kristalls zu einem Maximum bezüglich der Auflösung gebracht werden konnte, konnten mehrere Kristalle nacheinander in diesen Zustand gebracht werden und bei der Siedetemperatur von flüssigem Stickstoff für Messungen am Synchrotron weggefroren werden. 


\section{Datensammlung}

\subsubsection{Montieren der Proben}

Um die Kristalle untersuchen zu können, wurden sie mit einem sogenannten „Loop“ aus dem Muttertropfen gefischt. Bei einem Loop handelt es sich um eine Nylonschleife, die an einer Metallkapillare befestigt ist. Diese wiederum wird zuvor in eine Kupferhalterung eingeklebt (Crystal Cap Copper, Hampton Research, USA).

Nachdem der Kristall aus dem Muttertropfen gefischt worden war, wurde er kurz durch einen Tropfen des Cryoprotektants gezogen, am Goniometerkopf montiert und im Strahl fokussiert.

\subsubsection{Datensammlung an einer Drehanode}

Vor Ort erfolgte die Datenaufnahme an einer Drehanode (Rigaku, England). Hier werden Röntgenstrahlen dadurch erzeugt, dass von einem unter Hochspannung stehenden Wolframdraht Elektronen emitiert werden und in einem angelegten elektrischen Feld beschleunigt werden. Diese treffen mit hoher kinetischer Energie auf eine Kupferanode und ihre Energie wird vom Elektronengitter absorbiert. Ein Teil der Energie wird hierbei als sog. Bremsstrahlung abgestrahlt. Teilweise können auch Elektronen des Kupfers aus inneren Schalen herausgeschlagen werden. Diese werden durch Elektronen äußerer Schalen ersetzt, die bei diesem Übergang Energie durch Abgabe von Röntgenstrahlung freisetzen.

Die hier zu röntgenkristallographischen Untersuchungen genutzte Strahlung einer Wellenlänge von $1,542 \AA$ wird beim Übergang zwischen $L$ und $K-$ Schale des Kupfers emitiert.

Um an der Drehanode Daten aufzunehmen, musste mit Belichtungszeiten von 20- 30 min pro Aufnahme gearbeitet werden. 


\subsubsection{Datensammlung am Synchrotron}

In Synchrotronen werden Elektronen auf einer Kreisbahn auf sehr hohe Geschwindigkeiten beschleunigt. Die Elektronen befinden sich dabei in einem Hochvakuum und werden durch starke Magnetfelder auf ihrer Bahn stabilisiert, da sie sonst sehr schnell mit Materie wechselwirken würden. Durch die Bewegung der Ladung werden Röntgenstrahlen emitiert, jedoch ist hier die Wellenlänge der Strahlung eine Funktion der Beschleunigung, so dass mit einer Vielzahl verschiedener Röntgenstrahlenwellenlängen gearbeitet werden kann. Desweiteren besitzen die Röntgenstrahlen am Synchrotron im Vergleich zu den an Drehanoden erzeugten Röntgenstrahlen eine wesentlich höhere Energie. Aus diesem Grund kann die Belichtungszeit stark herabgesetzt werden.

Um Röntgenstrahlung mit diversen Wellenlängen für z.B MAD Experimente zu nutzen, wurden Kristallmessungen an Synchrotronen (BESSY, Berlin; DESY, Hamburg; ESRF, Grenoble) durchgeführt. Als zusätzlicher positiver Effekt war hier eine Verbesserung der Streuung und der Datenqualität im Ganzen zu beobachten.

Um an Synchrotronen Datensätze von Thil Kristallen aufzunehmen, wurde mit Belichtungszeiten zwischen 5 und 30 s pro Aufnahme gearbeitet.

\subsection{Datenprozessierung}

Nach erfolgreicher Datenaufnahme wurden die Datensätze mit Hilfe der Programme DENZO und SCALEPACK (Otwinowski und Minor, 1997) prozessiert. Die Suche nach Schwermetallen erfolgte mit den Programmen SHELX (Sheldrick, 1997), SHARP (de la Fortelle und Bricogne, 1997) und SOLVE (Terwilliger und Berendzen, 1999). Weiterhin wurde mit diversen Programmen z.B. zur Änderung des Dateienformats oder zur Datenverfeinerung aus dem Paket CCP4 (Daresbury Laboratory, 1994) wie z.B. POLARRFN (Kabsch, 1994) zur Berechnung der Selbstrotationsfunktion, gearbeitet. Elektronendichten wurden mit O (Jones und Kjeldgaard, 1991) oder mit XFIT (Ellis und Freeman, 1995) berechnet. 


\subsection{Chemikalien, Biochemikalien und Enzyme}

Soweit nicht anders angegeben, wurden Chemikalien und Biochemikalien der Reinheitsstufe pro analysi (p.a.) oder reinst und Enzyme von folgenden Firmen benutzt:

APPLICHEM (Darmstadt), FLUKA (Buchs, Schweiz), OXOID (Basingstoke, Hampshire), ROTH (Karlsruhe), SERVA (Heidelberg), SIGMA-ALDRICH (Steinheim)

Restriktionsendonukleasen und T4-DNA-Ligase stammten von den Firmen NEW ENGLAND BIOLABS (Frankfurt am Main) und MBI FERMENTAS (St. Leon-Rot)

Die verwendete RNA wurde von der Firma IBA (Göttingen) synthetisiert.

Kristallisationsbedarf wie Cryschem-Platten, Klebefolie, Loops und Kupferhalterungen, Screens (teilweise) und Screenbestandteile (MME-PEGs) stammten von der Firma HAMPTON RESEARCH (USA) 


\section{Ergebnisse}

3.1

Expression und Aufreinigung von Thil und MnmA aus Escherichia coli

Zu Beginn der Arbeiten waren die Gene thil und $m n m A$ aus Escherichia coli (E. coli) in die Vektoren pET21b (thil) oder pET21c (mnmA) kloniert. Diese waren freundlicherweise von Dr. Lauhon (Madison, USA) zur Verfügung gestellt worden. Ein erstes Aufreinigungsprotokoll war bereits von Fr. A. Berndt etabliert worden, und die Expression erfolgte nach Abschnitt 2.12.1.2 in E. coli BL21(DE3)pLysS. Zur Aufreinigung von Thil wurde dieses Protokoll unverändert übernommen, während im Falle des Aufreinigungsprotokolls von MnmA Modifikationen erfolgten (Wechsel von $\mathrm{NaCl} z u$ $\left(\mathrm{NH}_{4}\right)_{2} \mathrm{SO}_{4}$-Puffer). Die Reinigungen der Proteine Thil und MnmA erfolgte durch verschiedene FPLC-Reinigungsmethoden bei Raumtemperatur mit Hilfe eines Äkta-Purifier-Systems.

\subsubsection{Expression und Aufreinigung von Thil aus E. coli durch}

\section{Anionenaustauschchromatographie}

Das Gen thil, das für die 4-Thiouridin Synthetase Thil kodiert, lag bereits im Expressionsvektor pET21b kloniert vor (Abb. 10).

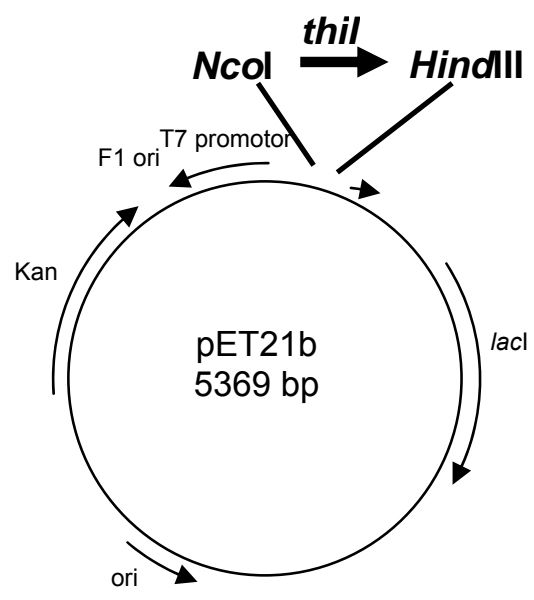

Abb. 10) Plasmidkarte des Expressionsvektors pET21b-thil 
Zu Abb. 10.)

Der Vektor besteht aus dem lacl Repressorgen, dem Replikationsursprung ori, dem Ampicillin-Resistenzgen und dem Replikationsursprung F1-ori. Die Expression des in die MCS einklonierten thil-Fragments stand unter Kontrolle des T7-Promotors. Die Klonierung des thil-Gens als Ncol-HindIII-Fragment resultiert in einem Tag-frei-exprimierten Zielprotein.

Die Expression wurde wie in Abschnitt 2.12.1.2 beschrieben durchgeführt. Es erfolgte eine Kontrolle der Expression durch SDS-PAGE-Analyse (Abb. 11). Dabei konnte festgestellt werden, dass Thil (57 kDa, Pfeil) exprimiert worden war.

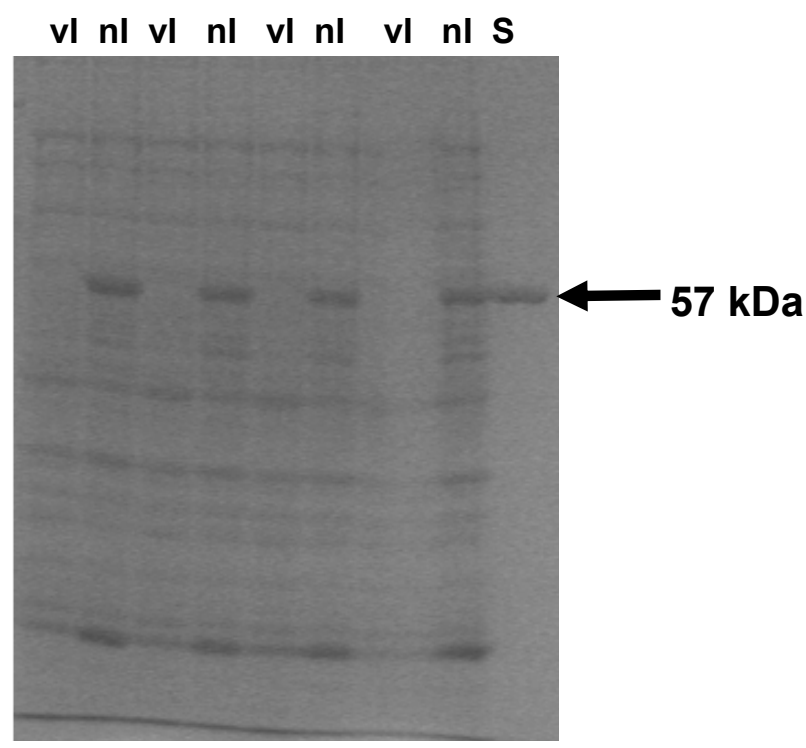

\section{Abb. 11) SDS-PAGE der Expression von Thil aus E. coli}

Die Gelelektrophorese fand unter denaturierenden Bedingungen in einem 12,5 \%-igen Gel statt. Die Anfärbung erfolgte nach Coomassie (2.13.1.1).

Es bedeuten: vl: vor Induktion

nl: nach Induktion

S: Standard $=$ Thil aus vorangegangener Aufreinigung

Mit pET21b-thil transformierte E. coli BL21 pLysS Zellen wurden bei $37^{\circ} \mathrm{C}$ inkubiert, und nach Erreichen einer $\mathrm{OD}_{600}$ von 0,5 wurde die Genexpression durch Zugabe von 0,5 mM IPTG induziert. Die Probenentnahme erfolgte vor Induktion (vl) und nach Induktion ( $\mathrm{nl}$ ) der Genexpression. Es ist deutlich ersichtlich, dass Thil (57 kDa, Pfeil) erfolgreich exprimiert werden konnte.

Nachdem so gezeigt werden konnte, dass Thil aus E. coli exprimiert wird, wurde damit begonnen, dieses aufzureinigen. Nach der Lyse der Zellen (siehe 2.12.1.4) erfolgte als initialer Aufreinigungsschritt eine Anionenaus- 
tauschchromatographie (ResourceQ). Die Probe wurde mit Hilfe eines Superloops auf die Säule aufgetragen. Anschließend wurden ungebundene Proteine durch Spülen mit Puffer A von der Säule gewaschen. Durch das Anlegen eines Gradienten von 0-1 $\mathrm{M}\left(\mathrm{NH}_{4}\right)_{2} \mathrm{SO}_{4}$ wurden die gebundenen Proteine von der Säule eluiert. Die Reinigung wurde über die Aufzeichnung der Extinktion bei einer Wellenlänge von $280 \mathrm{~nm}$ verfolgt (siehe Abb. 12).

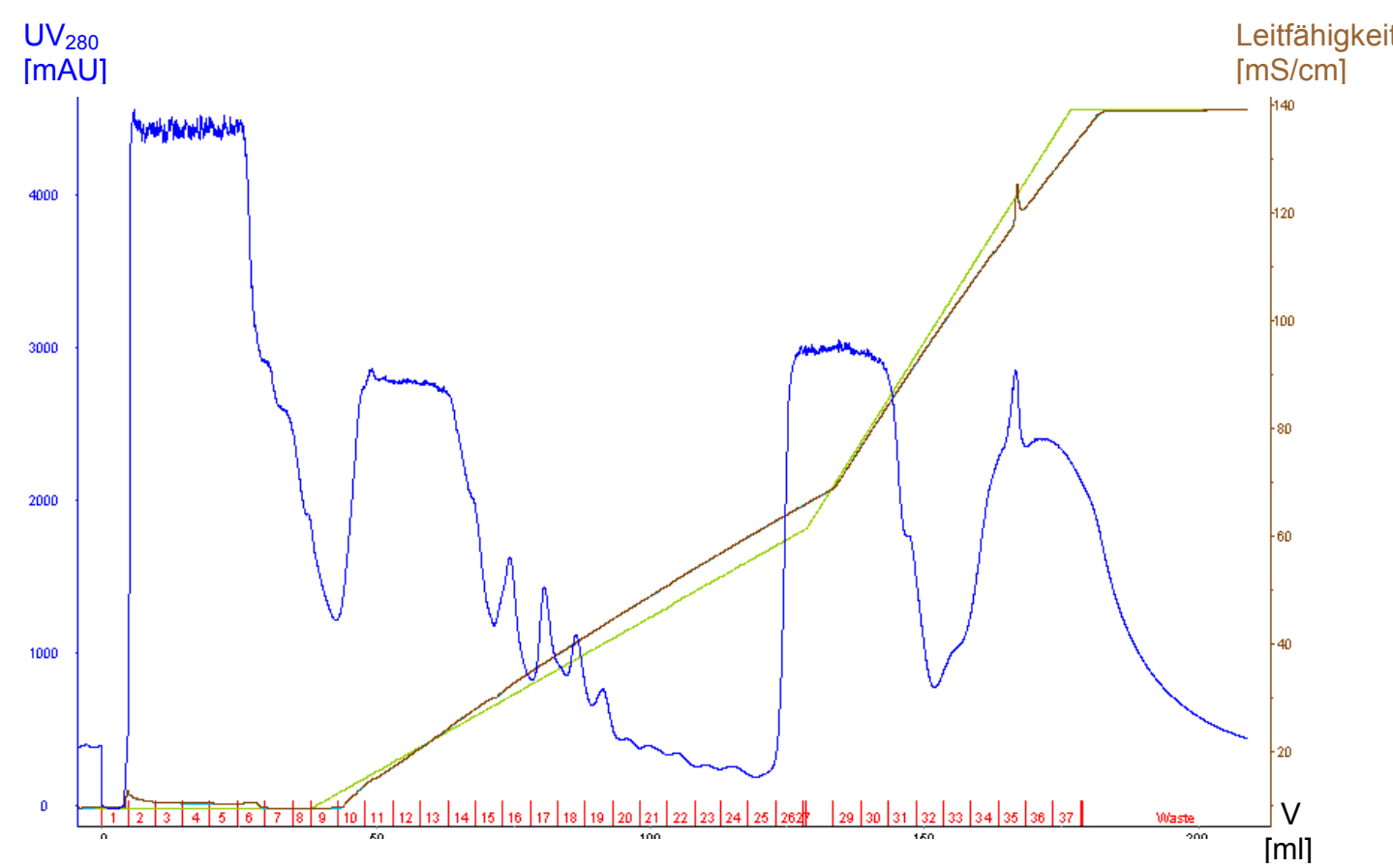

Abb. 12) Elutionsprofil der Aufreinigung von Thil aus E. coli über einen Anionenaustauscher (ResourceQ)

Die nach 2.12.1.4 vorbehandelte Probe wurde auf eine ResourceQ Säule $(6 \mathrm{ml})$ aufgetragen. Nach einem kurzen Waschschritt, um ungebundene Proteine zu entfernen (Extinktion sinkt), wurde durch Anlegen eines Gradienten (0 M - $\left.1 \mathrm{M}\left(\mathrm{NH}_{4}\right)_{2} \mathrm{SO}_{4}\right)$ damit begonnen, auch die gebundenen Proteine von der Säule zu eluieren. Die Flussgeschwindigkeit während der gesamten Aufreinigung betrug $1 \mathrm{ml} / \mathrm{min}$. Eine anschließende SDS-PAGE (Abb. 13) zeigte, in welchen Fraktionen das Zielprotein zu finden war.

Es gilt folgender Farbcode: Blau: Extinktion bei $280 \mathrm{~nm}$

Grün: Gradient [\% B]

Braun: Leitfähigkeit [mS/cm] 


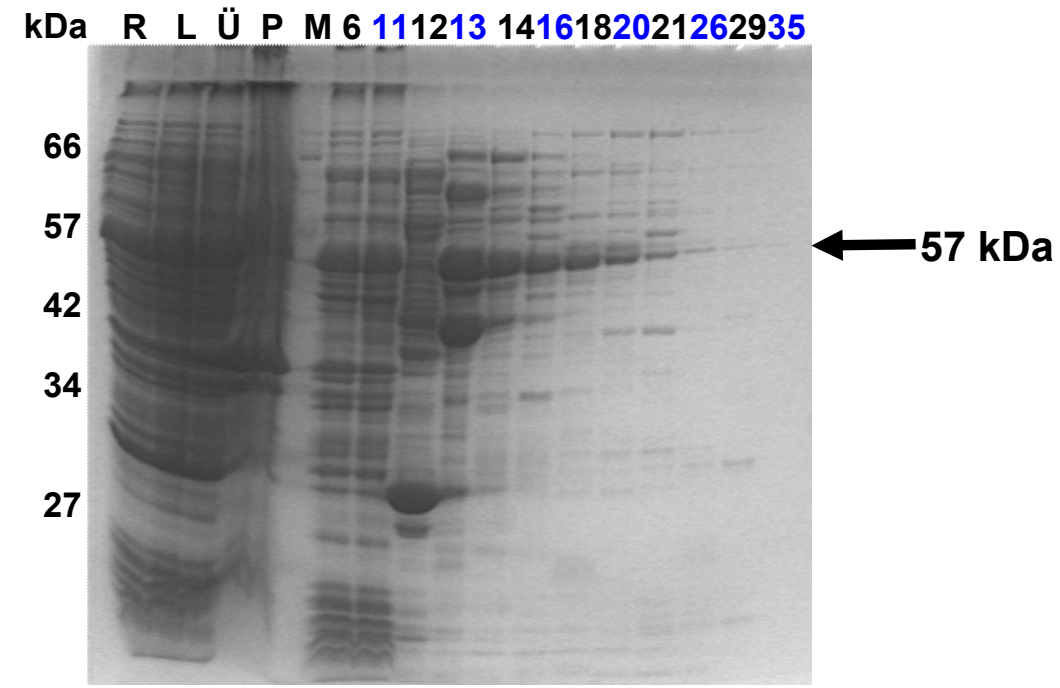

\section{Abb. 13) SDS-PAGE der Reinigung von Thil aus $E$. coli durch Anionenaustauschchromatographie (ResourceQ)}

Die Gelelektrophorese fand unter denaturierenden Bedingungen in einem 12,5\%-igen Gel statt. Die Anfärbung erfolgte nach Coomassie (2.13.1.1).

Es bedeuten: R: Rohextrakt = resuspendierte Zellen

L: Lysat $=$ Suspension nach Zellaufschluss

Ü: Überstand

P: Pellet

M: Größenstandard

Es ist zu erkennen, dass Thil bei ca. $30 \%$ Puffer B $\left(\sim 300 \mathrm{mM}\left(\mathrm{NH}_{4}\right)_{2} \mathrm{SO}_{4}\right)$ eluiert wurde (Fraktionen 13-21).

Während der Reinigung war zu erkennen, dass die Extinktion bei $280 \mathrm{~nm}$ beim Auftragen der Probe stark ansteigt und während des Spülens wieder abfällt (Abb. 12). Anhand des SDS-Gels (Abb. 13) wurde ersichtlich, dass während des Waschschritts schon Thil eluiert wurde, was darauf hinweist, dass die Bindekapazität der Säule überschritten wurde. Außerdem wurde deutlich, dass der Waschschritt insgesamt zu kurz verlief, da noch Proteine von der Säule gewaschen wurden, als der Gradient schon startete. Die Elution von Thil erfolgte hauptsächlich ab einer Salzkonzentration von ungefähr $30 \%\left(\mathrm{NH}_{4}\right)_{2} \mathrm{SO}_{4}$ (Fraktionen 13-21). Im Vergleich zur Intensität der Thil-Bande im Rohextrakt wird ersichtlich, dass bereits ein Teil der E. coliProteine von Thil abgetrennt werden konnte. Es wurden so - zusammen mit Thil - v.a. Proteine mit Größen von ca. 60 kDa, ca. 42 kDa und ca. 27 kDa eluiert. 
Weitere Anreicherung von Thil aus E. coli durch Hydrophobe Interaktions Chromatographie (HIC)

Zur weiteren Reinigung des Thil aus E. coli wurde eine hydrophobe Interaktionschromatographie mit Hilfe einer Phenylsepharosesäule durchgeführt. Dazu wurden die Fraktionen, in denen nach dem ResourceQ-Säulenlauf Thil durch SDS-PAGE nachgewiesen worden war, vereinigt, die lonenkonzentration durch Zugabe von $\left(\mathrm{NH}_{4}\right)_{2} \mathrm{SO}_{4}$ auf eine Endkonzentration von $1 \mathrm{M}$ angehoben und die sterilfiltrierte Probe auf eine Phenylsepharosesäule geladen. Die Elution erfolgte dann durch einen absteigenden Salzgradienten. Der Verlauf der Reinigung wurde durch Aufzeichnung der Extinktion bei $280 \mathrm{~nm}$ verfolgt (Abb. 14)

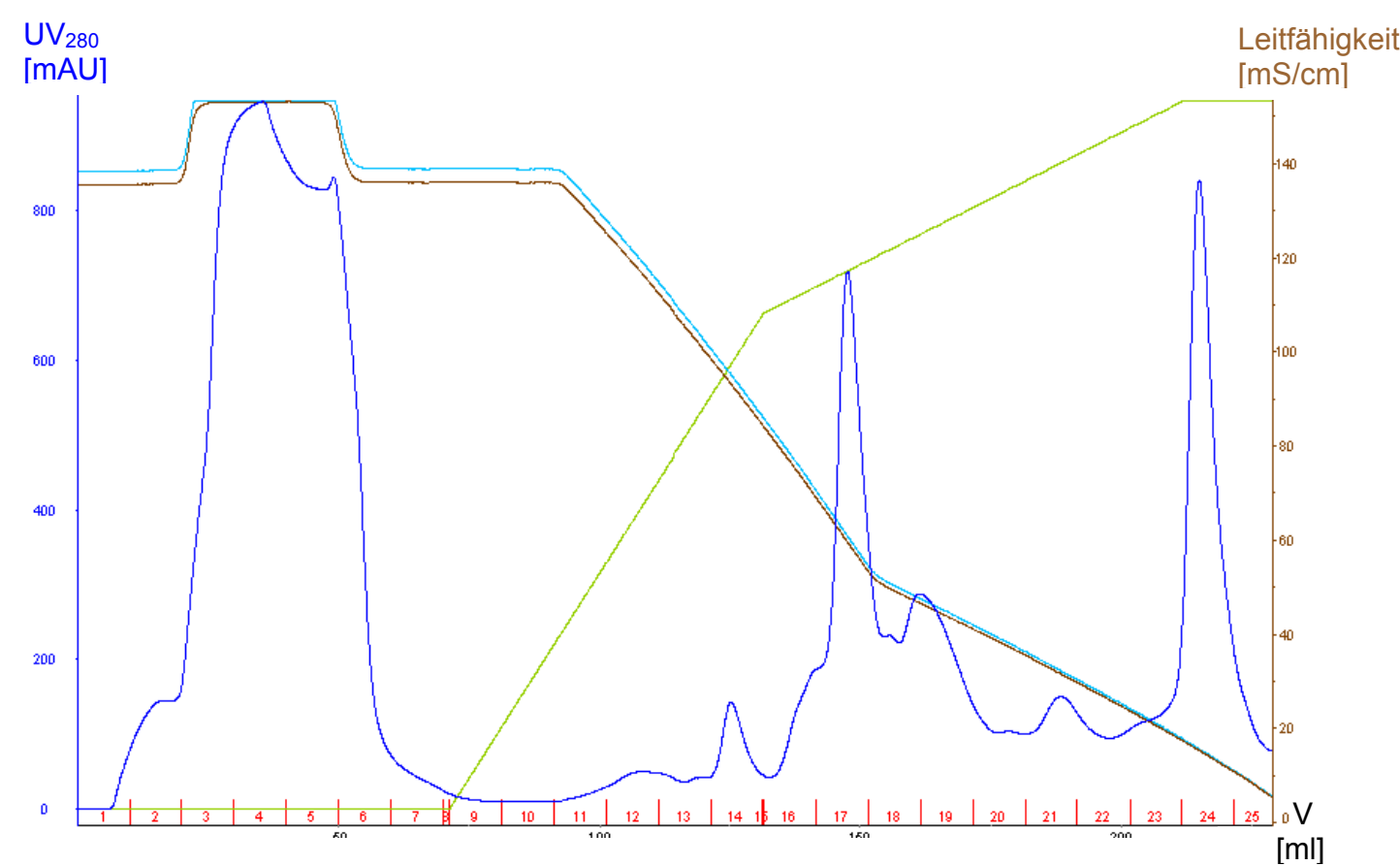

Abb. 14) Elutionsprofil der Reinigung von Thil aus $E$. coli über eine Phenylsepharosesäule

Die in 3.1.1.1 erhaltenen Fraktionen, in denen Thil durch SDS-PAGE Analyse nachgewiesen werden konnte, wurden vereinigt und durch Zugabe von $\left(\mathrm{NH}_{4}\right)_{2} \mathrm{SO}_{4}$ auf eine Salzkonzentration von $1 \mathrm{M}$ gebracht. Anschließend wurde die Probe auf eine Phenylsepharosesäule gegeben. Nach dem Spülen erfolgte die Elution der gebundenen Proteine durch einen absteigenden Salzgradienten (1 $\left.\mathrm{M}-0 \mathrm{M}\left(\mathrm{NH}_{4}\right)_{2} \mathrm{SO}_{4}\right)$. Die Flussgeschwindigkeit betrug $1,5 \mathrm{ml} / \mathrm{min}$. Die erhaltenen Fraktionen wurden mittels SDSPAGE analysiert (Abb. 15).

Es gilt folgender Farbcode: Blau: Extinktion bei $280 \mathrm{~nm} /$ Grün: Gradient [\% B]/ Braun: Leitfähigkeit $[\mathrm{mS} / \mathrm{cm}]$ 


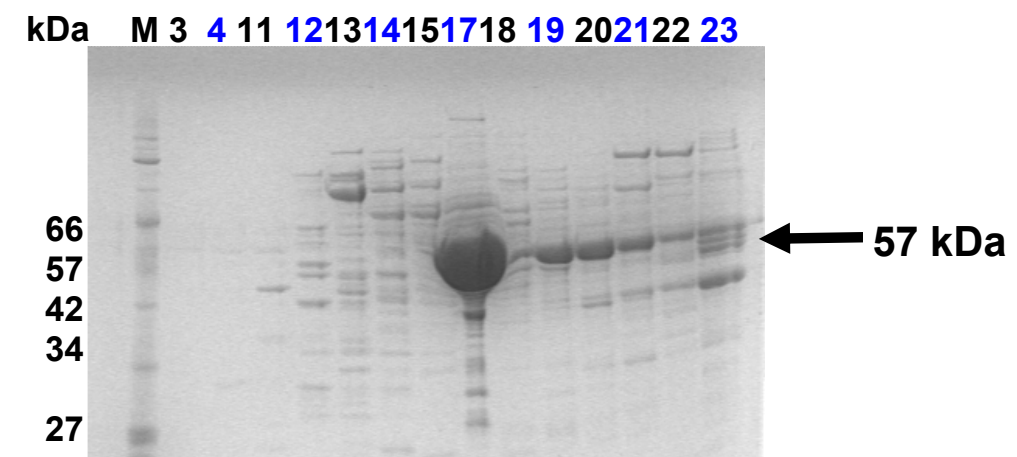

\section{Abb. 15) SDS-PAGE der Reinigung von Thil aus E. coli über eine Phenylsepharosesäule}

Die Gelelektrophorese fand unter denaturierenden Bedingungen in einem 12,5\%-igen Gel statt. Die Anfärbung erfolgte nach Coomassie (2.13.1.1).

Es bedeuten: M: Größenstandard

3-23: Fraktion 3-23

Man kann erkennen, dass Thil v.a. in den Fraktionen 17 bis 21 eluiert wurde. Dies korreliert auch mit dem Elutionsprofil (Abb. 14), in dem ein Peak mit einem Maximum in Fraktion $17 \mathrm{zu}$ erkennen ist.

Auch hier konnte in einer nachfolgenden SDS-PAGE (Abb. 15) nachgewiesen werden, dass eine weitere Anreicherung des Thil in den Fraktionen 17 bis 21 stattgefunden hatte. Zudem erkennt man, dass der größte Teil der an die Säulenmatrix gebundenen Proteine erst unterhalb einer Konzentration von $600 \mathrm{mM}\left(\mathrm{NH}_{4}\right)_{2} \mathrm{SO}_{4}(>40 \%$ B) von der Säule eluiert werden konnte. Ein Vergleich der Extinktionen im Durchfluss zwischen ResourceQ und Phenylsepharose zeigte, dass im Phenylsepharoselauf schon weniger Gesamtprotein vorlag (Abb. $12+14$ ). Im SDS-Gel erkennt man, dass Thil nur noch durch wenige Proteine kontaminiert war (Abb. 15). 
3.1.1.3

Letzter Reinigungsschritt von Thil aus E. coli durch Gelfiltration

Zwar konnte in den vorangegangenen Reinigungsschritten die Homogenität der Thil-Suspension erhöht werden, jedoch waren auch nach einer Reinigung durch Hydrophobe Interaktionschromatographie noch kontaminierende Proteine zu erkennen (Abb. 15). Da zur Kristallographie eine möglichst reine Proteinlösung eingesetzt werden muss (vgl. Bergfors, 2002), wurde ein weiterer Reinigungsschritt durch Gelfiltration angeschlossen. Dabei sollten diese verbliebenen Kontaminanten abgetrennt werden. Zusätzlich konnte die Proteinlösung so in einen Puffer mit niedrigerer Salzkonzentration gebracht werden.

Dazu wurden die Fraktionen aus der Hydrophoben Interaktionschromatographie, von denen durch SDS-PAGE gezeigt worden war, dass sie Thil enthielten, vereinigt und auf ein Volumen von $5 \mathrm{ml}$ gebracht. Beim Lauf über eine S200 Gelfiltrationssäule (26/60) konnte Thil von weiteren E. coliProteinen getrennt werden, so dass es im Anschluss in hoher Reinheit (ca. 90 \%) vorlag (vgl. Spur 37-40 im SDS-Gel, Abb. 17 und Fraktion 37-40 des Gelfiltrationslaufs, Abb. 16). Da Thil hier bei einem erwarteten Volumen von ca. $200 \mathrm{ml}$ von der Gelfiltrationssäule eluierte, wurde davon ausgegangen, dass es sich um ein monomeres Protein handelt. Es erscheint zwar ein sehr niedriger Peak bei ca. $160 \mathrm{ml}$, der eventuell auf Dimere von Thil hinweist, allerdings war der Proteingehalt so niedrig (Vergleich der Peak-Intensitäten), dass auf dem folgenden SDS-Gel keine Banden zu finden waren (nicht gezeigt). Die Fraktionen 37 bis 40 wurden vereinigt und die so erhaltene Proteinlösung auf eine Konzentration von $10 \mathrm{mg} / \mathrm{ml}$ ankonzentriert und $\mathrm{zu}$ Kristallisationsversuchen eingesetzt. Dabei konnten pro Liter Expressionkultur ca. $3 \mathrm{ml}$ Proteinlösung einer Konzentration von $10 \mathrm{mg} / \mathrm{ml}$ gewonnen werden, was einer Ausbeute an Thil von ca. $30 \mathrm{mg} / \mathrm{l}$ Expressionskultur entsprach. 


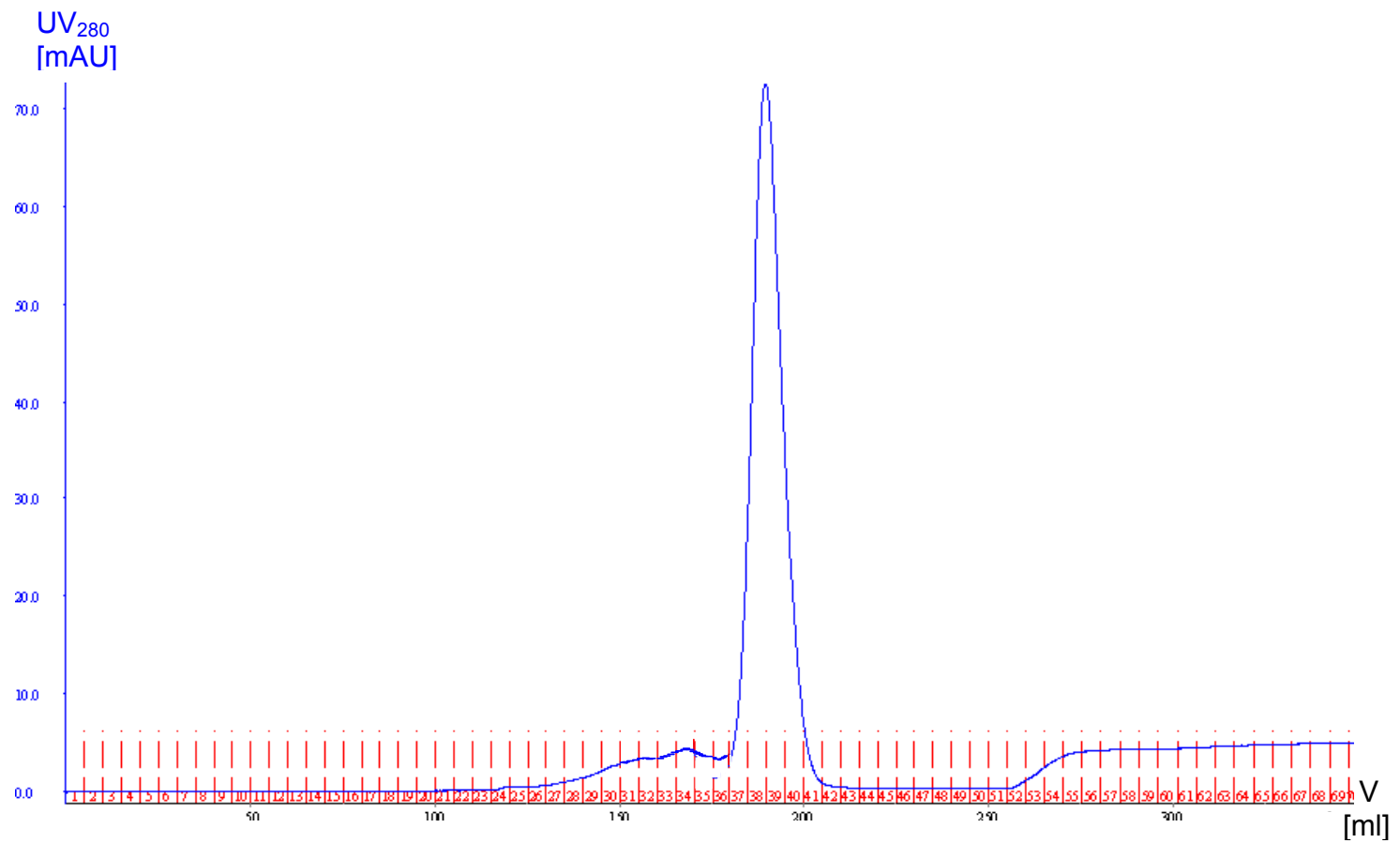

Abb. 16) Elutionsprofil der Reinigung von Thil aus E.coli durch Gelfiltration

Die in 3.1.1.2 erhaltenen Fraktionen, in denen Thil durch SDS-PAGE-Analyse nachgewiesen werden konnte, wurden vereinigt und auf ein Volumen von $5 \mathrm{ml}$ ankonzentriert. Anschließend erfolgte eine Reinigung durch eine S200 Gelfiltrationssäule (26/60) bei einer Flussgeschwindigkeit von $2 \mathrm{ml} / \mathrm{min}$. Dann wurden die Fraktionen mittels SDS-PAGE analysiert.

Es gilt folgender Farbcode: Blau: Extinktion bei $280 \mathrm{~nm}$ 


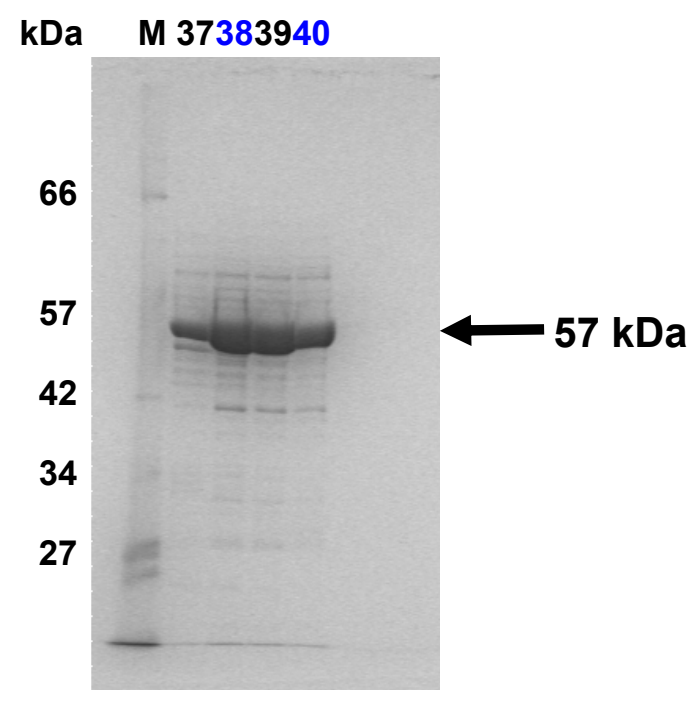

Abb. 17) SDS-PAGE der Reinigung von Thil aus E. coli durch Gelfiltration

Die Gelelektrophorese fand unter denaturierenden Bedingungen in einem 12,5\%-igen Gel statt. Die Anfärbung erfolgte nach Coomassie (2.13.1.1)

Es bedeuten $\quad \mathrm{M}$ : Größenstandard

Peak: Fraktionen 37 - 40

Es werden nur die Fraktionen dargestellt, die dem höchsten Peak im Elutionsprofil (Abb.16) entsprachen. Es ist zu erkennen, dass Thil in großer Reinheit (ca. $90 \%$ ) vorlag. Das so erhaltene Thil wurde zu Kristallisationsversuchen eingesetzt.

\subsubsection{1}

Expression und Aufreinigung von MnmA aus E. coli durch Anionenaustauschchromatographie

Ein weiteres Protein, die 2-Thiouridin-Synthetase MnmA aus E. coli sollte exprimiert, aufgereinigt und zu Kristallisationszwecken eingesetzt werden. Diese war vor Aufnahme der vorliegenden Arbeit in den Vektor pET21c kloniert worden (vgl. 3.1). Das bereits in der Abteilung etablierte Aufreinigungsprotokoll wurde so modifiziert, dass der Puffer von $\mathrm{NaCl} z u$ $\left(\mathrm{NH}_{4}\right)_{2} \mathrm{SO}_{4}$ geändert wurde und ein Wechsel des Anionenaustauschers von ResourceQ zu DEAE-Sepharose stattfand. 


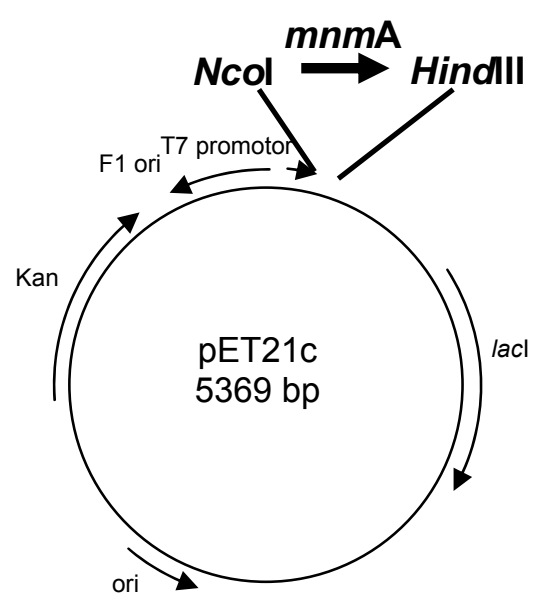

Abb. 18) Vektorkarte des Expressionsvektors pET21c-mnmA

Der Vektor besteht aus dem lacl Repressorgen, dem Replikationsursprung ori, dem Ampicillin-Resistenzgen, und dem Replikationsursprung F1 ori. Das als Ncol-HindIIIFragment klonierte mnmA-Gen stand unter Kontrolle des T7-Promotors.

Die Aufreinigung von MnmA erfolgte zum großen Teil analog zu der Aufreinigung von Thil aus E. coli (siehe 3.1.1.1 - 3.1.1.3). Während der Expression wurden nach 2.12.1.2 Proben gezogen und mittels SDS-PAGE analysiert. Hierbei zeigte sich, wie man anhand von Abb. 19 erkennen kann, dass auch MnmA (44 kDa) in großer Menge exprimiert wurde (Abb. 19, Pfeil). 


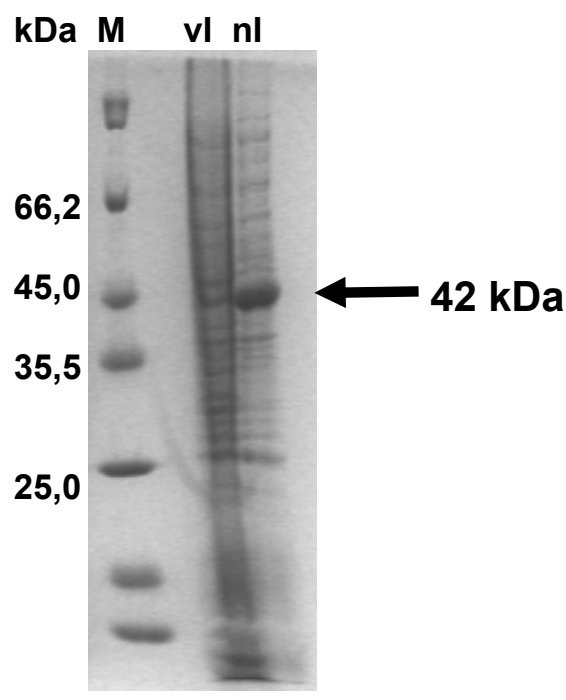

Abb. 19) SDS-PAGE der Expression von MnmA aus E. coli

Die Gelelektrophorese fand unter denaturierenden Bedingungen in einem 12,5\%-igen Gel statt. Die Anfärbung erfolgte nach Coomassie (2.13.1.1).

Es bedeuten: M: Marker

vl: $\quad$ vor Induktion

$\mathrm{nl} \quad$ nach Induktion

Mit pET21c-mnmA transformierte E. coli BL21 pLysS Zellen wurden bei $37^{\circ} \mathrm{C}$ inkubiert, und nach Erreichen einer $\mathrm{OD}_{600}$ von 0,5 wurde durch Zugabe von 0,5 mM IPTG die Induktion der Genexpression eingeleitet. Die Probenentnahme erfolgte vor Induktion ( $\mathrm{vl})$, und nach Induktion (nl) der Genexpression. Es ist ersichtlich, dass MnmA erfolgreich exprimiert werden konnte.

Der initiale Aufreinigungsschritt erfolgte hier mit Hilfe eines Anionentauschers (DEAE-Sepharose). Nachdem durch die SDS-PAGE Analyse der Expression von MnmA aus E. coli festgestellt worden war, dass auch dieses Protein sehr stark exprimiert wurde (Abb. 19), wurde das Anionenaustauschermaterial zu DEAE-Sepharose gewechselt. Diese ist zwar im Gegensatz zu ResourceQ ein schwacher Anionenaustauscher, besitzt aber dieselbe Bindungskapazität (20 mg/ml). Da eine Säule mit dem 5 -fachen Bettvolumen zur Verfügung stand, wurde gefolgert, dass hier eine komplette Bindung des MnmA aus E. coli möglich sei. Auch hier wurde der Lauf durch die Aufzeichnung der Extinktion bei einer Wellenlänge von $280 \mathrm{~nm}$ verfolgt (Abb. 20). 


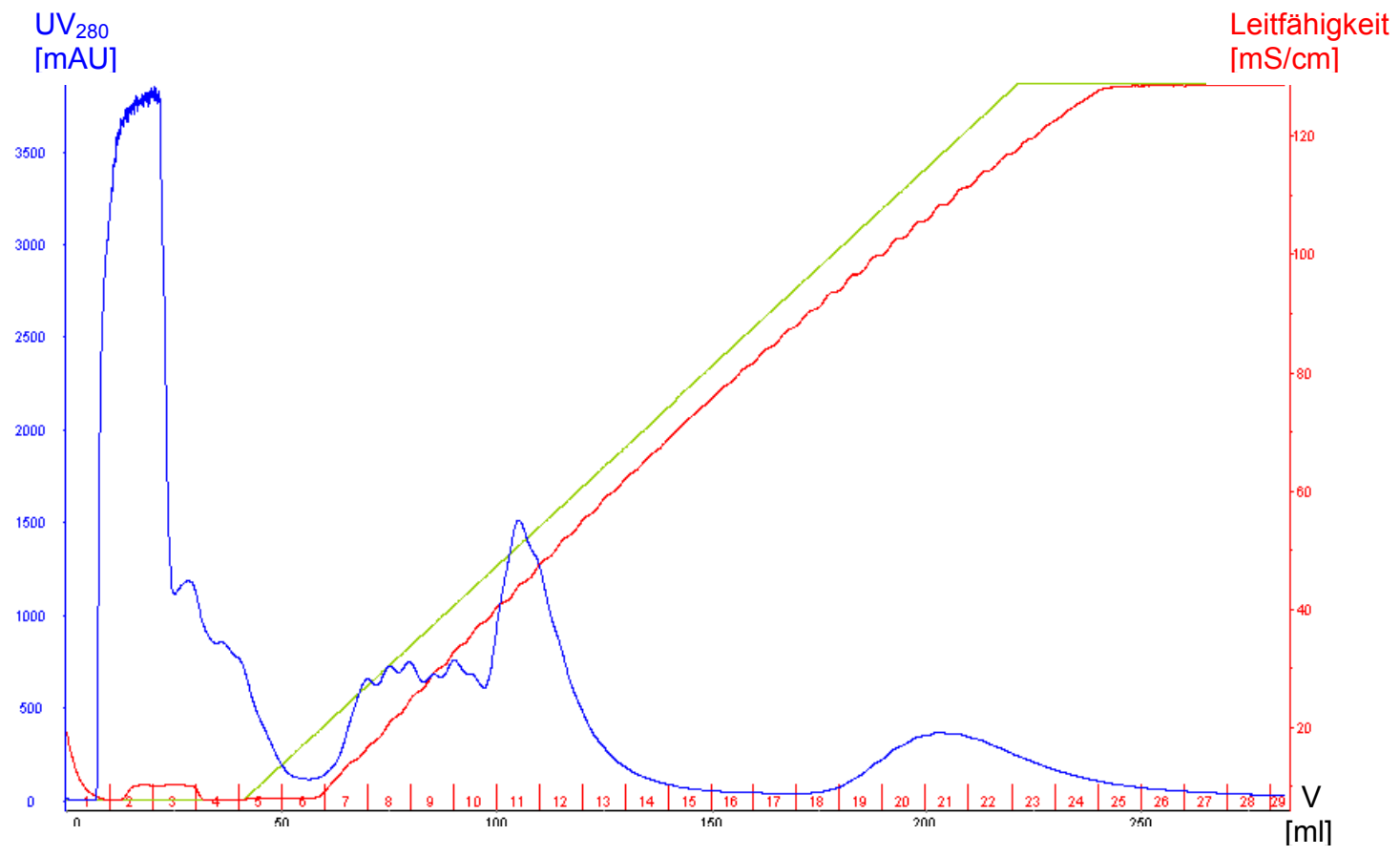

Abb. 20) Elutionsprofil der Reinigung von MnmA aus $E$. coli durch Anionenaustauschchromatographie (DEAE-Sepharose)

Die nach 2.12.1.4 vorbehandelte Probe wurde auf eine DEAE-Sepharose (30 ml) Säule aufgetragen. Nach dem Waschen der Säule, um ungebundene Proteine zu entfernen (Extinktion sinkt), wurde durch Anlegen eines Gradienten $\left(0-1 \quad \mathrm{M}\left(\mathrm{NH}_{4}\right)_{2} \mathrm{SO}_{4}\right)$ damit begonnen, die gebundenen Proteine von der Säule zu eluieren. Die Flussgeschwindigkeit während der gesamten Aufreinigung betrug $2 \mathrm{ml} / \mathrm{min}$. Eine anschließende SDS-PAGE (Abb. 21) zeigte, in welchen Fraktionen das Zielprotein zu finden ist.

Es gilt folgender Farbcode: Blau: Extinktion bei $280 \mathrm{~nm}$ Grün: Gradient [\% B]

Braun: Leitfähigkeit [mS/cm] 


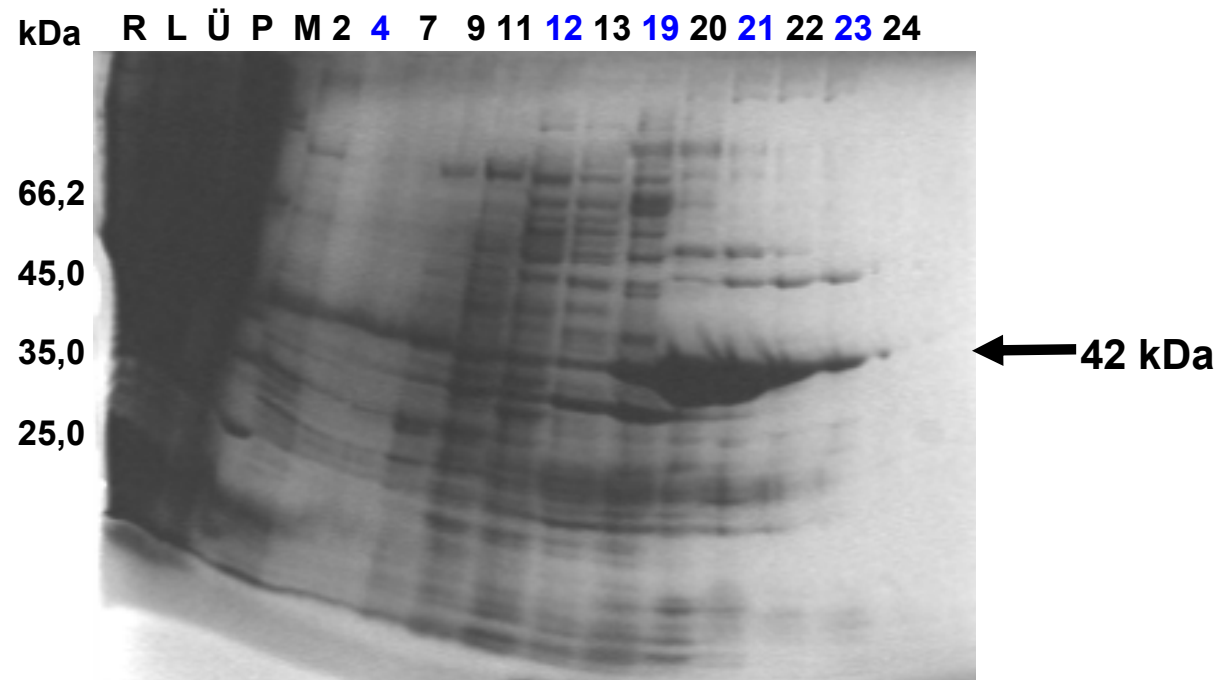

Abb. 21) SDS-PAGE der Reinigung von MnmA aus $E$. coli durch Anionenaustauschchromatographie

Die Gelelektrophorese fand unter denaturierenden Bedingungen in einem 12,5 \%-igen Gel statt. Die Anfärbung erfolgte nach Coomassie (2.13.1.1).

Es bedeuten: R: Rohextrakt = resuspendierte Zellen

L: Lysat $=$ Suspension nach Zellaufschluss

Ü: Überstand

P: Pellet

M: Größenstandard

Man kann erkennen, dass die Elution von MnmA ab einer Konzentration von ca. 70 \% Puffer B ( 700 mM $\left.\left(\mathrm{NH}_{4}\right)_{2} \mathrm{SO}_{4}\right)$ beginnt (Fraktionen 19-23).

Im Anschluss erfolgte eine Analyse der Fraktionen durch SDS-PAGE (Abb. 21). Hierbei war zu erkennen, dass MnmA bei ca. $70 \%$ B von der Säule eluiert wurde, was einer Salzkonzentration von ca. $700 \mathrm{mM}\left(\mathrm{NH}_{4}\right)_{2} \mathrm{SO}_{4}$ entsprach. Im Gegensatz zur Reinigung von Thil aus E. coli eluierte MnmA aus $E$. coli mit einer größeren Anzahl an kontaminierenden Proteinen von der Säule. Dieses kann man auch anhand des entsprechenden Elutionsprofils erkennen, in dem nur zwei langgestreckte Peaks auftauchen. Dies spricht dafür, dass die Proteine nicht gut getrennt wurden, so dass eine weitere Reinigung durch HIC nötig wurde. 


\subsubsection{Weitere Anreicherung von MnmA aus E. coli durch Hydrophobe Interaktions Chromatographie (HIC)}

Die Fraktionen der Reinigung durch Anionenaustauschchromatographie (3.1.2.1), von denen durch SDS-PAGE gezeigt werden konnte, dass sie MnmA enthielten (19-23), wurden vereinigt und durch Zugabe von $\left(\mathrm{NH}_{4}\right)_{2} \mathrm{SO}_{4}$ auf eine Endkonzentration von $1 \mathrm{M}\left(\mathrm{NH}_{4}\right)_{2} \mathrm{SO}_{4}$ gebracht. Es folgte eine Reinigung durch Hydrophobe Interaktions Chromatographie mit Hilfe einer Phenylsepharosesäule. Der Lauf wurde durch die Aufzeichnung der Extinktion bei einer Wellenlänge von $280 \mathrm{~nm}$ verfolgt (Abb. 22).

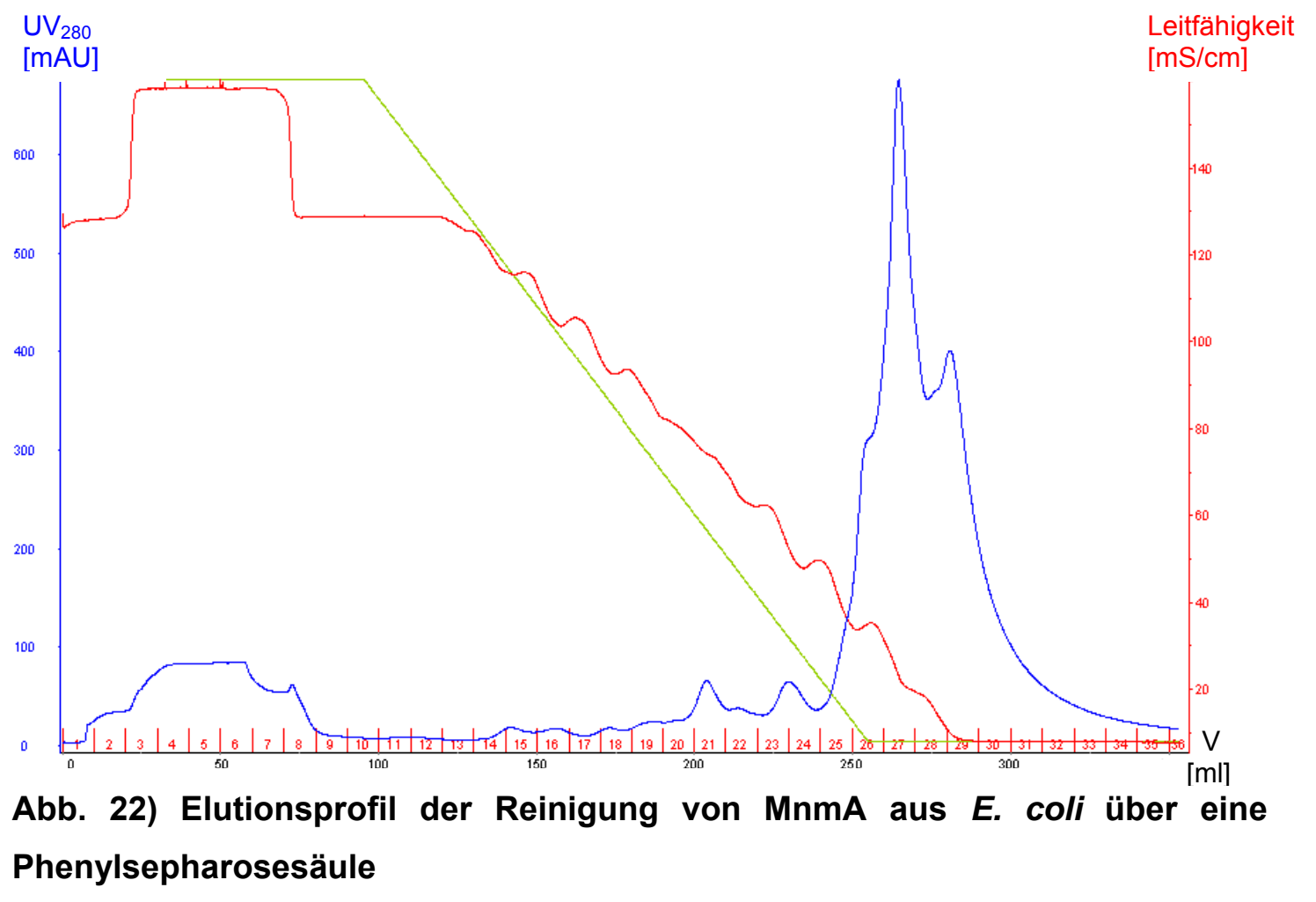

Die aus 3.1.2.1 erhaltenen Fraktionen, von denen durch SDS-PAGE Analyse gezeigt worden war, dass sie MnmA enthielten, wurden mit $\left(\mathrm{NH}_{4}\right)_{2} \mathrm{SO}_{4}$ auf eine Salzkonzentration von $1 \mathrm{M}$ hochgesalzt und auf eine Phenylsepharosesäule gegeben. Nach dem Spülen erfolgte die Elution der gebundenen Proteine mit einem absteigenden Salzgradienten (1 M - $0 \mathrm{M}$ $\left.\left(\mathrm{NH}_{4}\right)_{2} \mathrm{SO}_{4}\right)$.

Es gilt folgender Farbcode: Blau: Extinktion bei $280 \mathrm{~nm}$

Grün: Gradient [\% B]

Braun: Leitfähigkeit [mS/cm] 
Anschließend wurde durch eine SDS-PAGE-Analyse ermittelt, in welchen der gesammelten Fraktionen MnmA enthalten war (Abb. 23). Dabei konnte festgestellt werden (Abb. 22), dass MnmA aus E. coli ab einer $\left(\mathrm{NH}_{4}\right)_{2} \mathrm{SO}_{4}$ Konzentration von $700 \mathrm{mM}$ von der Säule eluiert wurde (vgl. Fraktionen 2732). Der Vergleich der Extinktionen des Durchflusspeaks aus der HIC und aus der Anionenaustauschchromatographie zeigte, dass die Extinktion im Durchflusspeak bei der HIC schon wesentlich geringer war, also weniger Protein enthalten war. Auch die Elution von MnmA selbst erfolgte wesentlich später als die von Thil (Abb. 15), was darauf hindeutete, dass MnmA mehr hydrophobe Bereiche aufweist als Thil. Der Vergleich der Reinigungseffizienz zeigte, dass MnmA nach der HIC wesentlich reiner erhalten wurde als Thil.

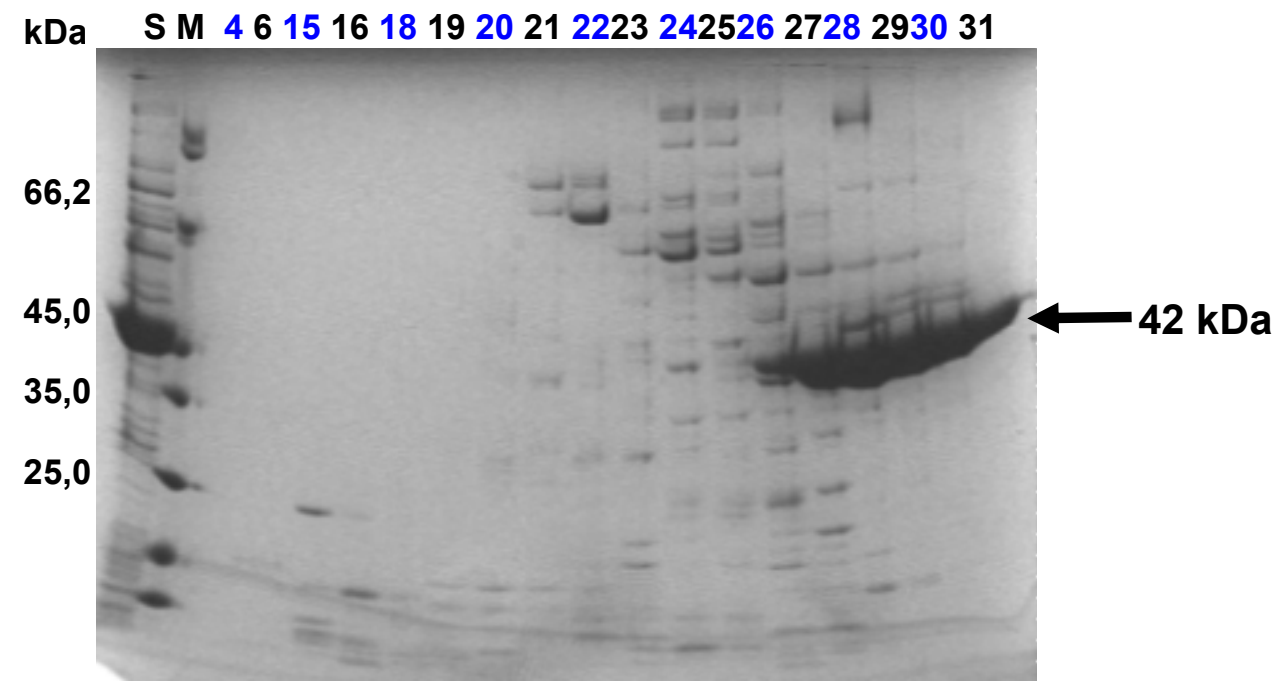

Abb. 23) SDS-PAGE der Reinigung von MnmA aus E. coli durch eine Phenylsepharosesäule

Die Gelelektrophorese fand unter denaturierenden Bedingungen in einem 12,5\%-igen Gel statt. Die Anfärbung erfolgte nach Coomassie (2.13.1.1).

Es bedeuten: S: sterilfiltrierte, hochgesalzte Proteinsuspension vor Säulenlauf

M: Größenstandard

4-31: Fraktionen 4 - 31

Man kann erkennen, dass MnmA (42 kDa) bei einer Konzentration von ungefähr $300 \mathrm{mM}$ $\left(\mathrm{NH}_{4}\right)_{2} \mathrm{SO}_{4}$ (ca. $70 \%$ B) von der Säule eluierte (Spur 26ff). 


\subsubsection{Letzter Reinigungsschritt von MnmA durch Gelfiltration}

Um die letzten Verunreinigungen von MnmA abzutrennen und so die Homogenität der Probe weitgehend sicherzustellen und um die Salzkonzentration der Proteinsuspension zu verringern, erfolgte ein letzter Reinigungsschritt über eine S200 Gelfiltrationssäule (26/60), (Abb. 24).

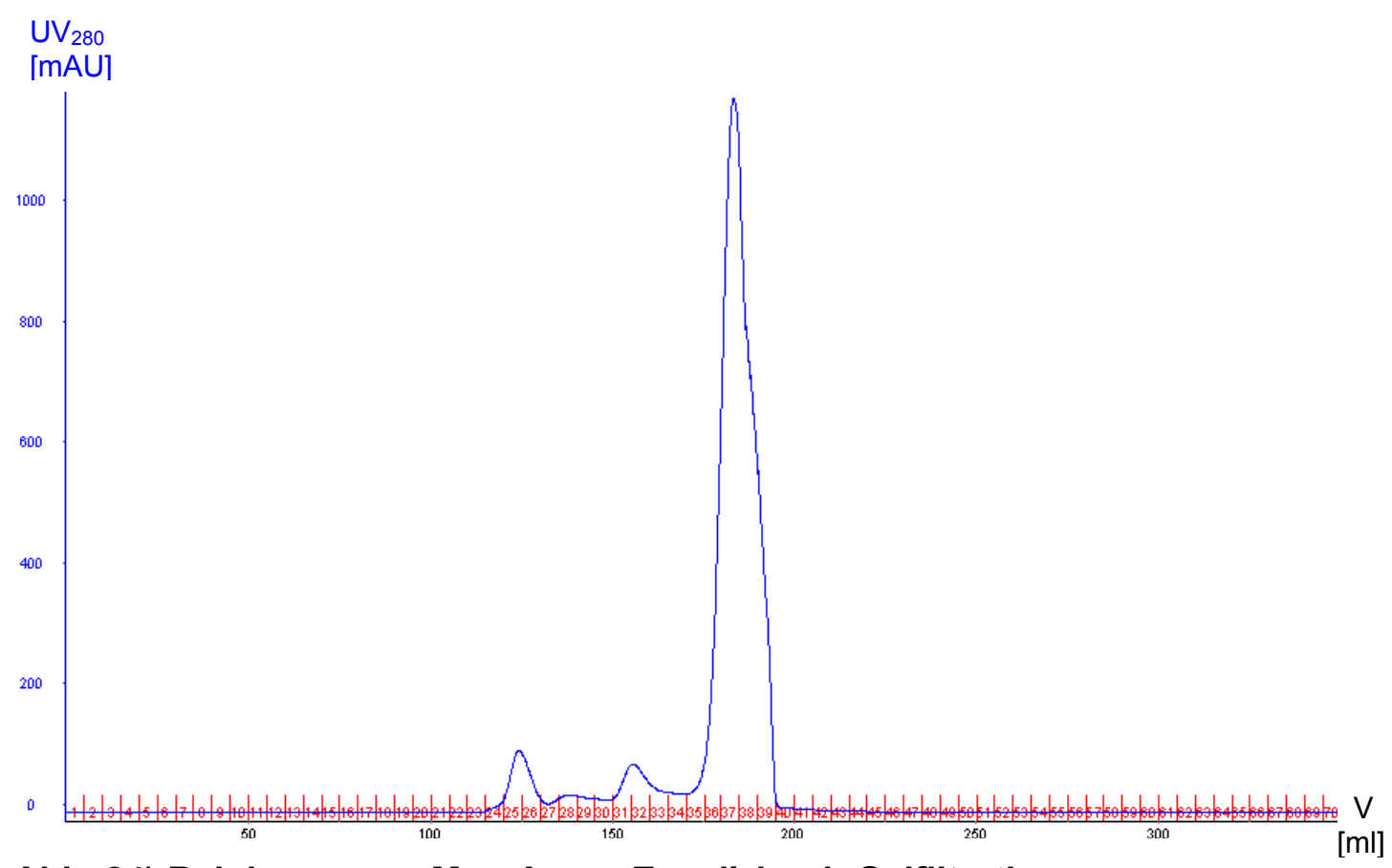

Abb. 24) Reinigung von MnmA aus $E$. coli durch Gelfiltration

Die aus 3.1.2.2 erhaltenen Fraktionen, von denen durch SDS-PAGE gezeigt worden war, dass sie MnmA enthielten, wurden vereinigt und auf ein Volumen von $5 \mathrm{ml}$ ankonzentriert. Anschließend erfolgte eine Reinigung über eine $\$ 200$ Gelfiltrationsäule (26/60) mit einer Flussgeschwindigkeit von $2 \mathrm{ml} / \mathrm{min}$. Im Anschluss wurden die Fraktionen mittels SDS-PAGE analysiert (Abb. 25).

Es gilt folgender Farbcode: Blau: Extinktion bei $280 \mathrm{~nm}$

Grün: Gradient [\% B]

Braun: Leitfähigkeit [mS/cm]

Hier konnte beobachtet werden, dass MnmA - wie bei einem Molekulargewicht von 42 kDa zu erwarten war - bei einem Elutionsvolumen von ca. $180 \mathrm{ml}$ eluiert wurde. Zusätzlich erschienen noch weitere Peaks im Elutionsprofil (Abb. 24), die als Dimer von MnmA (Elution bei $150 \mathrm{ml}$ ) oder auch unspezifische größere Aggregate (Elution bei $130 \mathrm{ml}$ ) im Ausschlussvolumen gedeutet wurden (keine Banden bei SDS-PAGE- 
Analyse). Die Proben aus den „Peak“-Fraktionen (35 - 39) wurden über SDS-PAGE auf ihren Reinheitsgrad untersucht (Abb. 25)

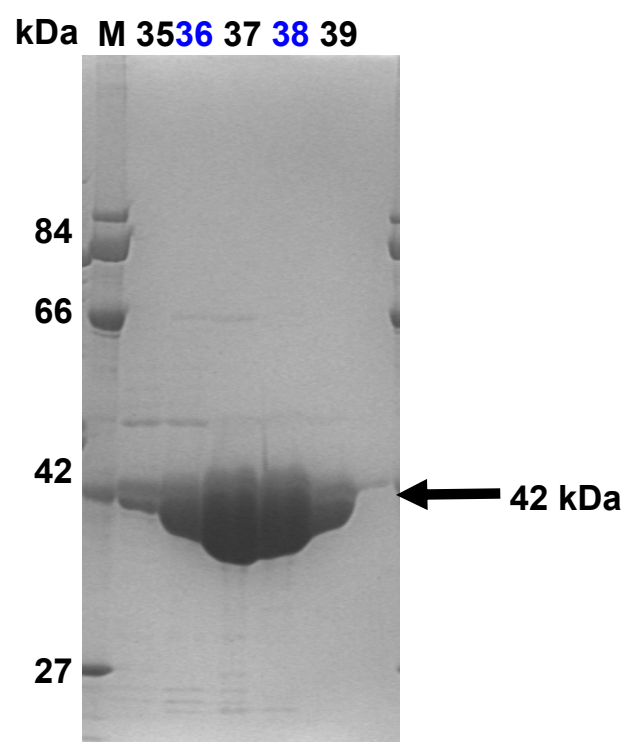

Abb. 25) SDS-PAGE der Reinigung von MnmA aus E. coli durch Gelfiltration

Die Gelelektrophorese fand unter denaturierenden Bedingungen in einem 12,5\%-igen Gel statt. Die Anfärbung erfolgte nach Coomassie (2.13.1.1).

Es bedeuten: M: Größenstandard

Peak: Fraktionen 35-39 aus obenstehendem Elutionsprofil (Abb. 24)

Hier war zu beobachten, dass die Fraktionen 35-39, die dem höchsten Peak des Elutionsprofils (Abb. 24) entsprachen, MnmA von großer Reinheit (ca. $99 \%$ ) enthielten. Dieses wurde unmittelbar zu Kristallisationsversuchen eingesetzt.

Mittels der SDS-PAGE (Abb. 25) konnte eine hohe Reinheit (ca. $99 \%$ ) des Proteins festgestellt werden, so dass die Fraktionen 35-39 vereinigt und für Kristallisationsversuche ankonzentriert wurden. Dabei konnten pro Liter Expressionskultur ca. $4 \mathrm{ml}$ Proteinsuspension mit einer Konzentration von $10 \mathrm{mg} / \mathrm{ml}$ erhalten werden, was einer Gesamtausbeute von $40 \mathrm{mg} \mathrm{MnmA} \mathrm{pro}$ Liter Expressionskultur entsprach.

Die Kristallisationsversuche erfolgten analog zu Thil aus E. coli (siehe 3.1.3). Es konnten auch hier keine Proteinkristalle erhalten werden. 


\subsubsection{Kristallisationsversuche von Thil und MnmA aus E. coli}

Nachdem Thil- und MnmA-Lösungen von hoher Reinheit gewonnen werden konnten, wurden die Proteinlösungen für diverse Kristallisationsversuche eingesetzt. Diese erfolgten in Cryschem Platten (Hampton Research, USA). Dazu wurde je $1 \mu \mathrm{l}$ Proteinlösung auf den Steg pipettiert und mit $1 \mu \mathrm{l}$ (je nach Versuchsbedingung auch $2 \mu \mathrm{l}$ ) Reservoirlösung gemischt. Die Platten wurden versiegelt und bei verschiedenen Temperaturen inkubiert. Um eine frühzeitige Oxidation der Proteine zu verhindern, lag in allen Bedingungen eine DTT-Endkonzentration von $2 \mathrm{mM}$ vor. Einen Überblick über die verwendeten Kristallscreens und die verschiedenen Kristallisationsansätze gibt Tab. 4 wieder.

Tab. 4) Auflistung der verwendeten Kristallisationslösungen

\begin{tabular}{|c|c|c|c|}
\hline Screen & Hersteller & Thil/MnmA & Zusätze \\
\hline Crystal Screen1 & Hampton Research & $+/+$ & $\begin{array}{l}\text { m/o ATP, m/o ATP }{ }_{n h}, \\
\text { m/o DTT, } 2 \text { o. } 5 \text { mM } \\
\text { DTT, tRNA }\end{array}$ \\
\hline Crystal Screen 2 & Hampton Research & $+/+$ & $\begin{array}{l}\mathrm{m} / \mathrm{o} \text { ATP, } \mathrm{m} / \mathrm{o} \mathrm{ATP}_{\mathrm{nh}}, \\
\mathrm{m} / \mathrm{o} \text { DTT, } 2 \text { o. } 5 \mathrm{mM} \\
\text { DTT, tRNA }\end{array}$ \\
\hline Crystal Screen Lite & Hampton Research & $+/+$ & $\begin{array}{llll}\mathrm{m} / \mathrm{o} & \text { ATP }_{\mathrm{nh}}, 2 \mathrm{mM} \\
\text { DTT } & & \\
\end{array}$ \\
\hline Crystal Screen Cryo & Hampton Research & $+/+$ & $\begin{array}{l}\text { m/o ATP, m/o ATP }{ }_{n h}, \\
\text { m/o DTT, } 2 \text { o. } 5 \text { mM } \\
\text { DTT, tRNA }\end{array}$ \\
\hline $\begin{array}{c}\text { Crystal Screen } \\
\text { PEG/lon }\end{array}$ & Hampton Research & $+1+$ & $\begin{array}{l}\text { m/o ATP, m/o ATP }{ }_{n h}, \\
\text { m/o DTT, } 2 \text { o. } 5 \text { mM } \\
\text { DTT, tRNA }\end{array}$ \\
\hline JBScreen 1-10 & Jena Bioscience & $+1+$ & $\begin{array}{l}\text { m/o ATP, m/o ATP }{ }_{n h}, \\
2 \text { o. } 5 \mathrm{mM} \text { DTT, } \\
\text { tRNA }\end{array}$ \\
\hline Magic Screen & Biogenova & teilw. / teilw. & $\begin{array}{l}\text { m/o ATP, m/o ATP }{ }_{n h}, \\
\text { m/o DTT, tRNA }\end{array}$ \\
\hline Footprint Screen & Molecular Dimension & $+1+$ & $\begin{array}{l}\text { m/o ATP, m/o ATP }{ }_{n h}, \\
\text { m/o DTT, tRNA }\end{array}$ \\
\hline
\end{tabular}




\begin{tabular}{|c|l|c|l|}
\hline Screen & \multicolumn{1}{|c|}{ Hersteller } & Thil/MnmA & Zusätze \\
\hline Structure Screen & Molecular Dimension & teilw. / teilw. & $\begin{array}{l}\text { m/o ATP } \\
\text { tRN, m/o DTT, }\end{array}$ \\
\hline $\begin{array}{c}\text { Ammoniumsulfat- } \\
\text { Screen }\end{array}$ & & $+/+$ & 2 mM DTT \\
\hline Abkürzungen: $+: \quad$ pipettiert & \\
m: $\quad$ mit & \\
ATP & & \\
teilw: & nicht hydrolysierbares ATP & \\
teilweise &
\end{tabular}

Die Screens wurden nach o.a. Bedingungen pipettiert. Manche Screens wurden zusätzlich unter Variation der Proteinkonzentration $(5 \mathrm{mg} / \mathrm{ml}$ bzw. $15 \mathrm{mg} / \mathrm{ml}$ ) verwendet (nicht aufgeführt).

Auf diese Weise konnten von Thil aus E. coli zwei unterschiedliche Kristallformen erhalten werden (Abb. 26). Ein Kristall wuchs in einer Bedingung, die $100 \mathrm{mM}$ Na-HEPES und 0,8 M Na/K-Tartrat enthielt, der andere Kristall wurde bei $100 \mathrm{mM}$ Tris, $\mathrm{pH} 7.5$ und 1,2 $\mathrm{M}\left(\mathrm{NH}_{4}\right)_{2} \mathrm{SO}_{4}$ erhalten. Beide Kristalle wurden jedoch bei röntgenkristallographischer Untersuchung als Salz identifiziert. Von MnmA wurden bisher keine Kristalle erhalten.

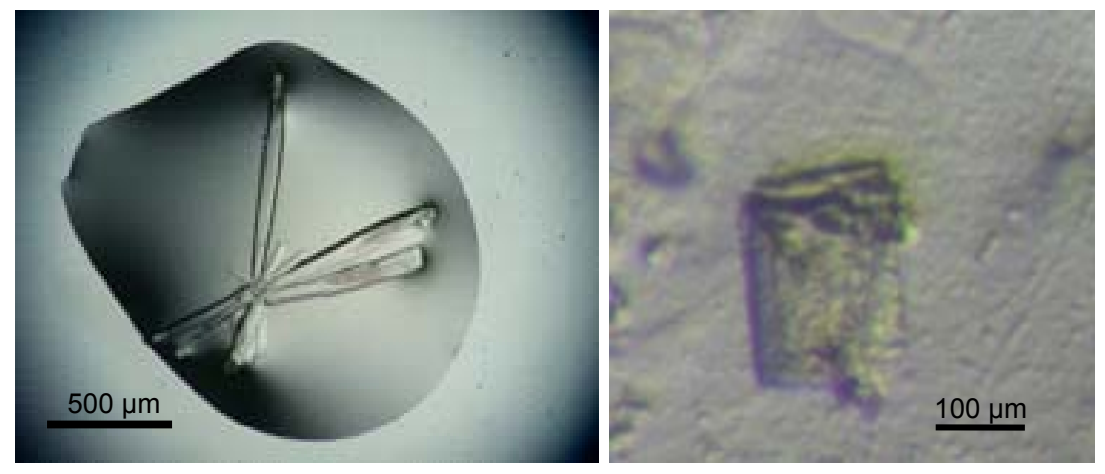

Abb. 26) Kristalle von Thil aus E. coli

Aufgereinigtes Thil war mit den oben erwähnten Kristallisationslösungen (Screens) versetzt worden $(1 \mu \mathrm{l}$ Protein $10 \mathrm{mg} / \mathrm{ml}$ und $1 \mu \mathrm{l}$ Reservoir). Die Kristalle wurden in $100 \mathrm{mM} \mathrm{Na}-$

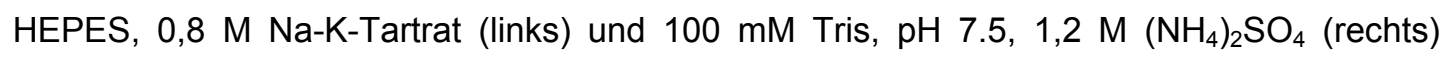
erhalten. 
Da in den Kristallisationsexperimenten mit Thil und MnmA aus E. coli keine Röntgenstrahlung beugenden Proteinkristalle erhalten werden konnten, wurden die Orthologe von Thil und MnmA aus Thermotoga maritima (T. maritima), einem hyperthermophilen Bakterium, als neuer Ansatz gewählt. Es hat sich oft gezeigt, dass bei Kristallisationsversuchen mit Proteinen der Wechsel zu einem Ortholog zu Proteinkristallen führen kann (Grimm et al., 2000).

\subsubsection{Expression von Thil aus T. maritima}

Nachdem die Genom-DNA aus T. maritima isoliert worden war (2.4.1), gelang es das Gen thil durch PCR zu amplifizieren. Anschließend konnte das Gen thil erfolgreich in den Vektor pET28a kloniert werden (2.9). Nachdem eine erfolgreiche Klonierung durch Restriktionsverdau und Colony-PCR nachgewiesen worden war, wurde der rekombinante Vektor zur Transformation des Expressionsstammes E. coli BL21(DE3)pLysS verwendet. 


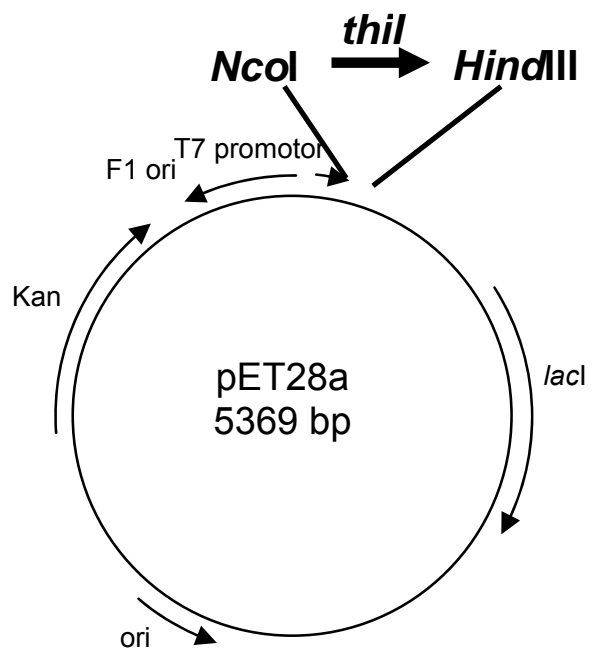

Abb. 27) Vektorkarte des verwendeten Expressionsvektors pET28a-thil

Der Vektor besteht aus dem lacl Repressorgen, dem Replikationsursprung ori, dem Kanamycin-Resistenzgen und dem Replikationsursprung F1-ori. Die Expression des in die MCS klonierten thil-Fragments steht unter Kontrolle des T7-Promotors. Die Klonierung des thil-Gens als Ncol-HindIII-Fragment resultiert in einem tag-frei-exprimierten Zielprotein.

Zur analytischen Expression wurden $50 \mathrm{ml}$ Kultur mit einer ÜN-Kultur angeimpft und diese bei Erreichen einer $O_{600}$ von 0,5 mit 0,5 mM IPTG induziert. Vor Induktion und während der Expression wurden nach einer, zwei und vier Stunden Proben zur SDS-PAGE Analyse entnommen (Abb. 28). 


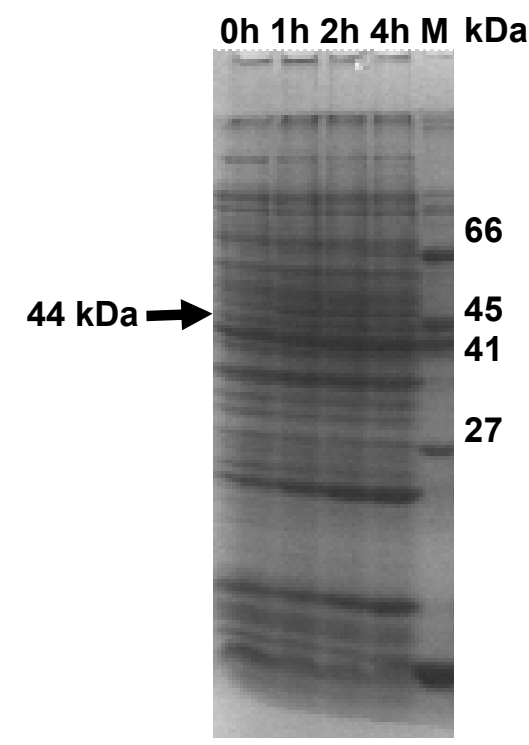

\section{Abb. 28) Expression von Thil aus T. maritima}

Die Gelelektrophorese fand unter denaturierenden Bedingungen in einem 12,5 \%-igen SDSGel statt. Die Anfärbung erfolgte nach Coomassie (2.13.1.1).

Es bedeuten: M: Größenstandard xh: $\quad$ Probe nach $x$ Stunden Induktion

Die Expression von Thil (Pfeil) bei $37^{\circ} \mathrm{C}$ (und $25^{\circ} \mathrm{C}$, nicht aufgeführt) konnte mit dieser Methode nicht eindeutig nachgewiesen werden. Nach Aufschluss der Zellen konnte Thil im Rohextrakt nachgewiesen werden (Abb. 29).

Mit Hilfe der SDS-PAGE (Abb. 28) war es nicht möglich, die Expression von Thil aus T. maritima (auch bei Wechsel der Expressionstemperatur) eindeutig nachzuweisen. Da aber zuvor durch Colony-PCR des Expressionsstamms nachgewiesen worden war, dass die verwendeten $E$. coliBL21(DE3)pLysS-Zellen Träger des Gens thil aus T. maritima waren (siehe 2.4), wurde die Expression trotzdem im präparativen Maßstab bei $37^{\circ} \mathrm{C}$ durchgeführt (siehe 2.12.1.2). Nach der Lyse des erhaltenen Pellets konnte dann die Expression von Thil eindeutig nachgewiesen werden (Ausbeute ca. 20 mg/ I Kultur) (vgl. 3.2.1.2, Abb. 29, Spuren R, L und Ü). 


\subsubsection{Reinigung von Thil aus T. maritima durch Hitzeschock}

Um gleich zu Beginn der Reinigung die Menge an kontaminierenden E. coliProteinen aus dem Expressionsstamm im Lysat zu verringern, wurden die thermophilen Eigenschaften von Thil aus T. maritima genutzt. Hierzu wurde der aus der Zentrifugation nach der Lyse mittels Ultraschall gewonnene Überstand für unterschiedliche Inkubationszeiten (je $2 \mathrm{Min}, 5 \mathrm{Min}$ und $10 \mathrm{Min}$ ) auf verschiedene Temperaturen $\left(40^{\circ} \mathrm{C}, 50^{\circ} \mathrm{C}, 60^{\circ} \mathrm{C}, 70^{\circ} \mathrm{C}, 80^{\circ} \mathrm{C}\right)$ erhitzt. Die präzipitierten E. coli-Proteine wurden durch Zentrifugation abgetrennt und die jeweiligen Überstände und Pellets durch eine SDS-PAGE analysiert. Wie man aus Abb. 29 erkennen kann, präzipitierte der größte Teil der E. coli Proteine ab einer Temperatur von $60{ }^{\circ} \mathrm{C}$. Neben Thil war nur ein Protein mit einer Größe von ca. $25 \mathrm{kDa}$ bei einer Inkubation von einer Minute bei einer Temperatur von $80{ }^{\circ} \mathrm{C}$ hitzestabil und im Überstand zu sehen (hervorgehoben, Abb. 29). Erst die Verlängerung der Inkubationszeit auf fünf bzw. zehn Minuten ermöglicht die Präzipitation dieses Proteins (evtl. Chaperon aus E. coli). Eine längere Inkubation und höhere Temperatur ergaben keine effektivere Nutzung der thermophilen Eigenschaften (nicht gezeigt). Eine analoge Behandlung von mit leerem pET28a exprimierten E. coli BL21(DE3)pLysS Zellen als Negativkontrolle zeigte, dass keine hitzestabilen Proteine vorhanden waren (nicht gezeigt). Deshalb konnte ein 10minütiger Hitzeschock bei $80^{\circ} \mathrm{C}$ als initialer Schritt der Aufreinigung von Thil aus T. maritima etabliert werden. 


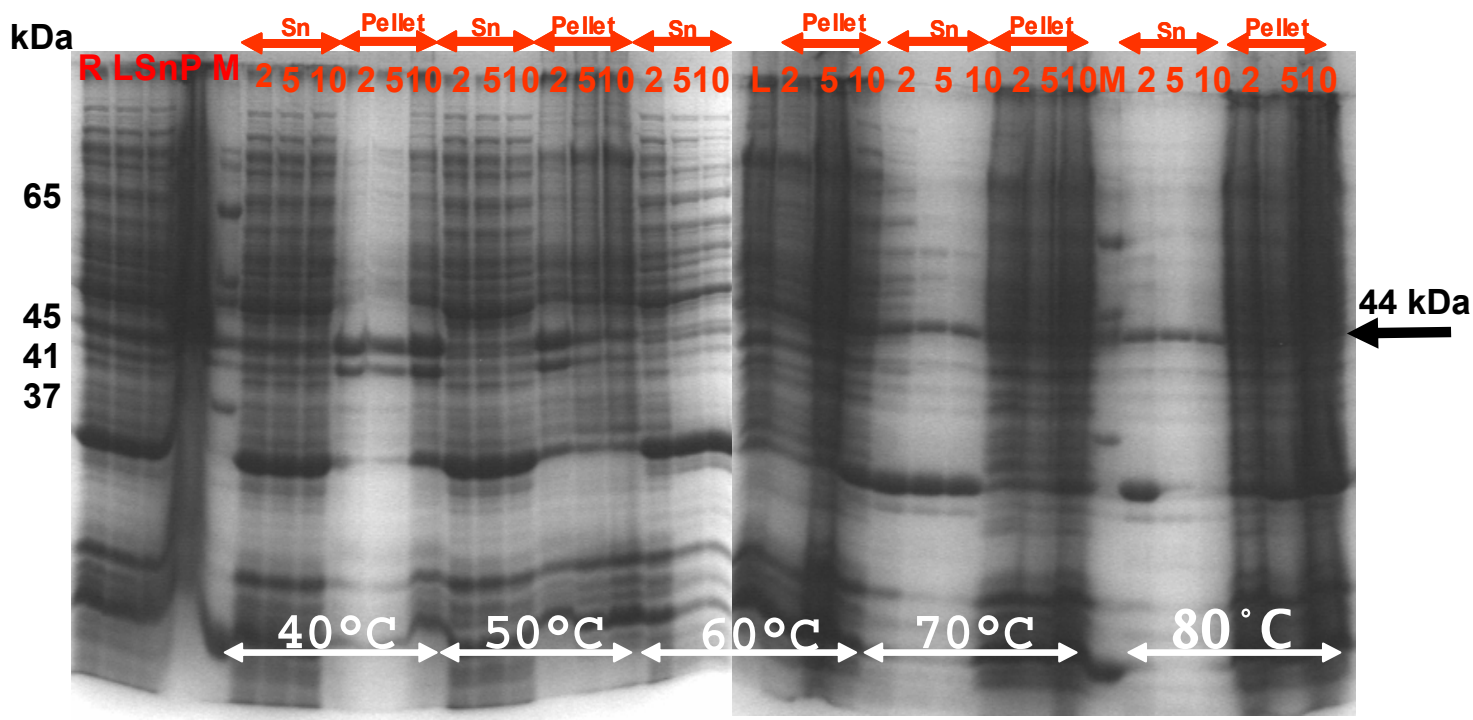

\section{Abb. 29) Hitzedenaturierung des Überstandes}

Die Gelelektrophorese fand unter denaturierenden Bedingungen in einem 12,5\%-igen Gel statt. Die Anfärbung erfolgte nach Coomassie (2.13.1.1).

Es bedeuten: R: Rohextrakt

L: $\quad$ Lysat

P: $\quad$ Pellet

M: Größenstandard

Sn: Überstand

Nach Lyse mit Hilfe eines Sonifiers wurde der durch Zentrifugation erhaltene Überstand (2.12.1.4) bei verschiedenen Temperaturen (s.o.) für unterschiedliche Inkubationszeiten (s.o.) inkubiert. Anschließend wurden die durch die Wärmeeinwirkung präzipitierten Proteine durch Zentrifugation abgetrennt und Überstand und Pellet auf einem SDS-Gel aufgetrennt. Man kann erkennen, dass bei einer Temperatur von $80^{\circ} \mathrm{C}$ und einer Inkubationsdauer von zehn Minuten der Großteil der E. coli-Proteine von Thil (44 kDa) abgetrennt wurde.

\subsubsection{Reinigung von Thil aus T. maritima durch Anionenaus- tauschchromatographie (DEAE-Sepharose)}

Nachdem ein Großteil der E. coli-Proteine von Thil durch den in 3.2.1.2 beschriebenen Hitzeschock abgetrennt werden konnte, wurde zur weiteren Reinigung von Thil die Ladung des Proteinmoleküls zur Durchführung einer Anionenaustauschchromatographie genutzt. Dazu wurde der in 3.2.1.2 erhaltene Überstand aus der Hitzedenaturierung auf eine DEAESepharosesäule geladen. Nach der Entfernung von ungebundenem Protein 
durch einen Waschschritt konnte Thil durch Anlegen eines Gradienten von $0 \mathrm{M}-1 \mathrm{M}\left(\mathrm{NH}_{4}\right)_{2} \mathrm{SO}_{4}$ eluiert werden. Der Verlauf der Reinigung wurde durch Aufzeichnung der Extinktion bei einer Wellenlänge von $280 \mathrm{~nm}$ dokumentiert (Abb. 30).

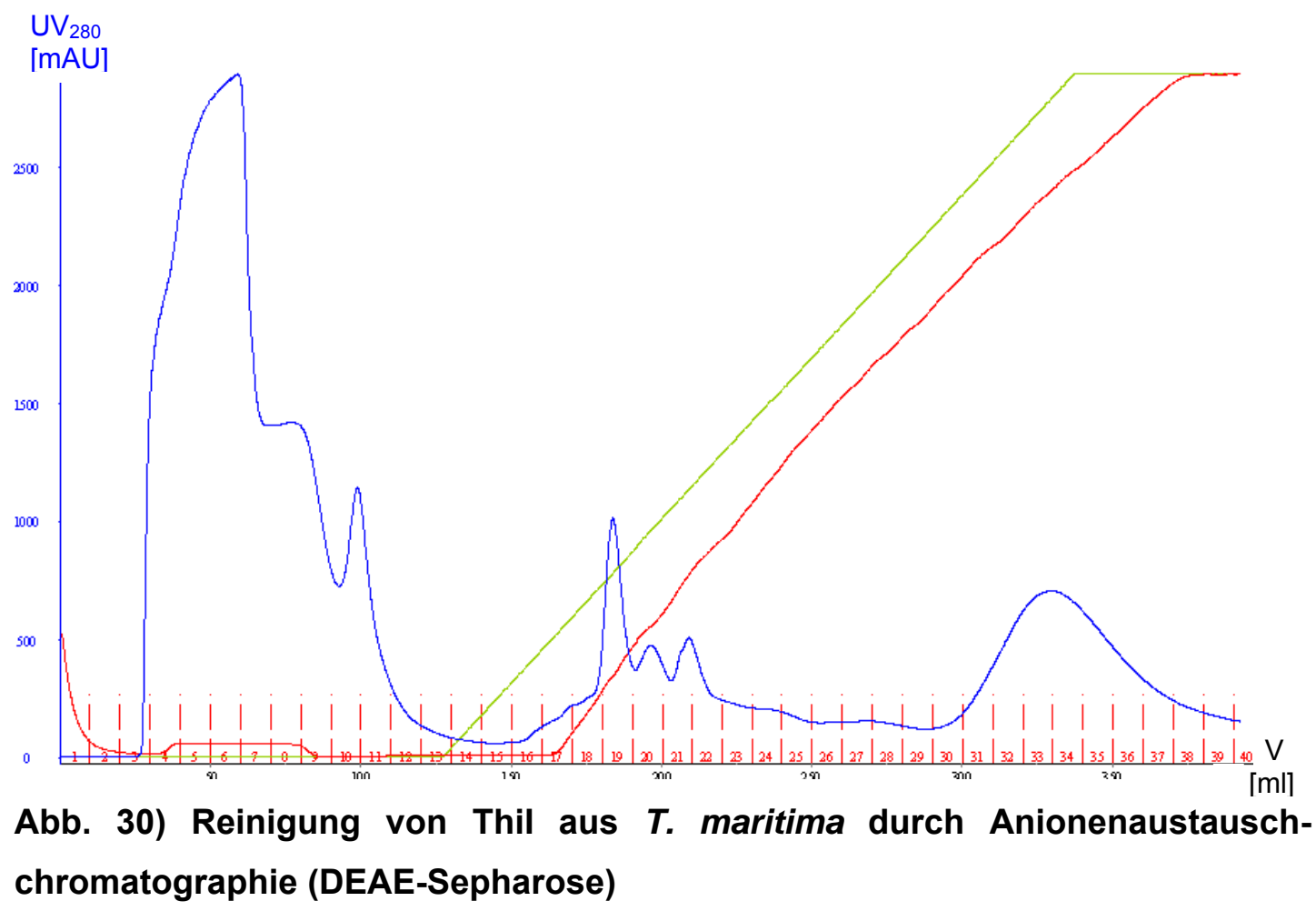

Die nach 2.12.1.4 vorbehandelte Probe wurde auf eine DEAE-Sepharosesäule aufgetragen. Nach kurzem Waschschritt, um ungebundene Proteine zu entfernen (Extinktion sinkt), wurde durch Anlegen eines Gradienten ( $\left.0 \mathrm{M}-1 \mathrm{M}\left(\mathrm{NH}_{4}\right)_{2} \mathrm{SO}_{4}\right)$ damit begonnen, die gebundenen Proteine von der Säule zu eluieren. Die Flussgeschwindigkeit während der gesamten Aufreinigung betrug $2 \mathrm{ml} / \mathrm{min}$. Eine anschließende SDS-PAGE (Abb. 31) zeigte, in welchen Fraktionen sich das Zielprotein befand.

Es gilt folgender Farbcode: Blau: Extinktion bei $280 \mathrm{~nm}$

Grün: Gradient [\% B]

Rot: Leitfähigkeit [mS/cm] 


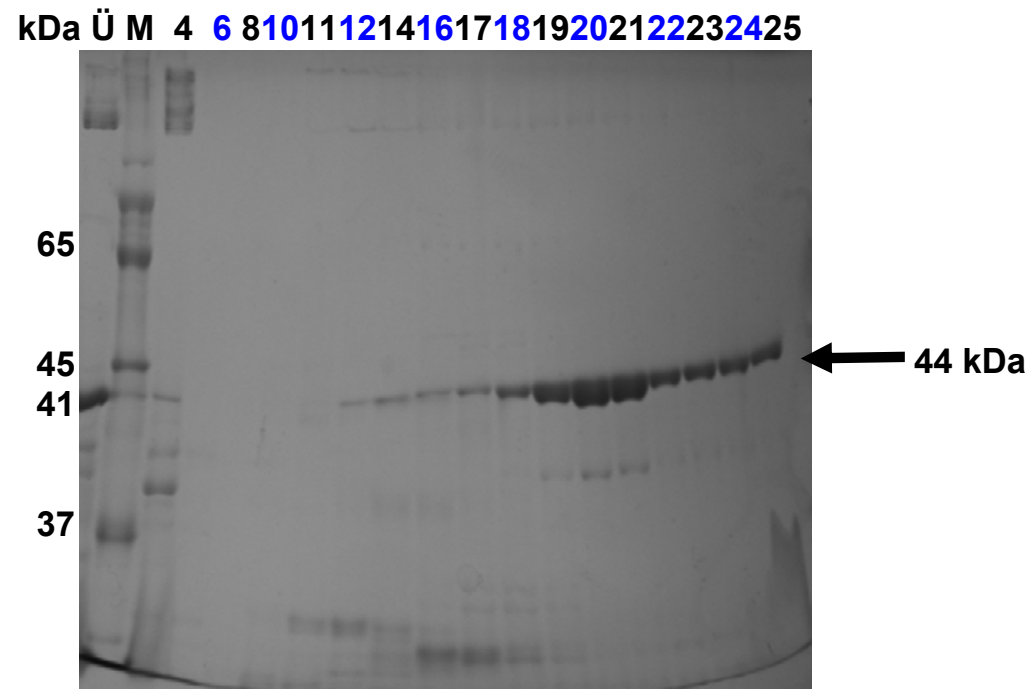

Abb. 31) SDS-PAGE der Reinigung von Thil aus $T$. maritima durch Anionenaustauschchromatographie

Die Gelelektrophorese fand unter denaturierenden Bedingungen in einem 12,5\%-igen Gel statt. Die Anfärbung erfolgte nach Coomassie (2.13.1.1).

Es bedeuten: Ü: Überstand nach Hitzedenaturierung

M: Größenstandard

Der aus der Hitzedenaturierung erhaltene Überstand (Ü) wurde über eine DEAESepharosesäule aufgetrennt. Thil eluierte bei einer Konzentration von ungefähr $300 \mathrm{mM}$ $\left(\mathrm{NH}_{4}\right)_{2} \mathrm{SO}_{4}$.

Es konnte so festgestellt werden, dass Thil aus T. maritima bei einer Salzkonzentration von ungefähr $300 \mathrm{mM}\left(\left(\mathrm{NH}_{4}\right)_{2} \mathrm{SO}_{4}\right)$ von der Säule eluiert wurde. Schon die - im Vergleich zu der Aufreinigung des Orthologs aus E. coli - sehr niedrige Höhe des Peaks der Durchflussfraktionen wies darauf hin, dass nur noch geringe Mengen an E. coli-Proteinen vorhanden waren. Während des Gradienten wurden nur zwei langgestreckte Peaks erhalten (Abb. 30). Anhand einer SDS-PAGE-Analyse (Abb. 31) konnte gezeigt werden, dass das Protein Thil im ersten Peak über eine große Anzahl an Fraktionen eluiert worden war (Spur 12-24). Dabei war Thil aus T. maritima bis auf leichte Verunreinigungen durch ein $<30 \mathrm{kDa}$ und ein ca. $15 \mathrm{kDa}$ großes Protein rein. Im zweiten Peak konnte mittels SDS-PAGE kein Protein nachgewiesen werden (Spur 25, Abb. 31). Hier wurde davon ausgegangen, dass es sich zum einen um Salz und zum anderen um kleinste Proteinreste von E. coli-Proteinen, die durch die Hitzedenaturierung geschädigt worden waren, handelte. 


\subsubsection{Gelfiltration von Thil aus T. maritima}

Um die noch leichten Verunreinigungen nach Hitzeschock und DEAESepharose Reinigung durch zwei E. coli-Proteine von jeweils $<30 \mathrm{kDa}$ von Thil aus T. maritima abzutrennen und um die Proteinlösung in einen Puffer mit niedriger Salzkonzentration zu überführen, wurde als finaler Schritt der Reinigung eine Gelfiltration über eine S75 Gelfiltrationssäule durchgeführt. Dazu wurden diejenigen Fraktionen aus dem DEAE-Lauf, von denen durch SDS-PAGE (Abb. 31) gezeigt worden war, dass sie Thil in großer Menge enthielten (19-23), vereinigt und auf ein Volumen von ca. $10 \mathrm{ml}$ gebracht. Hierbei wurden Fraktionen, in denen die Thil-Konzentration unterhalb von $30 \%$ am Gesamtprotein lag (makroskopische Abschätzung der Proteinbanden im SDS-Gel), verworfen. Die übrigen wurden mit einem sehr geringen Fluss $(<0,5 \mathrm{ml} / \mathrm{min})$ über eine $\mathrm{S} 75$ Gelfiltrationsäule (26/60) gegeben.

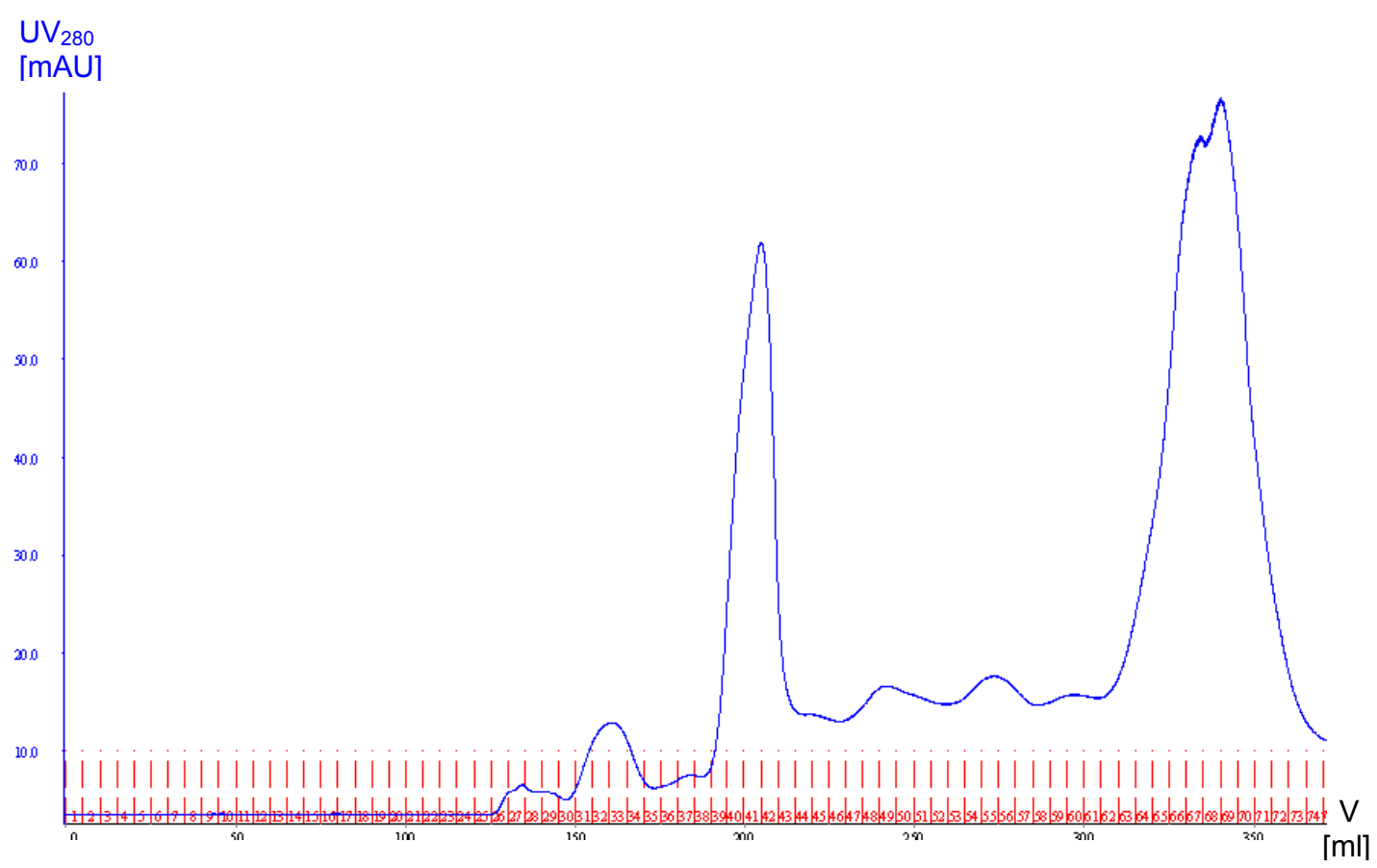

Abb. 32) S75 Gelfiltration von Thil aus T. maritima

Die Thil-enthaltenden Fraktionen aus der Reinigung durch eine DEAE-Sepharosesäule wurden vereinigt und auf ein Volumen von $10 \mathrm{ml}$ ankonzentriert. Diese Probe wurde dann mit einer Flussgeschwindigkeit von $0,5 \mathrm{ml} / \mathrm{min}$ über eine $\$ 75$ Gelfiltrationsäule (26/60) gegeben. Im Anschluss wurden Proben über eine SDS-PAGE analysiert. Dabei zeigte sich, dass Thil nach $200 \mathrm{ml}$ von der Säule eluierte.

Es gilt folgender Farbcode: Blau: Extinktion bei $280 \mathrm{~nm}$ 


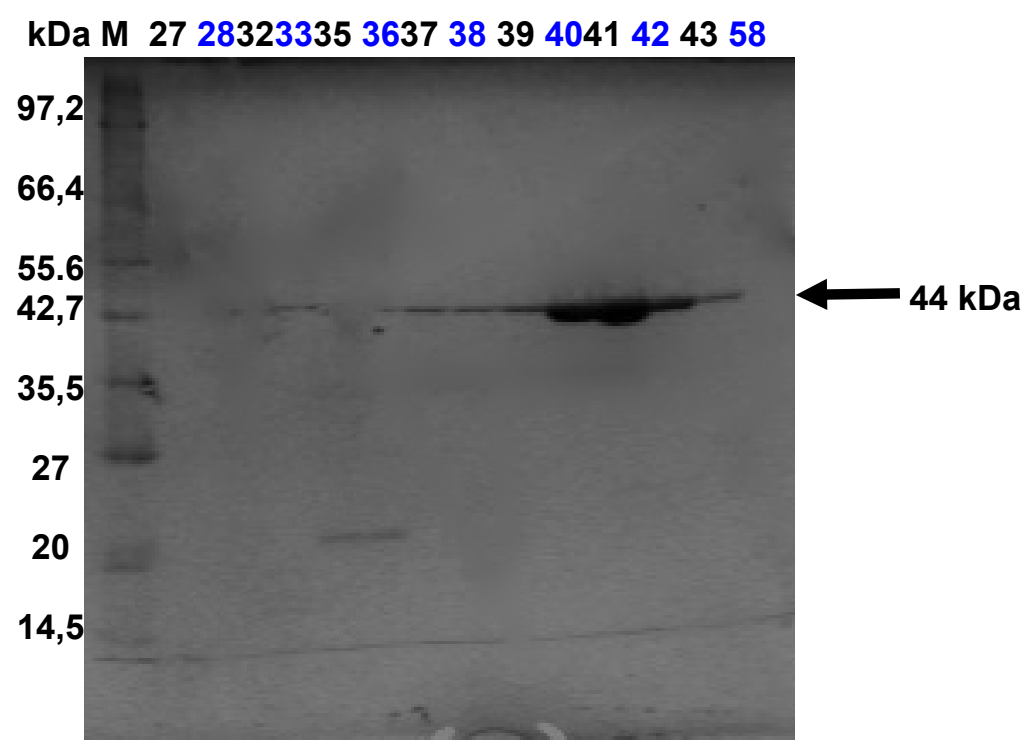

Abb. 33) SDS-PAGE der Reinigung von Thil aus T. maritima durch Gelfiltration Die Gelelektrophorese fand unter denaturierenden Bedingungen in einem 12,5\%-igen Gel statt. Die Anfärbung erfolgte nach Coomassie (2.13.1.1).

Die Proben aus der Reinigung durch eine S75 Gelfiltrationsäule (26/60) wurden nach 2.13 behandelt und aufgetrennt. Dabei wurde deutlich, dass Thil nach ca. $200 \mathrm{ml}$ Elutionsvolumen eluierte (Fraktionen $40-42$ ).

Bei der Betrachtung des Elutionsprofils der S75 Gelfiltration kann man ungefähr vier Peaks entdecken (Abb. 32). Aber nur in zwei Peaks (Elutionsvolumen $160 \mathrm{ml}$ und $210 \mathrm{ml}$ ) konnte bei Analyse durch SDS-PAGE Protein nachgewiesen werden (Abb. 33). Das Protein bei einem Elutionsvolumen von $160 \mathrm{ml}$ konnte im SDS-Gel als die ca. $20 \mathrm{kDa}$ große Verunreinigung, die schon während des Säulenlaufs über DEAE-Sepharose aufgefallen war, identifiziert werden. Aufgrund der in Bezug zur Größe von $20 \mathrm{kDa}$ frühen Elution kann davon ausgegangen werden, dass dieses Protein als Tri- oder sogar Tetramer vorlag. Bei $210 \mathrm{ml}$ Elutionsvolumen konnte Thil aus T. maritima identifiziert werden (Abb. 33, Spuren 40-42). Dieses Elutionsvolumen entsprach aber nicht den Erwartungen, da es für ein $44 \mathrm{kDa}$ Protein bei einer Gelfiltration über eine 26/60 S75 Superdexsäule zu hoch war. Eine komplette Analyse des Elutionsprofils zeigt aber, dass der gesamte Säulenlauf bis zu einem Elutionsvolumen von $380 \mathrm{ml}$ andauerte. Da die verwendete Säule nur ein Volumen von $320 \mathrm{ml}$ besaß, konnte bei einer Ursachenforschung nachgewiesen werden, dass das Pumpvolumen der 
Äkta-Prime nur $75 \%$ des Sollwertes betrug. Mit diesem „Korrekturfaktor“ erhält man für Thil aus T. maritima ein mit der Erwartung übereinstimmendes Elutionsvolumen von ca. $150 \mathrm{ml}$. Da in den übrigen Peaks $(120 \mathrm{ml}, 340 \mathrm{ml}$, Abb. 32) kein Protein nachgewiesen werden konnte, wurde davon ausgegangen, dass es sich im Falle des Peaks bei einem Elutionsvolumen von $120 \mathrm{ml}$ um unspezifische Aggregate und bei dem sehr hohen Peak bei $340 \mathrm{ml}$ um Salz und DNA-Reste gehandelt hat. Unterstützung für die Anwesenheit von DNA (oder RNA) lieferte die Tatsache, dass Thil aus T. maritima im Gegensatz zu Thil aus E. coli durch Bestimmung des Quotienten aus 260/280 nm mit einem Wert von 0,6 als reines Protein identifiziert werden konnte. Bei Thil aus E. coli, bei dessen Gelfiltration kein großer Peak gegen Ende des Säulenlaufes auftrat (Abb. 16), wurde jedoch ein Quotient 260/280 nm von 1,3 ermittelt, der auf eine Anwesenheit von DNA (oder RNA) im Protein hinwies. Zusätzlich konnte durch eine Bestimmung der DNA-Konzentration von Fraktionen aus dem letzten Peak zweifelsfrei DNA nachgewiesen werden. Thil aus T. maritima konnte mit annähernd 100 \%-iger Reinheit erhalten werden. Die Ausbeute lag (auch bedingt durch die großzügige Selektion der Fraktionen nach der Anionenaustauschchromatographie) mit ca. 6-7 mg/l Expressionskultur wesentlich niedriger als bei dem Thil Ortholog aus E. coli. 


\subsubsection{Untersuchung des Thil auf unspezifische Aggregation}

Zwar konnte durch Gelfiltration (3.2.1.4) weitgehend ausgeschlossen werden, dass Thil unspezifisch aggregiert war, da es sonst im Ausschlussvolumen eluiert wäre. Zur Bestätigung der Ergebnisse der Gelfiltration wurde jedoch zusätzlich ein Absorptionsspektrum von $200 \mathrm{~nm}$ bis $900 \mathrm{~nm}$ mit Hilfe eines Photometers aufgenommen (siehe 2.14.8).

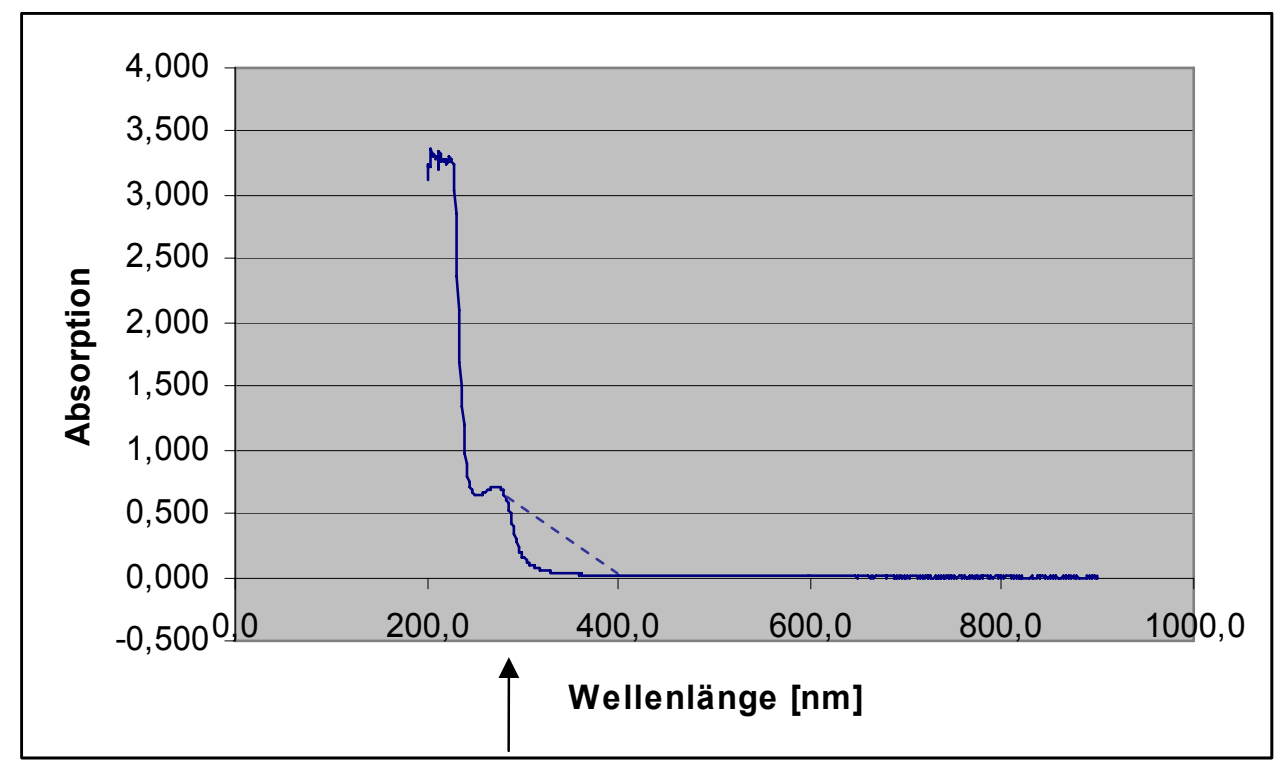

Abb. 34) Darstellung der Absorptionskurve zur Kontrolle auf eine unspezifische Aggregation von Thil aus T. maritima.

Die Absorption einer Thil-Lösung wurde bei verschiedenen Wellenlängen bestimmt. Der Auftrag der erhaltenen Werte ergibt einen Kurvenverlauf, der in seiner Charakteristik (steiler Abfall der Absorption ab einer Wellenlänge von $320 \mathrm{~nm}$, siehe Pfeil) aufzeigte, dass das untersuchte Protein ohne Aggregationen vorlag.

Das Absorptionsspektrum (Abb. 34) zeigte deutlich, dass Thil nicht unspezifisch aggregiert vorlag. Bei einem unspezifisch aggregierten Protein wäre der Abfall der Extinktion ab $320 \mathrm{~nm}$ wesentlich schwächer verlaufen (siehe Abb. 34, gestrichelter Kurvenverlauf). Da so das Ergebnis der Gelfiltration verifiziert worden war, wurde bei den Reinigungen der übrigen Proteine (vgl. 3.2.2) auf diesen Versuch verzichtet und die Kontrolle auf unspezifische Aggregation lediglich anhand der Gelfiltration durchgeführt.

Das oben untersuchte Thil wurde zu Kristallisationsversuchen bzw. zur Komplexformation eingesetzt $(3.3,3.4)$. 


\subsection{2}

\section{Alternative Aufreinigung von Selenomethionin ent- haltendem Thil ohne Hitzeschock}

Nachdem ein nativer Datensatz von Thil-RNA-Komplex-Kristallen aufgenommen worden war (3.7), sollte das Phasenproblem mittels eines MAD-Experiments gelöst werden. Dazu wurde Selenomethioninenthaltendes Thil (im Folgenden als Se-Thil bezeichnet) durch Expression in dem methioninauxotrophen Stamm E. coli B834(DE3) erzeugt. Die Aufreinigung erfolgte analog zum nativen Thil aus T. maritima (siehe 3.2.1.2 bis 3.2.1.4), es wurden jedoch wegen der Oxidationsempfindlichkeit von Selenomethionin $5 \mathrm{mM}$ (statt bisher $2 \mathrm{mM}$ ) DTT zugegeben.

In den Kristallen, die nach Komplexformation und Kristallisation des Se-Thil erhalten wurden, konnte jedoch nur ein sehr schwaches anomales Signal von Selen festgestellt werden (siehe 3.7.2). Da die Möglichkeit bestand, dass das sehr oxidationsempfindliche Selen während des Hitzeschocks (vgl. 3.2.1.2) trotz erhöhter DTT-Zugabe oxidiert worden war, wurde ein alternatives Aufreinigungsprogramm ohne Hitzeschock etabliert.

\subsubsection{Expression und Anionenaustauschchromatographie von}

\section{Se-Thil}

Methionin auxotrophe E. coli B834(DE3)-Zellen wurden mit dem rekombinanten Plasmid pET28a-thil transformiert und - ohne Induktionstest im analytischen Maßstab - gleich im präparativen Maßstab exprimiert (vgl. 2.12.1.2). Vor der Induktion mit IPTG und nach der anschließenden, vierstündigen Inkubation zur Expression von Se-Thil wurden Proben für eine SDS-PAGE-Analyse entnommen (vgl. 2.13). Da kein großer Unterschied im Verhalten des Se-Thil gegenüber dem nativen Thil erwartet wurde, begann die Reinigung auch hier mit einer Anionenaustauschchromatographie. Es wurde jedoch nicht damit gerechnet, dass Se-Thil nach diesem Reinigungsschritt von einer ähnlich hohen Reinheit erhalten wurde, wie dies im Falle des nativen Thil gelungen war (vgl. 3.2.1.3), da aufgrund des nicht erfolgten Hitzeschocks mit einer wesentlich höheren Proteinkonzentration in 
der Probe gearbeitet wurde (vgl. Abb. 30 und Abb. 35, Extinktion bei $280 \mathrm{~nm})$.

Der nach 2.12.1.4 erhaltene Überstand wurde auf eine DEAESepharosesäule geladen. Nach der Entfernung von ungebundenem Protein durch einen Waschschritt konnte Se-Thil durch Anlegen eines Gradienten von $0 \mathrm{M}-1 \mathrm{M}\left(\mathrm{NH}_{4}\right)_{2} \mathrm{SO}_{4}$ eluiert werden. Der Verlauf der Reinigung wurde durch Aufzeichnung der Extinktion bei einer Wellenlänge von $280 \mathrm{~nm}$ dokumentiert. Im Anschluss wurden die Proben der Reinigung zusammen mit den Proben der Expression auf einem SDS-Gel aufgetrennt und analysiert (Abb. 36).

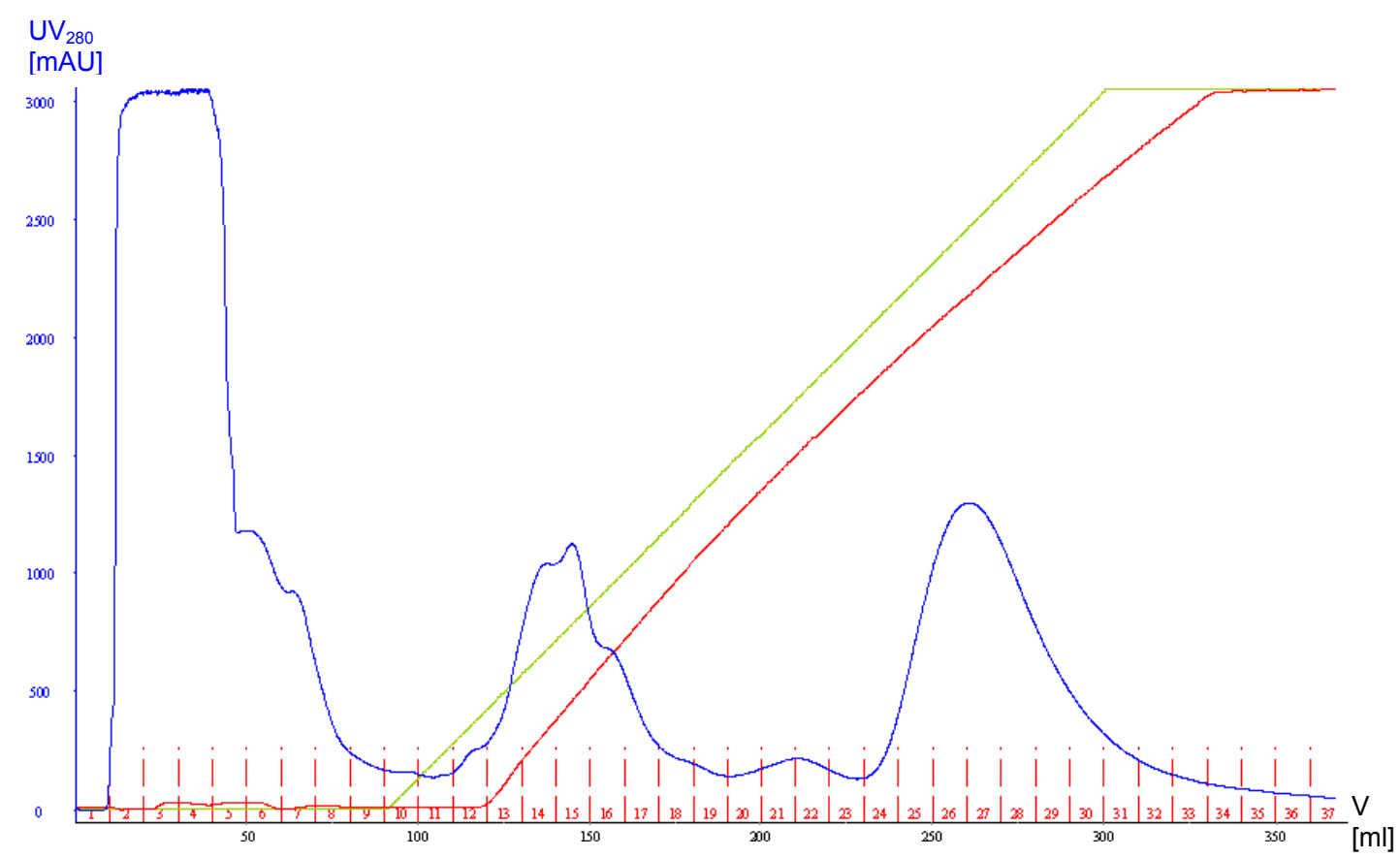

Abb. 35) Elutionsprofil der Reinigung von Se-Thil durch Anionenaustauschchromatographie (DEAE-Sepharose)

Die nach 2.12.1.4 vorbehandelte Probe wurde auf eine DEAE-Sepharose (30 ml) Säule aufgetragen. Nach dem Waschen der Säule zur Entfernung ungebundener Proteine (Extinktion sinkt), wurde durch Anlegen eines Gradienten (0-1 $\left.\mathrm{M}\left(\mathrm{NH}_{4}\right)_{2} \mathrm{SO}_{4}\right)$ damit begonnen, die gebundenen Proteine von der Säule zu eluieren. Die Flussgeschwindigkeit während der gesamten Aufreinigung betrug $2 \mathrm{ml} / \mathrm{min}$. Eine anschließende SDS-PAGE (Abb.

36) zeigte, in welchen Fraktionen das Zielprotein zu finden war.

Es gilt folgender Farbcode: Blau: Extinktion bei $280 \mathrm{~nm}$

Grün: Gradient [\% B]

Rot: Leitfähigkeit $[\mathrm{mS} / \mathrm{cm}]$ 
Anhand des Elutionsprofils der Anionenaustauschchromatographie konnte man erkennen, dass die Extinktion bei $280 \mathrm{~nm}$ wie erwartet höher ausfiel als bei der Reinigung des nativen Thil (Abb. 35). Der Wert für die Extinktion der Proteine im Durchfluss wurde hier um ca. 500 mAU höher bestimmt als bei der Auftragung des hitzegeschockten Lysats beim nativen Thil (Abb. 30). Bei näherer Betrachtung fiel aber auf, dass hier im Durchfluss ein Plateau von ca. $3000 \mathrm{mAU}$ nicht überschritten wurde. Dies wies darauf hin, dass der mögliche Maximalwert des Systems erreicht wurde. Der absolute Wert der Extinktion des Durchflusses lag folglich oberhalb von 3000 mAU.

Nach dem Waschen und dem Start des Gradienten wurden drei langgestreckte Peaks erhalten (Abb. 35). Eine Analyse von Proben aus diesen Peaks (Abb. 36) ergab, dass Se-Thil über einen weiten Bereich (Fraktion 15-20) bei einer Konzentration von $25 \%$ B $\left(\sim 250 \mathrm{mM}\left(\mathrm{NH}_{4}\right)_{2} \mathrm{SO}_{4}\right)$ eluierte. Allerdings eluierte Se-Thil nicht in einem prominenten Peak, sondern im Hintergrund. Man kann also davon ausgehen, dass der Kurvenverlauf stärker von den Kontaminanten als von Se-Thil bestimmt wurde. Unterstützung erfährt diese Vermutung auch dadurch, dass im SDSGel Kontaminanten mit vielen unterschiedlichen Größen auftraten. Die Analyse von Fraktion 3 zeigte, dass die Säule (wie z.B. bei der Reinigung von Thil aus E. coli) überladen wurde, was aber hier vermutlich eher an der Auftragung des Gesamtextraktes aus den Expressionszellen lag als an der Bindungskapazität der Säule. Gegen Ende des Gradienten (Fraktionen 3540) konnte mittels SDS-PAGE kein Protein mehr detektiert werden, was dafür spricht, dass hier Nukleinsäuren und/oder kleine Proteine und Aminosäuren eluiert wurden. 


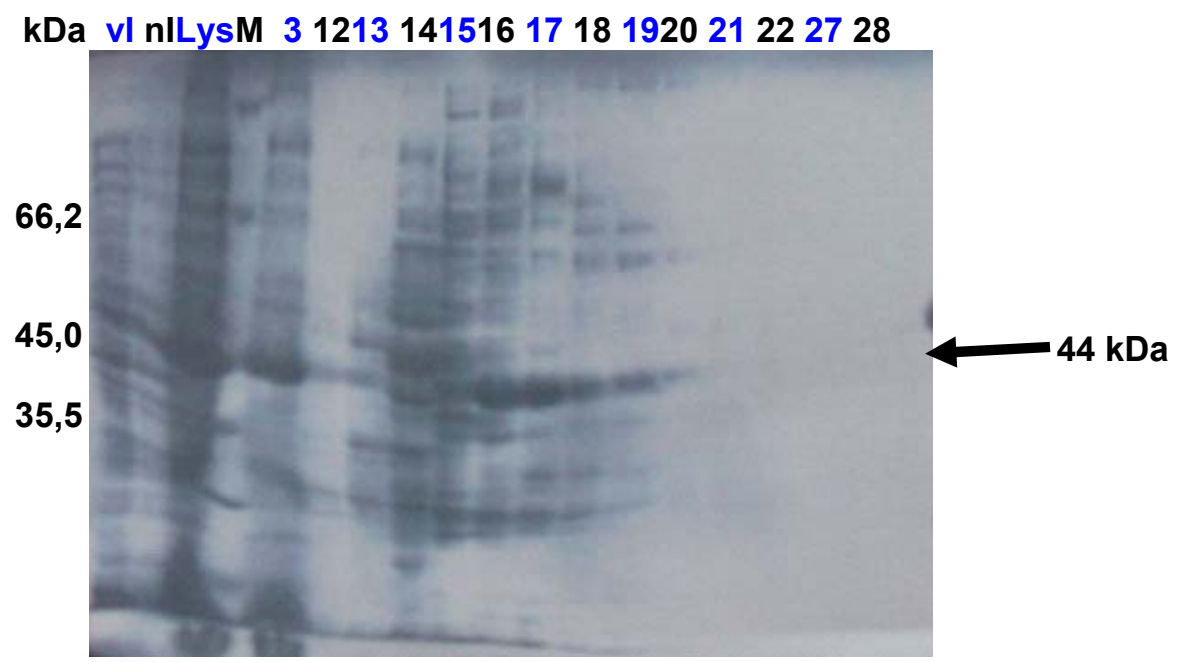

Abb. 36) Expression und Aufreinigung durch Anionenaustauschchromatographie (DEAE-Sepharose) von Se-Thil aus T. maritima

Die Gelelektrophorese fand unter denaturierenden Bedingungen in einem 12,5\%-igen Gel statt. Die Anfärbung erfolgte nach Coomassie (2.13.1.1).

Es bedeuten: vl: vor Induktion

nl: $\quad$ nach Induktion

Lys: Lysat

M: Größenstandard

3-28: Fraktionen 3-28

Auch hier konnte anhand der Auftragung der Induktionskontrollen ( $\mathrm{vl}, \mathrm{nl}$ ) keine Aussage über eine erfolgreiche Expression gemacht werden. Es kann aber festgestellt werden, dass nach Lyse der Zellen eine große Menge von Se-Thil im Lysat enthalten war (Spur Lys, Abb. 36). Neben der Tatsache, dass die Säule überladen wurde, konnte man erkennen, dass SeThil (Pfeil) ab einer Konzentration von $25 \%$ B $\left(\sim 250\right.$ mM $\left.\left(\mathrm{NH}_{4}\right)_{2} \mathrm{SO}_{4}\right)$ in den Fraktionen 16 20 eluiert wurde.

\section{Weitere Reinigung des Se-Thil durch Hydrophobe Interaktions Chromatographie (HIC)}

Da nach der Anionenaustauschchromatographie eine große Menge an kontaminierenden Proteinen im Gel nach der SDS-PAGE erkennbar war (vgl. Abb. 36), erfolgte eine Aufreinigung durch HIC.

Diese Methode wurde ausgewählt, da die Insertion von Selenomethionin zu einer Verstärkung der hydrophoben Eigenschaften von Proteinen führen kann (Rudolph, pers. Mitt.). Dazu wurden die Fraktionen der Reinigung durch 
Anionenaustauschchromatographie (3.2.2.1), von denen durch SDS-PAGE gezeigt werden konnte, dass sie Se-Thil enthielten (Spur 15-20, Abb. 36), vereinigt und durch Zugabe von $\left(\mathrm{NH}_{4}\right)_{2} \mathrm{SO}_{4}$ auf eine Endkonzentration von $1 \mathrm{M}\left(\mathrm{NH}_{4}\right)_{2} \mathrm{SO}_{4}$ gebracht. Die Reinigung durch Hydrophobe Interaktions Chromatographie erfolgte mit Hilfe einer Phenylsepharosesäule. Der Lauf wurde durch die Aufzeichnung der Extinktion bei einer Wellenlänge von $280 \mathrm{~nm}$ verfolgt (Abb. 37).

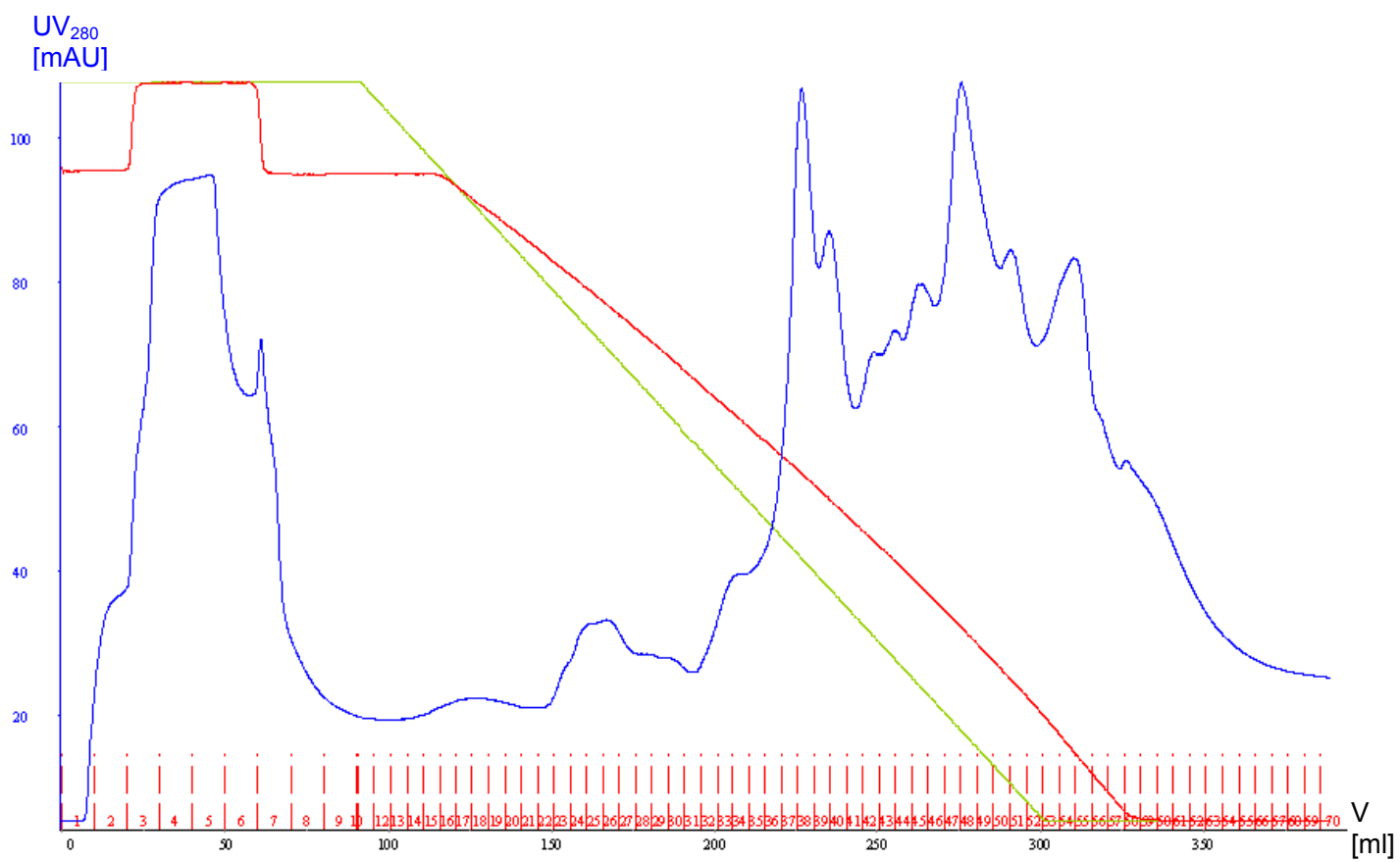

Abb. 37) Elutionsprofil der Reinigung von Se-Thil aus T. maritima durch HIC (Phenylsepharose)

Die in 3.2.2.1 erhaltenen Fraktionen, in denen Se-Thil durch SDS-PAGE-Analyse nachgewiesen werden konnte, wurden vereinigt und durch Zugabe von $\left(\mathrm{NH}_{4}\right)_{2} \mathrm{SO}_{4}$ auf eine Salzkonzentration von $1 \mathrm{M}$ gebracht. Anschließend wurde die Probe auf eine Phenylsepharosesäule gegeben. Nach dem Spülen erfolgte die Elution der gebundenen Proteine durch einen absteigenden Salzgradienten ( $\left.1 \mathrm{M}-0 \mathrm{M}\left(\mathrm{NH}_{4}\right)_{2} \mathrm{SO}_{4}\right)$. Die Flussgeschwindigkeit betrug $1,5 \mathrm{ml} / \mathrm{min}$. Die erhaltenen Fraktionen wurden mittels SDS-PAGE analysiert (Abb. 38).

Es gilt folgender Farbcode: Blau: Extinktion bei 280 nm/ Grün: Gradient [\% B]/

Rot: Leitfähigkeit [mS/cm]

Aus der Analyse des Gels der SDS-PAGE (Abb. 38) und dem Elutionsprofil des Säulenlaufs (Abb. 37) ging hervor, dass Se-Thil bei einer um ca. $10 \%$ niedrigeren Konzentration von $\left(\mathrm{NH}_{4}\right)_{2} \mathrm{SO}_{4}$ gegenüber der Elution des nativen Thil von der Säule eluiert wurde (Abb. 30+31). Dies bestätigt die Annahme, 
dass die Insertion von Selenomethionin die Hydrophobizität des Proteins erhöht hatte (s.o.). Man konnte zusätzlich erkennen, dass die Elution des Großteils der aufgetragenen Proteine, erst ab einer Konzentration von 50 \% B (500 mM $\left.\left(\mathrm{NH}_{4}\right)_{2} \mathrm{SO}_{4}\right)$ erfolgte. Vor der eigentlichen Elution von SeThil konnte man zwei weitere, sehr niedrige Peaks im Elutionsprofil erkennen (Abb. 37). Anhand des SDS-Gels konnte festgestellt werden, dass hier kleine Mengen eines ca. 25 kDa großen Proteins eluiert wurden (Fraktionen 15/16, Abb. 38). Im zweiten Peak (34-38) eluierte ein Protein mit einer Größe von über 66 kDa. Der eigentliche Elutionspeak, in dem Se-Thil eluiert wurde, war ein sehr inhomogener Peak. Die hierin enthaltenen Hauptkontaminanten des Se-Thil wiesen eine Größe von ca. 50 kDa und 30 kDa auf, so dass sich ein weiterer Reinigungsschritt durch Gelfiltration anbot (3.2.2.3).

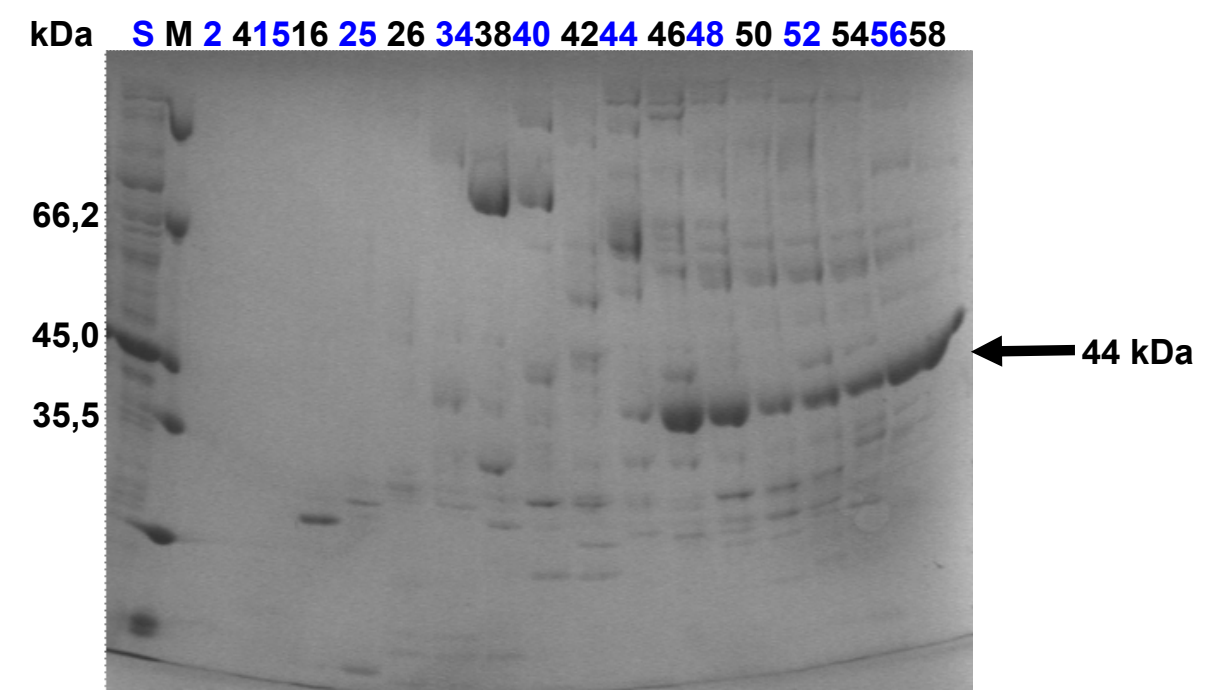

Abb. 38) SDS-PAGE der Reinigung von Se-Thil aus T. maritima durch HIC (Phenylsepharose)

Die Gelelektrophorese fand unter denaturierenden Bedingungen in einem 12,5 \%-igen SDSGel statt. Die Anfärbung erfolgte nach Coomassie (2.13.1.1).

Es bedeuten: $\mathrm{S}$ : hochgesalzte Probe vor HIC

M: Größenstandard

2-58: Fraktionen 2 bis 58

Nach dem Aufsalzen der Proben und dem Säulenlauf über eine Phenylsepharosesäule (ca. $30 \mathrm{ml}$ Bettvolumen) wurden aus den erhaltenen Fraktionen Proben gezogen und diese durch eine SDS-PAGE aufgetrennt. Die Analyse des SDS-Gels zeigte, dass Se-Thil ab Fraktion 46 von der Säule eluiert wurde. Dies entsprach einer Konzentration von $15 \%$ Puffer B $\left(\sim 150 \mathrm{mM}\left(\mathrm{NH}_{4}\right)_{2} \mathrm{SO}_{4}\right)$. 


\subsubsection{Letzter Reinigungsschritt von Se-Thil durch Gelfiltration}

Nach der Hydrophoben Interaktions Chromatographie wurde ein relativ reines Se-Thil erhalten. Auf dem Gel waren jedoch nach der SDS-PAGE noch einige Verunreinigungen zu erkennen (Abb. 38). Da es sich v.a. um ein Protein mit einer ungefähren Größe von 50 kDa und um ein Protein mit einer Größe von 30 kDa handelte, bot es sich an, diese durch eine Gelfiltration über eine S75 Superdexsäule von Se-Thil abzutrennen. Zusätzlich hatte dieser Reinigungsschritt den Vorteil, dass Se-Thil in einen Puffer mit niedrigerer Salzkonzentration umgepuffert werden konnte.

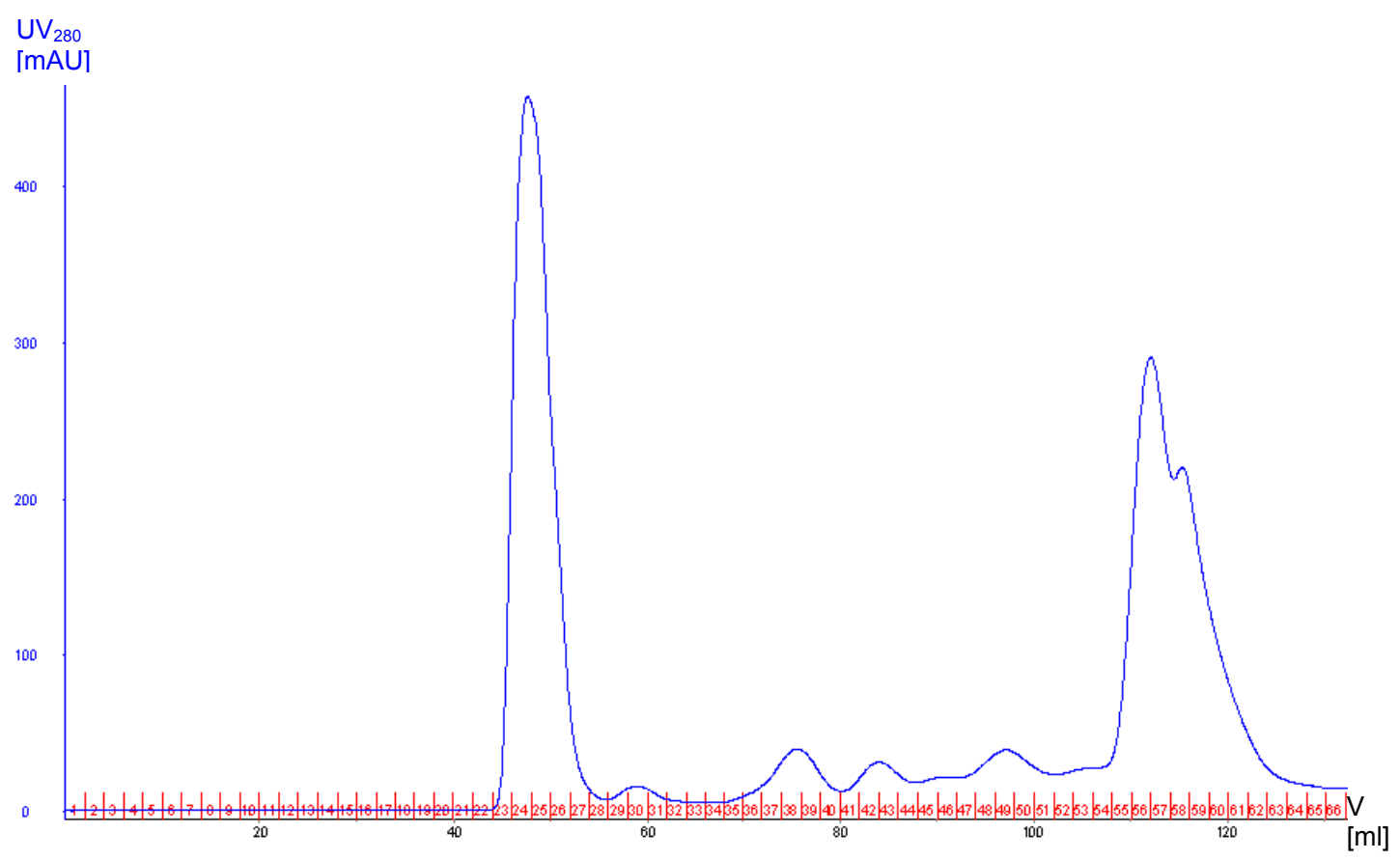

Abb. 39) Elutionsprofil der Reinigung von Se-Thil durch Gelfiltration

Die in 3.2.2.2 erhaltenen Fraktionen, in denen Se-Thil durch SDS-PAGE-Analyse nachgewiesen werden konnte, wurden vereinigt und auf ein Volumen von $10 \mathrm{ml}$ gebracht. Anschließend erfolgte eine Reinigung durch eine S75 Gelfiltrationssäule (16/60) mit einer Flussgeschwindigkeit von $0,5 \mathrm{ml} / \mathrm{min}$. Anschließend wurden die Fraktionen mittels SDSPAGE analysiert.

Es gilt folgender Farbcode: Blau: Extinktion bei $280 \mathrm{~nm}$ 
Durch die Analyse des Elutionsprofils konnte man erkennen, dass nur zwei große Peaks erhalten wurden (Abb. 39). Die Analyse von Proben aus dem ersten Peak mit einem Elutionsvolumen von ca. $45 \mathrm{ml}$ durch SDS-PAGE zeigte, dass hier Se-Thil eluiert worden war (Abb. 40). Da es sich um einen relativ symmetrischen Peak handelte, wurde davon ausgegangen, dass es sich bei den unter den jeweiligen Se-Thil-Banden erkennbaren Verunreinigungen um einen unspezifischen Abbau des Se-Thil durch den Probenpuffer handelte. Dieser Effekt war bereits beim nativen Thil beobachtet worden und trat immer dann auf, wenn die Proben nicht unmittelbar nach Kontakt mit dem Probenpuffer aufgetragen wurden (Gel nicht aufgeführt). Bei dem zweiten großen Peak (120 ml) handelte es sich um den sogenannten Salzpeak, in dem überschüssiges Salz eluiert wurde. Zwischen diesen beiden Peaks waren noch mehrere kleine Peaks bei Elutionsvolumina von $50 \mathrm{ml}, 75 \mathrm{ml}, 85 \mathrm{ml}$ und $95 \mathrm{ml}$ zu erkennen. Hier waren wahrscheinlich die kontaminierenden Proteine eluiert worden (vgl. Abb. 38). Da jedoch die Proteinkonzentrationen in diesen Fraktionen als zu niedrig bestimmt worden war, um nach einer SDS-PAGE durch Coomassie angefärbt zu werden, wurde darauf verzichtet, deren Proben auf das SDSGel aufzutragen.

Die Fraktionen 24-26 wurden vereinigt, ankonzentriert und zur Komplexformation eingesetzt (3.4). Dabei konnten ca. $2 \mathrm{mg}$ Se-Thil aus 1 Liter Expressionskultur erhalten werden. 


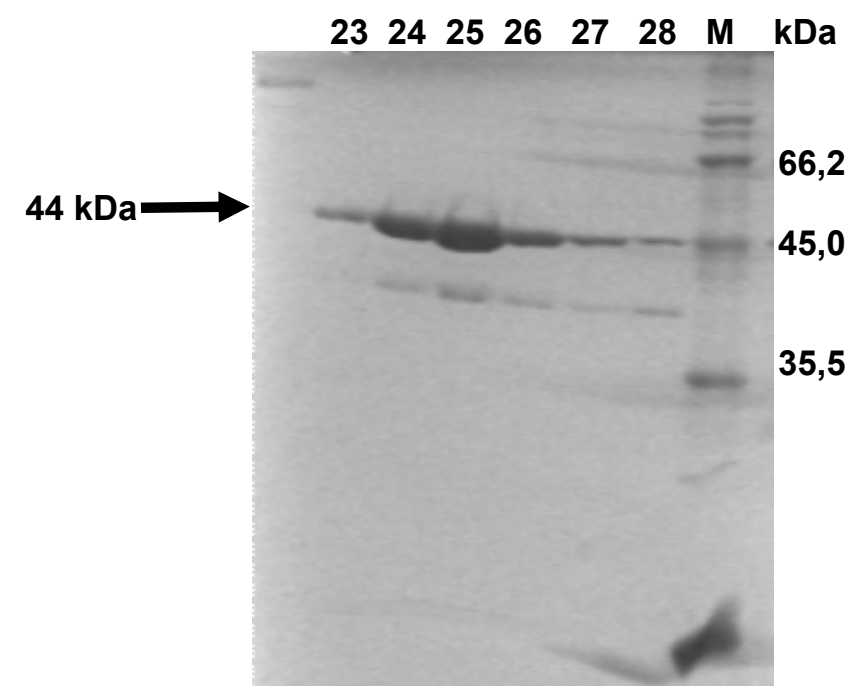

\section{Abb. 40) SDS-PAGE der Reinigung von Se-Thil durch Gelfiltration}

Die Gelelektrophorese fand unter denaturierenden Bedingungen in einem 12,5 \%-igen SDSGel statt. Die Anfärbung erfolgte nach Coomassie (2.13.1.1).

Es bedeuten: M: Größenstandard

23-28: Fraktionen 23 bis 28

Neben einer Verunreinigung, die als Abbauprodukt von Se-Thil identifiziert wurde (vgl. Haupttext), wurde Se-Thil mit einer Reinheit von > $99 \%$ erhalten. 
3.2.2.4

Kontrolle der Insertion von Selenomethionin durch

\section{MALDI-TOF}

Um die Insertion von Selenomethionin sicherzustellen, wurden mit nativem Thil und Selenomethionin enthaltendem Thil MALDI-TOF-Analysen durchgeführt. Diese erfolgten am MPI für experimentelle Medizin bei Herrn Dr. Bernhard Schmidt. Der Vergleich der Retentionszeiten von nativem Thil und Se-Thil zeigte, dass Se-Thil ca. 200 Da schwerer war als natives Thil. Da die Insertion eines Selenomethionins anstelle von Methionin zu einer Erhöhung der Masse des Proteins um ca. 45 Da führte, bedeutete dies die Insertion von vier Selenomethioninen pro Thil-Molekül (siehe Abb. 41).

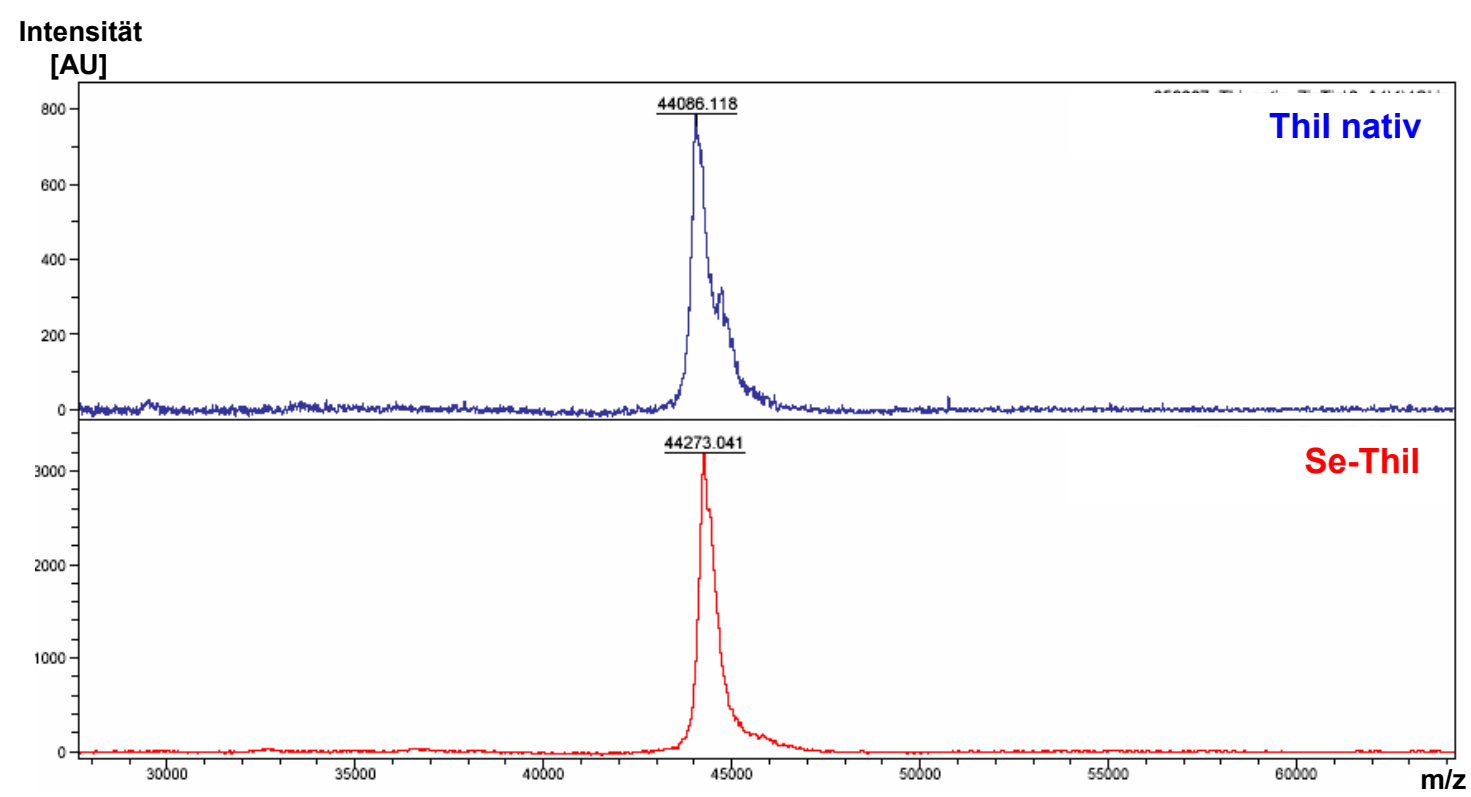

Abb. 41) MALDI-TOF Analyse von Se-Thil und nativem Thil aus T.maritima

Der Vergleich von nativem Thil und Selenomethionin enthaltendem Thil zeigt eine Vergrößerung der Masse von Thil um 200 Da. Dies entspricht ungefähr der Masse von vier Selenomethioninmolekülen pro Proteinmolekül. 


\subsubsection{Expression und Reinigung von MnmA aus T. maritima}

Aus den unter 3.2 angegebenen Gründen wurde auch das Ortholog von MnmA aus T. maritima kloniert. Nachdem die Genom-DNA aus T. maritima isoliert worden war (2.4.1), gelang es, das Gen mnmA durch PCR zu amplifizieren. Anschließend konnte auch das Gen mnmA erfolgreich in den Vektor pET28a kloniert werden (2.9). Nach der Transformation in E. coli BL21(DE3)pLysS erfolgte eine präparative Expression nach 2.12.1.2, die durch eine SDS-PAGE analysiert wurde (siehe Abb. 43).

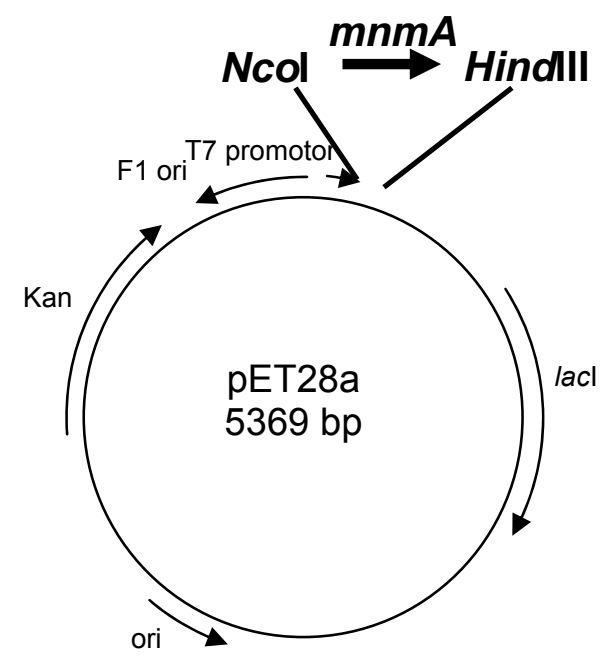

\section{Abb. 42) Darstellung des verwendeten Expressionsvektors pET28a-mnmA}

Der Vektor besteht aus dem lacl Repressorgen, dem Replikationsursprung ori, dem Kanamycin-Resistenzgen und dem Replikationsursprung F1 ori. Die Expression des in die MCS einklonierten mnmA-Fragments stand unter Kontrolle des T7-Promotors. Die Klonierung des mnmA-Gens als Ncol-HindllI-Fragment resultierte in einem tag-freiexprimierten Zielprotein. 


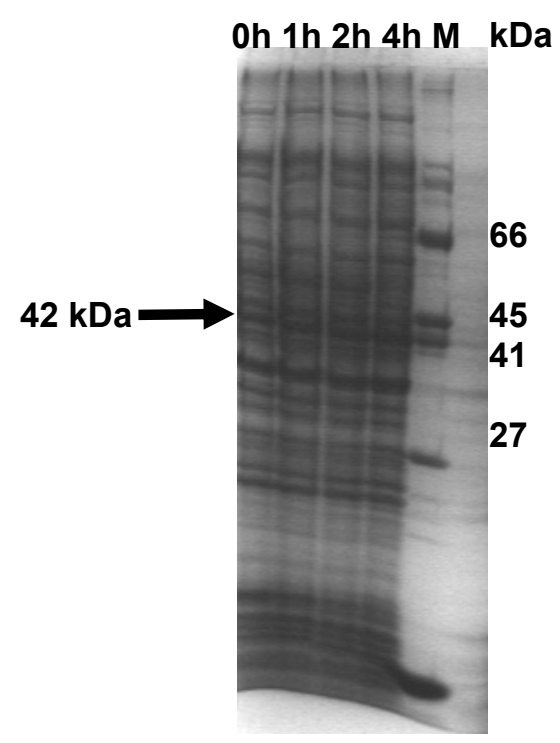

Abb. 43) Expression von MnmA aus T. maritima

Die Gelelektrophorese fand unter denaturierenden Bedingungen in einem 12,5 \%-igen SDSGel statt. Die Anfärbung erfolgte nach Coomassie (2.13.1.1).

Es bedeuten: M: Größenstandard

xh: $\quad$ Probe nach $x$ Stunden Expression

Eine Expression von MnmA (Pfeil) bei $37{ }^{\circ} \mathrm{C}$ (oder auch $25{ }^{\circ} \mathrm{C}$ ) konnte nicht eindeutig nachgewiesen werden, da keine Verstärkung der Intensität einer Bande, die dem zu erwartenden Molekulargewicht von 86 kDa entsprechen würde, nachgewiesen wurde.

Hierbei konnte anhand der SDS-PAGE nicht eindeutig festgestellt werden, ob eine Expression $\left(37^{\circ} \mathrm{C}\right.$ oder $25^{\circ} \mathrm{C}$ ) erfolgt war (Abb. 43).

Da dieses Problem schon bei Thil aufgetreten war (3.2.1.1) und auch im Falle des MnmA die Anwesenheit des Gens mnmA durch Colony-PCR des Expressionsstammes nachgewiesen worden war (nicht aufgeführt), wurde trotzdem eine Expression bei $37^{\circ} \mathrm{C}$ im präparativen Maßstab durchgeführt. So konnte auch hier MnmA nach Lyse der Zellen im Überstand nachgewiesen werden (siehe Abb. 44, Spur Ü).

Analog zur Aufreinigung von Thil wurde auch hier die Thermostabilität des Proteins für einen initialen Reinigungsschritt verwendet. Deshalb wurde der Rohextrakt von MnmA einer Hitzedenaturierung unterzogen (Abb. 44). 


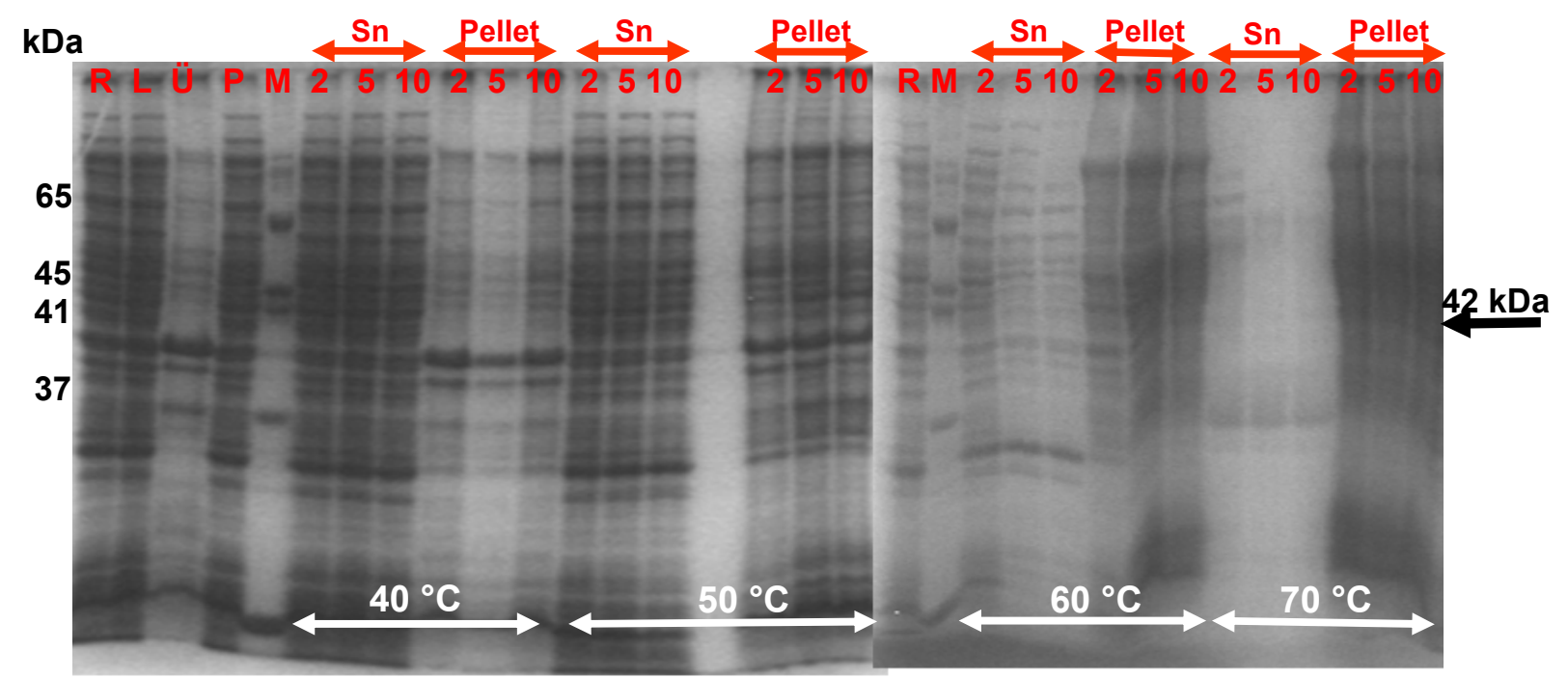

Abb. 44) Hitzedenaturierung des Rohextraktes

Die Gelelektrophorese fand unter denaturierenden Bedingungen in einem 12,5\%-igen Gel statt. Die Anfärbung erfolgte nach Coomassie (2.13.1.1).

$\begin{array}{lll}\text { Es bedeuten: } & \text { R: } & \text { Rohextrakt } \\ & \text { L: } & \text { Lysat } \\ \text { Ü: } & \text { Überstand } \\ \text { P: } & \text { Pellet } \\ \text { M: } & \text { Größenstandard } \\ \text { Sn: } & \text { Überstand }\end{array}$

Nach Lyse mit Hilfe eines Sonifiers wurde der durch Zentrifugation erhaltene Überstand bei verschiedenen Temperaturen (s.o.) für unterschiedliche Inkubationszeiten (s.o.) inkubiert. Anschließend wurden die durch die Wärmeeinwirkung präzipitierten Proteine durch Zentrifugation abgetrennt und Überstand und Pellet auf einem SDS-Gel aufgetrennt. Man kann erkennen, dass ab einer Temperatur von $60^{\circ} \mathrm{C}$ und einer Inkubationsdauer von einer Minute keine nennenswerten MnmA-Mengen im Überstand enthalten waren.

Nach Inkubation bei $40^{\circ} 150^{\circ} / 60^{\circ} / 70^{\circ} \mathrm{C}$ für eine, fünf und zehn Minuten konnte anhand der SDS-PAGE-Analyse gezeigt werden, dass MnmA bereits ab einer Temperatur von $60^{\circ} \mathrm{C}$ komplett ausgefallen war (Abb. 44). Auch die übrigen $E$. coli-Proteine waren zum größten Teil durch die Wärmeeinwirkung denaturiert worden. Nur das ca. $25 \mathrm{kDa}$ große Protein, das schon bei der Hitzedenaturierung von Thil aus $T$. maritima aufgefallen war, zeigte auch hier das gleiche Verhalten und blieb als letztes der E. coli- Proteine löslich. Da so eine Reinigung durch Hitzeschock unmöglich war, wurde weitere Reinigungsversuche vorerst eingestellt. 


\subsection{4}

Expression und Reinigung von Thil und MnmA als MBPFusionsproteine

Alternativ zur Tag-freien Expression im pET-System wurden die Gene von Thil und MnmA zusätzlich noch in das pMAL-System kloniert. Die Expression anderer Proteine in diesem System hatte gezeigt, dass im Vergleich zum pET-System, sowohl die Löslichkeit, als auch die Expressionsmengen erhöht werden konnten (Gouloudis, 2005). Als Vektor wurde pMAL-c2XP ausgewählt. Dieser war durch Insertion einer PreScission ${ }^{\mathrm{TM}}$-Protease-Erkennungssequenz (LEVLFQGP) in den kommerziell erhältlichen Vektor pMAL-c2X erzeugt worden (Gouloudis, 2005).

\subsubsection{Expression von Thil aus T. maritima als MBP-Fusions- protein}

Das Gen thil wurde über die Restriktionsschnittstellen BamHI und Hindlll in den Vektor pMAL-c2XP kloniert. Zuvor wurde die Genom-DNA aus T. maritima isoliert (2.4.1) und das Gen thil durch PCR amplifiziert.

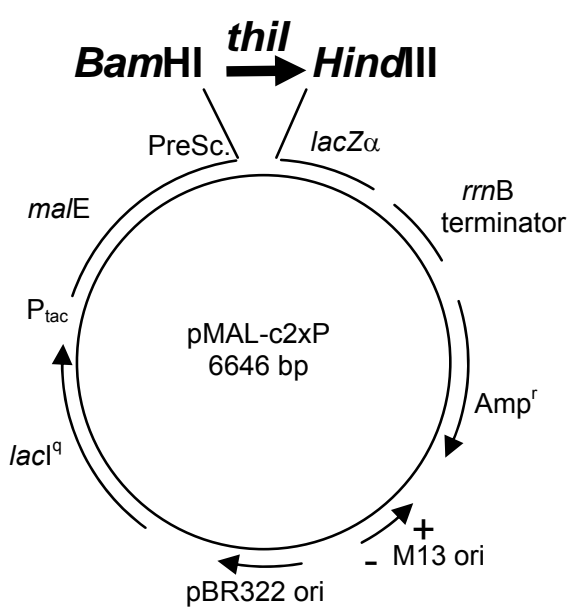

Abb. 45) Darstellung des Expressionsvektors pMAL-c2XP-thil

Der Vektor besteht aus dem rrnB Terminator, dem Ampicillinresistenzgen $\left(A m p^{r}\right)$, dem Replikationsursprung des Phagen M13 (M13 ori), dem Replikationsursprung des Plasmids pBR322 und dem lacl ${ }^{q}$ Repressorgen. Der tac-Promotor ist für die Expression des malEGens, der inserierten DNA und lacZ $\alpha$-Fragment verantwortlich. Das Zielgen wird in die MCS (Multiple Cloning Site) inseriert und als MBP-Fusionsprotein überexprimiert. MBP kann vom Fusionsprotein durch eine PreScission ${ }^{\mathrm{TM}}$-Protease abgespalten werden. 
Die Expression erfolgte im E. coli-Stamm ER2508. Dabei wurde, wie in Abschnitt 2.12.1.2 beschrieben, vorgegangen. Die im Versuchsverlauf erhaltenen Proben wurden einer SDS-PAGE-Analyse unterzogen. Dabei konnte beobachtet werden, dass die Intensität einer Bande zwischen $66 \mathrm{kDa}$ und $91 \mathrm{kDa}$ während des Expressionszeitraums (4 h) zunahm (Abb. 46, Pfeil). Da die Größe des Fusionsproteins MBP-Thil $86 \mathrm{kDa}$ betragen sollte (MBP $42 \mathrm{kDa}+$ Thil $44 \mathrm{kDa}$ ), wurde dieses Ergebnis als erfolgreiche Expression gewertet.

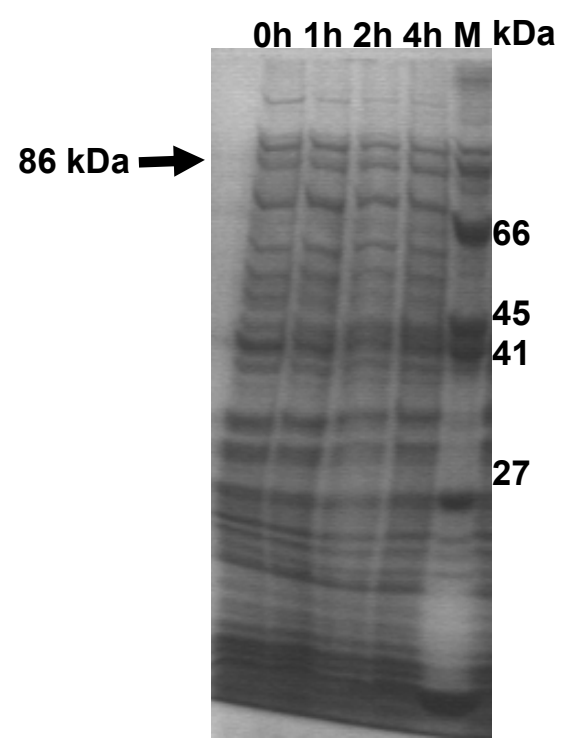

Abb. 46) Expression von MBP-Thil in E. coli ER2508

Es bedeuten: M: Größenstandard

xh: Probe nach $x$ Stunden Expression

Die Gelelektrophorese fand unter denaturierenden Bedingungen in einem 12,5\%-igen SDSGel statt. Die Anfärbung erfolgte nach Coomassie (2.13.1.1).

Die Expression von MBP-Thil konnte durch eine Verstärkung der Intensität der Bande mit einem erwarteten Molekulargewicht von ca. 80 kDa nachgewiesen werden.

\subsubsection{Reinigung des MBP-Thil im „,batch“-Verfahren}

Nachdem MBP-Thil erfolgreich exprimiert werden konnte, wurde es in größerem Maßstab in E. coli ER2508 exprimiert. Nach Präparation eines Rohextraktes (2.12.1.4) wurde dieser über Amylosebeads im batchVerfahren aufgereinigt. Durch eine anschließende SDS-PAGE-Analyse konnte gezeigt werden, dass MBP-Thil nach Auftrag auf die Amylosebeads 
komplett gebunden wurde und nach Waschen durch die Zugabe von $10 \mathrm{mM}$ Maltose eluiert werden konnte (Abb. 47). Dabei konnte festgestellt werden, dass das MBP-Thil zusammen mit einer großen Anzahl an Kontaminanten von den beads eluiert wurde. Da es sich hier um eine Affinitätschromatographie handelte, war dieses Ergebnis nicht erwartet worden. Es war vielmehr davon ausgegangen worden, dass im Anschluss an die Affinitätschromatographie ein sehr reines MBP-Fusionsprotein erhalten würde.

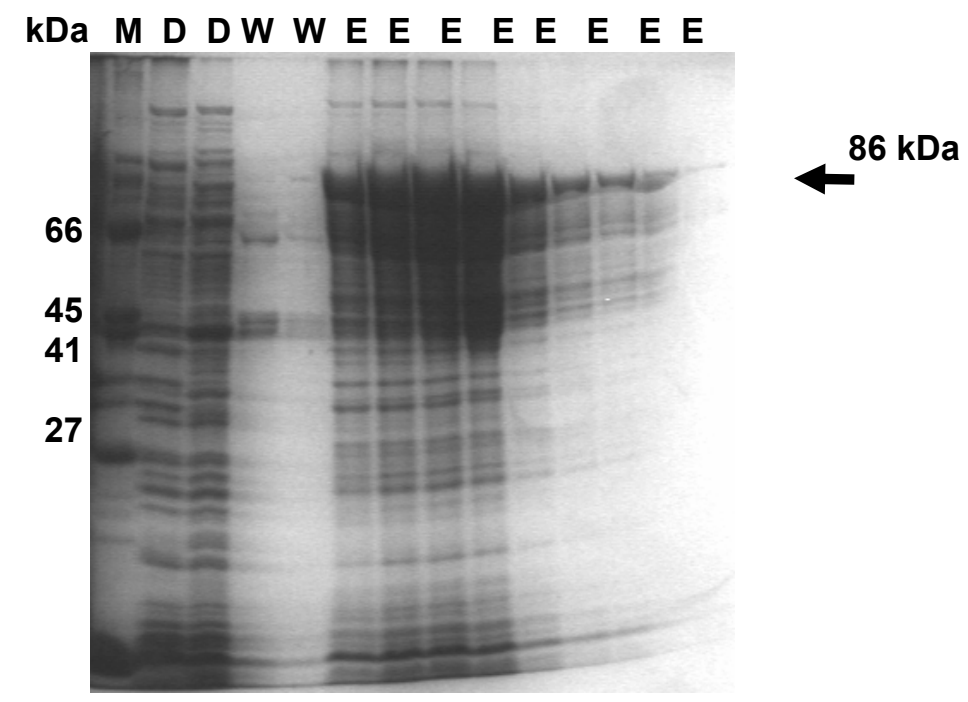

\section{Abb. 47) Affinitätsreinigung von MBP-Thil über Amylose-beads}

Es bedeuten: M: Größenstandard

D: Durchfluss

W: Waschen

E: Elution

Die Gelelektrophorese fand unter denaturierenden Bedingungen in einem 12,5 \%-igen SDSGel statt. Die Anfärbung erfolgte nach Coomassie (2.13.1.1).

Das Lysat (2.12.1.4) wurde auf Amylosebeads gegeben. Im Durchfluss (D) war kein MBPThil zu beobachten, da dass rekombinante MBP-Thil komplett an das Säulenmaterial gebunden wurde.

Nach dem Auswaschen von Kontaminationen (W) erfolgte die Elution von MBP-Thil (E) mit dem erwarteten Molekulargewicht von 86 kDa (Pfeil). 


\subsubsection{Spaltung von MBP-Thil mittels PreScission ${ }^{\mathrm{TM}}$ _Protease}

Um Thil vom MBP abzutrennen, erfolgte eine Spaltung mit PreScission ${ }^{\mathrm{TM}}$ Protease. Die Inkubation erfolgte nach 2.14.6. Anschließend wurden die Proben über eine SDS-PAGE analysiert (Abb. 48).

Dabei konnte beobachtet werden, dass bei einer Inkubation über Nacht (ÜN $\sim 16 \mathrm{~h}$ ) eine komplette Spaltung des MBP-Thil stattfand (siehe Abb. 48, Spur ÜN).

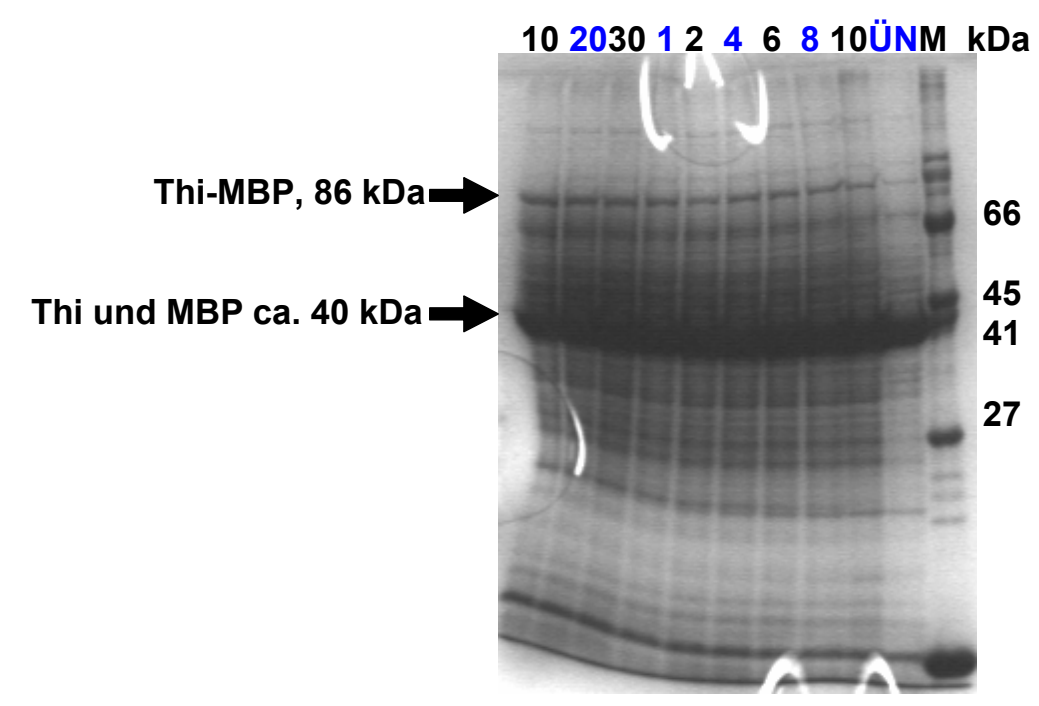

Abb. 48) PreScission ${ }^{\mathrm{TM}}$-Protease Spaltung von MBP-Thil

Es bedeuten: M: Größenstandard

$\mathrm{x}$ : Probe nach $\mathrm{x}$ Stunden Inkubation

ÜN: Inkubation der Probe über Nacht

Die Gelelektrophorese fand unter denaturierenden Bedingungen in einem 12,5 \%-igen SDSGel statt. Die Anfärbung erfolgte nach Coomassie (2.13.1.1).

Es konnte beobachtet werden, dass die Intensität der Bande die MBP-Thil repräsentierte (Pfeil bei $86 \mathrm{kDa}$ ) kontinuierlich abnahm, wohingegen die Intensität der Bande der Spaltprodukte (Pfeil bei $45 \mathrm{kDa}$ ) kontinuierlich zunahm. Die Spaltung verlief erfolgreich.

Da aufgrund der geringen Größenunterschiede von MBP (42 kDa) und Thil (44 kDa) der Versuch einer Trennung durch eine Gelfiltrationssäule sinnlos erschien, sollte wiederum die Thermostabilität des Thil genutzt werden. Diese Thermostabilität hatte bereits die Aufreinigung des ohne Tag exprimierten Thil aus T. maritima ermöglicht (3.2.1.2).

Zur Hitzedenaturierung wurden Proben des PreScission ${ }^{\mathrm{TM}}$-ProteaseVerdaus, für je eine, fünf und zehn Minuten bei einer Temperatur von $40^{\circ} \mathrm{C}$, $50{ }^{\circ} \mathrm{C}, 60^{\circ} \mathrm{C}, 70^{\circ} \mathrm{C}$ oder $80^{\circ} \mathrm{C}$ inkubiert. Nachdem präzipitierte Proteine 
durch Zentrifugation abgetrennt worden waren, erfolgte die Analyse der verschiedenen Überstände und Pellets durch SDS-PAGE. Eine Analyse des SDS-Gels zeigte, dass auch hier die E. coli-Proteine ab einer Temperatur von $60^{\circ} \mathrm{C}$ präzipitierten (Abb. 49). Neben dem schon in den anderen Hitzedenaturierungen aufgetretenen Protein mit einer Größe von ca. 25 kDa wurde ganz den Erwartungen entsprechend ein Protein erhalten, das als einziges nach einer Inkubation für 10 Minuten bei $80^{\circ} \mathrm{C}$ nicht präzipitiert war und eine Größe von ca. 40 kDa aufwies.

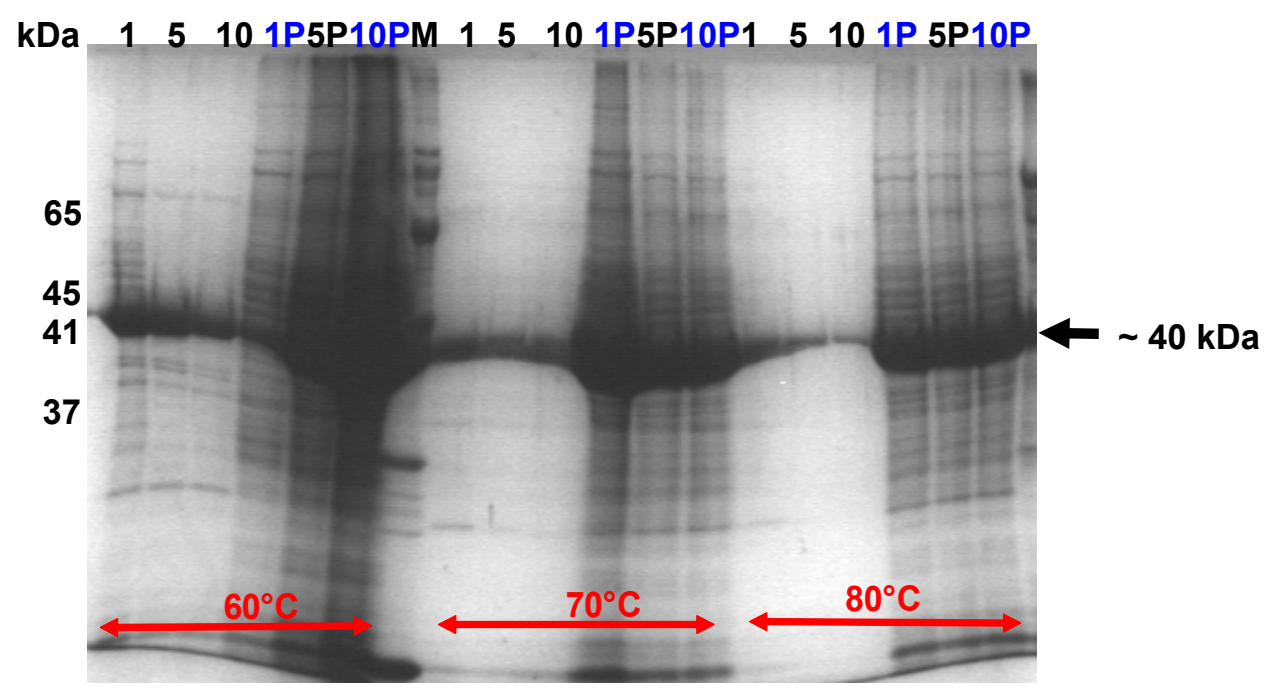

\section{Abb. 49) Trennung von MBP und Thil durch Hitzedenaturierung}

Es bedeuten: M: Größenstandard

$\mathrm{x}$ : Überstand nach $\mathrm{x}$ Minuten Inkubation

$x P$ : $\quad$ Pellet nach $x$ Minuten Inkubation

Die Gelelektrophorese fand unter denaturierenden Bedingungen in einem 12,5 \%igen SDSGel statt. Die Anfärbung erfolgte nach Coomassie (2.13.1.1).

Die Durchführung erfolgte analog zu 3.2.1.2. Nach einer Inkubation von zehn Minuten bei $80^{\circ} \mathrm{C}$ war nur noch ein Protein mit der erwarteten Größe von $45 \mathrm{kDa}$ im Überstand enthalten.

Da Thil und MBP ungefähr das gleiche Molekulargewicht aufweisen, konnte jedoch nicht sichergestellt werden, ob es sich bei dem erhaltenen thermostabilen Protein um Thil oder um MBP handelte. Zur Kontrolle wurde eine reine MBP-Lösung auf analoge Weise behandelt. Die anschließende SDS-PAGE zeigte deutlich, dass sich MBP analog zu Thil bei $80{ }^{\circ} \mathrm{C}$ nach zehn Minuten Inkubation im Überstand befand. Es konnte also durch diese Methode keine Trennung von MBP und Thil erreicht werden (Abb. 50). Da 
angenommen wurde, dass durch die nahe beieinanderliegenden Molekulargewichte mit keiner weiteren Aufreinigungsmethode (lonenaustausch, Reinigung des Spaltungsansatzes über Amylosebeads) eine vollständige Trennung der beiden Proteine durchgeführt und eindeutig nachgewiesen werden könnte, wurden die Arbeiten an diesem Punkt eingestellt. Es konnten hier aus 1 Liter Expressionskultur ca. 100 mg MBPThil-Fusionsprotein erhalten werden. Mit diesem erfolgten einige Kristallisationsversuche (CS1, CS2, CS Cryo, CS Natrix, CS PEG/ION und Footprint 1, 2, 3), die aber bisher ohne Erfolg blieben.

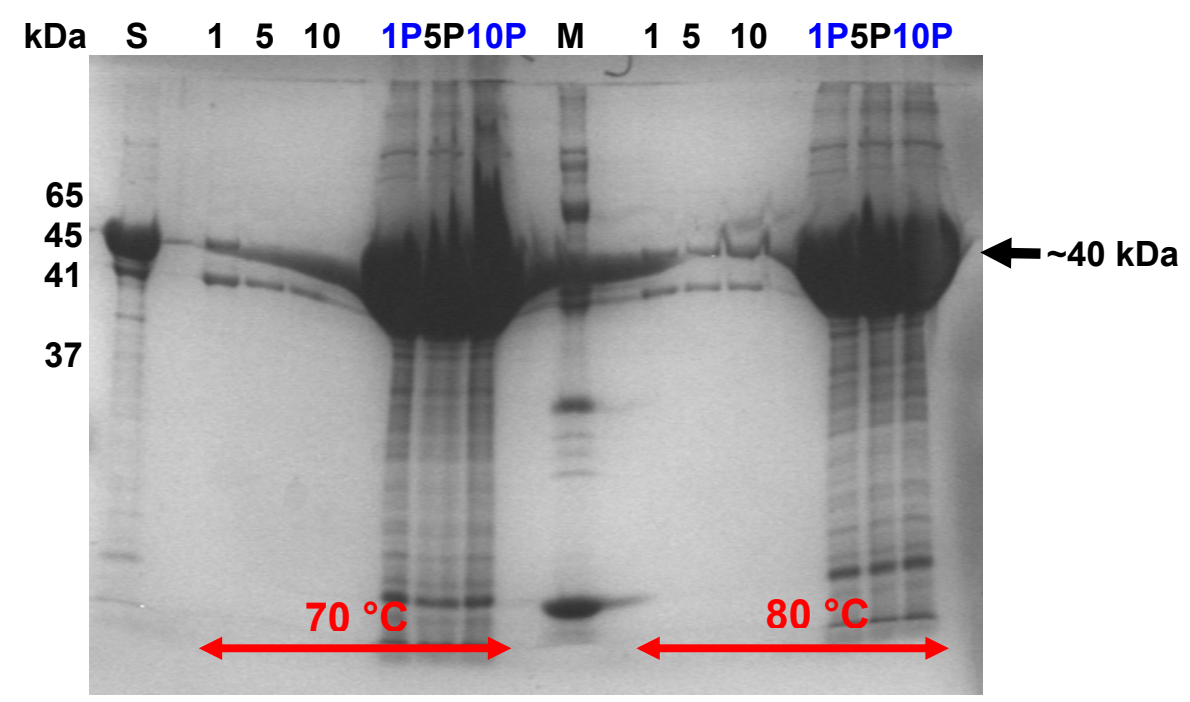

\section{Abb. 50) Hitzedenaturierung von MBP}

Es bedeuten: M: Größenstandard

$\mathrm{x}$ : Probe nach $\mathrm{x}$ Minuten Inkubation

Die Gelelektrophorese fand unter denaturierenden Bedingungen in einem 12,5\%-igen SDSGel statt. Die Anfärbung erfolgte nach Coomassie (2.13.1.1).

Die Durchführung erfolgte analog zu 3.2.1.2. Nach zehn Minuten Inkubation bei $80{ }^{\circ} \mathrm{C}$ wurde jedoch entgegen der Erwartung MBP im Überstand erhalten. Es scheint also, dass MBP zumindest unter diesen Versuchsbedingungen - wenn auch in sehr geringem Maße - (vgl. Spuren $80^{\circ} \mathrm{C}, \mathrm{U}$ + P 10 Minuten) „hitzestabil“ war. 
Expression und Reinigung von MBP-MnmA aus T. maritima

Aufgrund der schon unter 3.2.4 angeführten Gründe wurde auch MnmA aus T. maritima als MBP-Fusionsprotein kloniert. Nach der Amplifikation des Gens mnmA aus T. maritima Genom-DNA wurde es über die Restriktionsschnittstellen BamHI und HindIII in den Vektor pMAL-c2XP ligiert.

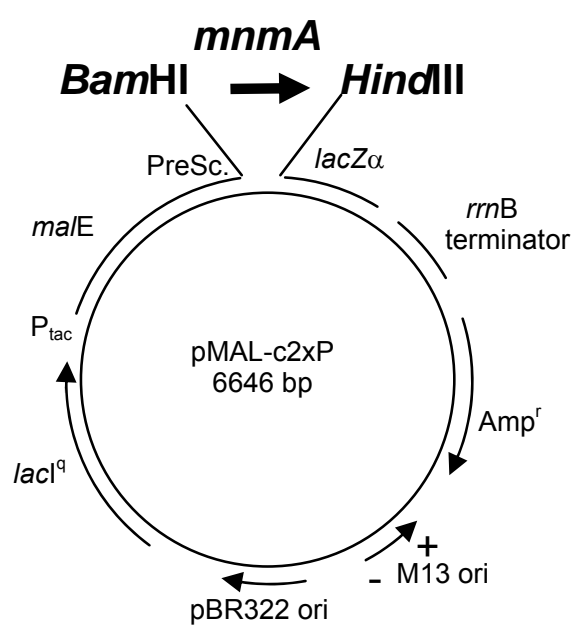

\section{Abb. 51) Darstellung des Expressionsvektors pMAL-c2XP-mnmA}

Der Vektor besteht aus dem rrnB Terminator, dem Ampicillinresistenzgen (Amp ${ }^{r}$ ), dem Replikationsursprung des Phagen M13 (M13 ori), dem Replikationsursprung des Plasmids pBR322 und dem lacl ${ }^{q}$ Repressorgen. Der tac-Promotor ist für die Expression des malE Gens, der inserierten DNA und des lacZ $\alpha$-Fragments verantwortlich. Das Zielgen wird in die MCS (Multiple Cloning Site) inseriert und als MBP-Fusionsprotein überexprimiert. MBP kann vom Fusionsprotein durch eine PreScission ${ }^{\mathrm{TM}}$-Protease abgespalten werden.

Die Expression von MnmA erfolgte im Expressionsstamm E.coli ER2508. Anschließend wurde durch eine SDS-PAGE-Analyse der Verlauf der Expression dokumentiert (Abb. 52). 


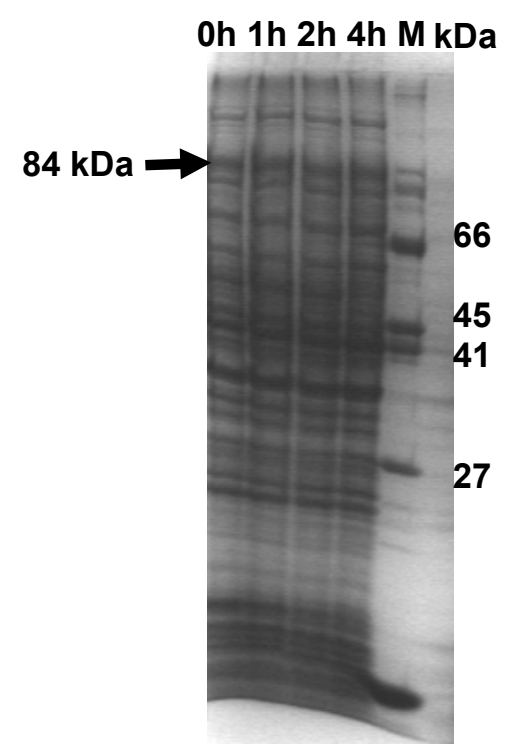

Abb. 52) Expression von MBP-MnmA in E. coli ER2508

Es bedeuten: M: Größenstandard

xh: $\quad$ Probe nach $\mathrm{x}$ Stunden Induktion

Die Gelelektrophorese fand unter denaturierenden Bedingungen in einem 12,5 \%-igen SDSGel statt. Die Anfärbung erfolgte nach Coomassie (2.13.1.1).

Die Expression von MBP-MnmA konnte durch eine Verstärkung der Intensität der Bande mit einem erwarteten Molekulargewicht von ca. 80 kDa nachgewiesen werden.

Analog zu MBP-Thil aus T. maritima konnte auch MBP-MnmA im batchVerfahren gereinigt werden (Abb. 53). 


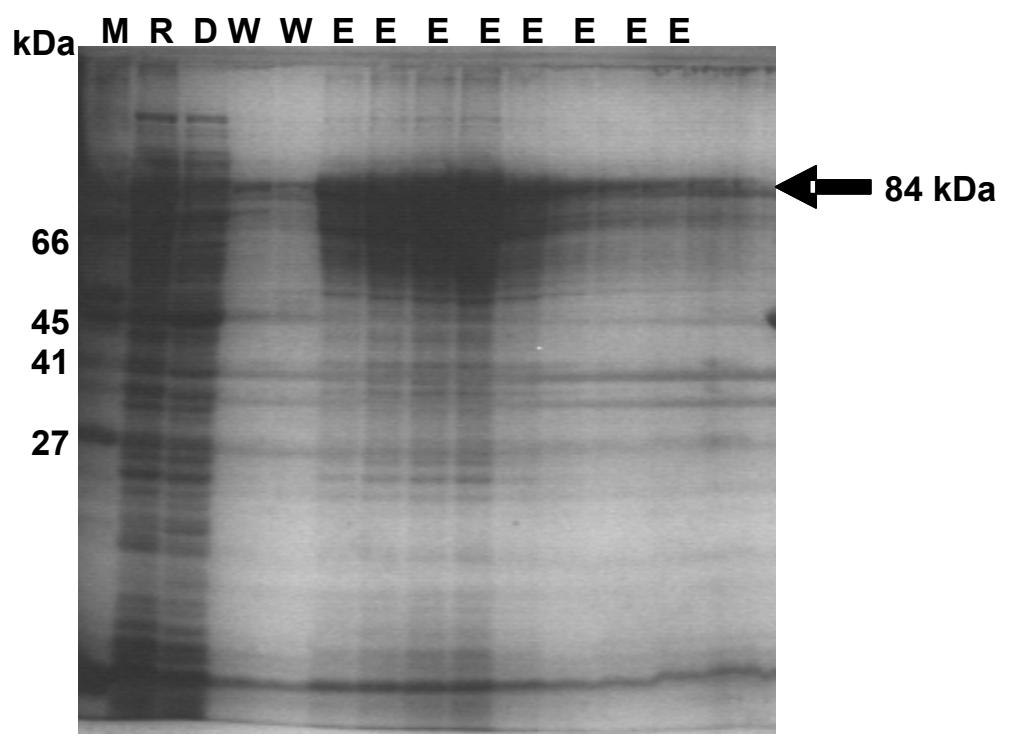

\section{Abb. 53) SDS-PAGE Aufreinigung von MBP-MnmA über Amylosebeads}

Die Gelelektrophorese fand unter denaturierenden Bedingungen in einem 12,5 \%-igen SDSGel statt. Die Anfärbung erfolgte nach Coomassie (2.13.1.1).

Es bedeuten: M: Größenstandard

R: $\quad$ Rohextrakt

D: Durchfluss

W: Waschen

E: Elution

Das Lysat (2.12.1.4) wurde auf Amylosebeads gegeben. Da im Durchfluss (D) kein MBPMnmA zu beobachten war, wurde gefolgert, dass MBP-MnmA an die Beads gebunden hatte. Nach dem Auswaschen von Kontaminanten (W) erfolgte die Elution von MBP-MnmA (E), mit dem erwarteten Molekulargewicht von 83 kDa (Pfeil).

Hier fiel auf, dass die aus der Affinitätschromatographie erhaltenen Fraktionen von größerer Reinheit waren als beim identischen Versuch mit MBP-Thil. Jedoch konnte MnmA nicht weiter gereinigt werden, da sich im Gegensatz zu MBP-Thil das Fusionsprotein nicht vollständig spalten ließ. In Abb. 53 kann man erkennen, dass zwar ein Teil des Fusionsproteins abgespalten wurde, die Intensität der Banden nimmt jedoch bei der Größe der zu erwartenden Spaltungsprodukte (42 kDa) nicht weiter zu. Die Intensität der Bande, die das MBP-Fusionsprotein repräsentiert (84 kDa), blieb über den gesamten beobachteten Zeitraum stabil. 


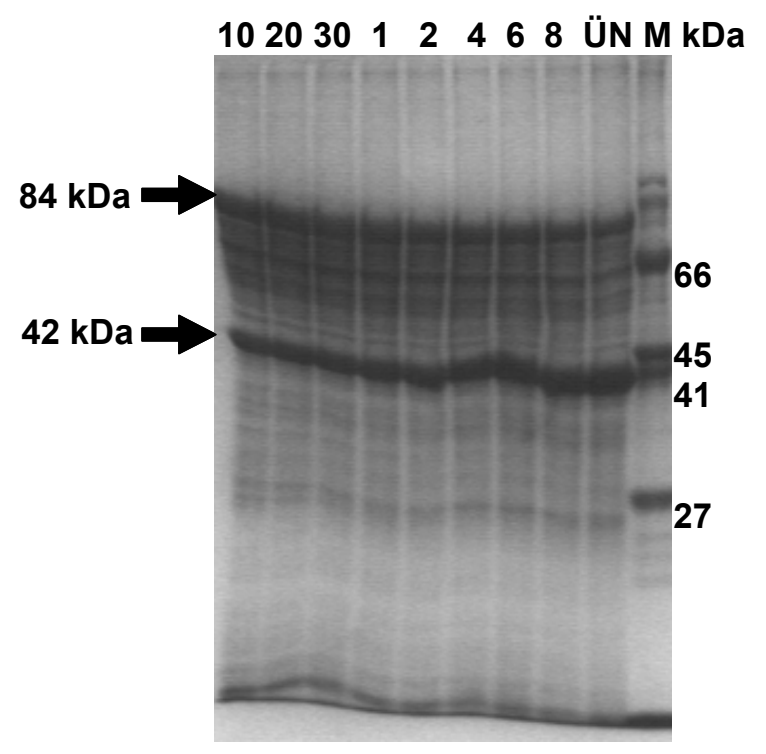

\section{Abb. 54) PreScission ${ }^{\mathrm{TM}}$-Protease Spaltung von MBP-MnmA}

Die Gelelektrophorese fand unter denaturierenden Bedingungen in einem 12,5 \%igen SDSGel statt. Die Anfärbung erfolgte nach Coomassie (2.13.1.1).

Es bedeuten: M: Größenstandard

$$
\mathrm{x} \text { : Probe nach } \mathrm{x} \text { Minuten /Stunden Inkubation }
$$

ÜN: Inkubation der Probe über Nacht

Es konnte beobachtet werden, dass die Intensität der Bande, die MBP-MnmA repräsentierte (Pfeil bei $83 \mathrm{kDa}$ ), nahezu konstant blieb. Es erfolgte zwar eine partielle Spaltung (Pfeil bei $45 \mathrm{kDa}$ ), diese nahm aber auch nach längerer Inkubationsdauer nicht zu (Spur, ÜN).

Auch längere Inkubationszeiten (bis $72 \mathrm{~h}$, Abb. 55 Spur 3d) und eine Variation der Salzkonzentration führten nicht zu einer weiteren Spaltung von MBP-MnmA (Abb. 55). Es wurde angenommen, dass die Spaltung durch verschiedene Konformationen des MBP-MnmA verhindert wurde. Die gespaltenen Anteile der Gesamtfraktion beruhten somit auf einer Konformation von MBP-MnmA, die eine frei zugängliche Erkennungssequenz für die PreScission ${ }^{\mathrm{TM}}$-Protease bot. In den ungespalteten MBP-MnmA-Anteilen war die Erkennungssequenz für die PreScission ${ }^{\text {TM}}$-Protease nicht zugänglich, da durch die andere Konformation des Fusionsproteins sterische Hinderungen der Protease vorlagen. Deshalb wurden weitere Versuche hierzu eingestellt. Da ca. 90 mg MBP-MnmA-Fusionsprotein aus 1 Liter Expressionskultur gewonnen wurden, wurde das ungespaltene Fusionsprotein zu einigen repräsentativen Kristallisationsversuchen eingesetzt (CS 1, CS 2, CS Cryo, CS PEG/ION, Footprint 1, 2, 3), die jedoch bisher ergebnislos blieben. 


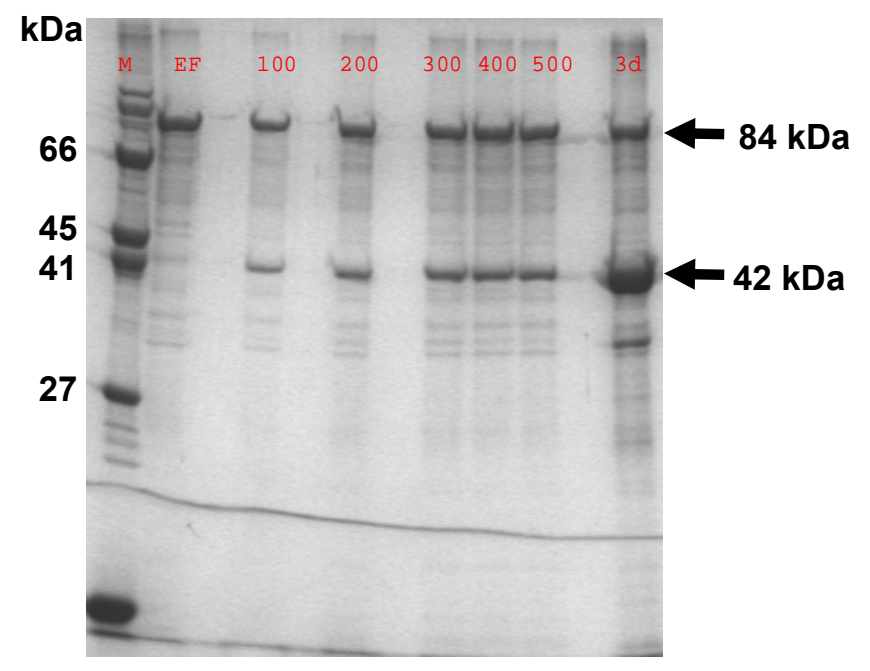

Abb. 55) PreScission ${ }^{\mathrm{TM}}$-Protease Spaltung von MBP-MnmA bei verschiedenen Salzkonzentrationen

Es bedeuten: M: Größenstandard

EF: Negativkontrolle

$\mathrm{x}$ : Probe bei einer Salzkonzentration von $\mathrm{x} \mathrm{mM}$

3d: Inkubation der Probe für 3 Tage

Die Gelelektrophorese fand unter denaturierenden Bedingungen in einem 12,5 \%-igen SDSGel statt. Die Anfärbung erfolgte nach Coomassie (2.13.1.1).

Es konnte beobachtet werden, dass auch bei verschiedenen Salzkonzentrationen die Intensität der Bande, die das Fusionsprotein MBP-MnmA repräsentierte (Pfeil bei $84 \mathrm{kDa}$ ), konstant blieb. Es erfolgte nur eine partielle Spaltung (Pfeil bei $42 \mathrm{kDa}$ ). 


\section{T. maritima}

Nachdem Thil und MnmA aus T. maritima erfolgreich aufgereinigt werden konnten, wurden die Proteine zu Kristallisationsversuchen eingesetzt. Hier werden im Folgenden v.a. die Kristallisationsversuche von Thil beschrieben. Die Versuche fanden unter Verwendung der üblichen Parameter statt, d.h es wurde zu $1 \mu$ l einer Proteinlösung einer Konzentration von 10 mg/ml jeweils $1 \mu \mathrm{l}$ Reservoirlösung zugegeben. Nach kurzer Inkubation der Platten (ca. $30 \mathrm{~min}$ ) konnte festgestellt werden, dass bei einer Proteinkonzentration von $10 \mathrm{mg} / \mathrm{ml}$ das Protein in ca. $80 \%$ der angesetzten Kristallisationsbedingungen komplett präzipitiert war. Da die Wahrscheinlichkeit, dass sich ausgefallenes Protein erst löst und dann zu regelmäßigen Kristallen umlagert, sehr gering ist, wurde die Proteinkonzentration auf $5 \mathrm{mg} / \mathrm{ml}$ heruntergesetzt. Nachdem alle verfügbaren Screens pipettiert worden waren, konnten bei 0,795 M NaCitrat, pH 5.5 und $6 \%$ MPD, 0,1 M Imidazol, pH 8.0 und $35 \%$ MPD und bei 0,8 M Na-K-Puffer, pH 8.5 und $10 \%$ Glycerin mehrere Kristallformen erhalten werden (siehe Abb. 56).

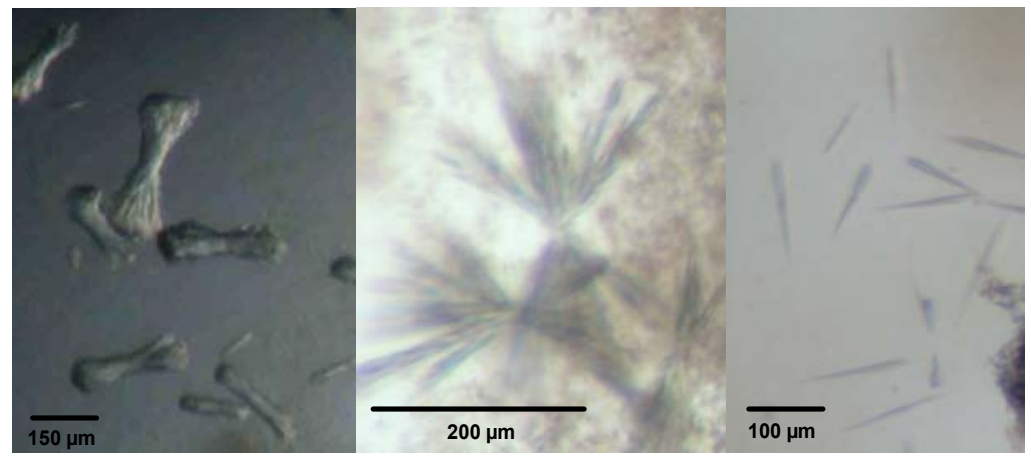

Abb. 56) Beispiele für Kristalle von Thil aus T. maritima

Aufgereinigtes Thil wurde zu verschiedenen Kristallisationsversuchen eingesetzt. Dazu wurden zu $1 \mu$ l Proteinlösung mit einer Proteinkonzentration von 5 mg/ml (oder 10 mg/ml) je $1 \mu \mathrm{l}$ Reservoirlösung gegeben. Um eine Oxidation des Proteins zu vermeiden, wurde den Ansätzen DTT in einer Endkonzentration von $2 \mathrm{mM}$ zugegeben. Die Inkubation erfolgte bei $20{ }^{\circ} \mathrm{C}$. Die Kristalle wurden erhalten bei: 0,795M NaCitrat, pH 5.5, 6 \% MPD (links)

0,1 M Imidazol, pH 8.0, 35 \% MPD (Mitte)

0,8 M Na-K-Puffer, $\mathrm{pH} 8.5,10 \%$ Glycerin (rechts) 
Um diese Kristalle in eine röntgenkristallographisch verwertbare Form zu überführen, d.h. einheitliche, regelmäßige Kristalle zu erhalten, wurde ein sogenanntes Feinscreening durchgeführt. Dabei werden einzelne Parameter der Kristallisationsbedingungen wie der $\mathrm{pH}-$ Wert, die Konzentration des Puffers, die Konzentration der Proteinlösung, die Konzentration des Präzipitants, oder Wechsel des Kations/Anions des Präzipitants variiert oder auch sog. Additive (z.B. verschiedene Alkohole) zum Ansatz zugegeben. Trotz dieser Bemühungen konnten jedoch keine größeren Einkristalle gefunden werden. Eine anschließende röntgenkristallographische Analyse der initial erhaltenen Kristalle zeigte jedoch, dass es sich bei diesen um Salz handelte, so dass weitere Kristalloptimierungen überflüssig wurden.

Nach einer Inkubation von ca. 10 Monaten wurden erneut mutmaßliche Thil Kristalle erhalten. Durch röntgenkristallographische Untersuchungen konnte bestätigt werden, dass es sich um Proteinkristalle handelte. Diese Kristalle (Abb. 57) waren aber nicht zur Strukturlösung einsetzbar, da ihre maximale Auflösung mit 7,5 A eindeutig zu niedrig war. Eine Reproduktion der Kristalle und das sog. Feinscreening um die Ursprungsbedingung herum, blieben aber bis jetzt (evtl. zu kurze Inkubationszeit) ohne Erfolg.

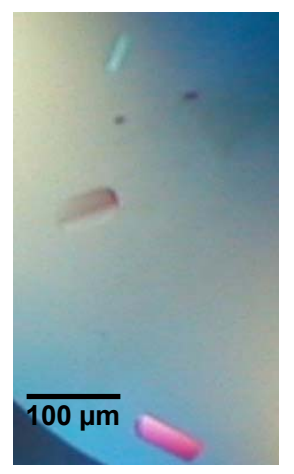

\section{Abb. 57) Kristalle von freiem Thil aus T. maritima}

Die abgebildeten Kristalle wurden nach 10 Monaten Inkubation in einer Bedingung mit

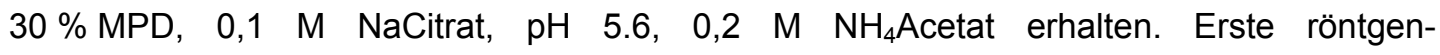
kristallographische Untersuchungen lieferten eine Streuung bis 7,5 $\AA$. Trotz Reproduktion der Kristallisationsansätze und Feinscreening um die ursprüngliche Bedingung herum, konnten diese Kristalle bisher nicht reproduziert werden. 


\subsection{Komplexierung von Thil aus T. maritima mit einer artifiziellen, verkürzten tRNA}

Nachdem die Kristallisationsversuche von Thil aus T. maritima nicht zu Kristallen geführt hatten, die für röntgenkristallographische Untersuchungen verwendbar waren, sollte Thil mit einem Substrat kristallisiert werden, um die Wahrscheinlichkeit von Proteinkristallen zu erhöhen. Dazu wurde eine verkürzte, artifizielle tRNA (im Folgenden nur noch als RNA bezeichnet) verwendet, von der gezeigt worden war, dass sie als Minimalsubstrat zur Enzymkatalyse fungiert (Lauhon, 2004). Die Komplexformation sollte durch S75 Gelfiltrationsläufe (10/30) verifiziert werden.

Als Referenzen zum Komplexlauf wurden zunächst Eichläufe mit freier RNA und freiem Protein durchgeführt.

\subsubsection{Gelfiltration von freiem Thil aus T. maritima}

Das gereinigte Thil wurde über eine S75 Gelfiltrationssäule (10/30) gegeben. Hierbei konnte anhand des Kurvenverlaufes erneut die Reinheit des Proteins überprüft werden. Als weiterer Parameter für die Komplexformation wurde der Quotient aus den Extinktionen bei den Wellenlängen $260 \mathrm{~nm}$ und $280 \mathrm{~nm}$ beobachtet. Reines ungebundenes Protein sollte einen Quotienten 260/280 nm von ca. 0.5, RNA von ca. 2.0 und der Komplex schließlich von ca. 1.5 aufweisen (Schrimpf, 2002). 


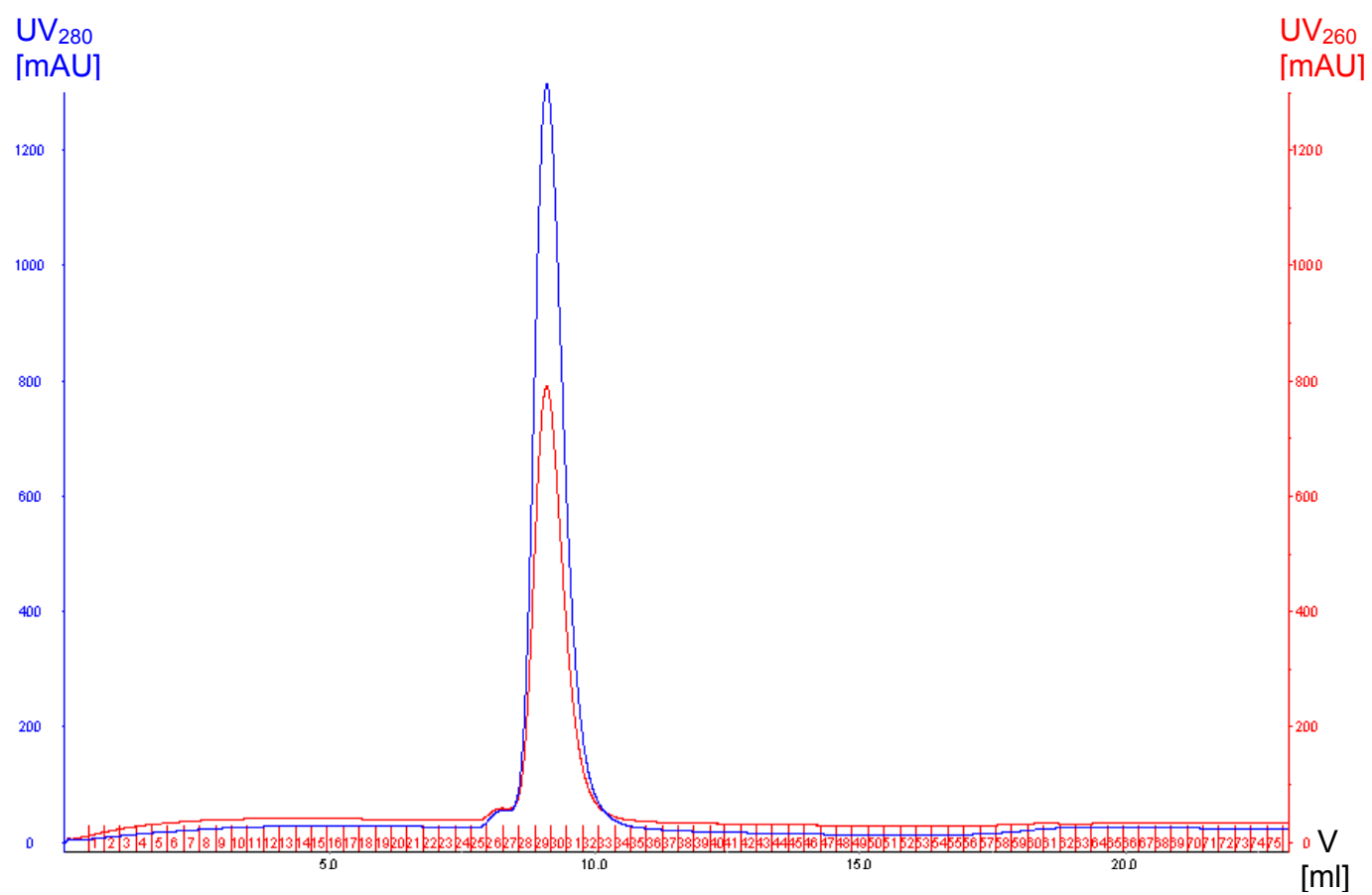

\section{Abb. 58) Gelfiltration von freiem Thil aus T. maritima}

Eine Probe des aus 3.2.1.4 erhaltenen Thil wurde mit einer Flussgeschwindigkeit von $0,5 \mathrm{ml} / \mathrm{min}$ über eine $\mathrm{S} 75$ Gelfiltrationssäule (10/30) gegeben. Das freie Thil eluierte bei $9,4 \mathrm{ml}$. Außerdem wurden die Extinktionen bei den Wellenlängen $260 \mathrm{~nm}$ und $280 \mathrm{~nm}$ aufgezeichnet. Der Wert 0,6 für den Quotienten 260/280 nm wies darauf hin, dass reines Protein eluiert wurde (vgl. Haupttext).

Es gilt folgender Farbcode: Blau: Extinktion bei $280 \mathrm{~nm}$

Rot: Extinktion bei $260 \mathrm{~nm}$

Das Elutionsprofil (Abb. 58) zeigte, dass Thil aus T. maritima nach 9,4 $\mathrm{ml}$ von der Säule eluierte. Es ist zwar zusätzlich ein kleines Plateau vor dem ThilPeak zu erkennen, dieses wurde jedoch vernachlässigt, da die gemessene Extinktion bei $280 \mathrm{~nm}$ im Vergleich zum „Maximal-Peak“ vernachlässigbar war (ca. 1\%). Als Quotient aus 260/280 nm wurde ein Wert von 0,6 ermittelt, der einem reinen Protein entspricht.

\subsubsection{Gelfiltration von freier RNA}

Die zur Komplexformation verwendete RNA, von der gezeigt worden war, dass sie als Minimalsubstrat zur Enzymkatalyse diente (Lauhon, 2004), war ein 39-mer (Abb. 59). Dieses war von der Transfer-RNA tRNA ${ }^{\text {Phe }}$, die in vivo Phenylalanin befördert, abgeleitet worden. 


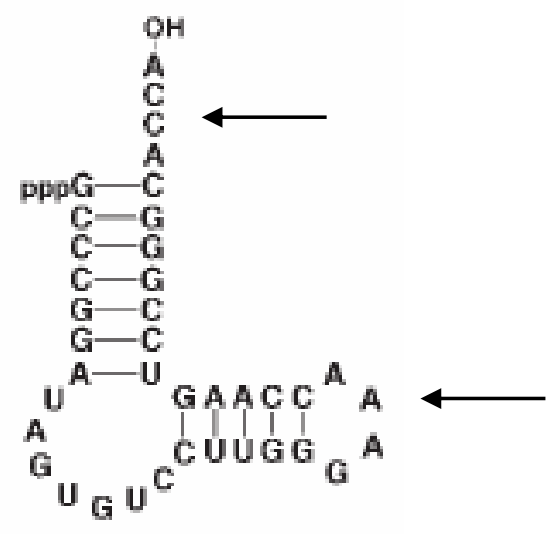

TPHE39A

\section{Abb. 59) Zur Komplexformation verwendetes Minimalsubstrat (39-mer)}

Minimalsubstrat zur Enzymkatalyse von Thil (Lauhon, 2004). Die gezeigte RNA wurde zur Komplexformation mit Thil aus T. maritima eingesetzt. Die Sequenz war von der in vivo Phenylalanin transportierenden tRNA ${ }^{\text {Phe }}$ abgeleitet worden.

Betrachtet man die Sequenz der RNA genauer (Abb. 59), so kann man erkennen, dass das RNA-Molekül v.a. aus der Aminosäurebindestelle (5`CCA-3', oberer Pfeil) und dem T-loop-Bereich einer nativen tRNA aufgebaut ist (unterer Pfeil). Diese Sequenz war so gewählt worden, dass das Uridin an Position $8\left(\mathrm{U}_{8}\right)$, an der auch in vivo die Enzymkatalyse stattfindet, wie im nativen Molekül exponiert liegt. Zusätzlich wurden die flankierenden Basen aus dem nativen Molekül übernommen, um eine eventuell zur Enzymkatalyse essentielle Interaktion zwischen diesen und dem Enzymmolekül zu gewährleisten.

Bei den ersten Gelfiltrationsläufen stellte sich heraus, dass die kommerziell erworbene RNA (IBA GmbH) in zwei Peaks eluierte (Ergebnis nicht aufgeführt). Es wurde davon ausgegangen, dass es sich um Artefakte aus der RNA-Synthese handelte, wobei die RNA durch intramolekulare Anlagerung der komplementären Bereiche einmal als Monomer und im Gegensatz dazu auch als Dimer (intermolekulare Anlagerung) vorlag.

Nach einer Hitzedenaturierung durch eine fünfminütige Inkubation bei $94{ }^{\circ} \mathrm{C}$ renaturierte die RNA während der folgenden Abkühlung auf RT über einen Zeitraum von 20 Minuten nur noch als Monomer, was durch eine anschließende Gelfiltration verifiziert werden konnte. 
Die so renaturierte RNA eluierte in einem Peak bei einem Elutionsvolumen von 12,5 $\mathrm{ml}$ und wies einen Quotienten 260/280 $\mathrm{nm}$ von 2,0 auf, der auf die Anwesenheit von reiner RNA hinwies (Abb. nicht aufgeführt, da Ergebnis in Form des Peaks mit ungebundener RNA im Komplex-Gelfiltrationslauf enthalten ist, siehe Abb. 60).

\subsubsection{Komplexformation von Thil aus T. maritima mit RNA}

Zur Komplexformation wurde das nach 3.2.1.4 erhaltene Thil auf eine Proteinkonzentration zwischen 4 und $7 \mathrm{mg} / \mathrm{ml}$ ankonzentriert. Nach Zugabe von RNA in einem 1,5-fachen molaren Überschuß wurde der Ansatz für 1 Stunde bei $4{ }^{\circ} \mathrm{C}$ inkubiert. Anschließend sollten Komplex und ungebundene RNA durch eine Gelfiltration voneinander getrennt werden. Durch diese Vorgehensweise sollte sichergestellt werden, dass das Gleichgewicht zwischen Komplex und freier RNA zugunsten des Komplexes verschoben wurde. 


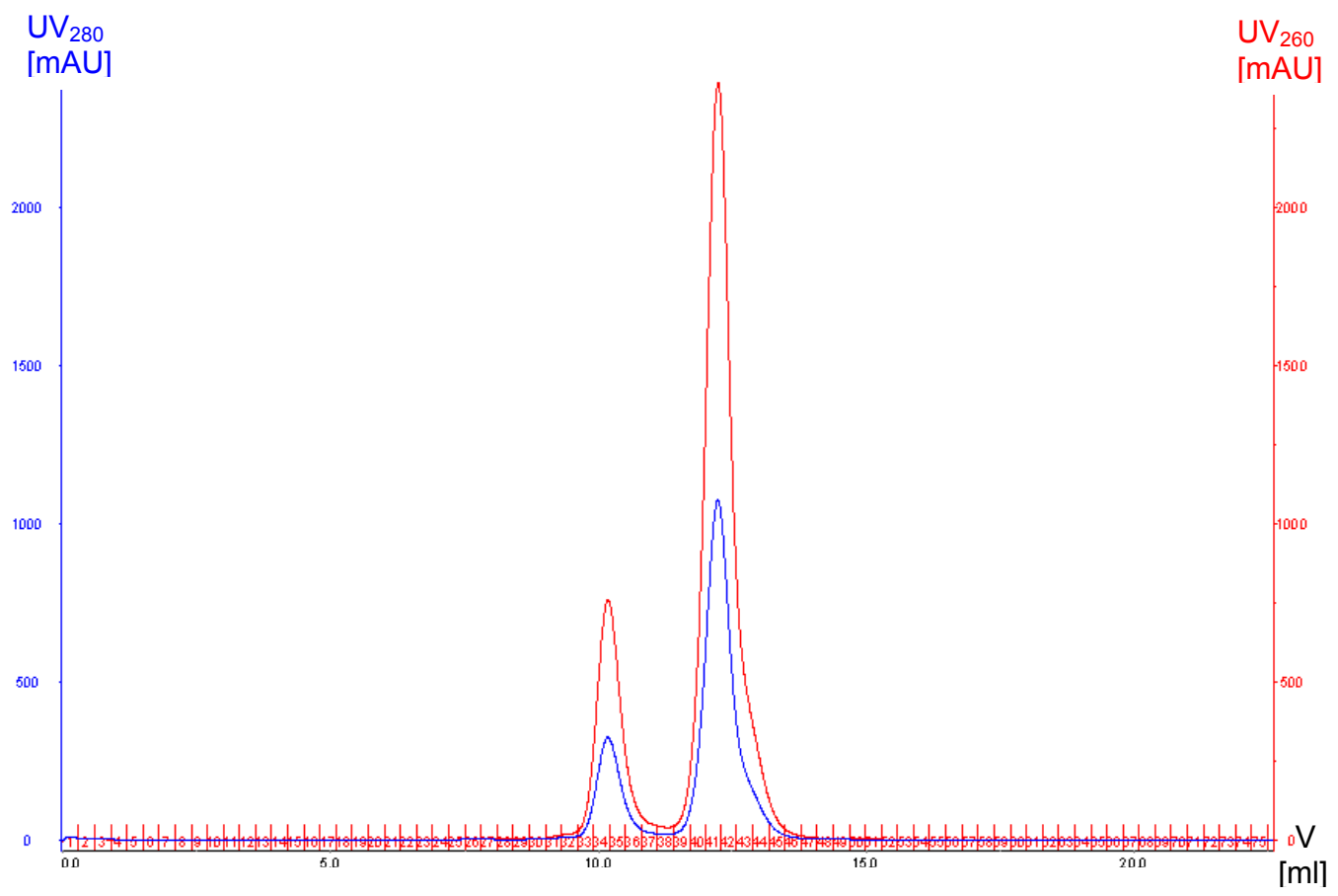

Abb. 60) Gelfiltrationslauf des Thil-RNA-Komplexes

Der nach 2.15 erhaltene Komplexansatz wurde mit einer Flussgeschwindigkeit von $0,5 \mathrm{ml} / \mathrm{min}$ über eine $\mathrm{S} 75$ Gelfiltrationssäule (10/30) gegeben. Es konnte beobachtet werden, dass der Thil-RNA-Komplex bei 10,4 ml (ungebundenes Thil 9,4 ml) eluierte. Die ungebundene RNA eluierte wie im RNA-Eichlauf bei $12,5 \mathrm{ml}$.

Für den Quotienten aus 260/280 nm konnte für den Komplex ein Wert von 1,5 und für die RNA ein Wert von 1,8 ermittelt werden. Im Anschluss wurden die Proben über eine SDSPAGE analysiert (Abb. 61).

Es gilt folgender Farbcode: Blau: Extinktion bei $280 \mathrm{~nm}$

Rot: Extinktion bei $260 \mathrm{~nm}$

Es konnte beobachtet werden, dass sich das Elutionsvolumen vom Komplex (Thil-RNA) gegenüber dem des ungebundenen Thil um $1 \mathrm{ml}$ von 9,4 $\mathrm{ml}$ auf 10,4 $\mathrm{ml}$ verschoben hatte (Abb. 60). Dies wurde als erster Hinweis einer erfolgreichen Komplexbildung gewertet. Zwar wurde durch die Vergrößerung des Gewichtes von Thil durch die Bindung der RNA mit einer im Vergleich zum reinen Protein früheren Elution des Komplexes gerechnet. Es wurde aber das gegenteilige Ergebnis erhalten. Dies konnte damit erklärt werden, dass die Trennung über eine Gelfiltrationssäule nicht nach Gewicht, sondern nach der Größe des Proteins inklusive seiner Hydrathülle (Stokes-Radius) stattfindet. Da nun der Komplex später eluiert wurde als das freie Protein, deutete dies darauf hin, dass wahrscheinlich eine Konformationsänderung durch die Bindung der RNA erfolgt war. 
Als weiterer Hinweis für eine erfolgreiche Komplexbildung war die Änderung des Quotienten aus 260/280 nm von 0,6 (reines, ungebundenes Protein) zu 1,5 (RNA-Protein-Gemisch) ermittelt worden. Die ungebundene RNA eluierte wie zuvor im Eichlauf nach 12,5 ml und wies einen 260/280 nm - Quotienten von 1,8 auf (vgl. Abb. 60).

Durch SDS-PAGE-Analyse der Proben aus Fraktion 33-36 sollte dieses Ergebnis endgültig bestätigt werden. Als Kontrollen wurden auf dem SDSGel noch freies Thil und freie RNA mitgeführt. Auf dem mit STAINS-ALL und Coomassie (2.13.1.2) angefärbten SDS-Gel (Abb. 61) kann man den Unterschied zwischen reiner RNA (Bande bei ungefähr 13 kDa, Spur 4), Protein (Bande bei 44 kDa, Spur 2) und dem Komplex (zwei Banden bei je 13 kDa und 44 kDa, Spur 3) erkennen. Zusätzlich erscheint in Spur 1 neben einer Bande von 13 kDa eine zusätzliche Bande mit einem Molekulargewicht von $\sim 25 \mathrm{kDa}$, da hier die unbehandelte RNA aufgetragen wurde. Die Fraktionen 13-18 wurden vereinigt und $\mathrm{zu}$ Kristallisationsversuchen eingesetzt. 


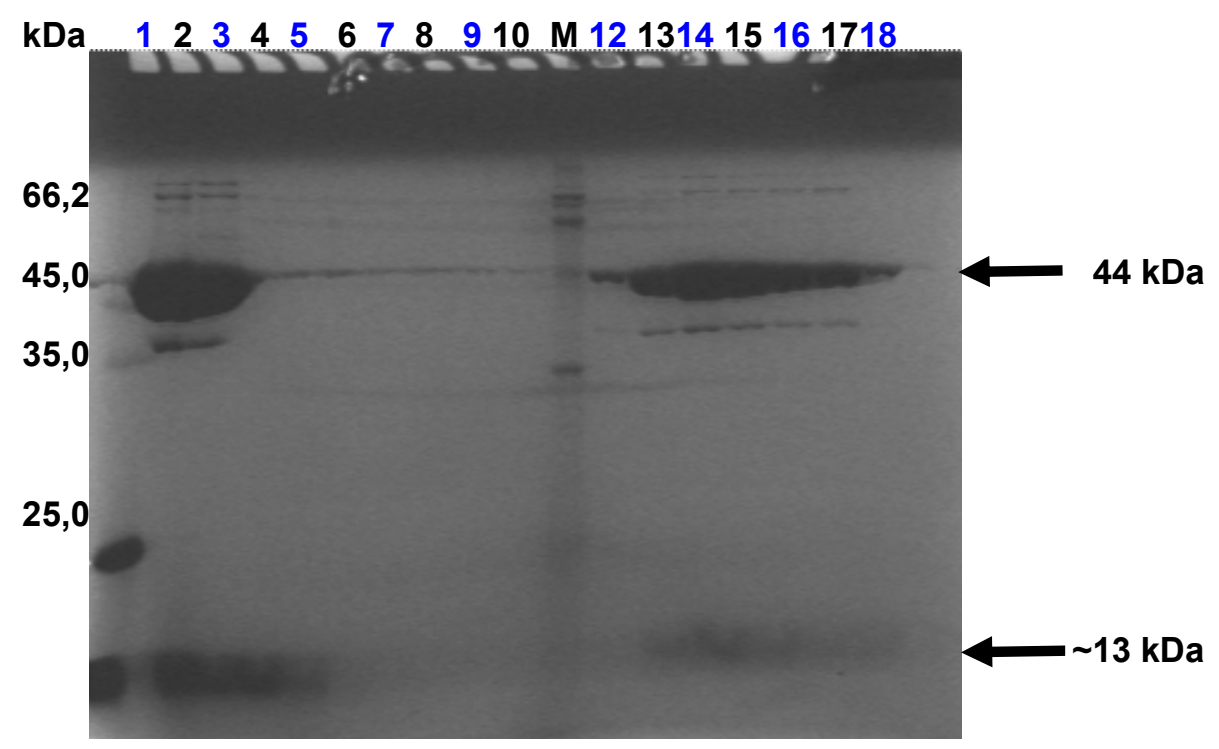

\section{Abb. 61) SDS-PAGE der Thil-RNA-Komplexformation}

Die Gelelektrophorese fand unter denaturierenden Bedingungen in einem 17,5 \%-igen SDSGel statt. Die Anfärbung erfolgte mit STAINS-ALL und nach Coomassie (2.13.1.2).

$\begin{array}{rll}\text { Es bedeuten: } & \text { M: } & \text { Größenstandard } \\ 1: & \text { RNA, unbehandelt (vgl. 3.4.2) } \\ 2: & \text { Thil } \\ 3: & \text { Komplex nach Ankonzentration } \\ 4: & \text { RNA renaturiert } \\ 5: & \text { Fraktion } 35 \text { aus Abb. } 60 \\ 6-10: & \text { restl. RNA-Peak-Fraktionen } \\ 12-18: & \text { Komplex-Peak-Fraktionen }\end{array}$

Wenn man den Komplex in Spur 3 mit den Referenzproben Thil (Spur 2) und RNA (Spur 4) vergleicht, kann man eine erfolgreiche Komplexformation erkennen. In Spur 1 kann man die unter 3.4.2 beschriebenen RNA-Mono und Dimere erkennen. Der hier erhaltene Komplex (Spur 3) wurde im Anschluss zu Kristallisationsexperimenten eingesetzt.

Bei weiteren Experimenten zur Kristalloptimierung (siehe 3.7.1) wurde analog zur oben beschriebenen Vorgehensweise auch ein Komplex aus Thil und einer auf 35 Basen verkürzten RNA-Version gewonnen. Hier wurde das ursprünglich verwendete 39-mer um die vier Basen (5 $5^{\circ}$-ACCA-3 $3^{\prime}$, von denen die drei Basen $5^{\prime}-\mathrm{CCA}-3{ }^{\prime}$ in vivo als Aminosäurebindestelle dienen verkürzt, um zu untersuchen, ob ein Zusammenhang zwischen der Länge der mit Thil komplexierten RNA und der röntgenkristallographischen Auflösung der Kristalle besteht.

Außerdem wurde ein Komplex aus Selenomethionin enthaltendem Thil und RNA analog zur beschriebenen Vorgehensweise generiert und zu 
Kristallisationsversuchen verwendet. Die so erhaltenen Kristalle wurden für MAD-Experimente eingesetzt (siehe 3.7.2).

\subsection{Kristallisationsversuche mit dem Thil-RNA- Komplex}

Nachdem Kristallisationsexperimente mit Thil erfolglos blieben, wurde ein Komplex bestehend aus Thil und einer verkürzten tRNA hergestellt und dieser zu Kristallisationsversuchen eingesetzt.

Es wurden Kristallisationsversuche in den schon erwähnten Initialscreens durchgeführt. Dabei wurde zu je $1 \mu$ l Proteinsuspension einer Konzentration von $5 \mathrm{mg} / \mathrm{ml}$ je $1 \mu \mathrm{l}$ Reservoirlösung gegeben. Nach 4 Tagen Inkubation bei $20{ }^{\circ} \mathrm{C}$ wurden in einer Bedingung (CS1 34: 0,1 M NaCitrat, $\mathrm{pH}$ 4.6, $2 \mathrm{M}$ NaFormiat) kartoffelähnliche Gebilde (Spheruliten) erhalten (vgl. Abb. 62).

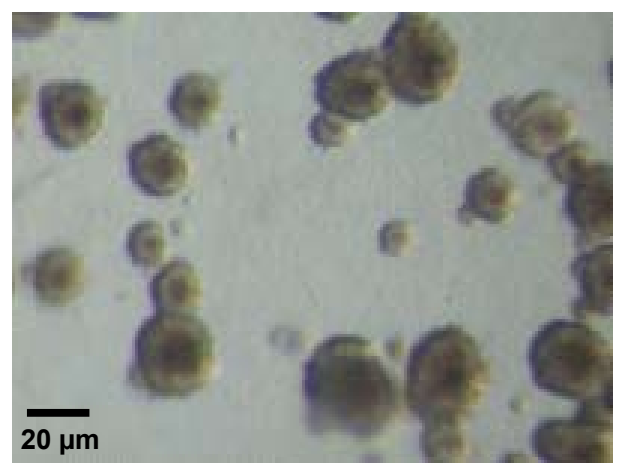

\section{Abb. 62) Kristallähnliche Aggregate des Thil-RNA-Komplex}

Der aus 3.4.3 erhaltene Komplex wurde in Initialscreens eingesetzt. Es wurde zu $1 \mu \mathrm{l}$ Proteinsuspension $(5 \mathrm{mg} / \mathrm{ml})$ je $1 \mu \mathrm{l}$ Reservoirlösung gegeben. Nach 4 Tagen Inkubation bei $20{ }^{\circ} \mathrm{C}$ wurden braune, kartoffelähnliche Aggregate einer durchschnittlichen Größe von $20 \mu \mathrm{m}$ erhalten.

Nachdem die betreffende Screenbedingung aus den einzelnen Komponenten eigenständig nachgemischt worden war, wurde der obige Versuch erneut durchgeführt. Dabei wurden alle oben angegebenen Parameter unverändert übernommen (100 mM NaCitrat, pH 4.6, 2 M NaFormiat, $1 \mu$ Protein $+1 \mu \mathrm{l}$ Reservoir). So wurden nach einer Inkubation von 4 Tagen viele kleine Einzelkristalle erhalten (Abb. 63). 


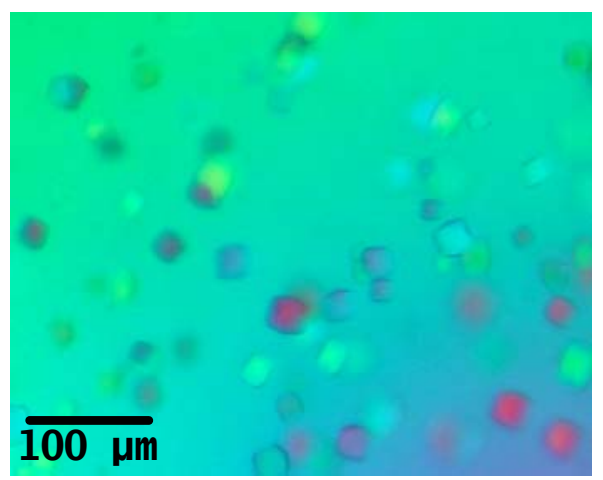

\section{Abb. 63) Erste Reproduktionsrunde von Thil-RNA-Komplex-Kristallen}

Der schon oben verwendete Ansatz zur Kristallisation wurde unverändert übernommen. Der Unterschied lag in der Kristallisationslösung selbst, die für diesen Versuch eigenständig aus den einzelnen Komponenten des Fertigscreens nachgemischt wurde.

So konnten nach 4 Tagen Inkubation bei $20{ }^{\circ} \mathrm{C}$ viele kleine Einzelkristalle einer durchschnittlichen Größe von ca $10 \mu \mathrm{m}$ erhalten werden.

$\mathrm{Da}$ diese Kristalle zu klein waren, um für röntgenkristallographische Untersuchungen verwendet zu werden, wurde bei weiteren Versuchen die Kristallisationsbedingung selbst variiert (Änderung von pH gegen Molaritäten). Allerdings konnten bei kleiner Abweichung von der Originalzusammensetzung (z.B. $2.1 \mathrm{M}$ statt $2.0 \mathrm{M}$ NaFormiat) keine regelmäßigen Kristalle mehr erhalten werden. Auch eine Änderung der Temperatur auf $4{ }^{\circ} \mathrm{C}$ führte nur zu dazu, dass das Protein nach kurzer Zeit (ca. $15 \min -1 / 2$ Tag) komplett präzipitierte. Erst die Änderung des Verhältnisses von Protein zu Reservoirlösung (1: 2 statt wie zuvor 1: 1) ergab nach 1 Woche Inkubation bei $20{ }^{\circ} \mathrm{C}$ trapezförmige Einzelkristalle von durchschnittlich $150 \mu \mathrm{m} \times 80 \mu \mathrm{m} \times 40 \mu \mathrm{m}$ (Abb. 64).

Weitere Experimente zeigten, dass die Zuverlässigkeit der Kristallisation des Thil-RNA-Komplexes durch eine Erhöhung der Proteinkonzentration auf $10 \mathrm{mg} / \mathrm{ml}$ und eine Änderung des Verhältnisses von Protein zu Reservoirlösung auf 1: 3 , noch weiter gesteigert werden konnte. 


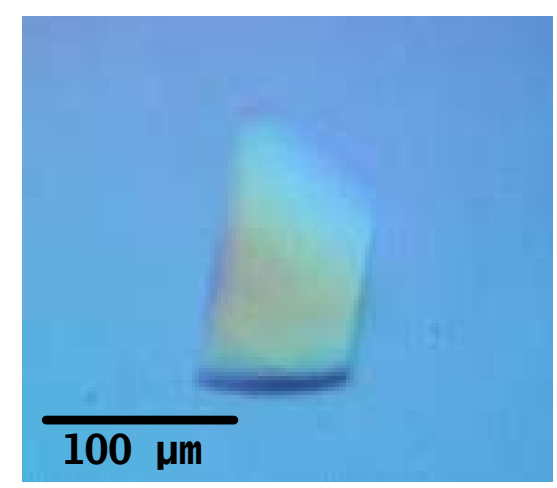

\section{Abb. 64) Kristall von Thil-RNA-Komplex}

$\mathrm{Da}$ eine Änderung der einzelnen Komponenten der Kristallisationsbedingung nicht zum Erfolg geführt hatte, wurde das Verhältnis von Proteinsuspension zu Reservoirlösung von 1:1 auf 1:2 geändert. Nach 1 Woche Inkubation bei $20{ }^{\circ} \mathrm{C}$ wurden Einkristalle von durchschnittlich $150 \mu \mathrm{m} \times 80 \mu \mathrm{m} \times 40 \mu \mathrm{m}$ erhalten.

\subsection{Nachweis der Kristallisation des Thil-RNA-Komplexes}

Um sicherzustellen, dass es sich bei den erhaltenen Kristallen um den ThilRNA-Komplex handelte, wurde das Kristallisationsexperiment, das zu den mutmaßlichen Thil-RNA-Komplex Kristallen geführt hatte, unter der Verwendung von freier RNA und freiem Thil aus $T$. maritima wiederholt. Dabei wurden keine Kristalle erhalten, was als ein erster Hinweis gewertet wurde, dass es sich bei den erhaltenen Kristallen um den Komplex aus Thil und RNA handelte. Als zusätzliche Kontrolle wurden Thil-RNA-KomplexKristalle gefischt, zwei Mal in $\mathrm{H}_{2} \mathrm{O}_{\text {bidest. }}$ gewaschen und anschließend in $\mathrm{H}_{2} \mathrm{O}_{\text {bidest. }}$ resuspendiert. Die erhaltene Suspension wurde auf einem 17,5\%igem SDS-Gel aufgetrennt und nach Färbung mit STAINS-ALL und Coomassie (siehe 2.13.1.2) analysiert. Dabei wurde festgestellt, dass die beiden erwarteten Bestandteile Thil und RNA nachgewiesen werden konnten. 


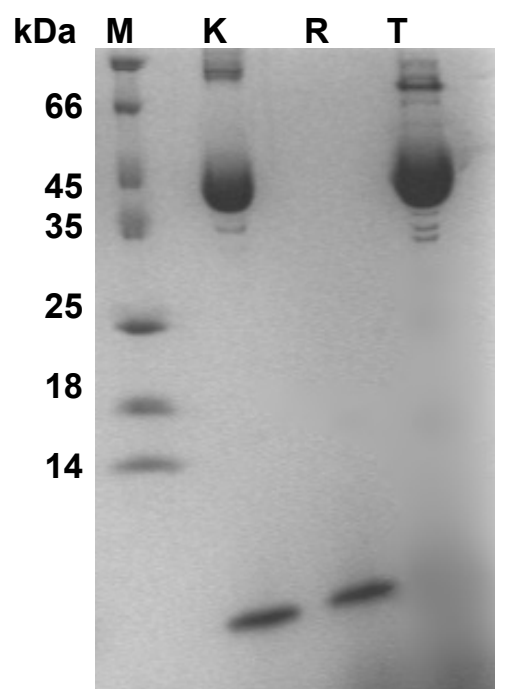

\section{Abb. 65) SDS-PAGE-Analyse von Thil-RNA-Komplex-Kristallen}

Die Gelelektrophorese fand unter denaturierenden Bedingungen in einem 17,5 \%-igen SDS-

Gel statt. Die Anfärbung erfolgte mit STAINS-ALL und nach Coomassie (2.13.1.2).

$\begin{array}{ccl}\text { Es bedeuten: } & \mathrm{M}: & \text { Größenstandard } \\ \mathrm{T}: & \text { freies Thil } \\ \mathrm{R}: & \text { freie RNA } \\ \mathrm{K}: & \text { Thil-RNA-Komplex }\end{array}$

Kristalle des mutmaßlichen Thil-RNA-Komplexes wurden gefischt, in $\mathrm{H}_{2} \mathrm{O}_{\text {bidest. }}$ gewaschen und im Anschluss in $\mathrm{H}_{2} \mathrm{O}_{\text {bidest. }}$ resuspendiert. Die erhaltene Lösung wurde mittels SDS-PAGE aufgetrennt. Die Bestandteile des Thil-RNA-Komplexes konnten eindeutig nachgewiesen werden. 
3.7

Röntgenkristallographische Untersuchungen am Thil-RNAKomplex

Nachdem Einkristalle des Thil-RNA-Komplexes erhalten worden waren, wurden sie ersten röntgenkristallographischen Untersuchungen unterzogen. Dabei konnte anhand des Streuverhaltens eindeutig festgestellt werden, dass es sich um Proteinkristalle handelte. Allerdings war die maximale Auflösung mit 7,5 Å für eine erfolgreiche Strukturaufklärung zu gering (Abb. $66)$.

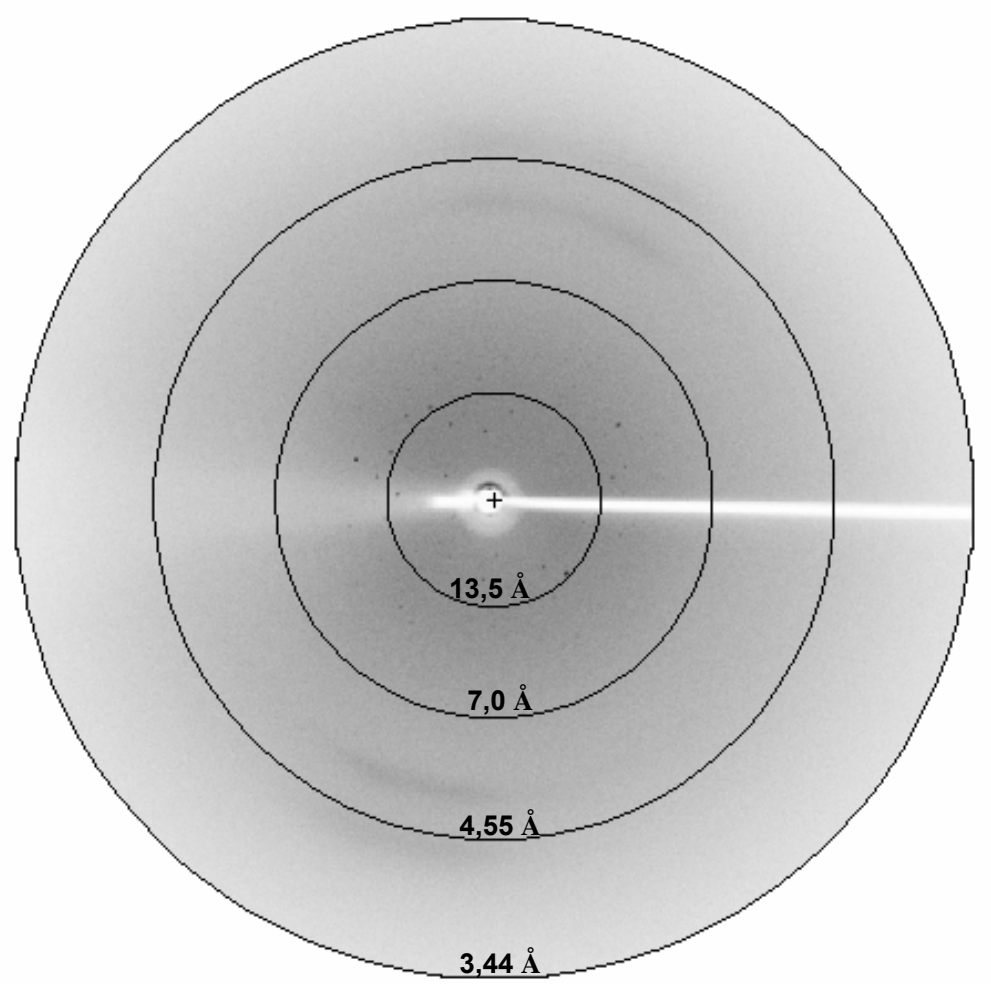

Abb. 66) Aufnahme eines der ersten erhaltenen Kristalle des Thil-RNAKomplex

Die Aufnahme entstand durch eine 20 minütige Belichtung des Kristalls während einer Drehung um $0,5^{\circ}$ an einer Cu-Drehanode. Die Anordnung der Reflexe, inre Intensität und ihre Anzahl zeigten auf, dass es sich hier um einen Proteinkristall handelte. Hätte es sich um Salz gehandelt, wären wenige (2-3) Reflexe von stärkerer Intensität aufgetreten. Die Auflösung (vgl. Auflösungsringe) lag bei ca. 7,5 $\AA$.

In der Erwartung, größere Kristalle mit einer besseren Streuung zu erhalten, wurden verschiedene Additive zur Kristallisationsbedingung gegeben. Da durch Additivverwendung jedoch keine Verbesserung erzielt werden konnte, wurden im Anschluss der Cryopuffer und das Tieffrieren der Kristalle 
modifiziert. So wurde festgestellt, dass eine Kristallisation unter den Ursprungsbedingungen ( $100 \mathrm{mM} \mathrm{NaCitrat,} \mathrm{pH} 4.6$, und $2 \mathrm{M} \mathrm{NaFormiat)} \mathrm{zu}$ den besten Ergebnissen führte (siehe Abb. 67). Nebenbei wurde festgestellt, dass die Änderung des Präzipitantskations von Natrium zu Kalium (Kaliumformiat statt Natriumformiat) einen positiven Effekt auf die Größe der Kristalle hatte, was jedoch nicht zu einer Änderung der maximalen Auflösung führte. Auch das Variieren der Cryobedingung ergab im Vergleich zum ursprünglich verwendeten Cryopuffer, bei dem $30 \%$ Glycerin zur Kristallisationsbedingung zugefügt wurden, keine Verbesserung der Auflösung. Einzig das sog. Annealing einzelner Kristalle führte zu einer besseren Auflösung. Bei dieser Methode werden montierte Kristalle durch kurze Unterbrechung des Stickstoffstroms aufgetaut und im Anschluss erneut gefroren (Juers und Matthews, 2004). Einen Überblick über die einzelnen Variationen geben Tab. 5 (Kristallisationsbedingungen) und Tab. 6 (Cryobedingungen). 


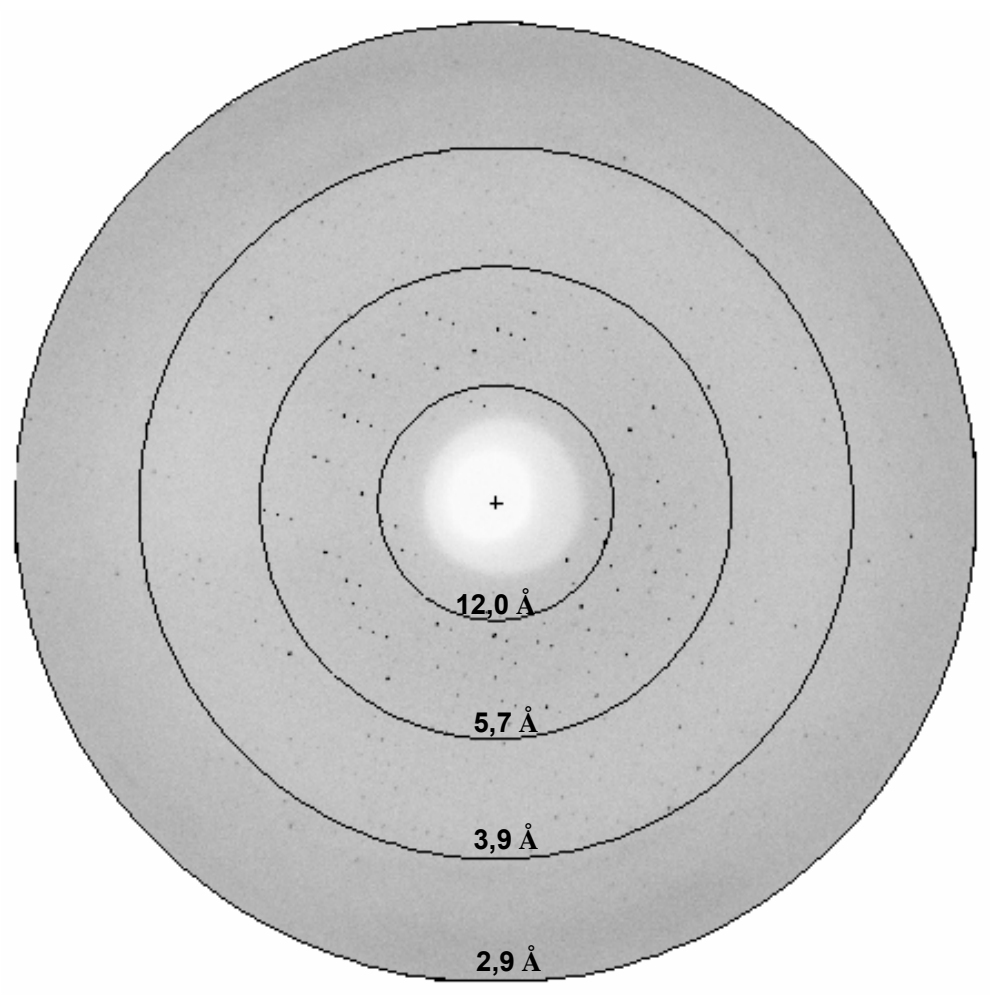

Abb. 67) Aufnahme eines Thil-RNA-Komplex-Kristalls nach Optimierung von Cryopuffer und Kristallisationsbedingung

Die Aufnahme entstand am DESY in Hamburg. Der Kristall wurde während der Messung bei einer Wellenlänge von $0,98 \AA$ um $1,5^{\circ}$ gedreht. Die Belichtungszeit betrug $25 \mathrm{~s}$. Man kann erkennen, dass die Auflösung im Vergleich zu den initialen Kristallen auf ca. 3,5 $\AA$ verbessert wurde. 
Tab. 5) Zusammenstellung der getesteten Cryobedingungen des Thil-RNAKomplex

\begin{tabular}{|l|l|}
\hline Maßnahme & resultierende Auflösung bis \\
\hline Frieren in Panjelly & $6 \AA$ \\
\hline Frieren in Parafin & $6 \AA$ \\
\hline Zugabe von $30 \%$ und $40 \%$ Glycerin & $3,7 \AA / 4,5 \AA$ \\
\hline $\begin{array}{l}\text { stufenweise Zugabe von Glycerin bis } 30 \% \\
(40 \%) \text { Endkonzentration }\end{array}$ & $4,5 \AA(4,5 \AA)$ \\
\hline $\begin{array}{l}\text { Inkubation in } 30 \% \text { Glycerin ÜN bei } 4{ }^{\circ} \mathrm{C} \\
\text { und } 20{ }^{\circ} \mathrm{C}\end{array}$ & $4,5 \AA / 4,5 \AA$ \\
\hline Saccharosezugabe $30 \%$ und $40 \%$ & Eiskristallbildung/ $6,5 \AA$ \\
\hline Stufenweise Zugabe von Saccharose & $6 \AA$ \\
\hline erhöhte Formiatkonzentrationen bis $4 \mathrm{M}$ & Eiskristallbildung \\
\hline Paratone N alt/neu & jeweils $6 \AA$ \\
\hline Zugabe von 1,4 Butandiol & $6 \AA$ \\
\hline direktes Frieren in flüssigem Stickstoff & $4,5 \AA$ \\
\hline Frieren ohne umgebende Flüssigkeit & $7 \AA$ \\
\hline Frieren mit Polyfluorether & $6 \AA$ \\
\hline Annealing in Glycerinpuffer & $3,5 \AA$ \\
\hline
\end{tabular}


Tab. 6) Variationen der Kristallisationsbedingung

\begin{tabular}{|c|c|}
\hline Maßnahme (Zugabe von $30 \%$ ) & resultierende Auflösung bis \\
\hline Methanol & $6 \AA$ \\
\hline Ethanol & $6 \AA$ \\
\hline 1-Propanol & Mikrokristalle \\
\hline 2-Propanol & $6 \AA$ \\
\hline 1,2 Propandiol & $6 \AA$ \\
\hline 1,3 Propandiol & $6 \AA$ \\
\hline Butandiol & $6 \AA$ \\
\hline 1-Butanol & $6 \AA$ \\
\hline 2-Butanol & $6 \AA$ \\
\hline tert. Butanol & keine Kristallisation \\
\hline 1,6 Hexandiol & $6 \AA$ \\
\hline 2,5 Hexandiol & $6 \AA$ \\
\hline 1,7 Heptandiol & $6 \AA$ \\
\hline Glycerin & $4,5 \AA$ \\
\hline MPD & $6 \AA$ \\
\hline TritonX100 & keine Kristallisation \\
\hline Nonidetp40 & keine Kristallisation \\
\hline ATP $2 \mathrm{mM} / 5 \mathrm{mM}$ & je $6 \AA$ \\
\hline ATP $2 \mathrm{mM} / 5 \mathrm{mM}+\mathrm{Mg}^{2+}$ & je $6 \AA$ \\
\hline ATP $\mathrm{nh} 2 \mathrm{mM} / 5 \mathrm{mM}$ & je $6 \AA$ \\
\hline ATP nh $2 \mathrm{mM} / 5 \mathrm{mM}+\mathrm{Mg}^{2+}$ & je $6 \AA$ \\
\hline $\mathrm{Mg}^{2+} 2 \mathrm{mM} / 5 \mathrm{mM}$ & je $6 \AA$ \\
\hline $\begin{array}{l}\text { Kationenwechsel } \mathrm{zu} \mathrm{NH}_{4}^{+} / \mathrm{K}^{+} / \mathrm{Mg}^{2+} \\
\text {-Formiat }\end{array}$ & $7 \AA / 6 \AA /$ keine Kristallisation \\
\hline $\begin{array}{l}\text { Anionenwechsel Malonat/ Acetat/ } \\
\text { Oxalat }\end{array}$ & $6 \AA / 5 \AA /$ Mikrokristalle \\
\hline $\begin{array}{l}\text { gleichzeitiger Wechsel von Anion } \\
\text { und Kation }\left(\mathrm{NH}_{4} \mathrm{Ac}, \mathrm{KAc}, \mathrm{MgAc} \text {, }\right. \\
\mathrm{NaAc})\end{array}$ & $\begin{array}{l}\text { keine Kristalle/ } 6 \AA / \text { keine Kristalle/ } \\
5 \AA\end{array}$ \\
\hline $\mathrm{pH}$ Wert Änderung \pm 0,2 Einheiten & Mikrokristalle \\
\hline Inkubation bei $4^{\circ} / 10^{\circ} / 20^{\circ} / 30^{\circ} \mathrm{C}$ & nur $20^{\circ} \mathrm{C}$ lieferte geeignete Kristalle \\
\hline
\end{tabular}




\begin{tabular}{|l|l|}
\hline Maßnahme (Zugabe von $30 \%$ ) & resultierende Auflösung bis \\
\hline $\begin{array}{l}\text { Temperaturwechsel } 20{ }^{\circ} \mathrm{C} \text { zu } 30{ }^{\circ} \mathrm{C} \\
{ }^{\circ} \mathrm{C}\end{array}$ & $7 \AA$ \\
\hline $\begin{array}{l}\text { Erhitzen der Proteinlösung vor dem } \\
\text { Pipettieren auf } 30 \% 50 \% 70{ }^{\circ} \mathrm{C}\end{array}$ & $6 \AA$ \\
\hline Macroseeds mit 10 und $5 \mathrm{mg} / \mathrm{ml}$ & keine Kristallisation \\
\hline Microseeds mit 10 und $5 \mathrm{mg} / \mathrm{ml}$ & keine Kristallisation \\
\hline Wechsel der RNA zu 35-mer & keine Kristallisation \\
\hline $\begin{array}{l}\text { Variation der Tropfengröße 1+1/ } \\
2+2 / 3+3 / 4+4 / 1+2 / 1+3 / 1+4\end{array}$ & $\begin{array}{l}\text { nur Verhältnis } 1+2 \text { und } 1+3 \text { lieferte } \\
\text { messbare Kristalle }\end{array}$ \\
\hline
\end{tabular}

\subsubsection{Datensammlung}

Nachdem die Kristallisation des Thil-RNA-Komplexes optimiert werden konnte, wurden Datensätze gesammelt und mit Denzo und Scalepack prozessiert. Es wurde festgestellt, dass Datensätze, die an einem Synchrotron (BESSY, DESY, ESRF) gesammelt wurden, immer von besserer Datenqualität waren als die Messungen an einer Cu-Drehanode (homesource). Vor der jeweiligen Datensammlung wurde zur optimalen Nutzung der Messzeit eine Strategie mit dem Programm Mosflm berechnet. Zur Aufnahme eines kompletten Datensatzes in der hier erhaltenen Raumgruppe $\mathrm{P} 22_{1} 2_{1} 2_{1}$, musste der Kristall während der Messung um $90^{\circ}$ gedreht werden. Um die Vollständigkeit und Redundanz der Daten zu erhöhen, startete die Datensammlung $5^{\circ}-10^{\circ}$ vor bzw. endete $5^{\circ}-10^{\circ}$ nach dem von Mosflm errechneten Start- und Endpunkt. Auf diese Weise gelang es, einen nativen Datensatz (nativhh) am Synchrotron Hamburg (DESY) aufzunehmen. 
Tab. 7) Datenstatistik nativhh

\begin{tabular}{|c|c|c|c|c|c|c|c|c|c|c|c|c|}
\hline & \multicolumn{8}{|c|}{$\mathrm{P} 2{ }_{1} 2_{1} 2_{1}$} \\
\hline \multicolumn{5}{|c|}{ Einheitszelle $[\AA]$ : } & \multicolumn{8}{|c|}{$102,898 \times 112,816 \times 132,771$} \\
\hline \multicolumn{5}{|c|}{ Auflösung $[\AA]$ : } & \multicolumn{8}{|c|}{$50-3,7$} \\
\hline \multicolumn{5}{|c|}{ Reflexe: } & \multicolumn{8}{|c|}{59863} \\
\hline \multicolumn{5}{|c|}{ Unabhängige Reflexe: } & \multicolumn{8}{|c|}{16763} \\
\hline \multicolumn{5}{|c|}{ Redundanz: } & \multicolumn{8}{|c|}{3,6} \\
\hline \multirow{2}{*}{\multicolumn{4}{|c|}{$\begin{array}{l}\text { Shell } \\
\text { Lower Upper }\end{array}$}} & \multicolumn{9}{|c|}{ Summary of observation redundancies: } \\
\hline & & & & & re & V & $N$ & N & o. of $\mathrm{c}$ & servat & IS & \\
\hline lin & $\begin{array}{l}\text { limit } \\
793\end{array}$ & $\begin{array}{c}0 \\
36\end{array}$ & $\begin{array}{c}1 \\
60\end{array}$ & $\begin{array}{c}2 \\
186\end{array}$ & $\begin{array}{c}3 \\
7.6\end{array}$ & $\begin{array}{c}4 \\
55.1\end{array}$ & $\begin{array}{l}5-6 \\
9.0\end{array}$ & $\begin{array}{l}7-8 \\
0\end{array}$ & $\begin{array}{l}9-12 \\
0.0\end{array}$ & $\begin{array}{c}13-19 \\
0.0\end{array}$ & $\begin{array}{l}>19 \\
0.0\end{array}$ & $\begin{array}{l}\text { total } \\
96.4\end{array}$ \\
\hline 7.93 & 6.31 & 1.7 & 5.8 & 10.8 & 9.2 & 60.9 & 11.7 & 0.0 & 0.0 & 0.0 & 0.0 & 98.3 \\
\hline 6.31 & 5.52 & 1.0 & 5.2 & 10.2 & 9.5 & 61.4 & 12.7 & 0.0 & 0.0 & 0.0 & 0.0 & 99.0 \\
\hline & 5.02 & 0.7 & 4.4 & 11.8 & 9.1 & 62.1 & 12.0 & 0.0 & 0.0 & 0.0 & 0.0 & 99.3 \\
\hline 5. & 4.66 & 0.5 & 3.9 & 12.1 & 9.0 & 62.1 & 12.3 & 0.0 & 0.0 & 0.0 & 0.0 & 99.5 \\
\hline 4. & 4.39 & 0.4 & 3.7 & 11.5 & 11.3 & 62.1 & 11.0 & 0.0 & 0.0 & 0.0 & 0.0 & 99.6 \\
\hline 4. & 4.17 & 0.4 & 4.0 & 11.8 & 12.2 & 62.3 & 9.2 & 0.0 & 0.0 & 0.0 & 0.0 & 99.6 \\
\hline & 3.99 & 0.4 & 4.3 & 12.7 & 14.2 & 59.3 & 9.2 & 0.0 & 0.0 & 0.0 & 0.0 & 99.6 \\
\hline & 3.83 & 2.0 & 7.0 & 12.6 & 17.2 & 52.9 & 8.1 & 0.1 & 0.0 & 0.0 & 0.0 & 98.0 \\
\hline 3.83 & 3.70 & 9.8 & 10.9 & 16.4 & 23.2 & 32.5 & 7.1 & 0.0 & 0.0 & 0.0 & 0.0 & 90.2 \\
\hline All hkl & & 2.0 & 5.5 & 12.9 & 12.2 & 57.1 & 10.3 & 0.0 & 0.0 & 0.0 & 0.0 & 98.0 \\
\hline
\end{tabular}

\begin{tabular}{|c|c|c|c|c|c|c|c|c|c|c|}
\hline \multicolumn{3}{|c|}{ Shell } & \multicolumn{8}{|c|}{ I/Sigma in resolution shells: } \\
\hline 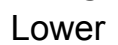 & Upper & & & of & & & & igma I & ess $t$ & \\
\hline$\therefore$ & limit & 0 & 1 & 2 & 3 & 5 & 10 & 20 & $>20$ & to \\
\hline 0.06 & 7.9 & 2.5 & & -0 & & & & 5.8 & & \\
\hline & & & & & & & & & & \\
\hline & & 1 & 5. & 9 & & & & & & \\
\hline & 5. & 8 & & 12 & & & & & & \\
\hline & & & & & & & & & & \\
\hline & 4. & 3 & & & & & & & & \\
\hline & 4. & 5 & 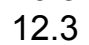 & 22 & & & & 8 & & \\
\hline & 3. & & & 30 & & & & & & \\
\hline & $3 . \varepsilon$ & & & & & & & & & \\
\hline & & 10 & & & & & & & & \\
\hline 14 & & 4.6 & 2.0 & 19.7 & 263 & 36 & 54 & 78.6 & 19.3 & \\
\hline
\end{tabular}

\begin{tabular}{|c|c|c|c|c|c|c|c|}
\hline $\begin{array}{l}\text { Shell } \\
\text { Lower }\end{array}$ & $\begin{array}{l}\text { limit } \\
\text { Upper }\end{array}$ & I & $\begin{array}{c}\text { Average } \\
\text { error }\end{array}$ & $\begin{array}{c}\text { Average } \\
\text { stat. }\end{array}$ & $\begin{array}{l}\text { Norm. } \\
\mathrm{Chi}^{\star \star} 2\end{array}$ & $\begin{array}{r}\text { Linear } \\
\text { R-fac }\end{array}$ & $\begin{array}{c}\text { Square } \\
\text { R-fac }\end{array}$ \\
\hline 30.00 & 7.93 & 4470.3 & 307.9 & 71.5 & 1.009 & 0.024 & 0.056 \\
\hline 7.93 & 6.3 & & & & & & \\
\hline 6.3 & 5. & 100 & & & & & \\
\hline 5.52 & 5.0 & 941.8 & 60 & & & & \\
\hline 5.02 & 4.6 & & & & & & 0.0 \\
\hline 4.6 & & & & & & & \\
\hline 4.3 & 4.17 & 710 & 82 & & 2 & 47 & 0.1 \\
\hline 4.1 & 3.9 & 504 & 8 & & & & \\
\hline & 3.8 & 3 & 10 & & & & \\
\hline & & & & & & 0. & 294 \\
\hline & & & & & & 10 & \\
\hline
\end{tabular}


Dieser Datensatz lieferte eine Auflösung von 3,7 $\AA$ bei einer Redundanz von 3,5 und einer durchschnittlichen Vollständigkeit der Daten von 98 \% (Tab. 7). Erste Prozessierungen der Daten zeigten, dass die Kristalle der Raumgruppe $\mathrm{P} 2{ }_{1} 2{ }_{1} 2_{1}$ angehörten, d.h. die Anordnung der Enzymmoleküle wies eine hohe Symmetrie auf. Bei dieser Raumgruppe sind drei zweifach Drehsymmetrien in der Einheitszelle vorhanden.

Nun erfolgte die Bestimmung des Matthews-Koeffizienten, der mit der Anzahl der Moleküle und dem Lösungsmittelgehalt der Einheitszelle korreliert. Dabei wurden Werte für den Matthews-Koeffizienten zwischen 6,8 und 1,7 erhalten, die mit der Anwesenheit von einem bis vier Molekülen pro asymmetrischer Einheit $(A U)$ und einem Lösungsmittelgehalt zwischen 81,7\% und 26,7 \% korrelierten (vgl. Tab. 8). Da in Proteinkristallen erfahrungsgemäß ein Lösungsmittelgehalt zwischen $40 \%$ und $80 \%$ vorliegt, war die Wahrscheinlichkeit für zwei Moleküle (Matthews-Koeffizient 3,4, Lösungsmittelgehalt $63,3 \%$ ) oder für drei Moleküle (Matthews-Koeffizient von 2,3, Lösungsmittelgehalt 45,0 \%) pro AU am höchsten.

Tab. 8) Matthews-Koeffizienten für den Thil-RNA-Komplex

\begin{tabular}{|c|c|c|}
\hline Matthews Koeffizient & Moleküle/AU & Lösungsmittelgehalt [\%] \\
\hline 6,8 & 1 & 81,7 \\
\hline 3,4 & 2 & 63,3 \\
\hline 2,3 & 3 & 45,0 \\
\hline 1,7 & 4 & 26,7 \\
\hline
\end{tabular}

Da durch den Matthews-Koeffizienten die Frage, ob sich zwei oder drei Moleküle in der AU befinden, nicht vollständig aufgeklärt werden konnte, wurde, um einen weiteren Hinweis zur Klärung dieser Frage zu erhalten, die Patterson-Selbstrotations-Funktion verwendet (Abb. 68). 


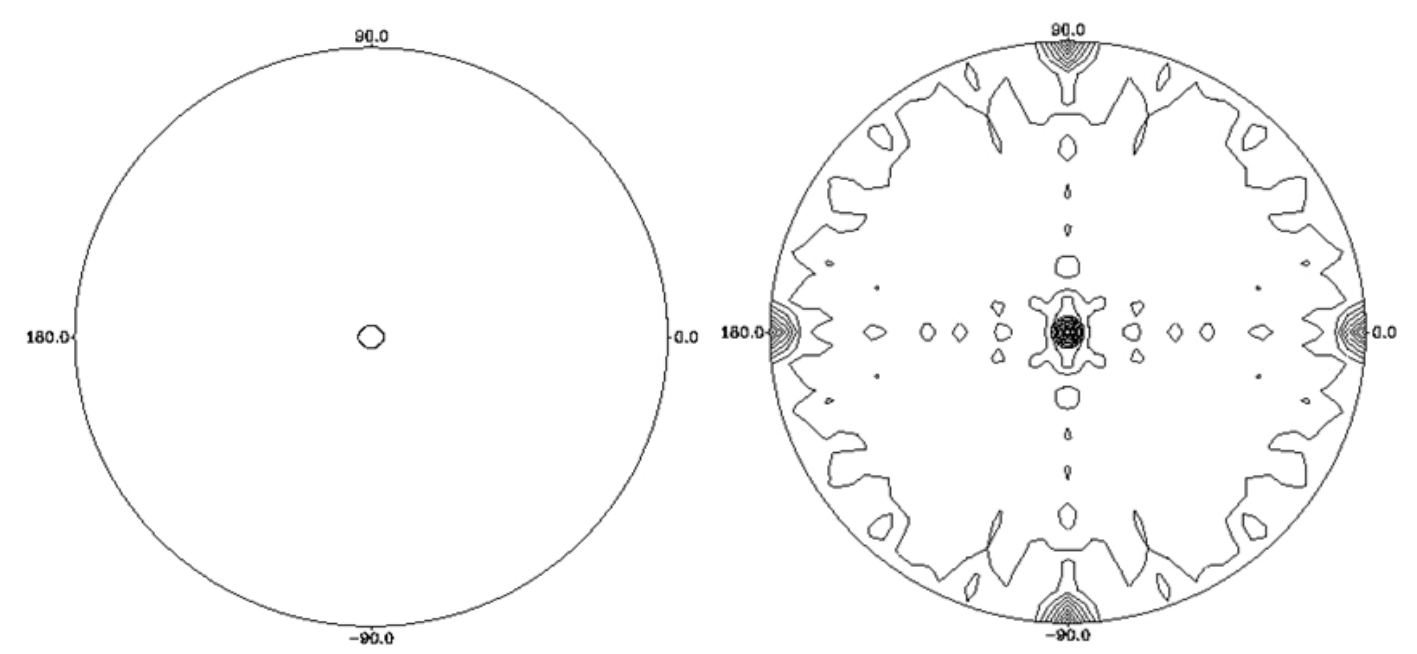

Abb. 68) Patterson-Selbstrotations-Funktion $k=120^{\circ}$ (links) und

$$
\mathrm{K}=180^{\circ} \text { (rechts) }
$$

Die Patterson-Selbstrotation wurde mit dem Programm Polarrfn (CCP4) durchgeführt. Durch das Fehlen von Symmetrieelementen bei $120^{\circ}$ und deren Vorhandensein bei $180^{\circ}$ konnte geschlossen werden, dass eine hohe Wahrscheinlichkeit für zwei Komplexmoleküle pro Einheitszelle vorlag. Durch dieses Ergebnis konnte jedoch nicht vollständig ausgeschlossen werden, dass drei Komplexmoleküle pro $A U$ vorlagen, da je nach Anordnung der Komplexmoleküle in der $\mathrm{AU}$ ein ähnliches Ergebnis zu erwarten gewesen wäre (vgl. Haupttext).

Bei der Patterson-Selbstrotations-Funktion wird die zuvor berechnete native Patterson-Map durch Rotation mit sich selbst verglichen. Die Patterson-Map beschreibt hier alle Vektoren, die in der Einheitszelle zwischen den Atomen vorliegen. Dabei werden die Punkte der Patterson-Map jeweils durch die Differenz der Vektoren zwischen zwei Atomen gebildet. Durch diese Patterson-Funktion werden alle möglichen Vektoren auf einen neu festgelegten Ursprung bezogen. Peaks, die nach der Selbstrotation gefunden werden, entsprechen den Rotationen, die nötig sind, diejenigen Moleküle aufeinander abzubilden, die einer nicht-kristallographischen Symmetrie gehorchen (asymmetrische Einheit!). Für die Analyse der in Abb. 68 erhaltenen Selbstrotationen bedeutet dies, dass höchstwahrscheinlich zwei Moleküle des Komplexes in der AU vorliegen, da bei Rotation um $180^{\circ}$ die vier zu erwartenden Symmetrieäquivalenzpeaks am Rande der Selbstrotationsabbildung erhalten wurden, während bei einer Rotation um $120^{\circ}$ keine Symmetrieäquivalente beobachtet werden konnten. Im Ursprung (Mitte) liegt - wie erwartet - bei beiden Ansätzen der höchste Peak. Dies 
resultiert daraus, dass hier alle Vektoren aufeinander abgebildet wurden, die ausgehend vom Ursprung zu jedem Atom in der AU möglich sind.

Obwohl die Selbstrotation bei $120^{\circ}$ keine Symmetrieäquivalente aufwies, bestand noch immer die Möglichkeit, dass drei Moleküle pro AU vorlagen. Wären nämlich diese drei Moleküle zueinander symmetrisch (kristallographische Symmetrie), würde man hier das gleiche Ergebnis bei $\mathrm{k}=120^{\circ}$ erhalten, da die Vektoren zwischen den Atomen jeweils auf sich selbst abgebildet würden.

\subsubsection{Phasierung mit Hilfe von Selenomethionin}

Es ist nicht möglich, die Phase jedes einzelnen gebeugten Röntgenstrahls zu messen. Zur Erzeugung von Elektronendichtekarten muss jedoch diese bei der Messung verlorengegangene Phaseninformation (siehe 2.17) zurückgewonnen werden.

Zur Strukturaufklärung des Thil-RNA-Komplexes sollte die Phaseninformation durch ein MAD-(multi wavelength anomalous diffraction) Experiment ermittelt werden. Dazu wurden Selenomethionin enthaltende Proteinkomplexe erzeugt, kristallisiert und gemessen (2.17.1). MAD-Experimente erfordern Datenaufnahmen bei unterschiedlichen Wellenlängen, so dass zur Aufnahme dieser Datensätze die Kristalle an Synchrotrons gemessen wurden. Hier besteht die Möglichkeit, die Wellenlänge zu variieren. Um die unterschiedlichen Wellenlängen, bei denen die Kristalle gemessen werden sollten, zu bestimmen, wurde zuvor die Fluoreszenz der SelenomethioninKristalle bestimmt (siehe Abb. 69). Aus dieser Kurve konnten dann die Wellenlängen für den Peak-Datensatz (maximales Signal für den imaginären Streufaktor $\Delta \mathrm{F}_{\mathrm{i}}$ ) und den Inflection-Datensatz (Minimum des realen Streufaktors $\Delta \mathrm{F}_{\mathrm{r}}$ ) abgelesen werden. Als Referenzwert (Remote) sollte ein Datensatz mit höherer Wellenlänge in relativ großer Entfernung zu den beiden erstgenannten Datensätzen bestimmt werden. 


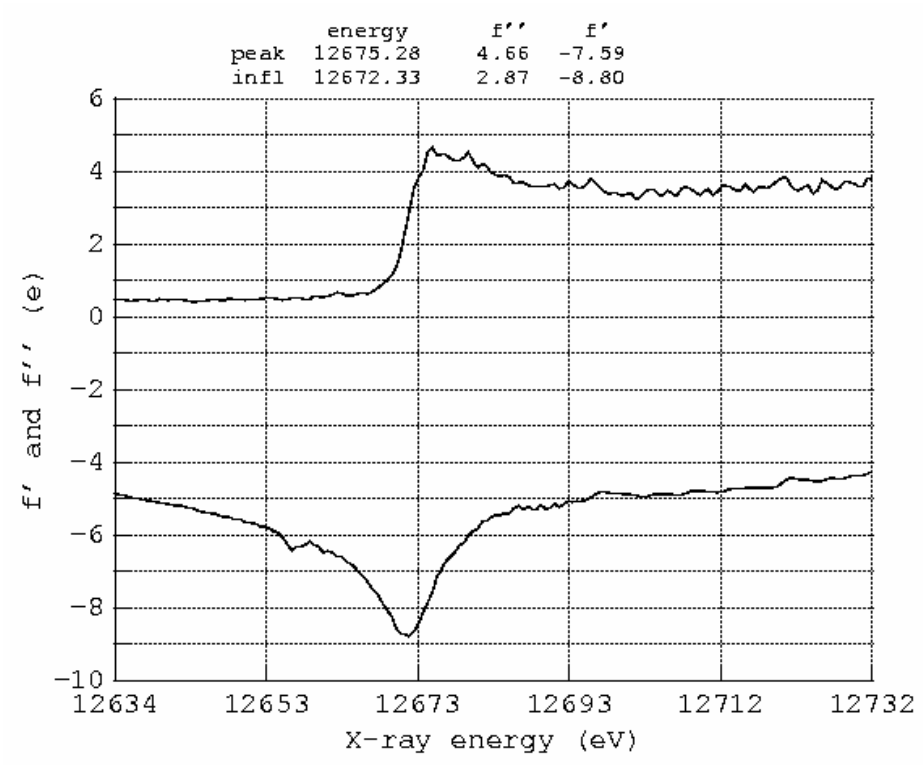

\section{Abb. 69) Fluoreszenzspektrum eines Se-Thil-RNA-Komplex-Kristalls}

Das Spektrum wurde am ESRF, Grenoble aufgenommen. Mit Hilfe dieses Spektrums konnte die Wellenlänge für die Datenaufnahme der zur MAD benötigten Datensätze Peak, Inflection und Remote (vgl. Text) als Röntgenstrahlenenergie abgelesen und umgerechnet werden.

Das Fluoreszenspektrum wurde gegen die Energie der Röntgenstrahlen aufgezeichnet. Hierbei konnten für den Peak-Datensatz $12675.28 \mathrm{eV}$ und für den Inflection-Datensatz $12672.33 \mathrm{eV}$ ermittelt werden (Abb. 69). Diese ließen sich in die Wellenlängen $\lambda_{\text {Peak }}=0.978023 \mathrm{~nm}, \lambda_{\text {Inflection }}=0.978482 \mathrm{~nm}$ umrechnen. Die Aufnahme des Remote-Datensatzes sollte bei Röntgenstrahlung ab einer Energie von 12700 eV erfolgen. 
Tab. 9) Datenstatistik Selenomethionin Thil-RNA-Komplex

\begin{tabular}{|c|c|c|c|c|c|c|c|c|c|c|c|c|}
\hline \multicolumn{5}{|c|}{ Raumgruppe: } & \multicolumn{8}{|c|}{$\mathrm{P} 2{ }_{1} 2_{1} 2_{1}$} \\
\hline \multicolumn{5}{|c|}{ Einheitszelle $[\AA]$ : } & \multicolumn{8}{|c|}{$103,4 \times 113,6 \times 133,4$} \\
\hline \multicolumn{5}{|c|}{ Auflösung $[\AA]$ : } & \multicolumn{8}{|c|}{$50-5.0$} \\
\hline \multicolumn{5}{|c|}{ Reflexe: } & \multicolumn{8}{|c|}{23542} \\
\hline \multicolumn{5}{|c|}{ unabhängige Reflexe: } & \multicolumn{8}{|c|}{6864} \\
\hline \multicolumn{5}{|c|}{ Redundanz: } & \multicolumn{8}{|l|}{3,4} \\
\hline \multicolumn{4}{|c|}{ Shell } & \multicolumn{9}{|c|}{ Summary of observation redundancies: } \\
\hline pwer & Upper & & & $\%$ of re & eflectio & ons witl & th giver & n No. & of obs & ervati & ions & \\
\hline limit & limit & 0 & 1 & 2 & 3 & 4 & $5-6$ & 7-8 & $9-12$ & $13-19$ & $>19$ & total \\
\hline 30.00 & 10.63 & 0.5 & 1.4 & 17.7 & 11.8 & 45.2 & 21.9 & 1.5 & 0.0 & 0.0 & 0.0 & 99.5 \\
\hline 10.63 & 8.50 & 0.0 & 0.1 & 11.2 & 7.2 & 48.6 & 29.5 & 3.4 & 0.0 & 0.0 & 0.0 & 100.0 \\
\hline 8.50 & 7.44 & 0.0 & 0.4 & 9.5 & 9.3 & 48.0 & 29.3 & 3.5 & 0.0 & 0.0 & 0.0 & 100.0 \\
\hline 7.44 & 6.77 & 0.0 & 1.7 & 10.9 & 12.9 & 43.8 & 27.9 & 2.8 & 0.0 & 0.0 & 0.0 & 100.0 \\
\hline 6.77 & 6.29 & 0.4 & 2.9 & 13.9 & 22.7 & 37.3 & 20.8 & 2.0 & 0.0 & 0.0 & 0.0 & 99.6 \\
\hline 6.29 & 5.92 & 1.7 & 7.8 & 15.4 & 26.6 & 32.8 & 15.4 & 0.4 & 0.0 & 0.0 & 0.0 & 98.3 \\
\hline 92 & 5.63 & 4.3 & 13.3 & 2.9 & 27.3 & 22.0 & 10.0 & 0.1 & 0.0 & 0.0 & 0.0 & 95.7 \\
\hline 63 & 5.38 & 6.2 & 17.2 & 24.9 & 29.0 & 15.6 & 6.8 & 0.3 & 0.0 & 0.0 & 0.0 & 93.8 \\
\hline & 5.18 & 11.6 & 22.2 & 26.8 & 21.8 & 13.2 & 4.4 & 0.0 & 0.0 & 0.0 & 0.0 & 88.4 \\
\hline & 5.00 & 17.2 & 27.5 & 24.9 & 18.6 & 8.4 & 3.5 & 0.0 & 0.0 & 0.0 & 0.0 & 82.8 \\
\hline I hkl & & 4.1 & 9.2 & 17.7 & 18.6 & 31.8 & 17.1 & 1.4 & 0.0 & 0.0 & 0.0 & 95.9 \\
\hline
\end{tabular}

\begin{tabular}{|c|c|c|c|c|c|c|c|c|c|c|}
\hline \multicolumn{2}{|c|}{ Shell } & \multicolumn{9}{|c|}{ I/Sigma in resolution shells } \\
\hline 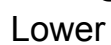 & Upper & & & of of & & & & Sim & less & \\
\hline & nit & 0 & 1 & 2 & & 5 & 10 & 20 & $>20$ & tot \\
\hline 00 & 10.63 & 0.6 & 23 & 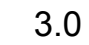 & 3.8 & 6.9 & .2 & 99.5 & .0 & \\
\hline & & & & & & & & & & \\
\hline & & & 2 & 4 & & & & & & \\
\hline & & & 3. & S. & & & & & & \\
\hline & & & & & & & & & & \\
\hline & & & & & & & & & & \\
\hline & & .9 & 10.9 & 18.2 & & 3 & 5 & 80 & & 5.7 \\
\hline & & 3.1 & & 21.4 & & 4 & & & & \\
\hline & &. & 12 & 21 & & & & & & \\
\hline & & 3. & 12 & & & & & & & \\
\hline & & & 7 & 13 & & 27 & 50.3 & & 21.0 & \\
\hline
\end{tabular}

$\begin{array}{rrrrrrrr}\begin{array}{r}\text { Shell } \\ \text { Lower Upper }\end{array} & \text { I } & \begin{array}{c}\text { Average } \\ \text { error }\end{array} & \begin{array}{c}\text { Average } \\ \text { stat. }\end{array} & \begin{array}{c}\text { Norm. } \\ \text { Chi**2 }\end{array} & \begin{array}{c}\text { Linear } \\ \text { R-fac }\end{array} & \begin{array}{c}\text { Square } \\ \text { R-fac }\end{array} \\ 30.00 & 10.63 & 2431.4 & 283.8 & 35.7 & 1.040 & 0.063 & 0.109 \\ 10.63 & 8.50 & 1888.0 & 91.2 & 27.3 & 1.011 & 0.045 & 0.063 \\ 8.50 & 7.44 & 918.8 & 40.6 & 20.8 & 1.052 & 0.056 & 0.060 \\ 7.44 & 6.77 & 474.6 & 28.8 & 18.7 & 1.092 & 0.078 & 0.092 \\ 6.77 & 6.29 & 313.0 & 21.2 & 19.3 & 1.068 & 0.089 & 0.090 \\ 6.29 & 5.92 & 261.4 & 21.8 & 21.4 & 1.010 & 0.094 & 0.114 \\ 5.92 & 5.63 & 248.6 & 24.8 & 24.7 & 0.796 & 0.089 & 0.090 \\ 5.63 & 5.38 & 243.0 & 28.0 & 27.9 & 0.828 & 0.093 & 0.105 \\ 5.38 & 5.18 & 222.2 & 32.5 & 31.3 & 1.063 & 0.111 & 0.142 \\ 5.18 & 5.00 & 200.9 & 34.5 & 34.4 & 0.665 & 0.112 & 0.104 \\ \text { All reflections } & 765.8 & 64.6 & 26.0 & 0.997 & 0.063 & 0.093\end{array}$


Da jedoch die gemessenen Kristalle durch Strahlenschäden zerstört wurden, konnte lediglich ein Datensatz (Peak) aufgenommen werden. Aus diesem Grund war es nur möglich, die Daten als SAD-Experiment auszuwerten. Dieses erfolgte mit dem Programm ShelxC (Tab. 10).

Tab. 10) Prozessierung des Selenomethionin-Datensatzes mit Hilfe des Programms ShelxC als SAD-Experiment

\begin{tabular}{|c|c|c|c|c|c|c|}
\hline Auflösung $[\AA]$ & -8.0 & -6.0 & -5.6 & -5.4 & -5.2 & -5.0 \\
\hline $\mathrm{N}($ data) & 1801 & 2364 & 914 & 538 & 591 & 640 \\
\hline$<$ l/sig> & 17.9 & 14.5 & 10.7 & 9.4 & 8.3 & 6.7 \\
\hline Vollständigkeit [\%] & 96.7 & 99.0 & 96.2 & 93.1 & 88.6 & 83.4 \\
\hline$<$ d"/sig> & 0.97 & 1.00 & 0.91 & 0.85 & 0.83 & 0.82 \\
\hline
\end{tabular}

Ein Wert d“/sig von ca 0.8 zeigt hierbei an, dass kein anomales Signal vorliegt. Anhand von Tabelle 10 kann man erkennen, dass im Selenomethionin-Datensatz ein anomales Signal bis zu einer Auflösung von $5.6 \AA$ vorlag. Unterhalb dieser Auflösung ( $-5 \AA$ ) zeigen die Werte für d“/sig jedoch, dass kein anomales Signal vorlag.

\subsubsection{Harker-Sektionen}

Um dieses Ergebnis nochmals zu überprüfen, wurde der Datensatz mit dem Programm SHARP als MIR-Experiment gegen den nativen Datensatz (nativhh) ausgewertet. Zur Suche nach einem anomalen Signal wurde die für $z=1 / 2$ errechnete Harker-Sektion für das anomale und das isomorphe Signal betrachtet (Abb. 70 ano und iso). Die Raumgruppe $P 2{ }_{1} 2{ }_{1}{ }_{1}$ bedeutet, dass hier die symmetrieäquivalente Position, bezogen auf die z-Achse eines Atoms mit den Koordinaten $\mathrm{x}, \mathrm{y}, \mathrm{z}$, bei $-\mathrm{x},-\mathrm{y},-\mathrm{z}+\frac{1}{2} 2$ liegt. Die Differenz der beiden Vektoren zur Bildung der Patterson-Map beträgt also 2x, 2y, 1/2. Dadurch verrät sich die Anwesenheit eines anomalen Signals durch die Bildung eines Peaks in der anomalen Harker-Sektion von $z=1 / 2$. 


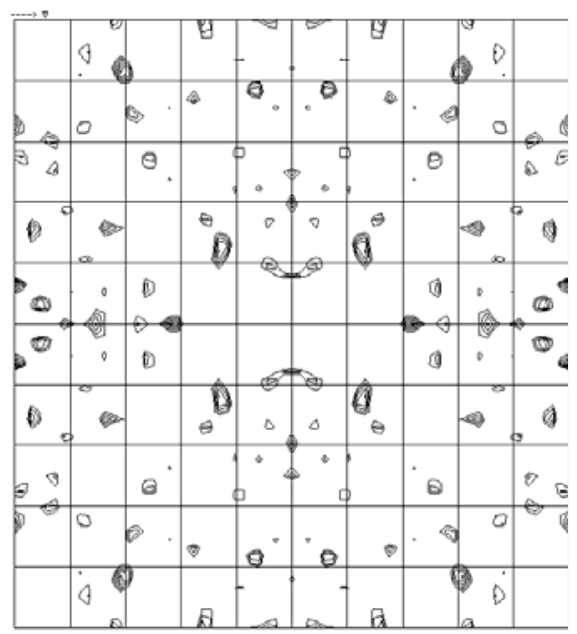

ano

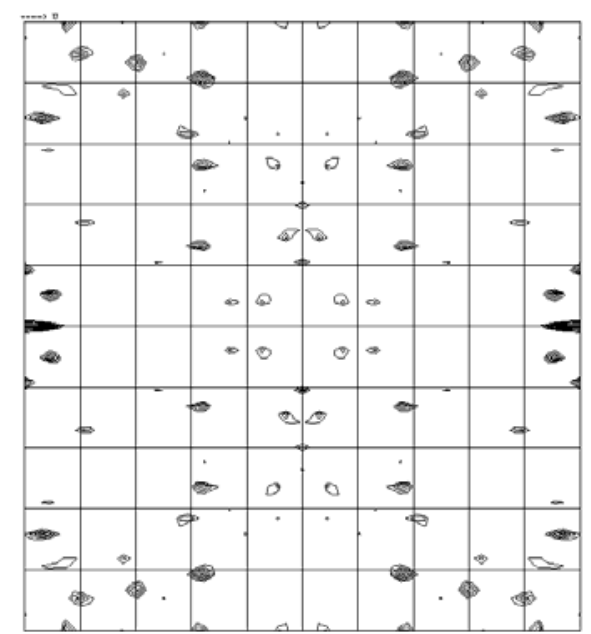

iso

Abb. 70) Harker-Sektion $(z=1 / 2)$ des Selenomethionin enthaltenden Thil-RNA-

\section{Komplexes}

Zur Erzeugung von Harker-Sektionen wurden die Datensätze mittels des Programms Sharp analysiert und prozessiert. Man kann hier an den Intensitäten der Peaks ablesen, dass die zu erwartenden 12 anomalen Signale nicht eindeutig zu erkennen waren. Zusätzlich bestand das Problem, dass entgegen der Erwartung die Harker-Sektionen für das anomale Signal (ano, links) und das isomorphe Signal (iso, rechts) ein unterschiedliches Muster aufzeigten. Dies bedeutet, dass keine Isomorphie zwischen dem nativen und dem Se-Thil-Kristall vorlag. Die Prozessierung dieser Unterschiede kann zu falschen anomalen Signalen führen.

Bei Analyse der Harker-Sektion für Selenomethionin enthaltende Thil-RNAKomplex-Kristalle (Abb. 70) konnten jedoch die 12 zu erwartenden anomalen Signale nicht eindeutig detektiert werden. Bei einem Vergleich der HarkerSektionen für das anomale (ano, Abb. 70, links) und das isomorphe (iso, Abb. 70, rechts) Signal fiel auf, dass sich die Muster der beiden HarkerSektionen unterschieden. Dies ließ den Schluss zu, dass zwischen den nativen Kristallen und den Selenomethionin enthaltenden Kristallen Unterschiede in der Kristallmorphologie vorlagen (vgl. Tab. 9 und 7). Diese Unterschiede in der Kristallmorphologie können bei der Datenprozessierung zu falschen anomalen Signalen führen, so dass die aufgetretenen Signale in der anomalen Harker-Sektion nicht sehr aussagekräftig waren. Da zusätzlich vermutet wurde, dass die enthaltenen Selenomethionine während der Aufreinigung mittels Hitzeschock (3.2.1.2) zerstört worden waren - sei es durch die Temperatur oder auch durch temperaturbeschleunigte Oxidationsvorgänge - wurde ein Aufreinigungsprotokoll ohne Hitzedenaturierung etabliert (siehe 3.2.2). Mit dem so gewonnenen Protein konnte ebenfalls 
ein Se-Thil-RNA-Komplex konstituiert werden, der erfolgreich kristallisiert wurde. Allerdings wiesen die bisher erhaltenen Kristalle nur eine Streuung zwischen 4,5 $\AA-5 \AA$ auf. Die Messung dieser Kristalle am Synchrotron brachte hier keine Verbesserung, so dass noch keine vollständigen Datensätze aufgenommen werden konnten. Weitere Test-Datensätze wurden an einer Kupfer-Drehanode aufgenommen. Da die Wellenlänge der Röntgenstrahlung einer Kupfer-Drehanode (1,54 $\AA$ ) bei Selen kein anomales Signal hervorruft, konnten diese jedoch bisher nicht auf die Anwesenheit eines anomalen Signals untersucht werden. Die Insertion von Selen konnte aber durch MALDI-TOF-Analyse (siehe 3.2.2.4) nachgewiesen werden.

\subsubsection{Phasierung mit Hilfe von Schwermetallsoaks}

$\mathrm{Da}$ in den Harker-Sektionen der Selenomethionin enthaltenden Kristalle keine eindeutigen Schwermetallsignale entdeckt werden konnten (siehe Abb. 70), wurden alternativ mehrere Schwermetalle zum sog. Soaken der Kristalle herangezogen und die Kristalle im Anschluss röntgenkristallographisch analysiert. Diese Daten sollten zur Durchführung von MIR-Experimenten genutzt werden. Eine Übersicht über die verwendeten Schwermetalle gibt Tab. 11. 
Tab. 11) Im Zuge der Prozessierung von Thil-RNA-Komplex-Kristallen verwendete Schwermetalle (Verbindungen) und die erhaltenen Auflösungen.

\begin{tabular}{|l|l|l|}
\hline Schwermetall & $\begin{array}{l}\text { verwendete } \\
\text { Verbindung }\end{array}$ & $\begin{array}{l}\text { Auflösung des Daten- } \\
\text { satzes bis }\end{array}$ \\
\hline $\mathrm{Hg}$ & $\mathrm{HgCl}_{2}$ & $6,0 \AA+$ \\
\hline & $\mathrm{EMTS}$ & $6,0 \AA$ \\
\hline $\mathrm{Pt}$ & $\mathrm{HgOAc}$ & $6,0 \AA$ \\
\hline & $\mathrm{K}_{2} \mathrm{PtCl}_{4}$ & $5,0 \AA$ \\
\hline $\mathrm{Au}$ & $\mathrm{KPtCl}_{6}$ & $5,0 \AA+$ \\
\hline $\mathrm{U}$ & $\mathrm{AuCl}_{3}$ & $5,0 \AA$ \\
\hline $\mathrm{I}$ & $\mathrm{UAc}$ & $4,5 \AA+$ \\
\hline $\mathrm{Sm}$ & $\mathrm{KI}$ & $4,5 \AA+$ \\
\hline $\mathrm{Xe}$ & $\mathrm{SmCl}$ & \\
\hline $\mathrm{Zus}$ & $\mathrm{Xenon}-$ Gas & $5,0 \AA+$ \\
\hline
\end{tabular}

Zusätzlich wurden Soaks mit folgenden Verbindungen durchgeführt: Methylblei, Ethylblei, Bleiacetat, Bleinitrat, Ytterbiumnitrat, Europiumnitrat und Gadoliniumchlorid. Diese zerstörten jedoch die Kristalle, so dass keine Streuung ermittelt werden konnte.

Es gilt: $A c=$ Acetat $/+=$ erfolgreiche Aufnahme eines Datensatzes

Es wurden mehrere Datensätze pro Schwermetall aufgenommen. Die Prozessierung erfolgte mit Sharp als MIR-Experiment. Die Harker-Sektionen für das anomale und das isomorphe Signal für die aussichtsreichsten Datensätze werden im Folgenden aufgelistet:

\section{a.) Quecksilber: $\mathrm{HgCl}_{2}$}

Raumgruppe:

Einheitszelle $[\AA]$ :

Auflösung $[\AA]$ :

Vollständigkeit:

Anomale Vollständigkeit: 27,0 \%
Redundanz:
1,7
R-Faktor:
4,7

$\mathrm{P} 2{ }_{1} 2{ }_{1}{ }_{1}$

$105,5 \times 113,7 \times 134,2$

$50-6.0$

$53,5 \%$ 


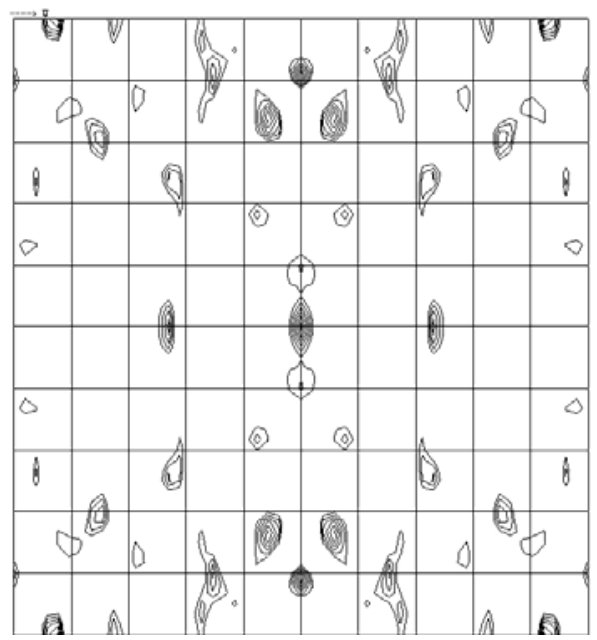

ano

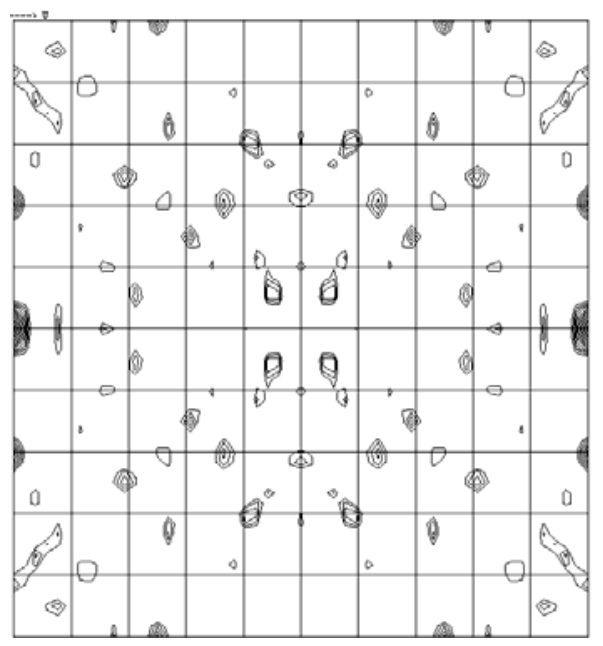

iso

Abb. 71) Anomale (ano) und isomorphe (iso) Harker-Sektion ( $z=1 / 2)$ der anomalen Patterson-Map von $\mathrm{HgCl}_{2}$ gesoakten Thil-RNA-Komplex Kristallen

Die Prozessierung der Daten erfolgte mit dem Programm Sharp. Bei Vergleich der beiden Harker-Sektionen fällt auf, dass große Unterschiede in der Peakverteilung bestehen. Dies weist darauf hin, dass durch die Insertion des $\mathrm{HgCl}_{2}$ die Morphologie des Kristalls gestört wurde. Zusätzlich lag eine sehr niedrige anomale Vollständigkeit vor, so dass es nicht verwunderlich ist, dass kein anomales Signal von Quecksilber gefunden wurde.

Nach dem Soaken mit $\mathrm{HgCl}_{2}$ wurde ein Datensatz aufgenommen. Bei der Prozessierung der Daten wurde eine leichte Änderung der Dimensionen der Einheitszelle festgestellt (vgl. Tab. 7). Der Vergleich der anomalen und isomorphen Harker-Sektionen der anomalen Patterson-Map, zeigte deutliche Unterschiede in der Peakverteilung (siehe Abb. 71). Dies wies darauf hin, dass eine Änderung der Kristallmorphologie eingetreten war, die auch zu falschen Signalen in der anomalen Harker-Sektion der anomalen PattersonMap führen kann. Die Tatsache, dass dieser Datensatz an einer KupferDrehanode bei einer Wellenlänge von 1,54 $\AA$ aufgenommen wurde, hat keinen großen Einfluss auf die Qualität des Signals, da Quecksilberatome ein starkes anomales Signal über weite Teile des Spektrums zeigen (FieberErdmann, pers. Mitt.). Wesentlich größer dürfte in diesem Fall der Einfluss der Vollständigkeit des anomalen Signals gewesen sein, die nur $27 \%$ aufwies. Zusätzlich war die Auflösung mit 6,0 $\AA$ zu niedrig, um mit diesem Datensatz eine interpretierbare Elektronendichte zu berechnen. 
b.) Jod: KI

Raumgruppe:

$\mathrm{P} 2{ }_{1} 2{ }_{1}{ }_{1}$

Einheitszelle $[\AA]$ : $105,3 \times 113,9 \times 134,3$

Auflösung $[\AA]$ :

$50-5.0$

Vollständigkeit:

$83.5 \%$

Anomale Vollständigkeit: $63.0 \%$

Redundanz:

R-Faktor:

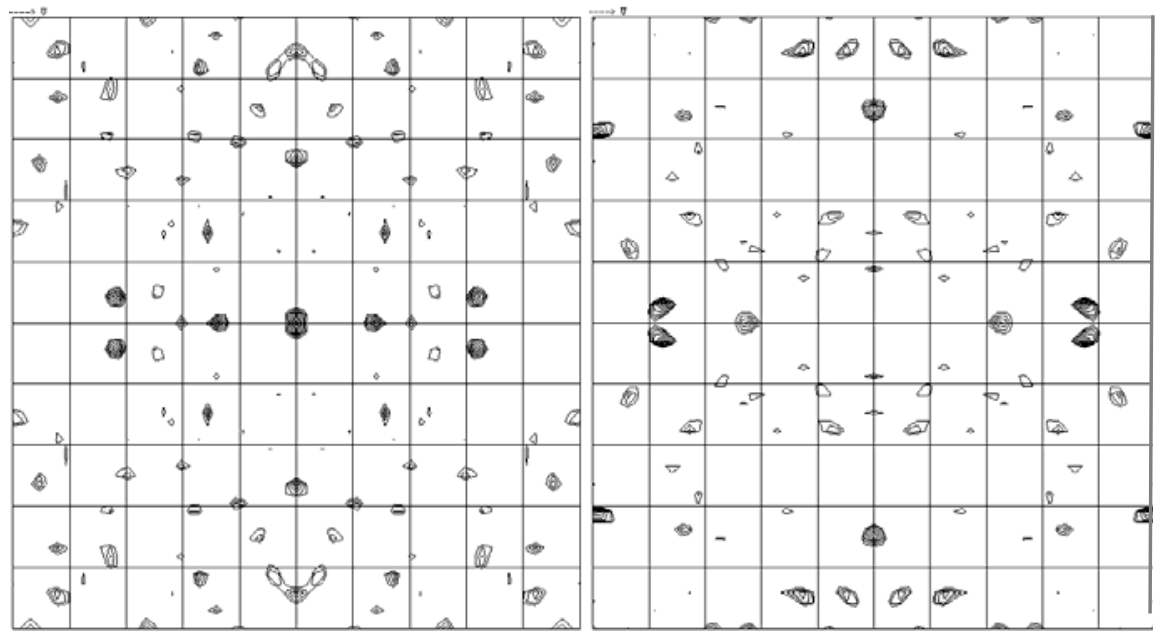

ano

iso

Abb. 72) Anomale (ano) und isomorphe (iso) Harker-Sektion ( $z=1 / 2)$ der anomalen Patterson-Map von KI-gesoakten Thil-RNA-Komplex-Kristallen

Die Prozessierung der Daten erfolgte mit dem Programm Sharp. Bei Vergleich der beiden Harker-Sektionen fällt auf, dass Unterschiede in der Peakverteilung bestehen. Dies weist darauf hin, dass durch die Insertion von KI die Morphologie des Kristalls gestört wurde.

Bei der Verwendung von Kaliumiodid konnte ebenfalls kein anomales Signal gefunden werden, obwohl hier die Vollständigkeit der Daten höher lag (83 \% und $63 \%$, s.o.) als bei Quecksilber (a). Die verwendete Wellenlänge lag fast am Absorptionsmaximum (Kante) von Jod. Trotzdem zeigte eine Analyse der anomalen und isomorphen Harker-Sektionen der anomalen Patterson-Map, dass kein deutliches Signal erhalten wurde. Auch hier zeigten die beiden Harker-Sektionen der anomalen Patterson-Map eine unterschiedliche Peakverteilung, so dass davon ausgegangen wurde, dass auch hier keine perfekte Isomorphie der Kristalle vorlag. Dieses wurde auch bei Vergleich der 
Größen der Einheitszellen von nativem und gesoaktem Kristall bestätigt (vgl. Tab. 7). Da das Signal von Jod im Vergleich zu anderen Schwermetallen sehr gering ist, genügte die hier erhaltene Auflösung von $5 \AA$ nicht, um eine Elektronendichte zu ermitteln.

\section{c.) Platin: $\mathrm{KPtCl}_{6}$}

Raumgruppe:

$\mathrm{P} 2{ }_{1} 2{ }_{1}{ }_{1}$

Einheitszelle $[\AA]$ : $102,5 \times 112,9 \times 131,1$

Auflösung $[\AA]$ :

$50-4.2$

Vollständigkeit:

$93,4 \%$

Anomale Vollständigkeit: $71,9 \%$

$\begin{array}{ll}\text { Redundanz: } & 2,7 \\ \text { R-Faktor: } & 9,0\end{array}$

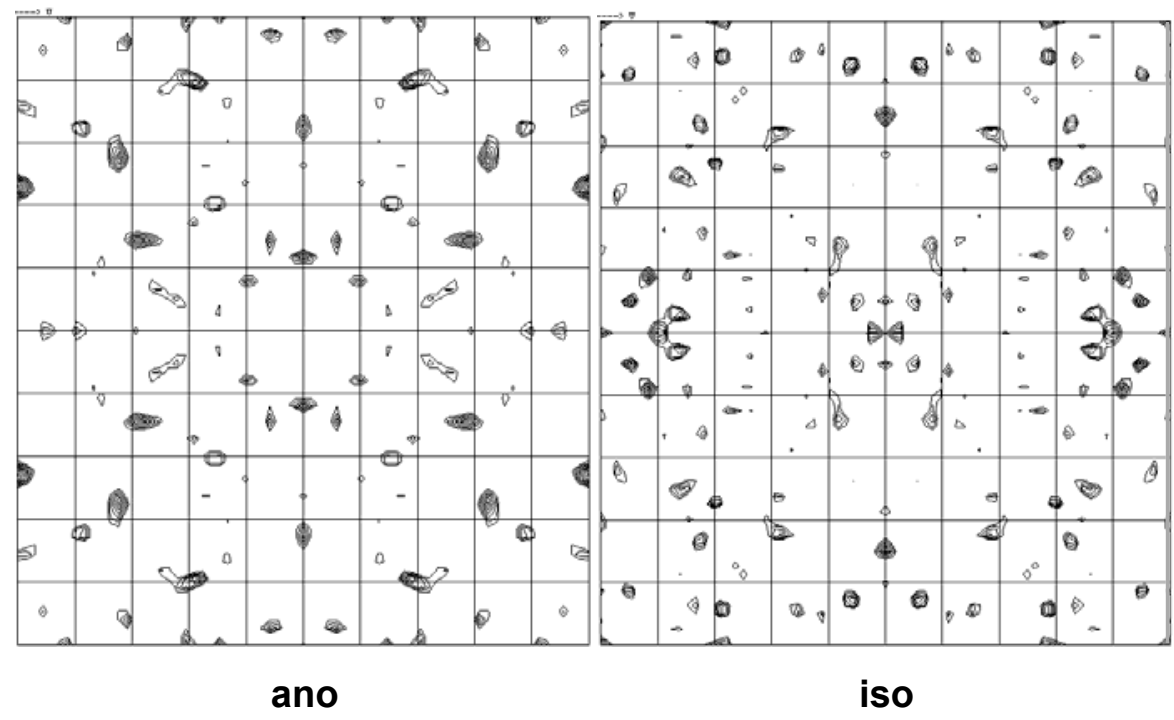

Abb. 73) Anomale (ano) und isomorphe (iso) Harker-Sektion ( $z=1 / 2)$ der anomalen Patterson-Map von $\mathrm{KPtCl}_{6}$ gesoakten Thil-RNA-Komplex-Kristallen

Die Prozessierung der Daten erfolgte mit dem Programm Sharp. Bei Vergleich der beiden Harker-Sektionen fällt auf, dass große Unterschiede in der Peakverteilung bestehen. Dies weist darauf hin, dass durch die Insertion des $\mathrm{KPtCl}_{6}$ die Morphologie des Kristalls gestört wurde. Zusätzlich lag eine sehr niedrige anomale Vollständigkeit vor, so dass es nicht verwunderlich ist, dass kein anomales Signal von Platin gefunden wurde. 
Der nach dem Soaken mit $\mathrm{KPtCl}_{6}$ aufgenommene Datensatz zeigte ebenfalls deutliche Unterschiede in Art und Lage der Peaks in der anomalen und isomorphen Harker-Sektionen der anomalen Patterson-Map (Abb. 73). Dies wies darauf hin, dass eine Änderung der Kristallmorphologie eingetreten war, so dass davon ausgegangen wurde, dass die stellenweise deutlichen Signale in der anomalen Harker-Sektion der anomalen Patterson-Map durch diese Isomorphieprobleme erhalten wurden. Obwohl die Vollständigkeit der Daten hier besser war als bei den zuvor untersuchten Derivaten, war die Auflösung mit $5 \AA$ nicht sehr hoch. Eine weitere Prozessierung der Daten führte zu keiner interpretierbaren Elektronendichte.

\section{d.) Uran: Uranylacetat (UAc)}

Raumgruppe:

Einheitszelle $[\AA]$ :

Auflösung $[\AA]$ :

Vollständigkeit:

Anomale Vollständigkeit: nicht bestimmt

Redundanz:

3,4

R-Factor:
$\mathrm{P} 2{ }_{1} 2{ }_{1} 2_{1}$ $99,9 \times 112,6 \times 131,0$

$50-4,2$

$97,4 \%$

Tab. 12) Auswertung des UAC gesoakten Datensatzes als SAD-Experiment mit ShelxC

\begin{tabular}{|c|c|c|c|c|c|c|c|c|c|c|}
\hline Auflösung $[\AA]$ & -8.0 & -6.0 & -5.6 & -5.4 & -5.2 & -5.0 & -4.8 & -4.6 & -4.4 & -4.2 \\
\hline $\mathrm{N}($ data) & 1673 & 2240 & 869 & 541 & 620 & 721 & 861 & 999 & 1150 & 1316 \\
\hline$<\mathrm{l} / \mathrm{sig}>$ & 28.0 & 9.9 & 6.0 & 5.0 & 5.6 & 4.3 & 4.2 & 4.0 & 3.2 & 2.8 \\
\hline $\begin{array}{c}\text { Vollständigkeit } \\
{[\%]}\end{array}$ & 95.5 & 98.9 & 98.6 & 99.1 & 98.9 & 99.2 & 98.9 & 98.5 & 96.2 & 92.1 \\
\hline$<\mathrm{d} /$ /sig & 0.86 & 0.78 & 0.80 & 0.79 & 0.82 & 0.83 & 0.81 & 0.80 & 0.76 & 0.81 \\
\hline
\end{tabular}

Dieser Versuch wurde am Synchrotron (DESY, Hamburg) durchgeführt. Dabei wurden die Daten bei einer Wellenlänge von $0.843 \AA$ aufgenommen. Beim Prozessieren der Daten mit ShelxC wurde kein anomales Signal erhalten (Tab. 12). Aus diesem Grunde konnte darauf verzichtet werden die anomalen und isomorphen Harker-Sektionen der anomalen Patterson-Map zu generieren. Später wurde festgestellt, dass Uran bei der gewählten Wellenlänge kein anomales Signal besitzt, es somit also zu erwarten war, 
dass bei der Prozessierung mit ShelxC kein anomales Signal gefunden werden konnte.

\section{e.) Xenon: Xe (g)}

Raumgruppe:

$\mathrm{P} 2{ }_{1}{ }_{1} 2_{1}$

Einheitszelle $[\AA]$ : $109,1 \times 114,7 \times 135,3$

Auflösung $[\AA]$ :

$50-4,5$

Vollständigkeit:

$95,5 \%$

Anomale Vollständigkeit: $75,4 \%$

Redundanz: $\quad 5,5$

R-Faktor: $\quad 10,8$

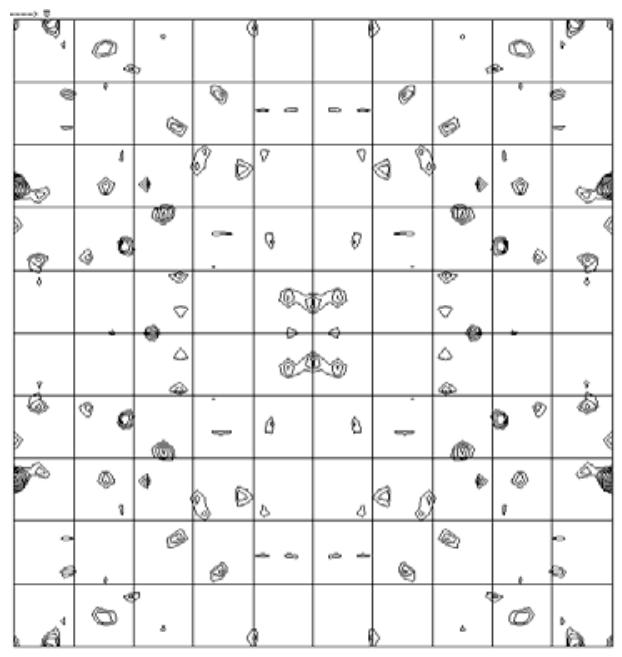

ano

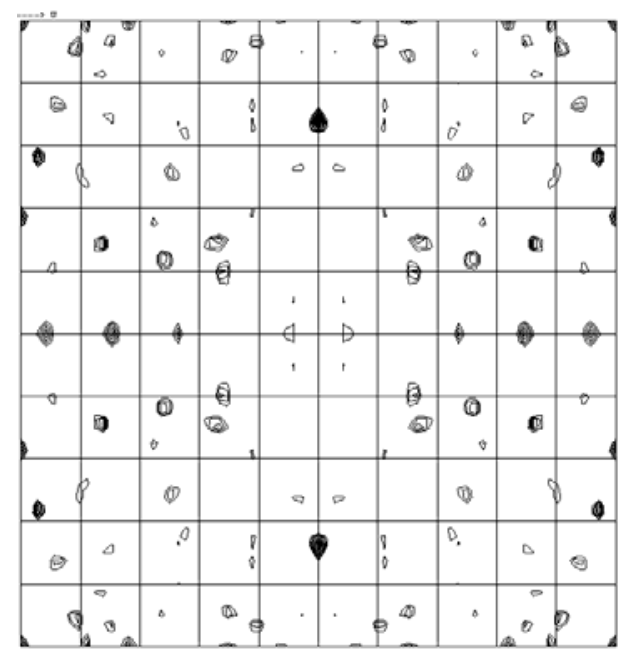

iso

Abb. 74) Anomale (ano) und isomorphe (iso) Harker-Sektion ( $z=1 / 2)$ der anomalen Patterson-Map von Xenon gesoakten Thil-RNA-Komplex-Kristallen

Die Prozessierung der Daten erfolgte mit dem Programm Sharp. Bei Vergleich der beiden Harker-Sektionen fällt auf, dass große Unterschiede in der Peakverteilung bestehen. Dies weist darauf hin, dass durch die Insertion von Xenon die Morphologie des Kristalls gestört wurde. Dies konnte auch dadurch belegt werden, dass eine große Änderung der Dimensionen der Einheitszelle erfolgt war.

Das Soaken mit Xenon bewirkte im Vergleich zu allen anderen aufgeführten Schwermetallen (a-d) die größte Änderung an der Einheitszelle (bis zu $5 \%$ ). So wurde das obige Ergebnis (Abb. 74) bei Vergleich der anomalen und isomorphen Harker-Sektionen der anomalen Patterson-Map erwartet. Obwohl es gelungen war, einen Datensatz von hoher Vollständigkeit (95 \%) 
zu erhalten, konnte deshalb keine interpretierbare Elektronendichte erhalten werden.

\section{8}

\section{Free Mounting System (FMS)}

$\mathrm{Da}$ in allen bisher durchgeführten Versuchen zur Phasenbestimmung die Kristalle nur Daten bis zu einer Auflösung von ca. 4,5 $\AA$ geliefert hatten, wurde versucht, die Datenqualität mit Hilfe des Free Mounting Systems (FMS) zu verbessern. In diesem System ist es möglich, den Feuchtigkeitsgehalt eines Kristalls kontrolliert zu senken. Dazu wird der betreffende Kristall ohne Mutterlauge am FMS montiert. Hierbei ist er einem steten Gasstrom einer bestimmten Humidität ausgesetzt. Die Humidität dieses Gasstroms kann durch das FMS gesenkt werden (2.18). Da der Kristall ohne umgebende Flüssigkeit im Gasstrom hängt, beginnt er zu trocknen. Durch diesen Vorgang kann in manchen Kristallen eine Verbesserung der Datenqualität erreicht werden (Kiefersauer et al., 2000).

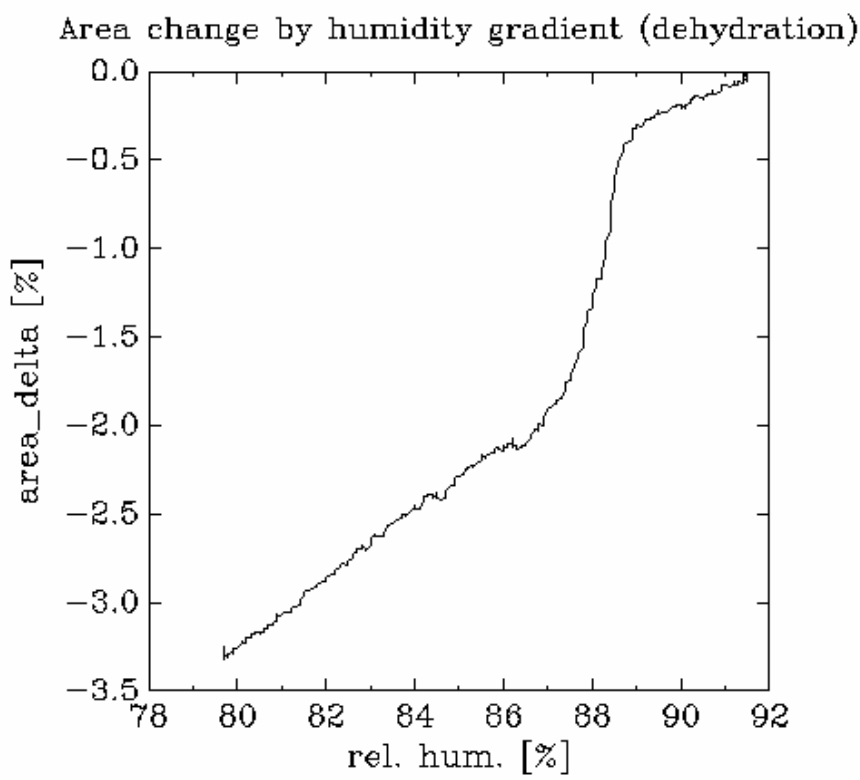

\section{Abb. 75) Änderung der Kristallgröße während der Trocknung im FMS}

Der Kristall wurde im FMS eingespannt, und die Humidität des Luftstroms wurde von dem zuvor ermittelten Startwert von 91,8 \% zum Endwert bei 79,8 \% gesenkt. Dabei verringerte sich die Größe des Kristalls um ca. 3,2 \%. Während des Trocknungsvorgangs wurde die Streuung des Kristalls durch kontinuierliche Messung überwacht. So konnte die optimale Streuung bei einer Humidiät von $83 \%$ ermittelt werden. 
Zur Durchführung von FMS-Optimierungen (2.18) wurde der jeweilige Kristall ausgehend von der zuvor ermittelten Ausgangshumidität von 91,8 \% bis zu einer Humidität von $79 \%$ getrocknet (siehe Abb. 75). Während des Trocknungsvorgangs wurde die Streuung des Kristalls kontinuierlich verfolgt. Die Beobachtung der Größe des Kristalls zeigte, dass während der Trocknung die Größe um 3,3 \% abnahm (vgl. Abb. 75). Durch die Analyse der Streuung konnte gezeigt werden, dass bei einer Humidität von $83 \%$ der maximale Effekt erreicht wurde (Streuungsbilder nicht aufgeführt). Im Anschluss konnte der Ausgangszustand des Kristalls durch Steigerung der Humidität auf 91,8 \% annähernd wiederhergestellt werden (Abb. 76). Diese Kurve ist aber meist fehlerbehaftet, da sich häufig Wasser an den Außenseiten des Kristalls ablagert und so falsche Werte für die Kristallgröße verursacht. Betrachtet man die Kurve der Rehydration (Abb. 76), so kann man erkennen, dass die Kristallgröße um einen höheren Faktor steigt (ca. $7 \%$ ) als sie im Dehydrationsexperiment (Abb. 75$)$ abgenommen hat (3,2 \%). Dieser „Fehler" liefert einen Hinweis, dass der oben beschriebene Effekt auch hier aufgetreten war. Die Betrachtung des Kristalls unter einem Binokular bestätigte die Annahme. 


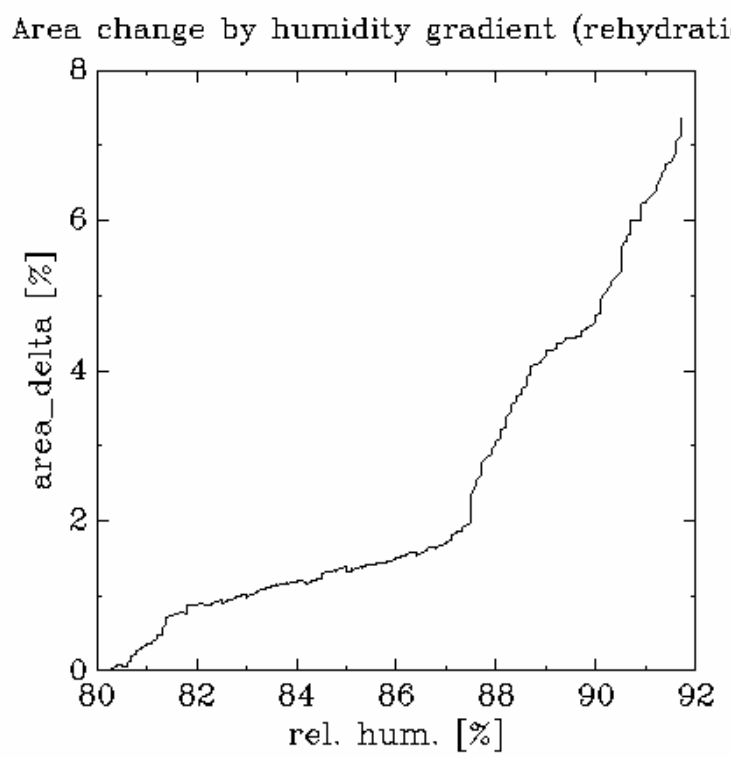

\section{Abb. 76) Änderung der Kristallgröße während der Rehydration im FMS}

Der oben getrocknete Kristall (vgl. Abb. 75) wurde durch eine Steigerung der Humidität des Luftstroms wieder auf die Ausgangshumidität von 91,8 \% gebracht. Dabei steigerte sich die Größe des Kristalls um ca. 7,0 \%. Da dieser Wert wesentlich höher war als der bei der Dehydration bestimmte, wurde davon ausgegangen, dass sich Feuchtigkeit auf der Außenseite des Kristalls abgelagert und so die Messung verfälscht hatte.

Im Anschluss wurden mehrere Kristalle auf eine Humidität von $83 \%$ gesenkt und tiefgefroren, um von innen einen Datensatz am Synchrotron aufzunehmen.

Am Synchrotron (BESSY, Berlin) gelang es dann, Datensätze von $\mathrm{HgCl}_{2}-$ getränkten Kristallen bis zu einer Auflösung von 3,1 $\AA$ (Abb. 77) und von mit $\mathrm{KPtCl}_{6}$ getränkten Kristallen bis zu einer Auflösung von 4,5 $\AA$ aufzunehmen. Die maximale Streuung konnte also wesentlich verbessert werden (vgl. Tab. 12, siehe Abb. 77).

Bei der anschließenden Prozessierung der Daten wurde festgestellt, dass sich eine Seite der Einheitszelle von ca. $130 \AA$ (vgl. Tab. 7) auf $119 \AA(124 \AA$ bei Platin) verringert hatte (vgl. Tab. 12). Die Ergebnisse der Datenprozessierungen werden im Folgenden näher beschrieben. 


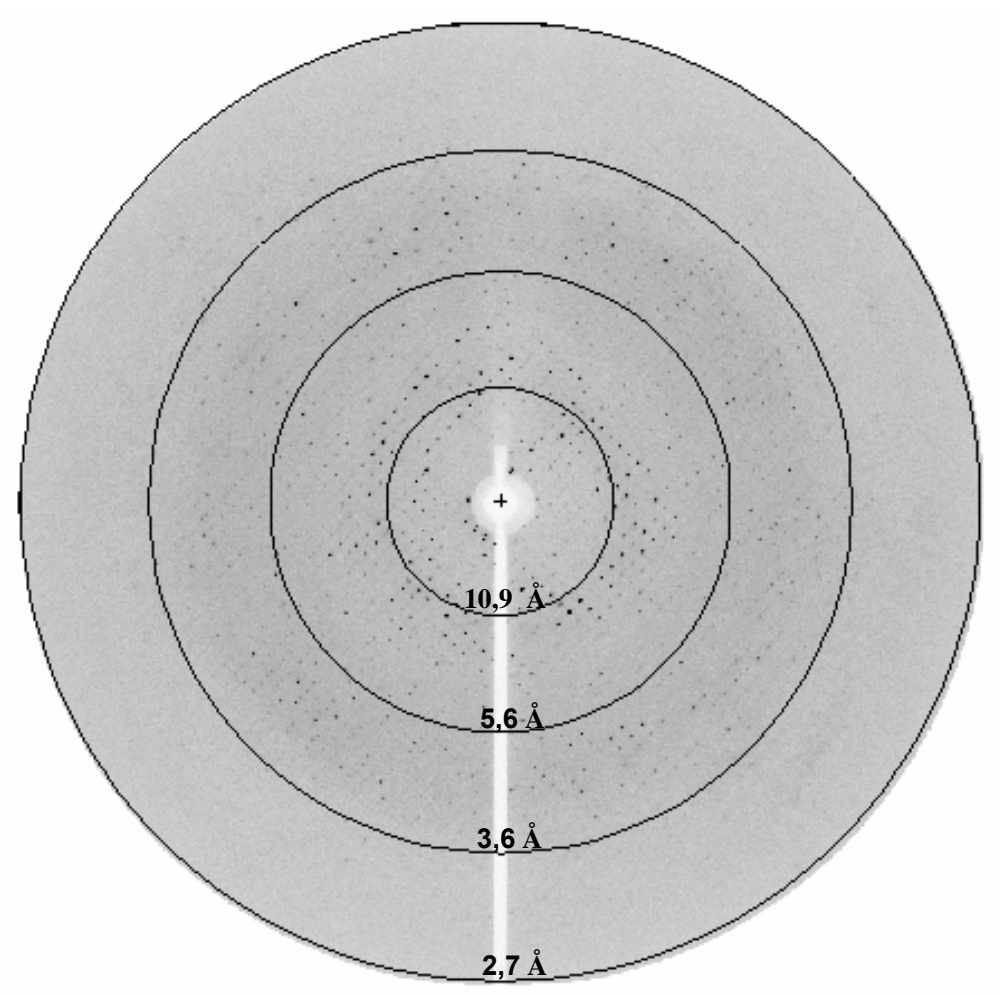

Abb. 77) Aufnahme eines durch das FMS optimierten Kristalls des Thil-RNAKomplex

Die Aufnahme entstand am BESSY (Berlin) bei einer Wellenlänge von 1,0085 $\AA$. Während der 10 sekündigen „Belichtung“ wurde der Kristall um $1^{\circ}$ gedreht. Man kann erkennen, dass die Auflösung durch das FMS auf bis zu 3,1 $\AA$ verbessert werden konnte.

\section{a.) Quecksilberderivat}

Nach der Optimierung der Kristalle durch das FMS gelang es, einen Datensatz eines mit $\mathrm{HgCl}_{2}$ gesoakten Kristalls aufzunehmen und $\mathrm{zu}$ prozessieren. Dabei konnte festgestellt werden, dass sich die Größe der Einheitszelle verändert hatte (Tab. 12). Neben einer Redundanz von 4,1 war es gelungen, diesen Datensatz (hgclberlin) mit einer Vollständigkeit von 99,9\% aufzunehmen: 
Tab. 12) Datenstatistik hgclberlin

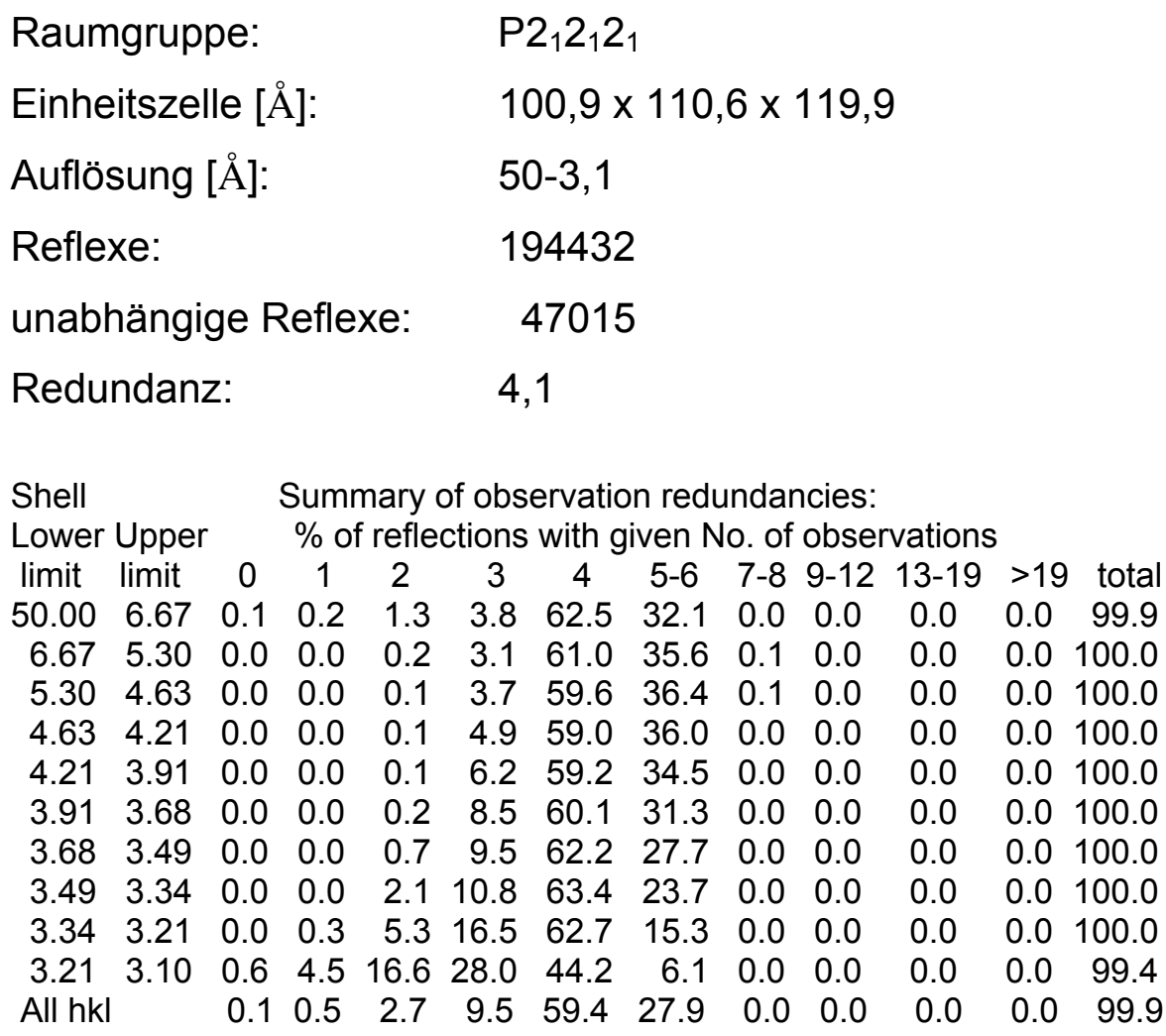

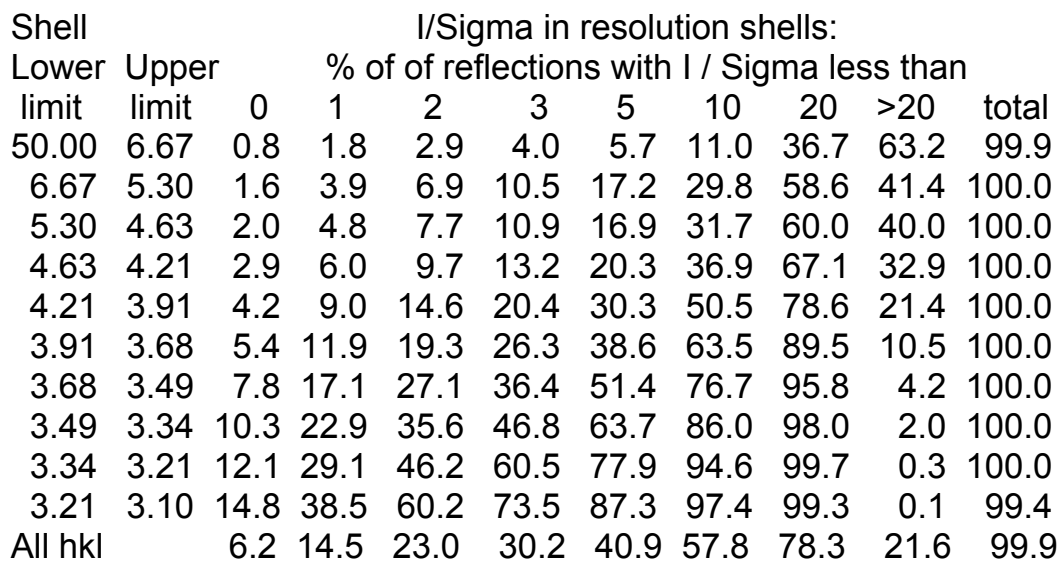

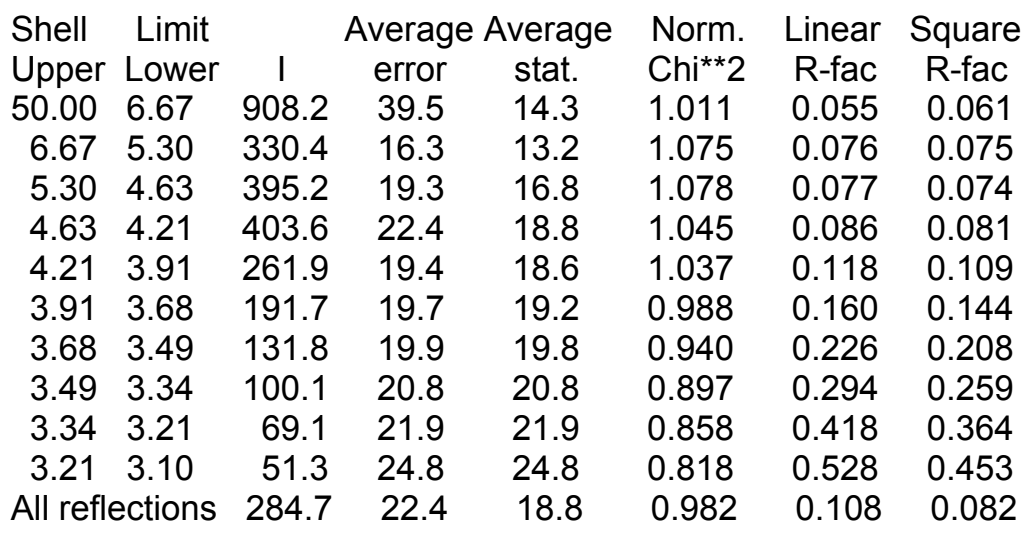


Mit dem Programm ShelxC wurde nach einem anomalen Signal gesucht. Dabei konnte festgestellt werden, dass bis zu einer Auflösung von $6 \AA$ ein schwaches anomales Signal vorlag (siehe Tab. 13, Spalte d"/sig; bei einem Wert von 0.8 liegt kein anomales Signal vor). Um zu überprüfen, ob in der dazugehörigen Harker-Sektion der anomalen Patterson-Map ein anomales Signal gefunden werden kann, wurde der Datensatz im Anschluss mit dem Programm Sharp ausgewertet. Da jedoch eine Änderung der Parameter der Einheitszelle stattgefunden hatte, existierte kein entsprechender nativer Datensatz, so dass die Auswertung nur als SAD-Experiment erfolgte. Die Nicht-Isomorphie der Kristalle hätte sonst zu „Prozessierungsartefakten“ geführt.

Die Analyse der Harker-Sektion der anomalen Patterson-Map bei $z=1 / 2$ zeigte, dass keine signifikanten Peaks, die auf ein anomales Signal hingewiesen hätten, vorlagen (siehe Abb. 78). Zwar konnte man in manchen Peaks (Pfeile) einen Hinweis auf ein schwaches Signal vermuten, allerdings war der Unterschied zwischen der Intensität dieser eventuellen, anomalen Signale im Vergleich zum Hintergrundrauschen sehr schwach. So war es nicht möglich eine interpretierbare Elektronendichte $\mathrm{zu}$ berechnen. Die Ursache lag wahrscheinlich darin, dass die Auflösung des anomalen Signals bis $6 \AA \mathrm{zu}$ niedrig war.

Tab. 13) Prozessierung des hgclberlin-Datensatzes mit Hilfe des Programms ShelxC als SAD-Experiment

\begin{tabular}{|l|l|l|l|l|l|l|l|l|l|l|l|}
\hline Auflösung & -8.0 & -6.0 & -5.0 & -4.5 & -4.3 & -4.1 & -3.9 & -3.7 & -3.5 & -3.3 & -3.1 \\
\hline N(data) & 1573 & 2034 & 2544 & 2233 & 1183 & 1425 & 1741 & 2125 & 2635 & 3314 & 4149 \\
\hline$<$ l/sig> & 27.7 & 23.2 & 22.0 & 22.6 & 20.3 & 18.3 & 15.1 & 12.3 & 9.0 & 6.1 & 3.3 \\
\hline Vollst.[\%] & 98.0 & 99.7 & 99.8 & 99.9 & 99.7 & 99.9 & 99.9 & 99.9 & 99.9 & 99.9 & 98.6 \\
\hline$<$ d“/sig> & 1.35 & 1.06 & 0.89 & 0.80 & 0.77 & 0.79 & 0.80 & 0.78 & 0.77 & 0.76 & 0.73 \\
\hline
\end{tabular}




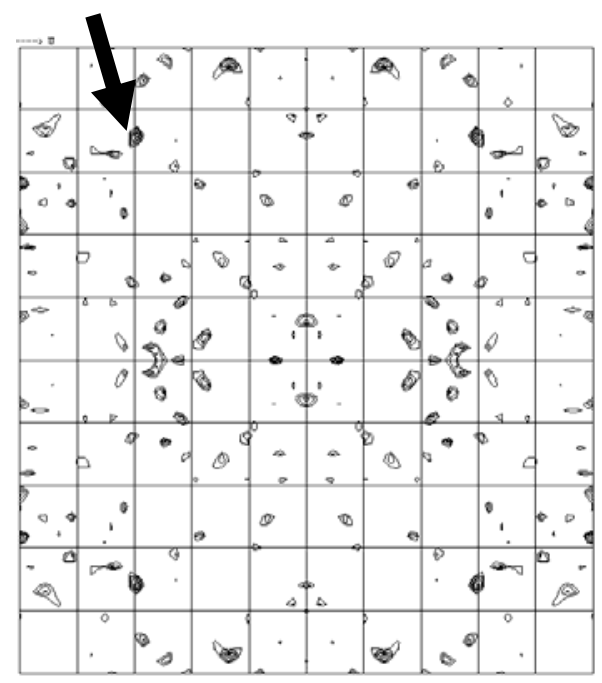

Abb. 78) Harker-Sektion ( $z=1 / 2)$ der anomalen Patterson-Map des mit $\mathbf{H g C l}_{2}$ gesoakten und mit Hilfe des FMS optimierten Kristalls

Die Prozessierung der Daten erfolgte mit dem Programm Sharp als SAD-Experiment. Man könnte in manchen Peaks (mit Pfeil markiert) einen Hinweis auf ein anomales Signal vermuten. Allerdings ist die Intensität des Signals im Vergleich zum Hintergrundrauschen sehr schwach.

\section{b.) Quecksilberderivat-Datensatz über $360^{\circ}$}

Zusätzlich war es gelungen, obigen Kristall über eine komplette Drehung von $360^{\circ}$ zu messen. Dieser Datensatz (hgclzwo) lieferte erwartungsgemäß eine sehr hohe Redundanz der Daten $(13,4)$ und eine Vollständigkeit von $100 \%$ (siehe Tab. 14).

Tab. 14) Datenstatistik von hgclzwo

$\begin{array}{ll}\text { Raumgruppe: } & \mathrm{P} 2{ }_{1} 2{ }_{1} 1 \\ \text { Einheitszelle }[\AA]: & 100,9 \times 110,6 \times 119,9 \\ \text { Auflösung }[\AA]: & 50-3,1 \\ \text { Reflexe: } & 335830 \\ \text { unabhängige Reflexe: } & 250320 \\ \text { Redundanz: } & 13,4\end{array}$




\begin{tabular}{|c|c|c|c|c|c|c|c|c|c|c|}
\hline \multicolumn{3}{|l|}{ Shell } & \multicolumn{7}{|c|}{ I/Sigma in resolution shells: } & \\
\hline \multicolumn{3}{|c|}{ Lower Upper } & \multicolumn{8}{|c|}{ No. of reflections with I / Sigma less than } \\
\hline Limit & limit & 0 & 1 & 2 & 3 & - & 10 & 20 & 20 & \\
\hline 4 & & 29 & & 65 & & 121 & 1 & 6 & & \\
\hline & & & & 107 & & & & & & \\
\hline & & & & 12 & & & & & & \\
\hline & & & & 15 & & & & & & \\
\hline & 3. & 8 & 149 & 208 & & & & 3 & & \\
\hline 3. & 3. & 94 & & 279 & & 545 & & & & \\
\hline & & & & $3 \varsigma$ & & & & & & \\
\hline & & & & 51 & & & & & & \\
\hline & & 165 & 4 & 657 & & & & 78 & & \\
\hline 1 & 3.10 & 210 & 569 & 899 & 1182 & 1583 & 2075 & 2370 & o & \\
\hline & & & & & & & & 10010 & & \\
\hline
\end{tabular}

\begin{tabular}{|c|c|c|c|c|c|c|c|c|c|c|}
\hline \multicolumn{2}{|c|}{$\begin{array}{l}\text { Shell } \\
\text { Lower Upper }\end{array}$} & & & \multicolumn{6}{|c|}{ I/Sigma in resolution shells: } & \\
\hline & & 0 & 1 & 2 & 3 & & & & 20 & \\
\hline & & 1.1 & & 2.4 & & & & & & \\
\hline & & 1. & & & & & & & & \\
\hline & & & & & & & & & & \\
\hline & & 2. & & & & & & & & \\
\hline 4 & & 3.5 & & & 11 & & & & & \\
\hline & & 3.8 & & & & & & & & \\
\hline & & 5.2 & & & & & & & & \\
\hline & & 6.0 & & & & & & & & \\
\hline & & 6. & & & & & & & 6 & \\
\hline & & 8.6 & 2 & & 48.7 & & & & -1 & \\
\hline & & 1. & & 10.1 & 10.2 & 0.0 & 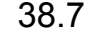 & 0.6 & 3.7 & 10 \\
\hline
\end{tabular}

\begin{tabular}{|c|c|c|c|c|c|c|c|}
\hline ell & Limit & Average & \multicolumn{2}{|c|}{ Average } & Norm. & Linear & Square \\
\hline & Upper & 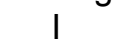 & error & stat. & $\mathrm{Chi}^{\star \star 2} 2$ & R-fac & R-fac \\
\hline .00 & 6.66 & 2316.0 & 45.5 & 19.5 & 1.023 & 0.050 & 0.054 \\
\hline 6.66 & 5.29 & 815.3 & 21.3 & 16.5 & 1.026 & 0.086 & 0.090 \\
\hline 5.29 & 4.63 & 988.0 & 28.4 & 20.6 & 1.032 & 0.096 & 0.102 \\
\hline 4.63 & 4.21 & 1005.2 & 32.5 & 22.7 & 1.021 & 0.109 & 15 \\
\hline 4.21 & 3.90 & 628.4 & 24.3 & 21.2 & 1.054 & 0.148 & 0.161 \\
\hline & 3.6 & 457 & 21.9 & 21.1 & 1.065 & 0.189 & 202 \\
\hline 3.67 & 3.49 & 305.8 & 21.2 & 21.1 & 1.001 & 0.249 & 0.275 \\
\hline 3.49 & 3.34 & 229.3 & 21.5 & 21.5 & 0.903 & 0.294 & 0.297 \\
\hline 3.34 & 3.21 & 155.5 & 22.6 & 22.6 & 0.819 & 0.367 & 0.361 \\
\hline 21 & 3.10 & 113.2 & 25.0 & 25.0 & 0.783 & 0.453 & 0.416 \\
\hline All refl & 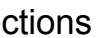 & 716.4 & 26.6 & 21.2 & 0.986 & 0.113 & $0.0 \varsigma$ \\
\hline
\end{tabular}

Die weitere Prozessierung (ShelxC, siehe Tab. 14, Harker-Sektion siehe Abb. 79) bestätigte das unter (a) gefundene Ergebnis. Es lag also ein schwaches anomales Signal vor, das aber nicht zur Erzeugung einer Elektronendichte genügte. Bei näherer Betrachtung der Harker-Sektion der anomalen Patterson-Map (Abb. 79) des $360^{\circ}$-Datensatzes kann man allerdings erkennen, dass sich die Intensität der Peaks des anomalen Signals im Gegensatz zum um $100^{\circ}$ gedrehten Kristall leicht erhöht hat. Das 
gleiche Ergebnis konnte nach der Prozessierung mit ShelxC beobachtet werden. Hier unterschied sich der Wert von d"/sig deutlicher von 0.8 als beim Datensatz aus (a). Trotzdem war es nicht möglich, mit diesem Datensatz eine interpretierbare Elektronendichte zu berechnen.

Dasselbe Ergebnis ergab eine Vereinigung der beiden Datensätze mit Hilfe des Programms Scalepack und eine daran anschließende Prozessierung.

Auch Experimente, bei denen durch lange Belichtungszeit induzierte Strahlenschäden an Disulfidbrücken innerhalb des Kristalls zur Phasierung genutzt werden sollten, blieben ergebnislos. Da der R-Faktor im $360^{\circ}$ Datensatz trotz der langen Belichtungszeit (Datenaufnahme in $0,5^{\circ}$ Schritten über einen Zeitraum von 6 h) kaum Veränderungen zeigte, wurde dieses Ergebnis erwartet. Ein Strahlenschaden hätte sich durch eine starke Erhöhung des R-Faktors spätestens gegen Ende der Datenaufnahme (ab ca. $260^{\circ}$ bis $360^{\circ}$ ) verraten. Ebenso lieferte die Verwendung eines alternativen Prozessierungsprogramms (Solve) kein verwertbares Signal.

Tab 14) Prozessierung des hgclzwo Datensatzes mit Hilfe des Programms ShelxC als SAD-Experiment

\begin{tabular}{|l|l|l|l|l|l|l|l|l|l|l|l|}
\hline Auflösung & -8.0 & -6.0 & -5.0 & -4.5 & -4.3 & -4.1 & -3.9 & -3.7 & -3.5 & -3.3 & -3.1 \\
\hline N(data) & 1545 & 2041 & 2537 & 2235 & 1179 & 1438 & 1737 & 2131 & 2616 & 3333 & 4193 \\
\hline$<$ l/sig> & 47.9 & 35.5 & 30.0 & 28.4 & 25.7 & 24.1 & 20.8 & 19.0 & 14.4 & 10.0 & 5.4 \\
\hline Vollst.[\%] & 96.2 & 99.7 & 99.8 & 99.9 & 99.7 & 99.9 & 99.9 & 99.9 & 99.9 & 99.9 & 99.9 \\
\hline <d“/sig> & 1.56 & 1.06 & 0.85 & 0.71 & 0.67 & 0.71 & 0.70 & 0.74 & 0.75 & 0.74 & 0.77 \\
\hline
\end{tabular}




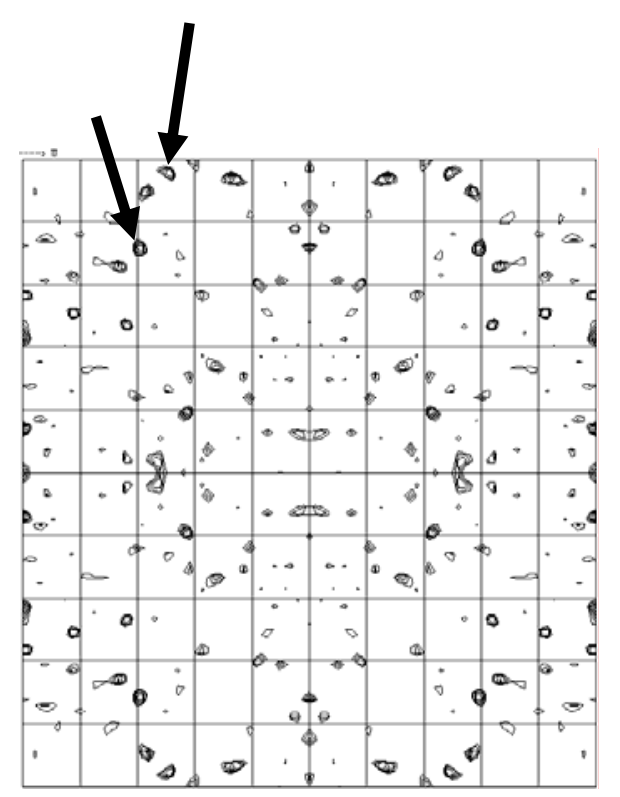

Abb. 79) Harker-Sektion ( $z=1 / 2)$ der anomalen Patterson-Map des mit $\mathbf{H g C l}_{2}$ gesoakten und mit dem FMS optimierten Kristalls (Langzeitmessung)

Die Prozessierung der Daten erfolgte mit dem Programm Sharp als SAD-Experiment. Man könnte in den mit Pfeilen markierten Peaks einen Hinweis auf ein anomales Signal vermuten. Allerdings ist die Intensität des Signals im Vergleich zum Hintergrundrauschen zu schwach.

\section{c.) Platinderivat}

Auch mit Platin $\left(\mathrm{KPtCl}_{6}\right)$ gesoakte Kristallen konnten mit dem FMS optimiert werden. Zwar hatte sich hier die Auflösung im Gegensatz zu den unbehandelten Kristallen nur unwesentlich geändert, trotzdem wurde ein Datensatz der vorhandenen Kristalle aufgenommen. Zunächst wurde jedoch ein Fluoreszenzspektrum bestimmt (Abb. 80). Hierdurch konnte die Anwesenheit von Platin im Kristall bestätigt werden. Außerdem sollten die Wellenlängen für eine Auswertung des Platin-gesoakten Kristalls als MADExperiment bestimmt werden. Diese bisher unübliche Vorgehensweise sollte einen positiven Effekt auf die Qualität der Daten haben und bessere Elektronendichten nach der Phasierung liefern (Fieber-Erdmann, pers. Mitt.). 


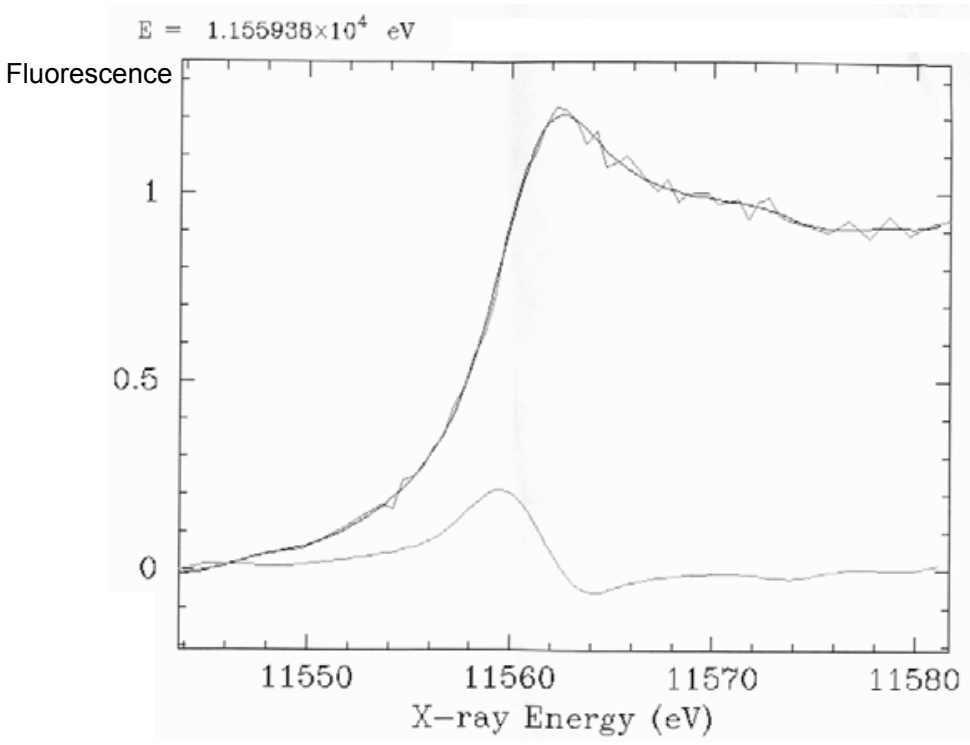

Abb. 80) Fluoreszenzspektrum von mit Platin $\left(\mathrm{KPtCl}_{6}\right)$ gesoakten Kristallen

Ausgehend vom Fluoreszenzspektrum sollten die Wellenlängen für ein MAD-Experiment bestimmt werden (vgl. Haupttext).

Dazu wurden analog zur Vorgehensweise bei den Selenomethionin enthaltenen Kristallen anhand des Fluoreszenzspektrums (Abb. 80) die Wellenlängen für einen Peak- und einen Inflection-Datensatz bestimmt. Im Anschluss wurden ein Datensatz für Peak (11562,5 eV, $\lambda=1,0723 \AA$ ) und Inflection $(11558,9 \mathrm{eV}, \lambda=1,0726 \AA)$ aufgenommen. Bei den ersten Prozessierungen zeigte sich, dass sich auch hier die Größe der Einheitszelle geändert hatte. Es gelang diesen Kristall (ptsoak) mit einer Redundanz von 4.0 und einer Vollständigkeit von 93,8 \% aufzunehmen (Tab. 15).

Tab. 15) Datenstatistik von ptsoak

Raumgruppe:

$\mathrm{P} 2{ }_{1} 2_{1} 2_{1}$

Einheitszelle $[\AA]$ : $98,9 \times 111,9 \times 124,9$

Auflösung $[\AA]$ : $50-4,7$

Vollständigkeit: $93.8 \%$

Reflexe: 66225

unabhängige Reflexe: $\quad 16307$

Redundanz:

R-Faktor: 
Bei der weiteren Analyse der Daten mit dem Programm ShelxC zeigte sich, dass hier außer zwischen 6,0 $\AA$ und 5,6 $\AA$ ein anomales Signal vorlag (siehe Tab. 16). Da die Aufnahme des Inflection-Datensatzes kein anomales Signal lieferte (Daten nicht gezeigt) erfolgte eine Auswertung als SAD-Experiment. Die so errechnete Harker-Sektion der anomalen Patterson-Map für $z=1 / 2$ enthielt Peaks (Abb. 81, Pfeile), die eventuell von einem anomalen Signal erzeugt worden waren. Bei einer weiteren Prozessierung, um eine Elektronendichte zu erzeugen, ergab sich jedoch keine interpretierbare Elektronendichtekarte.

Tab 16) Prozessierung des ptsoak Datensatzes mit Hilfe des Programms ShelxC als SAD-Experiment

\begin{tabular}{|l|l|l|l|l|l|l|l|l|}
\hline Auflösung & -8.0 & -6.0 & -5.6 & -5.4 & -5.2 & -5.0 & -4.8 & -4.6 \\
\hline $\mathrm{N}$ (data) & 1621 & 2111 & 825 & 517 & 584 & 685 & 795 & 891 \\
\hline$<\mathrm{l} /$ sig> & 56.2 & 26.0 & 12.7 & 11.0 & 8.2 & 6.7 & 5.7 & 4.3 \\
\hline Vollst.[\%] & 98.1 & 99.7 & 99.6 & 99.8 & 99.7 & 100.0 & 97.5 & 93.0 \\
\hline$<$ d“'sig> & 1.28 & 1.04 & 0.84 & 0.70 & 0.67 & 0.70 & 0.69 & 0.74 \\
\hline
\end{tabular}

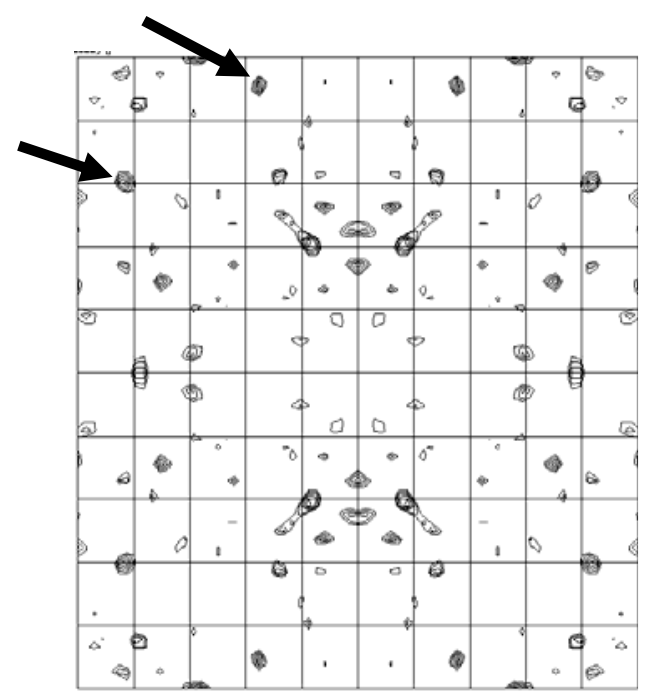

Abb. 81) Harker Sektion ( $z=1 / 2)$ der anomalen Patterson Map des Datensatzes eines mit $\mathrm{KPtCl}_{6}$ gesoakten und mit dem FMS optimierten Kristalls (ptsoak)

Die Prozessierung der Daten erfolgte mit dem Programm Sharp als SAD-Experiment. Man könnte in den mit Pfeilen markierten Peaks einen Hinweis auf ein anomales Signal vermuten. Allerdings ist die Intensität des Signals im Vergleich zum Hintergrundrauschen sehr schwach. 


\section{d.) lodderivat}

Zusätzlich war es gelungen einen mit Kaliumjodid gesoakten Kristall zu optimieren. Auch hier hatte sich die Einheitszelle verkleinert. Die Auswertung des Datensatzes (kifms) ergab, dass eine Vollständigkeit der Daten bis 99,7 \% bei einer Auflösung von 4,7 $\AA$ erhalten wurde (Tab. 17).

Tab. 17) Datenstatistik von kifms

Raumgruppe:

$\mathrm{P} 2{ }_{1} 2_{1} 2_{1}$

Einheitszelle $[\AA]$ :

$98,9 \times 111,9 \times 124,9$

Auflösung $[\AA]$ :

$50-4,7$

Vollständigkeit:

$99.7 \%$

Reflexe:

68127

unabhängige Reflexe: $\quad 9077$

Redundanz: $\quad 7.5$

R-Faktor $\quad 7.3$

Obwohl auch hier ein in den niedrigen Auflösungsbereichen schwaches anomales Signal gefunden wurde (Tab. 18), konnte aus dem Datensatz (kifms) keine verwertbare Elektronendichte generiert werden.

Tab. 18) Prozessierung des kifms Datensatzes mit Hilfe des Programms ShelxC als SAD-Experiment

\begin{tabular}{|l|l|l|l|l|l|l|l|l|l|}
\hline Auflösung & -8.0 & -6.0 & -5.6 & -5.4 & -5.2 & -5.0 & -4.8 & -4.6 & -4.4 \\
\hline $\mathrm{N}$ (data) & 1675 & 2228 & 870 & 532 & 626 & 733 & 833 & 987 & 561 \\
\hline$<$ l/sig> & 32.3 & 20.6 & 13.1 & 8.4 & 8.8 & 8.5 & 7.3 & 5.5 & 4.1 \\
\hline Vollst.[\%] & 96.4 & 99.7 & 99.8 & 99.8 & 99.7 & 99.9 & 99.9 & 99.0 & 47.1 \\
\hline$<$ d“/sig> & 1.47 & 1.13 & 0.94 & 0.71 & 0.77 & 0.89 & 0.81 & 0.79 & 0.76 \\
\hline
\end{tabular}




\subsection{Strukturbestimmung durch Molekularen Ersatz}

Als eine zusätzlich Alternative zur Aufklärung der Struktur des Thil-RNAKomplexes wurde die Methode des Molekularen Ersatzes durchgeführt. Hier wird die Phaseninformation aus bereits vorhandenen Strukturen (Protein, DNA und auch RNA) gewonnen. Dazu nutzt man Strukturen, die eine größtmögliche Homologie (>40 \%) zur noch unbestimmten Struktur aufweisen.

Im Falle der Thil-RNA-Komplex-Kristalle wurde dabei von zwei Ansätzen ausgegangen. Zum einen wurde nach der Struktur eines Proteins gesucht (Protein Data Base), dessen Aminosäuresequenz eine größtmögliche Homologie zur Aminosäuresequenz von Thil selbst besaß, zum anderen wurde versucht, die enthaltene RNA als Suchmodell zu nutzen.

Es scheiterten jedoch beide Ansätze. Bei der Suche nach einem Thil Homolog mit bereits aufgeklärter Struktur konnte kein Protein mit einer höheren Aminosäuresequenzhomologie als 13,5 \% gefunden werden (Pyrophosphokinase aus Saccharomyces cerevisiae). Die Verwendung des RNA-Bestandteils scheiterte daran, dass in der Datenbank nur die 3DStruktur der tRNA ${ }^{\text {Phe }}$ aus $S$. cerevisiae vorhanden war, die jedoch stellenweise erhebliche Unterschiede zur verwendeten (verkürzten) tRNA ${ }^{\text {Phe }}$ aus E. coli aufwies (siehe Anhang). Zusätzlich bestand noch das Problem, dass die RNA nur einen Anteil von 22,8 \% am gesamten Komplex stellt. Es bestand also wiederum die Schwierigkeit, dass das Suchmodell weit unterhalb der üblicherweise verwendeten Homologie lag. So war es nicht verwunderlich, dass die Strukturen nicht in die aus den Datensätzen errechneten Elektronendichtewolken passten. 


\section{Diskussion}

\subsection{Thil und MnmA aus E. coli}

Bei Aufnahme der vorliegenden Arbeit wurde zunächst mit den Enzymen Thil und $\mathrm{MnmA}$ aus E. coli gearbeitet. Diese lagen in Expressionssystemen kloniert vor, die freundlicherweise von Dr. Lauhon (Madison, USA) zur Verfügung gestellt worden waren. Ebenso waren bereits arbeitsgruppenintern Aufreinigungsprotokolle etabliert worden. Während das Aufreinigungsprotokoll für Thil ohne Änderung übernommen wurde, wurde das Protokoll zur Aufreinigung von MnmA modifiziert.

Thil konnte in großer Menge (50 - 80 mg /l Expressionskultur) bis zur Homogenität aufgereinigt werden (3.1.1.3). Trotz diverser Kristallisationsexperimente (3.1.3) gelang es aber nicht, Proteinkristalle, die zu weiterführenden röntgenkristallographischen Untersuchungen geeignet gewesen wären, zu erhalten.

Da nicht genau bekannt ist, warum Proteinlösungen Kristalle bilden (siehe 4.3.1), wäre eine Suche nach den Ursachen an dieser Stelle müßig, da es einerseits Beispiele für Proteinkristallisationen gibt, bei denen es erst nach umfangreichen Kristallisationsexperimenten zu Proteinkristallen gekommen ist (Einsle, pers. Mitt.), andererseits sind aber auch Beispiele zu finden, bei denen ohne größeres Zutun des jeweiligen Experimentators Proteinkristalle erhalten werden konnten. Dies gilt z.B. für Lysozym. Statistische Auswertung von Kristallisationsexperimenten (Rudolph, pers. Mitt.) zeigten, dass bisher nur $12 \%$ der durchgeführten Kristallisationprojekte zur Kristallisation des eingesetzten Proteins führten.

Neben diesen geringen Aussichten auf Erfolg könnte man im Falle von Thil einen zusätzlichen Grund für die bisher erfolglosen Kristallisationsexperimente in der Aminosäuresequenz vermuten:

Vergleicht man die Proteinsequenz von Thil aus E. coli mit der seines Orthologs aus T. maritima (Abb. 82), so ist festzustellen, dass Thil aus T. maritima eine gegenüber Thil aus $E$. coli verkürzte AS-Sequenz aufweist. 


\begin{tabular}{|c|c|c|}
\hline$>>$ Thi ITm & MKELRVYIVRYSEIGLKGK-NRKDFEEALRRNIERVTG- - - - MKVKRQWGRFLI PIDEN & 54 \\
\hline$>>$ ThiIEC & - - -MKFI IKLFPEITIKSQSVRLRFIKILTGNIRNVLKHYDETLAVVRḦWDNIEVRAKDE & 57 \\
\hline & 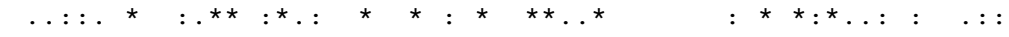 & \\
\hline >>ThiITm & - - -VTLDDKLKKIFGIQNFSKGFLVSH-DFEEVKKYSLIAVKEKLEKGNYRTFKVQAKKA & 110 \\
\hline$>$ ThiIEC & NQRLAIRDALTRI PGIHHILEVEDVPFTDMHDI FEKALVQYRDQLEG- - -KTFCVRVKRR & \\
\hline & 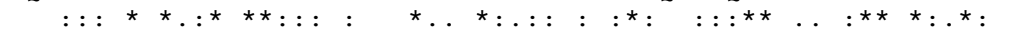 & \\
\hline$>>$ ThiITm & YKEYKKGVYEINSELGALILKNFKELSVDVRNPDFVLGVEVRPEGVLIFTDRVECYGGLP & \\
\hline$>>$ ThiIEC & -GKHDFSSIDVERYVGGGLNQHIESARVKLTNPDVTVHLEVEDDRLLLIKGRYEGIFFFP & \\
\hline & 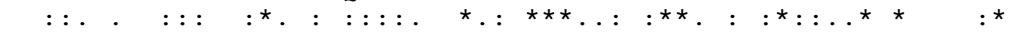 & \\
\hline$>>$ ThiITm & VGTGGKAVLLLSGGIDSPVAGWYALKRGVLIESVTFVSPPFTSEGAVEKVRDILRVLREF & \\
\hline$>>$ ThiIEC & IGTQEDVLSLISGGFDSGVSSYMLMRRGCRVHYCFFNLGGAAHEIGVRQVAHYLWNR - - F & 1 \\
\hline & 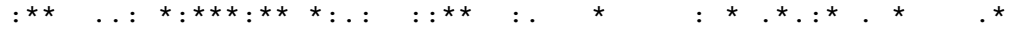 & \\
\hline >>ThiITm & SGGHPLRLHIVNLTKLQLEVKKRVPDKYSLIMYRRSMFRIAEKIAEETGAVAFYTGENIG & \\
\hline$>>$ ThiIEC & GSSHRVRFVAINFEPVVGEILEKIDDGQMGVILKRMMVRAASKVAERYGVQALVTGEALG & 1 \\
\hline & 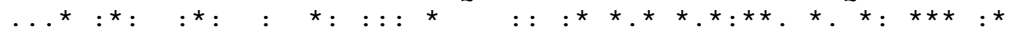 & \\
\hline$>>$ ThiITm & QVASQTLENLWSIESVTTRPVIRPLSGFDKTEIVEKAKEIGTYEIS - IKPYQDSCVFFAP & \\
\hline$>>$ ThiIEC & Q̃VSSQTTLTNLRLIDNVSDTLILRPLISYDKEHI INLARQIGTEDFARTMPEỸCGVISKSP & \\
\hline & 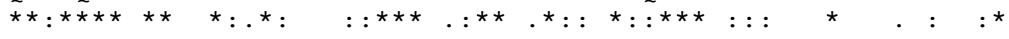 & \\
\hline$>$ ThiITm & KNPATRS - - - - - - HPS ILEKLEQQVPDLPVLEEEAFTSRKVEVIE $-\cdots-\cdots$ & \\
\hline$>>$ ThiIEC & TVKAVKSKIEAEEEKFDFSILDKVVEEANNVDIREIAQQTEQEVVEVETVNGFGPNDVIL & \\
\hline & 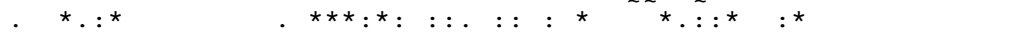 & \\
\hline$>>$ ThiITm & 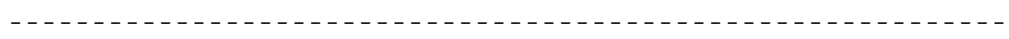 & \\
\hline$>>\mathrm{Th}$ & DIRSIDEQEDKPLKVEGIDVVSLPFYKLSTKFGDLDQNKTWLLWCERGVMSRLQALYLRE & \\
\hline$>\mathrm{T}$ & -------- & \\
\hline$>$ Th & QGFNNVKVYRP 482 & \\
\hline
\end{tabular}

Abb. 82) Vergleich der AS-Sequenz von Thil aus T. maritima (Tm) und E. coli (Ec)

Der unmittelbare Vergleich der Aminosäuresequenzen von Thil aus T. maritima ( $\mathrm{Tm}$ ) und E. coli (Ec) zeigt, dass Thil aus T. maritima eine um 96 AS verkürzte Sequenz (rot dargestellt) aufweist.

Trotz dieses offensichtlichen Unterschieds, der auch bei anderen Orthologen gefunden werden kann (siehe Anhang), katalysiert Thil aus T. maritima die komplette Enzymkatalyse zu 4-Thiouridin (Lauhon, pers. Mitt.). Da es im Zuge dieser Arbeit jedoch gelungen ist, von dem kürzeren Thil aus T. maritima Proteinkristalle zu erhalten, wäre es möglich, dass dieser Bereich des E. coli-Proteins als Ursache für das Ausbleiben von Kristallen in Betracht kommt. Zwar liegt die Sequenzidentität der beiden Proteine bei nur ca. $22 \%$, was einen unmittelbaren Vergleich der beiden Proteine erschwert, es wäre aber z.B. möglich, dass dieser verlängerte Teil der Sequenz von Thil aus E. coli die in der 3D-Struktur zur Kristallisation essentiellen Protein-ProteinKontakte verhindert. Da Thil aus T. maritima zu den thermophilen Proteinen gehört, von denen berichtet wird, dass ihre thermophilen Eigenschaften unter anderem ein Resultat einer Verkürzung von den an der Oberfläche des Proteins liegenden „Loop“-Bereichen ist (Thompson und Eisenberg, 1999), könnte man darin sogar einen Hinweis erkennen, dass dieser Bereich in der 
Tertiärstruktur von Thil an der Proteinoberfläche liegt. Die Ausbildung von Protein-Protein-Kontakten ist jedoch zur Ausbildung von Kristallen unverzichtbar (McPherson, 2001).

Thil aus $E$. coli konnte nicht erfolgreich mit einer artifiziellen, verkürzten tRNA (39-mer, Minimalsubstrat, vgl. 3.4), die bei der Komplexierung des Thil Orthologs aus T. maritima verwendet worden war, komplexiert werden.

Eine Analyse des gereinigten Thil aus E. coli zeigte, dass der Quotient 260/280 nm bei 1,3 lag. Da für ein reines Protein ein Quotient 260/280 nm von ca. 0,5 zu erwarten ist (Schrimpf, 2002), wurde davon ausgegangen, dass die Ursache für den deutlich höheren Quotienten darin lag, dass Thil aus $E$. coli während der Aufreinigung unspezifisch Nukleinsäuren aus $E$. coli gebunden hatte. Versuche, die diese Interaktion z.B. durch höhere Salzkonzentrationen $\left(>1 \mathrm{M}, \mathrm{NaCl}\right.$ und $\left.\left(\mathrm{NH}_{4}\right)_{2} \mathrm{SO}_{4}\right)$ unterbinden sollten, blieben erfolglos.

MnmA aus $E$. coli konnte ebenfalls in großen Mengen exprimiert und aufgereinigt werden (40 mg/l Expressionkultur). Auch hier lag bereits ein etabliertes Aufreinigungsprotokoll vor, als die Arbeiten aufgenommen wurden. Dieses wurde jedoch bei Übernahme der Versuche dahingehend modifiziert, dass das Puffersystem von $\mathrm{NaCl}$ auf $\left(\mathrm{NH}_{4}\right)_{2} \mathrm{SO}_{4}$ umgestellt wurde, da $\left(\mathrm{NH}_{4}\right)_{2} \mathrm{SO}_{4}$ für seine stabilisierenden Eigenschaften auf Proteine bekannt ist (Gagnon, 1998). Auch hier konnten keine Proteinkristalle erhalten werden.

Zusätzlich wurde auch hier vergeblich versucht, einen Komplex mit einer artifiziellen, verkürzten tRNA zu generieren. Untersuchungen von MnmA zeigten, dass auch das gereinigte MnmA aus E. coli einen Quotienten 260/280 nm von ca. 1,3 aufwies. Da es sich ebenfalls um ein reines Protein handelte, wäre wie im Falle von Thil ein Quotient 260/280 nm von 0,5 zu erwarten gewesen. Es wurde deshalb ebenfalls davon ausgegangen, dass MnmA aus E. coli während der Aufreinigung unspezifisch Nukleinsäuren aus E. coli gebunden hatte. Auch hier ließ sich diese Bindung nicht durch Variation der verwendeten Salzkonzentration auflösen. 


\subsubsection{Klonierung und Reinigung von Thil und MnmA aus \\ T. maritima als MBP-Fusionsproteine}

Um die exprimierten Mengen an Thil und MnmA zu steigern, wurden die jeweiligen Gene, nach ihrer Amplifikation aus Genom-DNA von T. maritima als MBP-Fusionsproteine kloniert. MBP-Fusionsproteine hatten gezeigt, dass sie im Vergleich zu Tag-freier Expression und anderen Tagsystemen sowohl die Menge an exprimiertem, rekombinantem Protein als auch dessen Löslichkeit steigerten (Gouloudis, 2005). Da es zur Durchführung von Kristallisationsexperimenten großer Mengen an reinem Protein bedarf, wurden die Gene für Thil und MnmA aus T. maritima in dieses Vektorsystem kloniert.

Nach erfolgreicher Klonierung und Expression von Thil aus T. maritima in E. coli ER2508 (dieser Stamm war aufgrund seiner Protease-Defizienz zur Expression gewählt worden) konnte das MBP-Thil-Fusionsprotein durch PreScission ${ }^{\mathrm{TM}}$-Protease-Spaltung erfolgreich gespalten werden. Probleme traten erst auf, als die Spaltprodukte Thil und MBP voneinander getrennt werden sollten, da ihre Molekulargewichte sehr nahe beieinander liegen (44/42 kDa). Zunächst wurde versucht, MBP und Thil durch einen Hitzeschock bei $80{ }^{\circ} \mathrm{C} \mathrm{zu}$ trennen, jedoch konnte in Kontrollversuchen gezeigt werden, dass auch MBP teilweise hitzestabil ist (siehe 3.2.4). Aufgrund des sehr ähnlichen Molekulargewichts entfiel auch die Möglichkeit einer Trennung durch Gelfiltration. Als weitere Möglichkeit bestand außerdem die Auftrennung durch Ionenaustauschchromatographie, da MBP einen pl bei pH 5,0 und Thil einen berechneten pl bei $\mathrm{pH} \mathrm{9,2} \mathrm{aufwies.} \mathrm{Da}$ aber nicht gewährleistet werden konnte, dass bei diesem Reinigungsschritt eine zufriedenstellende Trennung der Proteine MBP und Thil erfolgen würde und zur Kristallisation eine möglichst hohe Homogenität der Proben gewährleistet sein muss (Bergfors, 2002), wurde diese Möglichkeit verworfen. Es sollte verhindert werden, dass MBP-Kristalle (Struktur bereits 
determiniert, Duan et al., 2001) oder auch MBP+Thil Mischkristalle entstehen.

In Folge dessen wurden weitere Versuche hierzu eingestellt und MBP-Thil zu einigen repräsentativen Kristallisationsexperimenten eingesetzt, in denen aber keine Kristalle erhalten wurden (3.2.4.3).

MnmA aus T. maritima konnte ebenfalls exprimiert werden. Trotz verschiedener Ansätze gelang es nicht eine komplette Spaltung von MBPMnmA zu erreichen. Da die Spaltung nur partiell erfolgte (siehe 3.2.5), wurde angenommen, dass MBP-MnmA in mehreren unterschiedlichen Konformationen vorlag, so dass nur MBP-MnmA-Moleküle gespalten werden konnten, deren PreScission ${ }^{\mathrm{TM}}$ _Protease-Erkennungssequenz frei zugänglich war. Dies bedeutete aber, dass die Homogenität der MBP-MnmAProteinlösung, die zu Kristallisationsversuchen eingesetzt werden sollte, nicht gewährleistet werden konnte. Deshalb wurde die Möglichkeit der Aufreinigung von $\mathrm{MnmA}$ aus T. maritima über ein MBP-Fusionsprotein verworfen. Das MBP-MnmA wurde dann trotzdem zu Kristallisationsexperimenten eingesetzt. In diesen wurden aber bisher keine Kristalle erhalten (3.2.5). 


\subsubsection{Klonierung und Reinigung von Thil und MnmA (pET-System)}

Im Rahmen dieser Arbeit gelang es, die Gene der beiden Enzyme Thil und MnmA aus T. maritima zunächst aus Genom-DNA von T. maritima zu amplifizieren und anschließend in den Expressionsvektor pET28a zu klonieren. Die dazugehörigen Aufreinigungsprotokolle konnten etabliert werden. Die erhaltenen Ausbeuten waren mit je ca. 10 mg // Ausgangskultur geringer als bei Thil und MnmA aus E. coli.

Kristallisationsversuche von Thil blieben zunächst erfolglos. Jedoch konnten nach ungefähr 10 Monaten Kristalle gewonnen werden (siehe 3.3), deren Auflösung jedoch mit 7,5 $\AA$ zu gering für eine Strukturbestimmung war. Eine Reproduktion der Kristalle blieb bisher, evtl. auch wegen des langen Inkubationszeitraums zwischen Ansatz und Kristallisation, ohne Ergebnis.

Gleichzeitig war Thil aus T. maritima jedoch zur Komplexformation mit einer artifiziellen, verkürzten tRNA eingesetzt worden, wobei es tatsächlich gelang, Proteinkristalle zu generieren (siehe 3.5).

Von MnmA aus T. maritima wurden bisher keine Proteinkristalle erhalten. 


\subsection{Kristallographische Untersuchungen am Thil-RNA- Komplex}

\subsubsection{Kristallographie}

Wie bereits an früherer Stelle (4.1) dargestellt, wurden von Thil und MnmA aus E. coli keine Proteinkristalle erhalten. Dasselbe galt auch für die Kristallisation von MnmA aus T. maritima. Da bis heute die Kristallisation von Proteinen auf „Versuch und Irrtum“ beruht, ist die Angabe von Gründen für ein Scheitern der Experimente zur Kristallisation von Thil und MnmA aus E. coli und MnmA aus T. maritima unmöglich. Es wurde an anderer Stelle die Vermutung aufgestellt, dass z.B. allein die Verunreinigung von Kristallisationsansätzen durch Luftpartikel Kristallisationskeime liefert, oder, dass die in diesen Staubpartikeln enthaltenen Schwermetalle die Proteinlösung dahingehend modifizieren, dass eine Kristallbildung möglich wird (Lehmann, 2000).

Im Falle von Thil aus T. maritima konnten im Gegensatz zum Thil aus E. coli Kristalle gewonnen werden. Hier ermöglicht der Unterschied in den Aminosäuresequenzen zu spekulieren, ob diesem eine Beteiligung zukommt. Man könnte annehmen, dass der zusätzliche Abschnitt von 96 AS einen Einfluss auf die Interaktion zwischen den Thil-Molekülen hat, der die Annäherung und auch die Bildung eines geordneten Kristallgitters verhinderte. Andererseits bedeutet die relativ geringe Sequenzidentität von ca. $22 \%$ auch, dass in Thil aus T. maritima andere Aminosäuren vorliegen als in Thil aus E. coli. Deshalb könnte man die Vermutung aufstellen, dass eine andere Ladungsverteilung auf der Proteinoberfläche vorliegt, die dann zu den erforderlichen Protein-Protein-Kontakten führte.

Allgemein geht man heute davon aus, dass zum Wachstum von Kristallen in wässriger Lösung die Konzentration eines Proteins in einen Übersättigungsbereich (metastabiler Bereich) gebracht werden muss (vgl. Abb. 83). Dieser Punkt wird durch den Entzug von Lösungsmittel (meist $\mathrm{H}_{2} \mathrm{O}$ ) aus einer Proteinlösung erreicht. Nachdem sich hier kleine Nukleationskeime gebildet haben (vgl. Abb. 83, Punkt A), beginnen diese unter Verringerung der Proteinkonzentration des Systems zu makroskopischen Proteinkristallen 
heranzuwachsen (vgl. Abb. 83, Punkt B). Das Ende des Kristallwachstums beruht in diesem System dann darauf, dass sich entweder ein Gleichgewicht zwischen den Proteinmolekülen in Lösung und den Proteinmolekülen im Kristall ausbildet, oder aber die Oberfläche des Kristalls durch Anlagerung von Kontaminanten (andere Proteine, Puffer) aus der Proteinlösung blockiert wird, was eine weitere Anlagerung von Proteinmolekülen verhindert.

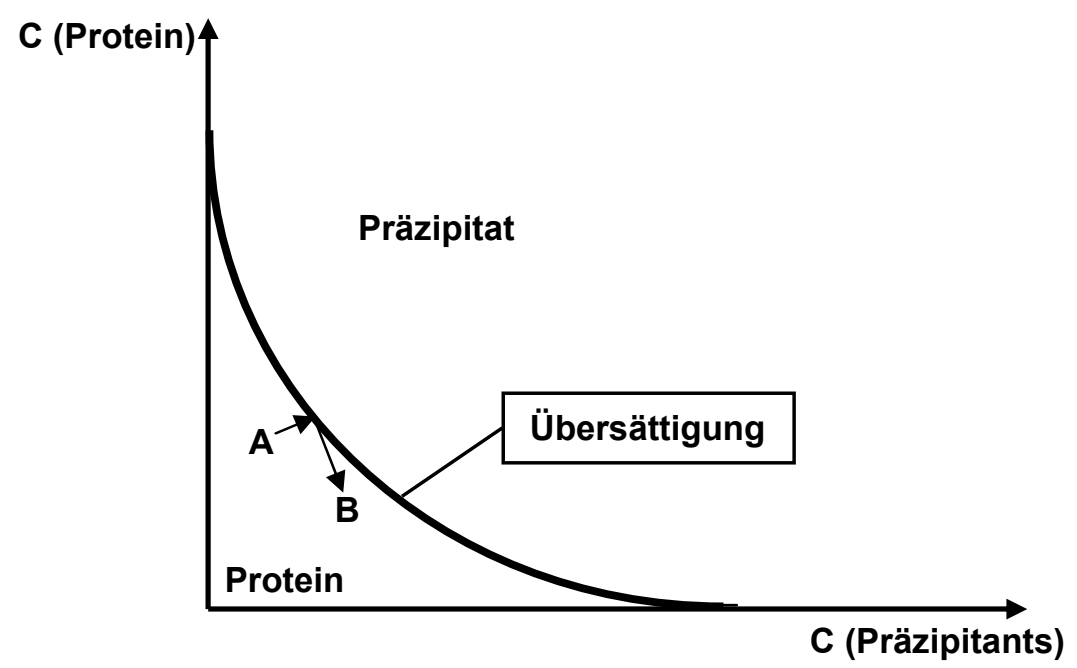

\section{Abb. 83) Phasendiagramm}

Dargestellt sind die verschiedenen Phasen, die in einer Proteinlösung auftreten können. Die Pfeile repräsentieren die Vorgänge während eines erfolgreichen Kristallisationsereignisses $(A \rightarrow B)$.

Diese Vorgänge sind in engen Grenzen durch die Kristallisationsversuchsdurchführung beeinflussbar. So kann z.B. durch Verringerung der Temperatur die Anzahl der Nukleationskeime verringert werden.

Beim Thil-RNA-Komplex wurden zunächst kartoffelähnliche Aggregate (Spheruliten) erhalten (siehe 3.5). Hier führte die eigenständige Reproduktion der Bestandteile der Kristallisationsbedingung (100 mM NaCitrat, pH 4.6 und $2 \mathrm{M} \mathrm{NaFormiat)}$ zu ersten kleinen Kristallen. Es muss also ein Unterschied zwischen dem kommerziell erworbenen Screen und den eigenständig angesetzten Lösungen vorgelegen haben. Da der verwendete Screen im Gegensatz zu den reproduzierten Lösungen nicht "frisch" angesetzt war, könnte man die Vermutung aufstellen, dass der niedrige $\mathrm{pH}$-Wert $(\mathrm{pH} 4.6)$ dazu geführt hat, dass Teile der Formiat-Ionen zu Ameisensäure protoniert wurden. Da Ameisensäure aber flüchtiger ist als Formiationen, könnte die 
Präzipitantskonzentration im kommerziell erworbenen Screen im Laufe der Zeit stark abgenommen haben. In Bezug auf das oben angegebene Phasendiagramm (Abb. 83) bedeutet dies wiederum, dass bei gleichbleibender Proteinkonzentration und sinkender Präzipitantskonzentration der Präzipitationsbereich schneller erreicht wurde. Eventuell hatten die Proteinmoleküle gerade noch ausreichend „Zeit“, um sich zu Spheruliten zusammenzulagern, wobei die braune Farbe der Spheruliten schon einen Hinweis auf präzipitiertes Protein liefert. Unterstützung finden diese Überlegungen dadurch, dass eine Variation der NaFormiatKonzentration $( \pm 0,1 \mathrm{M})$ dazu führte, dass keine Proteinkristalle mehr erhalten wurden (vgl. Tab. 6).

Die Veränderung des Mischverhältnisses zwischen Proteinlösung und Reservoirlösung (1+1 zu 1+2) führte zu größeren Kristallen. Dies erklärt sich in Übereinstimmung mit Abb. 83 dadurch, dass sich durch die stärkere Verdünnung der Proteinlösung der Zeitraum bis zum Erreichen der übersättigten Lösung wesentlich verlängert hat bzw. der Zeitraum zwischen Erreichen des Übersättigungszustandes und Übergang in die Präzipitation des Proteins verlängert wurde. In diesem verlängerten Zeitraum hatte die Lösung genügend Zeit, erste Kristallisationskeime zu erzeugen, die zu Kristallen heranwuchsen (vgl. 3.5). Eine noch stärkere Verdünnung $(1+3)$ führte schließlich - analog zum oben beschriebenen Effekt - zur Bildung einer geringeren Anzahl an Kristallisationskeimen, die dann zu wenigen (1-3 Kristalle, pro Tropfen), großen Kristallen heranwuchsen.

Auch nach einer langen Inkubation der Kristallisationsansätze konnten im Falle des freien Thil aus T. maritima Proteinkristalle gewonnen werden. Aufgrund des langen Inkubationszeitraums (10 Monate) kann aber hier eher davon ausgegangen werden, dass diese Kristalle durch Veränderung des Proteinmoleküls (Oxidation, Proteasen) entstanden. Da diese Kristalle aufgrund des recht langen Inkubationszeitraums bisher nicht reproduziert werden konnten, bleibt dies jedoch rein spekulativ. Auch das sogenannte Feinscreening, bei dem einzelne Parameter variiert wurden, blieb bisher erfolglos, was als Hinweis auf eine zufällig enthaltene Protease (Kontamination durch Luft etc.) gewertet werden kann. 
Wichtig im Falle des Thil-RNA-Komplexes ist die Tatsache, dass eine Komplexierung des Proteins Thil aus T. maritima mit RNA dazu führte, dass im Gegensatz zum freien Protein keine Präzipitation während der Konzentrierung auftrat. Dies deutet darauf hin, dass durch die Komplexbildung die Löslichkeit gesteigert werden konnte.

Wurde jedoch zur Komplexformation eine auf 35 Basen verkürzte RNA verwendet, präzipitierte das gesamte Protein nach kurzer Zeit im Kristallisationsansatz. Da diese RNA-Variation um vier Nukleotide, nämlich die Aminosäurebindungsstelle $5^{\prime}$-CCA-3` und die folgende Base verkürzt worden war, scheint dieser Bereich zur Kristallisation essentiell zu sein. Eventuell beruhen die erhaltenen Kristalle des Thil-RNA-Komplexes nur darauf, dass die zur Kristallisation essentiellen Interaktionen zwischen den Molekülen durch die Aminosäurebindungsstelle ermöglicht wurden. Dies würde eine hohe Flexibilität im Kristall ermöglichen, und könnte so die schlechte Streuung der Kristalle erklären (4.3.3.1).

Andererseits könnte die Komplexierung des Thil aus T. maritima auch dazu geführt haben, dass der Einbau der RNA in das aktive Zentrum des Proteins zu einer Konformationsänderung von Thil geführt hat. Unterstützung erfährt dieser Ansatz vor allem in der Beobachtung, dass das Elutionsvolumen vom Thil-RNA-Komplex im Vergleich zu freiem Thil bei der Gelfiltration von 9,4 ml auf $10,4 \mathrm{ml}$ verschoben wurde. Da die Trennung von Proteingemischen in einer Gelfiltrationssäule auf den Größenunterschieden der einzelnen Proteine inkl. ihrer Hydrathülle (Stokes-Radius) beruht (Röhm, 1998), bedeutet diese Beobachtung, dass Thil mit gebundener RNA kleiner ist als das freie Thil. Dies könnte seine Ursache in einer kompletten oder auch nur teilweisen Konformationsänderung von Thil aus T. maritima haben. 


\subsubsection{Röntgenkristallographische Untersuchungen und FMS}

Die ersten erhaltenen Kristalle des Thil-RNA-Komplexes wiesen eine Auflösung bis ca. 7,5 $\AA$ auf. Die Auflösung konnte durch die Variierung der Cryobedingungen bis auf 3,7 $\AA$ verbessert werden. Die Kristalle konnten der Raumgruppe $\mathrm{P} 2{ }_{1} 2{ }_{1}{ }_{1}$ zugeordnet werden. Die Einheitszelle hatte die Maße $103 \AA$ x $113 \AA$ x $133 \AA$, und es konnte durch die Selbstrotationsfunktion eine hohe Wahrscheinlichkeit für die Anwesenheit von zwei Molekülen pro asymmetrischer Einheit (AU) ermittelt werden (vgl. Selbstrotationsfunktion, 3.7.1). Für den Matthews-Koeffizienten (vgl. Tab. 8) wurden Werte zwischen 6,8 (1 Molekül/AU) und 1,7 (4 Moleküle/AU) bestimmt. Diese hatten einen Lösungsmittelgehalt in der Einheitszelle von $83,3 \%$ bis $26,7 \%$ zur Folge. Die Größe des Moleküls des Thil-RNA-Komplex im Vergleich zur Einheitszelle und dem damit korrelierenden Lösungsmittelgehalt deuten wiederum auf die Anwesenheit von zwei Molekülen in der asymmetrischen Einheit bei einem Lösungsmittelgehalt von 63,3 \% hin. Man kann aber durch diese Erkenntnisse nicht vollständig ausschließen, dass drei Moleküle in der $\mathrm{AU}$ vorlagen, da bei Vorliegen einer kristallographischen Symmetrie zwischen drei Moleküle das gleiche Ergebnis erhalten worden wäre.

Die Verringerung des Wassergehaltes durch das FMS führte zu Kristallen mit einer Auflösung von bis zu 3,1 $\AA$ (siehe 3.8). Hierbei wurde festgestellt, dass die Länge einer Seite der Einheitszelle von $133 \AA$ auf $120 \AA$ verringert wurde.

Ein Ansatz, eine geringe Auflösung eines Kristalls zu erklären, liegt darin, dass die in der Einheitszelle liegenden Moleküle eine hohe Flexibilität aufweisen (Ficner, pers. Mitt.). Bringt man dies in Verbindung mit der Feststellung, dass eine Verringerung des Wassergehaltes mit einer Verringerung der Größe der Einheitszelle korrelierte und dieser Umstand eine Verbesserung der Auflösung mit sich brachte, so liegt der Schluss nahe, dass dies eventuell mit der Reduktion der Flexibilität der Moleküle in der Einheitszelle zusammenhängt. Es sollte also in zukünftigen Experimenten, ein Hauptaugenmerk darauf gelegt werden in diese Richtung zu arbeiten. 


\subsubsection{Phasenbestimmung von Thil-RNA-Komplex-Kristallen}

\subsubsection{Phasierung mit Selenomethionin}

Das Phasenproblem (2.17) sollte zunächst durch ein MAD (multi wavelength anomalous diffraction)-Experiment gelöst werden. Hierzu wurde Selenomethionin in die Kristalle inseriert (2.12.1.3). Für ein MAD-Experiment werden drei verschiedene Datensätze gemessen. Einer nahe des Röntgenstrahlabsorptionsmaximums (peak), an dem das Signal des realen Streufaktors am größten ist, einer an der Kante des Absorptionsspektrums (inflection), wo das Signal des irrealen Streufaktors am größten ist, und einer abseits des Maximums (remote). Vor der Aufnahme des Datensatzes werden diese Punkte durch die Aufnahme eines Fluoreszenzspektrums bestimmt (siehe 3.7.2).

Im Fall von Thil aus T. maritima konnte Selen in Form von Selenomethionin während der Expression in Thil inseriert werden. Eine Prozessierung der Datensätze mit dem Programm Shelx lieferte zwar einen Hinweis auf ein anomales Signal bis $6 \AA$, die weitere Prozessierung (auch unter Verwendung des Programmes Solve) zeigte aber kein zur Phasenbestimmung verwertbares anomales Signal. Die Ursache lag in erster Linie darin, dass von den drei benötigten Datensätzen nur der erste Datensatz (peak) zur Prozessierung zur Verfügung stand. Die übrigen Datensätze konnten nicht aufgenommen werden, da die Kristalle wegen hoher Strahlungssensitivität während der Aufnahme des zweiten Datensatzes zerstört wurden. Zusätzlich zeigte die komplette Analyse des Datensatzes, dass die Auflösung nur bis $5,0 \AA$ verlässliche Daten lieferte (3.7.2). Üblich sind in einem MADExperiment im Allgemeinen Daten mit einer Auflösung <3 A. Zusätzlich besteht das Problem, dass pro Thil-Molekül nur vier Methioninmoleküle (inkl. Start-Methionin) enthalten sind, was bedeutet, dass auch nur vier Selenomethioninmoleküle inseriert werden konnten. Daraus folgt, dass pro $15 \mathrm{kDa}$ des Komplexes ein Selenomethionin als anomaler Streuer zur Signalsuche verfügbar war. Dieser Wert liegt im Vergleich zu dem in der Literatur angegebenen üblichen Richtwert von mindestens einem Selen pro $10 \mathrm{kDa}$ des zu bestimmenden Proteins (Ficner, pers. Mitt.) sehr niedrig. 
Hieraus kann wiederum geschlossen werden, dass ein eventuell aufgetretenes anomales Signal von sehr geringer Intensität war und so im immer vorhandenen Hintergrundrauschen untergegangen ist.

\subsubsection{Phasierung durch Schwermetallsoaks}

Der Versuch, das Phasenproblem schließlich durch sog. Schwermetallsoaks für ein MIR (multi isomorphous replacement)-Experiment zu lösen, blieb ebenfalls erfolglos. Eine Analyse der Harker-Sektionen der Datensätze der verwendeten Schwermetalle zeigt, dass meist nur ein schwaches anomales Signal erhalten wurde. Zwar konnte die Insertion von Platin anhand eines Floureszenzscans nachgewiesen werden (Abb. 80), jedoch konnte nach Datenprozessierung nur ein schwaches anomales Signal detektiert werden. Die Ursache hierzu liegt wohl v.a. darin, dass hier und auch bei den übrigen Schwermetallen keine Bindung an die Proteinmoleküle erfolgte. Die positiven Ergebnisse der Fluoreszenzscans wären in diesem Fall damit zu erklären, dass die Schwermetallionen nur in die Lösungsmittelbereiche (Lösungsmittelkanäle) des Kristalls diffundiert waren. Außerdem könnte es sein, dass die Schwermetallionen ungeordnet über das Molekül verteilt vorlagen, so dass kein einheitliches Signal erhalten wurde.

Ein weiteres, wichtiges Problem war, dass einige Schwermetalle $(\mathrm{Pt}, \mathrm{Xe})$ die Größe der Einheitszelle veränderten. Hierdurch wurde die sog. Isomorphie zwischen nativem Kristall und Schwermetall-enthaltendem Kristall zerstört. Da diese Unterschiede bei der Datenanalyse durch die Programme ebenfalls als Signal gewertet werden, kann das Signal des Schwermetalls im Vergleich zum „nicht-Isomorphie“-Signal untergegangen sein.

Im Falle von Quecksilber, das bevorzugt an Cysteinreste gebunden wird, bestand zusätzlich das Problem, dass bei Thil aus T. maritima nur zwei Cysteine pro Molekül vorliegen, von denen eines im aktiven Zentrum liegt (vgl. Abb. 82). Da aber die Kristallisation von Thil als Substratkomplex erfolgte, war das Cystein im aktiven Zentrum bereits durch die Anwesenheit des RNA-Moleküls blockiert, was einen Zutritt der Quecksilberionen verhinderte. Eventuell verursachte das an das zweite Cystein gebundene Quecksilberion ein zu schwaches Signal. 


\section{$4.4 \quad$ Ausblick}

Der wichtigste Punkt, der in diesem Status des Projektes zu untersuchen wäre, ist der Einfluss von FMS auf Selenomethionin-Thil-RNA-KomplexKristalle. Da bereits ein nativer Datensatz vorliegt und hier die FMS Behandlung von Kristallen zu einer besseren Auflösung geführt hat, ist die Wahrscheinlichkeit sehr hoch, dass bei einer Verbesserung der Auflösung von Selenomethionin-Thil-RNA-Komplex-Kristallen, das bisher bei niedriger Auflösung detektierte schwache anomale Signal auch bei größerer Auflösung gefunden werden kann. Da erst wenige Tests mit dem FMS erfolgt sind und die Variationsmöglichkeiten für die Optimierung von Selenomethionin-ThilRNA-Komplex-Kristalle beim FMS noch großes Potential aufweisen (Kiefersauer, pers. Mitt.), scheint hier die sinnvollste Zukunftsstrategie zu liegen.

Für den Fall, dass diese Versuche nicht zum Erfolg führen, könnte versucht werden, mit dem bisher etablierten Thil-RNA-Komplex nach neuen Kristallisationsbedingungen zu suchen, um eine neue Kristallform zu finden. Vielleicht gibt diese Kristallform eine von Anfang an bessere Auflösung, oder es gelingt durch Variation der „neuen“ Kristallisationsbedingungen, eine bessere Auflösung als die der momentan vorhandenen Kristalle zu erreichen. Weiterhin bleibt auch im Falle des Scheiterns dieser Option die Möglichkeit, die Art der komplexierten RNA zu ändern. Es wäre z.B. interessant, den Einfluss einer Vollängen-tRNA zu untersuchen.

Eine Möglichkeit, um auch die Proteine Thil aus E. coli und MnmA aus E. coli und T. maritima zu kristallisieren, wäre die Co-Kristallisation mit den Enzymen IscS und dessen Ortholog aus T. maritima NifS, die in vivo Schwefel auf Thil und MnmA übertragen. Hier bestünde der große Vorteil darin, dass die Struktur von IscS schon bekannt ist (Cupp-Vickery et al., 2003). Da IscS ca. 44 kDa groß ist, hätte man so ein hervorragendes Suchmodell zur Strukturbestimmung mittels der Methode des „Molekularen Ersatzes“.

Auch ein Umklonieren der Gene der vier Proteine in andere Vektorsysteme wäre eine Möglichkeit, zumal diese Option oft als Alternative bei Kristallisationsproblemen angegeben wird (Hassel, 2005). 
Man könnte aber auch durch die Verwendung eines 2D-Strukturvorhersageprogramms (z.B. SOPMA, www.expasy.ch) untersuchen, wie das jeweilige Proteine Thil (oder MnmA) strukturiert ist (siehe Anhang). Anschließend könnte man Fragmente, deren C- und N-Terminus jeweils mit einem random-coil-Bereich endet (=> stabile Faltung des Proteinfragments), generieren und versuchen, diese verkürzten Fragmente zu kristallisieren und deren Struktur aufzuklären. So könnte man die Bereiche, die eventuell einen Einfluss auf die beobachtete schlechte Streuung der Proteinkristalle hatten, identifizieren und entfernen.

Und auch der Neubeginn unter Verwendung eines anderen Orthologs von Thil wäre eine Alternative (vgl. Orthologe, Anhang). 


\section{Anhang}

\section{a.) Nukleotidsequenz Thil aus E. coli}

ATGAAGTTTATCATTAAATTGTTCCCGGAAATCACCATCAAAAGCCAATCTG TGCGCTTGCGCTTTATAAAAATCCTTACCGGGAACATTCGTAACGTTTTAAA GCACTATGATGAGACGCTCGCTGTCGTCCGCCACTGGGATAACATCGAAG TTCGCGCAAAAGATGAAAACCAGCGTCTGGCTATTCGCGACGCTCTGACC CGTATTCCGGGTATCCACCATATTCTCGAAGTCGAAGACGTGCCGTTTACC GACATGCACGATATTTTCGAGAAAGCGTTGGTTCAGTATCGCGATCAGCTG GAAGGCAAAACCTTCTGCGTACGCGTGAAGCGCCGTGGCAAACATGATTT TAGCTCGATTGATGTGGAACGTTACGTCGGCGGCGGTTTAAATCAGCATAT TGAATCCGCGCGCGTGAAGCTGACCAATCCGGATGTGACTGTCCATCTGG AAGTGGAAGACGATCGTCTCCTGCTGATTAAAGGCCGCTACGAAGGTATT GGCGGTTTCCCGATCGGCACCCAGGAAGATGTGCTGTCGCTCATTTCCGG TGGTTTCGACTCCGGTGTTTCCAGTTATATGTTGATGCGTCGCGGCTGCC GCGTGCATTACTGCTTCTTTAACCTCGGCGGCGCGGCGCATGAAATTGGC GTGCGTCAGGTGGCGCATTATCTGTGGAACCGCTTTGGCAGCTCCCACCG CGTGCGTTTTGTCGCTATTAATTTCGAACCGGTCGTCGGGGAAATTCTCGA GAAAATCGACGACGGTCAGATGGGCGTTATCCTCAAACGTATGATGGTGC GTGCCGCATCTAAAGTGGCTGAACGTTACGGCGTACAGGCGCTGGTCACC GGCGAAGCGCTCGGCCAGGTGTCCAGCCAGACGCTGACCAACCTGCGCC TGATTGATAACGTCTCCGACACGCTGATCCTGCGTCCGCTGATCTCTTACG ACAAAGAGCACATCATCAACCTGGCCCGCCAGATTGGCACCGAAGACTTT GCTCGCACGATGCCGGAATATTGTGGTGTGATCTCCAAAAGCCCGACGGT GAAAGCAGTTAAATCGAAGATTGAAGCGGAAGAAGAGAAGTTCGACTTCA GCATTCTCGATAAAGTGGTTGAGGAAGCGAATAACGTTGATATCCGCGAAA TCGCCCAGCAGACCGAGCAGGAAGTGGTGGAAGTGGAAACCGTCAATGG CTTCGGCCCGAACGACGTGATCCTCGATATCCGTTCTATCGATGAACAGG AAGATAAGCCACTGAAAGTCGAAGGGATTGATGTGGTTTCTCTGCCGTTCT ATAAACTGAGCACCAAATTTGGCGATCTCGACCAGAACAAAACCTGGCTGC TGTGGTGTGAGCGCGGGGTGATGAGCCGTCTGCAGGCGCTCTATCTGCG CGAGCAGGGCTTTAACAATGTGAAGGTATATCGCCCGTAA 


\section{b.) Nukleotidsequenz Thil aus T. maritima}

GTGAAAGAGTTGAGAGTTTACATAGTGAGATATTCCGAGATAGGTCTCAAA GGAAAGAACAGAAAAGATTTTGAAGAAGCTCTTAGAAGAAACATCGAGAGA GTAACCGGAATGAAGGTGAAGAGACAGTGGGGAAGATTTCTCATTCCAAT AGATGAAAACGTAACACTCGATGACAAGCTGAAGAAAATCTTTGGAATTCA AAATTTCAGCAAAGGATTTCTGGTGAGTCACGATTTCGAGGAAGTGAAGAA ATATTCACTGATCGCGGTGAAAGAAAAGCTGGAAAAAGGAAATTACAGAAC TTTCAAGGTGCAGGCCAAAAAGGCCTACAAGGAATACAAAAAAGGTGTGTA CGAAATAAACAGTGAACTCGGTGCTTTGATACTCAAAAACTTCAAGGAACT TTCCGTTGATGTACGCAATCCGGATTTTGTTCTCGGGGTGGAAGTGAGAC CGGAAGGGGTTCTGATTTTCACAGACAGGGTGGAGTGCTACGGTGGACTT CCCGTGGGAACGGGAGGAAAAGCGGTTCTTCTTCTCTCTGGAGGAATAGA CAGTCCTGTGGCAGGCTGGTACGCACTGAAAAGAGGAGTTCTCATAGAGT CCGTCACGTTCGTGTCTCCTCCGTTTACATCGGAGGGGGCCGTGGAAAAA GTGAGAGACATATTGAGAGTTCTCAGGGAATTCAGTGGAGGTCATCCCTT GAGATTGCACATTGTGAATCTCACAAAGCTGCAGCTTGAGGTCAAAAAGAG GGTGCCGGACAAATACTCGCTGATCATGTACAGAAGGTCCATGTTCAGAAT AGCGGAAAAAATAGCAGAGGAAACCGGTGCGGTTGCTTTTTACACGGGAG AGAACATAGGACAGGTGGCGAGCCAGACGCTGGAAAACCTCTGGTCTATA GAGAGCGTGACTACAAGACCCGTGATAAGGCCTCTTTCCGGTTTCGACAA AACAGAGATCGTCGAAAAGGCGAAAGAGATCGGAACCTACGAGATCTCTA TAAAGCCTTACCAGGACAGCTGTGTTTTCTTCGCTCCGAAAAATCCTGCAA CGAGATCTCATCCCTCGATCCTCGAGAAGCTGGAACAGCAGGTTCCAGAT CTTCCCGTTCTCGAAGAAGAAGCGTTCACCTCCAGAAAAGTCGAGGTGAT AGAGTGA 
c.) Nukleotidsequenz MnmA aus E. coli

ATGTCTGAAACCGCAAAAAAAGTAATCGTCGGCATGTCCGGCGGTGTCGA TTCCTCCGTTTCTGCCTGGCTGTTGCAACAACAGGGATATCAGGTCGAAG GCCTGTTTATGAAGAACTGGGAAGAAGACGACGGTGAGGAATATTGCACA GCGGCAGCGGATCTGGCTGATGCCCAGGCTGTCTGCGACAAGCTCGGCA TTGAACTGCACACCGTTAACTTTGCTGCCGAGTACTGGGACAACGTCTTCG AACTGTTCCTTGCCGAATATAAAGCCGGTCGCACGCCGAATCCGGATATTC TGTGCAACAAAGAGATCAAATTTAAAGCCTTCCTCGAATTTGCCGCCGAAG ATTTAGGTGCCGATTATATCGCTACCGGTCATTACGTACGTCGGGCCGATG TCGATGGCAAGAGCCGCCTGCTGCGTGGTCTGGACAGCAATAAAGACCAG AGCTACTTCCTTTATACGCTCAGCCATGAGCAGATTGCGCAAAGCCTGTTC CCGGTCGGCGAACTGGAAAAACCGCAGGTGCGTAAGATTGCTGAAGATCT TGGTCTGGTCACCGCGAAGAAAAAAGACTCTACCGGCATTTGCTTCATTGG CGAACGTAAATTCCGCGAGTTCCTGGGCCGTTATCTCCCGGCGCAACCGG GCAAAATCATTACCGTCGATGGCGATGAAATTGGTGAGCACCAGGGGCTG ATGTATCACACTCTCGGTCAGCGTAAAGGTCTGGGTATCGGTGGCACCAA AGAAGGTACCGAAGAACCGTGGTATGTGGTGGACAAAGACGTCGAAAACA ACATTCTGGTTGTCGCTCAGGGCCATGAACACCCGCGGCTGATGTCTGTC GGGTTGATTGCCCAGCAGTTGCACTGGGTCGATCGCGAACCATTCACCGG CACTATGCGTTGCACGGTAAAAACCCGCTATCGCCAGACCGATATCCCTT GCACCGTCAAGGCGCTGGACGATGATCGCATTGAAGTGATTTTCGATGAA CCGGTTGCCGCCGTGACGCCGGGCCAGTCTGCCGTCTTCTATAACGGTG AAGTGTGCCTCGGTGGCGGTATTATTGAGCAGCGTCTGCCGCTGCCGGTC TGA 


\section{d.) Nukleotidsequenz MnmA aus T. maritima}

TTGAAAGTAGGGGTAGCACTCAGTGGAGGAGTGGACAGTGCGGTAGCTCT CTATCTGTTGCTGAAAGAAGGGCACGAGGTAAAGGCTTTCCACATGAAAAC GAAGGAAGATGAATTCTTCATCAAAAAAGAGATAAAGAAGAAGGTCTGTTG CAGTCCATCGGATACGGCCGACGCGATGAGAATAGCACACTTTCTCGGAG TGGAGATAGAGATCGTCGATGTGAAGGAGATCTTCAGAGAGAAAGTCATC GAACCGTTCAAGAGGGATCTTCTCAAAGGCCTCACTCCGAATCCCTGCGC ACACTGCAATCGTTTCGTGAAATTTGGATACCTCATGGATTACGTTCTCAAC CAGGGATTCGATGCGTTTGCGAGTGGACACTACGCGAGAATAGAGTTCAG CGAAAAGTACGGAAGAAAGGTGATAAAAAAGGGTGTGGATCTGAAGAAAG ATCAGTCGTATTTCCTTGCCAGGATCGAGCCCTGGAGAATAGAAAGACTCA TCTTCCCAAACGGTATCTACACGAAAGAAGAGATCAGAAAAATCGCAGAAG AAGCGGGAATACACGTTGCAAAGAAACAGGAAAGTCAGGATGTGTGCTTC ATACCGGATGGCAGCATCGAAAACTTTTTGAAAGACGAAGGTATAACGCTC AAAGATGGAGATATCATCACACCCGAGGGAGAGGTCGTTGGTCGGCATTT CGGGTATCCTCTCTACACAATCGGTCAGAGGAAGGGCTTCAAAATAGAAAA ATTCGGAAGAAGGTACTACGTGAGGGGCAAGATTCCGGAGAAGAACGTTG TTGTCGTATCAGATCTGGAAGATGTTTTCTTCTCCGGTTTGATCGCAGAAG ATCCCGTCTGGCATGTTGAAGTGCCTGAAGAGTTCAGATGTGTCTGCAGA GTGAGGAAAAAATCGGAAGAAGCTCCTGCAGTTGTCAAGGTGAAAGATAA CGAAGTGGAGGTCAGTTTCGAGAAGAAAGTCTTCGCCGTCACACCGGGTC AGATTGCCGCCTTTTACGATGGAGACACACTCCTTGGAGGAGCGATTATAA AGGAGGGAATACGATGA 


\section{e.) Orthologe von Thil}

\author{
$>$ Mjannaschii \\ > Bsubtilis \\ $>$ Tthermophilus \\ $>$ Ecoli \\ $>$ Mjannaschii \\ >Bsubtilis \\ $>$ Tthermophilus \\ $>$ Ecoli \\ $>$ Mjannaschii \\ $>$ Bsubtilis \\ $>$ Thermophilus \\ $>$ ECOli \\ $>$ Mjannaschii \\ $>$ Bsubtilis \\ $>$ Tthermophilus \\ $>$ Ecoli \\ $>$ Mjannaschii \\ $>$ Bsubtilis \\ $>$ Tthermophilus \\ $>$ Ecoli \\ $>$ Mjannaschii \\ $>$ Bsubtilis \\ $>$ Tthermophilus \\ $>$ ECOli \\ $>$ Mjannaschii \\ $>$ Bsubtilis \\ $>$ Tthermophilus \\ $>$ ECOli \\ $>$ Mjannaschii \\ $>$ Bsubtilis \\ $>$ Tthermophilus \\ $>$ Ecoli \\ $>$ Mjannaschii \\ $>$ Bsubtilis \\ $>$ Tthermophilus \\ $>$ Ecoli
}

\section{Es bedeuten:}

Bsubtilis:

Ecoli:

Mjannaschii:

Tthermophilus:
MKKLKVSKMEILVRYGEIGLKSDPIRKNLEEILRKNI I KLLRKYEIDAEVKILHRKLLVK 60 - - - - MNYDHILIRFGEISTKGK-NRKSFIERLKQNIRLVLKDYPNLKYFSNRD-RMTIT 53 - - - -METLLLVQLFHELALKGK-NRPFFLKRAKAHVRRALKGLGVALEGEWPM-ALLFR 53 - - - - -MKFI I KLFPEITIKSQSVRLRF I KILTGNIRNVLKHYDETLAVVRHWDNIEVR 53

$$
:: \quad * \quad * . \quad * \quad: \quad: \quad:: \quad *: \quad \text { : . }
$$

INTKDKEDLALKLLKKVAGIVSYSPVYECPL-DINEIVSFAVQIMKKKLKTLNKEKVTFA 119 LNGEDPE-ALFPHLKQVFGIQSFSLAIKCDS-RLDDIKATALKAIKDQYKPGD - - - TFK 107 LPEEAWP - EAKARLQDTLGVERFARVHRTPP - DLEALKAALEKALEGQAFG - - - - - SFR 105 AKDENQRLAIRDALTRI PGIHHILEVEDVPFTDMHDIFEKALVQYRDQLEG - - - - KTFC 108

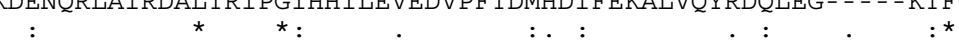

VKTKRSYKKFPFTSVEVNKKVG-EAIVEKLGLEVDLENPDIVLGIEILNDGAYIFTEKYE 178 VATKRAYKOFELDTNOMNAE I GGH I LRNTEGLTVDVRNPDI PLRIEIREEATFLTIRDEK 167 ITAKRSDKAFPLTSPEIERALG-AFVKGKTGAPVRLKGAEREFVVRVLPGAALLEVERHP 164 VRVKRR-GKHDFSS IDVERYVGGGLNQHIESARVKLTNPDVTVHLEVEDDRLLLIKGRYE 167 $:{ }^{\star} * \quad$. $:$ : : : : $\quad{ }^{*}$.

$$
\text { * : . : . . . : }
$$

GIGGLPAGSOGKVLCLISDGIDSPVAAFMMIRRGCRAVLLHLKMSEEALNKVRKIVEVLS 238 GAGGLPVGSAGKAMLMLSGGFDSPVAGFYAMKRGLSVEAVHFFSPPYTSERAKOKVMDLA 227 GPGGLPPGVSGR - VVALSGGIDSPVAAYRLMRRGAEVVLVHFHPFPLLSGASREKAKALA 223 GIGGFPIGTQEDVLSLISGGFDSGVSSYMLMRRGCRVHYCFFNLGGAAHEIGVRQVAHYL 227 ***.* *

DYDTELEFVVYDYKKDIEDIVEKLKSIKKENYTCIFCKRKMLKVAEKYAKYLDCDAIVTG 298 KCLSRFGGSMTLHIVPFTKTQELIQKQIPENYTMTATRRLMLQIADRIREKRNGLAIITG 287 ERLARFQHRLRLHLVPFSEVQRHI IVEAPTAYRVVLYRRYMLRIAEAIAREEGALALCTG 283 WNRFGSSHRVRFVAINFEPVVGEILEKIDDGQMGVILKRMMVRAASKVAERYGVQALVTG 287

DNLGQVASQTLKNLRVISENINYPILRPLIGLDKNDIVKIAKEIGTYEISTEKEIKCPYL 358 ESLGQVASOTLESMYAINAVTSTPILRPLIAMDKTEI IEKSREIGTYETSIOPFEDCCTI 347 DSLGOVASOTLENLHAVNOAATLPVFRPLIGWDKEEIVAEAORIGTYATSILPDEECCTL 343 EALGQVSSQTLTNLRLIDNVSDTLILRPLISYDKEHI INLARQIGTEDFARTMPEYCGVI 347

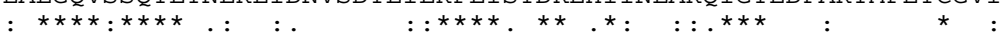

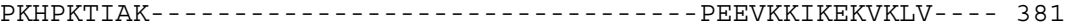
FTTAK-_. FAPKHPVTRARLEVVLETEARLPTEELLALALKEREVLTYTWPGKPLPEEPEGAFIMEHG 403 SKSPTVKAVKSKIEAEEEKFDFSILDKVVEEAN - -NVDIREIAQQTEQEVVEVETVNGFG 405

- - - - - - - - - - - - - - - - - - - - - - - - - - - - - - - - - - - - - - - - - -

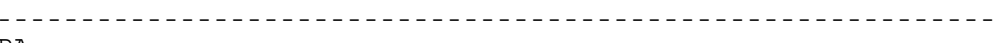

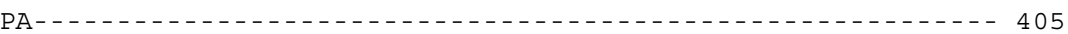
PNDVILDIRSIDEQEDKPLKVEGIDVVSLPFYKLSTKFGDLDQNKTWLLWCERGVMSRLQ 465

-

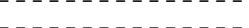

ALYLREQGFNNVKVYRP 482

\section{Der Sequenzvergleich erfolgte mit dem Programm CLUSTALW (www.ebi.ac.uk/clustalw/)}

\author{
Bacillus subtilis \\ Escherichia coli \\ Methanocaldococcus jannaschii \\ Thermus thermophilus
}




\section{f. ) Sekundärstrukturvorhersagen (SOPMA, www.expasy.ch)}

Thil aus E. coli:

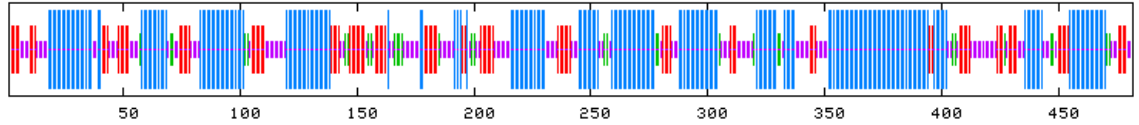

Thil aus T. maritima:

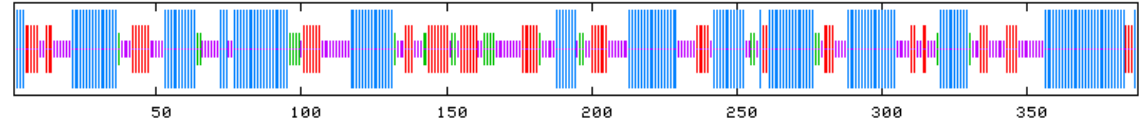

MnmA aus E. coli:

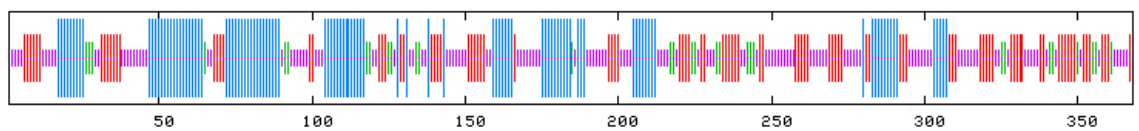

MnmA aus T. maritima:

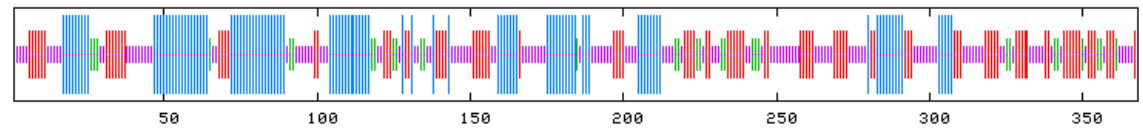

Es bedeuten:

-blau: helix

-rot: sheet

-grün: turn

-violett: coil 
g.) 2D-Struktur von tRNA ${ }^{\text {Phe }}$ aus E. coli und S. cerevisiae
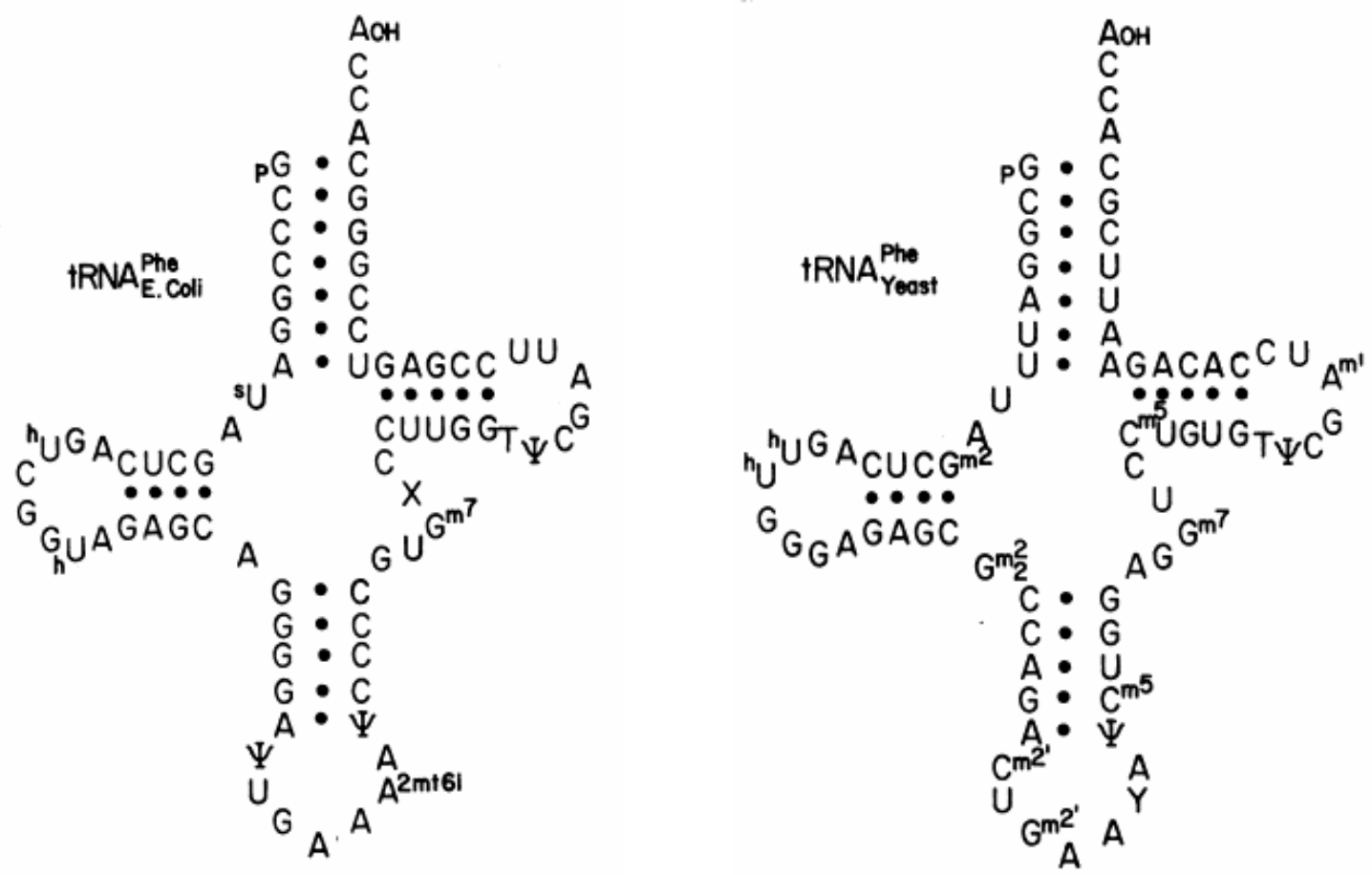


\section{Zusammenfassung}

1.) Die beiden Thiouridin synthetisierenden Enzyme Thil und MnmA aus Escherichia coli wurden exprimiert und bis zur Homogenität aufgereinigt. Im Anschluss wurde erfolglos versucht, unter verschiedenen Kristallisationsbedingungen und Zugabe von Zusätzen (z.B. Substrat) Proteinkristalle zu erhalten.

2.) Die Orthologe von Thil und MnmA aus Thermotoga maritima wurden in E. coli kloniert und Expressions- und Reinigungsprotokolle konnten erfolgreich etabliert werden.

3.) Für das Enzym Thil aus T. maritima konnte ein Protokoll zur Komplexierung mit verkürzter artifizieller tRNA über Gelfiltration etabliert werden. Außerdem wurde eine Färbungskombination zur Visualisierung von RNA und Protein in SDS-Gelen optimiert.

4.) Dieser Komplex von Thil aus T. maritima und verkürzter artifizieller tRNA konnte erfolgreich kristallisiert werden. Die zu Beginn sehr schlechte Auflösung der Kristalle $(7,5 \AA)$ konnte durch umfangreiche Versuche bis auf $3,1 \AA$ gesteigert werden.

5.) Selenomethionin enthaltendes Thil aus T. maritima (Se-Thil) konnte exprimiert werden. Es gelang zwei verschiedene Aufreinigungsprotokolle für unterschiedliche röntgenkristallographische Anforderungen $\mathrm{zu}$ etablieren. Auch hier konnte ein tRNA-Komplex produziert werden, und es gelang diesen erfolgreich zu Kristallisieren.

6.) Die Kristalle des Thil-tRNA-Komplexes und des Se-Thil-tRNA-Komplexes wurden zu kristallographischen Untersuchungen herangezogen. Allerdings war es nicht möglich das Phasenproblem zu lösen, da trotz umfangreicher Experimente kein ausreichendes anomales Signal detektiert werden konnte. 


\section{Literaturverzeichnis}

AGARWAL, K. C., MIECH, R. P., PARKS, R. E. (1987): Guanylate kinases from human erythrocytes, hog brain and rat liver. Methods. Enzymol. 51, 483-490

AGRESTI, J.J., KELLY, B.T., JÄSCHKE, A., GRIFFITH, A.D. (2005): Selection of ribozymes that catalyse multiple-turnover Diels-Alder cycloadditions by using in vitro compartmentalization. PNAS 102, 1617016175

ASHRAF, S.S., SOCHACKA, E., CAIN, R ., GUENTHER, R., MALKIEWICZ, A., AGRIS, P.F. (1999): Single atom modification $(\mathrm{O} \rightarrow \mathrm{S})$ of tRNA confers ribosome binding. RNA 5, 188-194

BAUMANN, U., FISCHER, W., SPRINZL, M. (1985): Analyses of modification-dependent structural alterations in the anticodon loop of Escherichia coli tRNA ${ }^{\text {Arg }}$ and their effects on the translation of MS2 RNA. Eur. J. Biochem. 152, 645-649

BEGLEY, T.P., DOWNS, D.M., EALICK, S.E., MCLAFFERTY, F.W., VAN LOON, A.P.G.M., TAYLOR, S., CAMPOBASSO, N., CHIU, H.J., KINSLAND, C., REDDICK, J.J., XI, J. (1999): Thiamin biosynthesis in prokaryotes. Arch. Microbiol. 171, 293-300

BEIER, H., GRIMM, M. (2001): Misreading of termination codons in eukaryotes by natural nonsense suppressor tRNAs. Nucleic Acids Res. 29, 4767-4782

BEREZOVSKY, I.N., SHAKHNOVICH, E.I. (2005): Physics and evolution of thermophilic adaption. PNAS, 102, 12742-12747 
BEREZOVSKY, I.N., TUMANYAN, V.G., ESIPOVA, N.G. (1997): Representation of amino acid sequences in terms of interaction energy in protein globules. FEBS Lett. 418, 43-46

BERG, P., SINGER, M. (1993): Die Sprache der Gene, Grundlagen der Molekulargenetik. Spektrum Akademischer Verlag $\mathrm{GmbH}$, Heidelberg, Berlin, Oxford

BERGFORS, T. (1990): The Crystallization Lab Manual. 2001er Update, www.shapirolab.org/lab-links/lab-links.html

BJÖRK, G.R., JACOBSSON, K., NILSSON, K., JOHANSSON, M.J.O., BYSTRÖM, A.S., PERSSON, O.P. (2001): A primordial tRNA modification required for the evolution of life? EMBO J. 20, 231-239

BJÖRK, G.R., WIKSTRÖM, P.M., BYSTRÖM, A.S. (1989): Prevention of translational frameshifting by the modified nucleoside 1-methyl-guanosin. Science 244, 986-989

BOHLER, C., NIELSON, P.E., ORGEL, L.E. (1995): Template switching between PNA and RNA oligonucleotides. Nature 17, 548-549

BORCHARD-OTT, W.: Kristallographie, 6. Aufl., Springer Verlag Berlin, Heidelberg, New York, 2002

BRADFORD, M. M. (1976): A rapid and sensitive method for quantitation of microgram quantities of protein utilizing the prinziple of protein-dye binding. Anal. Biochem. 72, 248-254

BREGEON, D., COLOT, V., RADMAN, M., TADDEI, F. (2001): Translational misreading: a tRNA modification counteracts a +2 ribosomal frameshift. Genes Dev. 15, 2295-2306 
BROCK, T.D., MADIGAN, M.T., MARTINKO, J.M., PARKER, J. (2001): Mikrobiologie. Spektrum Akademischer Verlag $\mathrm{GmbH}$, Heidelberg, Berlin

BUCK, A.H., DALBY, A.B., POOLE, A.W., KAZANTSEV, A.V., PACE, N.R. (2005): Protein activation of a ribozyme: the role of bacterial Rnase $P$ protein. EMBO J. 24, 3360-3368

CARRE, D.S., THOMAS, G., FAVRE, A. (1974): Conformation and functioning of tRNAs: cross-linked tRNAs as a substrate for tRNA nucleotidyltransferase and aminoacyl-synthetases. Biochimie 56, 1089-1101

CHABRA, S.R., SHOCKLEY, K.R., WARD, D.E., KELLY, R.M. (2002): Regulation of endo-acting glycosyl hydrolases in the hyperthermophilic bacterium Thermotoga maritima grown on glucan- and mannan-based polysaccharides. Appl. Environ. Microbiol. 68, 545-554

CHEN, J., LI, D.C., ZHANG, Y.Q., ZHOU, Q.X. (2005): Purification and characterization of a thermostable glucoamylase from Chaetomium thermophilum. J. Gen. Appl. Microbiol., 51, 175-181

CUPP-VICKERY, J.R., URBINA, H., VICKERY, L.E. (2003): Crystal Structure of IscS, a Cysteine Desulfurase from Escherichia coli. J. Mol. Biol. 330, 1049-1059

DALLUGE, J.J., HAMAMOTO, T., HORIKOSHI, K., MORITA, R.Y., STETTER, K.O., MCCLOSKEY, J.A. (1997): Posttranscriptional Modification of tRNA in Psychrophilic Bacteria. J. Bacteriol. 179, 1918-1923

DAUTER, Z., BOTOS, I., LARONDE-LEBLANC, N., WLODAWER, A. (2005): Pathological crystallography: case studies of several unusual macromolecular crystals. Acta Cryst. D61, 967-975 
DIOP-FRIMPONG, B., PRAKASH, T.P., RAJEEV, K.G., MANOHARAN, M., EGLI, M. (2005): Stabilizing contributions of sulfur-modified nucleotides: crystal structure of a DNA duplex with 2'-O-[2-(methoxy)ethyl]-2thiothymidines. Nucleic Acid Res. 33, 5297-5307

DUAN, X., HALL, J.A., NIKAIDO, H., QUIOCHO, F.A. (2001): Crystal structures of the maltodextrin/maltose-binding protein complexed with reduced oligosaccharides: flexibility of tertiary structure and ligand binding. J. Mol. Biol., 306, 1115-1126

DURANT, P.C., BAJJI, A.C., SUNDARAM, M., KUMAR, R.K., DAVIS, D.R. (2005): Structural Effects of Hypermodified Nucleosides in the Escherichia coli and Human tRNA ${ }^{\text {Lys }}$ Anticodon Loop: The Effect of Nucleosides $s^{2} U$, $m c m^{5} U, m c m^{5} s^{2} U, m n m^{5} s^{2} U, t^{6} A$ and $m^{2} t^{6} A$. Biochem. 44, 8078-8089

ESBERG, B., EASTWOOD, L.H., TSUI, H.T., BJÖRK, G.R., WINKLER, M.E. (1999): Identification of the miaB Gene, Involved in Methylthiolation of Isopentenylated A37 Derivatives in the tRNA of Salmonella typhimurium and Escherichia coli. J. Bacteriol. 181, 7256-7265

FAVRE, A., MICHELSON, A.M., YANIV, M. (1971): Photochemistry of 4thiouridine in Escherichia coli transfer RNA1 Val. J. Mol. Biol. 58, 367-379

FUJITA, C., NISHIMURA, A., IWAMOTO, R., IKEHARA, K. (2002): Guanosine 5`-diposphate 3`'-diphosphate (ppGpp) Synthetic Activities on Escherichia coli Spo T Domains. Biosci. Biotechnol. Biochem. 66, 1515-1523

GAGNON, P. (1998): Expand Your Processing Options with Hydrophilic Interaction Chromatography. Validated Biosystems Quaterly Resource Guide to Downstream Processing, Autumn 1998. www.validated.com

GARCIA, G.A., KITTENDORF, J.D. (2005): Transglycosylation: A mechanism for RNA modification (and editing?). Bioorg. Chem. 33, 229-251 
GILBERT, W. (1986): The RNA world. Nature 319, 618

GOULOUDIS, C. (2005): Expression, Charakterisierung und Kristallisation der spleißosomalen Proteine SMNrp, U4/U6-60k und U4/U6-90k. Diss. Georg-August-Universität, Göttingen

GRIFFEY, R.H., DAVIS, D.R., YAMAIZUMI, Z., NISHIMURA, S., HAWKINS, B.L., POULTER, C.D. (1986): 15N-labeled tRNA. Identification of 4thiouridine in Escherichia coli tRNASer1 and tRNATyr2 by $1 \mathrm{H}-15 \mathrm{~N}$ twodimensional NMR spectroscopy. J. Biol. Chem. 261, 12074-12078

GRIFFITH, E., HUMPHRIES, J., LEACH, A., SCANLON, L. (1978): Alterations in the tRNAs of Escherichia coli recovered from lethally infected animals. Infect. Immun. 22, 312-317

GRIMM, C., KLEBE, G., FICNER, R., REUTER, K. (2000): Screening orthologues as an important variable in crystallization: preliminary $\mathrm{X}$-ray diffraction studies of the tRNA-modifying enzyme S-adenosyl-methionine: tRNA ribosyl transferase/isomerase. Acta cryst. D56, 484-488

GUERRIER-TAKADA, C., GARDINER, K., MARSH, K., PACE, N., ALTMAN, S. (1983): The RNA moiety of Ribonuclease $P$ is the catalytic subunit of the enzyme. Cell 35, 849-857

HAEBERLI, P., BERGER, I., PALLAN, P.S., EGLI, M. (2005): Syntheses of 4 -thioribonucleosides and thermodynamic stability and crystal structure of RNA oligomers with incorporated 4'-thiocytosine. Nucleic Acids Res. 33, 3965-3975

HAGERVALL, T.G., POMERANTZ, S.C., MCCLOSKEY, J.A. (1998): Reduced misreading of Asparagine Codons by Escherichia coli tRNA ${ }^{\text {Lys }}$ with hypomodified derivatives of 5-Methylaminomethyl-2-thiouridine in the wobble Position. J. Mol. Biol. 284, 33-42 
HAGERVALL, T.G., TUOHY, T.M., ATKINS, J.F., BJÖRK, G.R. (1993): Deficiency of 1-methylguanosine in tRNA of Salmonella typhimurium induces frameshifting by quadruplet translocation. J. Mol. Biol. 232, 756-765

HAKI, G.D., RAKSHIT, S.K. (2003): Developments in industrially important thermostable enzymes: a review. Biores. Technol. 89, 17-34

HECKMAN, J.E., LAMBERT, D., BURKE, J.M. (2005): Photocrosslinking Defects a Compact, Active Structure of the Hammerhead Ribozyme. Biochem. 44, 4148-4156

helM, M., Petermeier, M., GE, B., fiAmmengo, R., JASCHKe, A. (2005): Allosterically activated Diels-Alder catalysis by a ribozyme. J. Am. Chem. Soc. 127, 10492-10493

HENRICH, S. (2004): Röntgenstrukturanalyse der Proproteinkonvertase Furin und der nicht-kollagenen Domäne NC1 von Kollagen IV. Dissertation, Technische Universität, München

HENRICH, S., CAMERON, A., BOURENKOV, G.P., KIEFERSAUER, R., HUBER, R., LINDBERG, I., BODE, W., THAN, M.E. (2003): Crystal structure of the Proprotein Convertase Furin. HASYLAB am DESY, Jahresbericht 2003, Hamburg

HUBER, R., LANGWORTHY, T.A., KÖNIG, H., THOMM, M., WOESE, C.R., SLEYTR, U.B., STETTER, K.O. (1986): Thermotoga maritima sp. Nov. represents a new genus of unique extremely thermophilic eubacteria growing up to $90^{\circ} \mathrm{C}$. Arch. Microbiol. 144, 324-333

HURLEY, J.H., BAASE, W.A., MATTHEWS, B.W. (1992): Design and structural analysis of alternative hydrophobic core packing arrangements in bacteriophage T4 lysozyme. J. Mol. Biol. 224, 1143-1159 
IKEHARA, K. (2002): Origins of gene, genetic code, protein and life: comprehensive view of life systems from a GNC-SNS primitive genetic code hypothesis. J. Biosci. 27, 165-186

ISHITANI, R., NUREKI, O., NAMEKI, N., OKADA, N., NISHIMURA, S., YOKOYAMA, S. (2003): Alternative Tertiary Structure of tRNA for Recognition by a Posttranscriptional Modification Enzyme. Cell. 113, 383-394

JAENICKE, R., BOHM, G. (1998): The stability of proteins in extreme environments. Curr. Opin. Struct. Biol. 8, 738-748

JUERS, D.H., MATTHEWS, B.W. (2004): The role of solvent transport in cryo-annealing of macromolecular crystals. Acta Cryst. D60, 412-421

KALHOR, H.R., PENJWINI, M., CLARKE, S. (2005): A novel methyltransferase required for the formation of the hypermodified nucleoside wybutosine in eucaryotic tRNA. Biochem. Biophys. Res. Comm. 334, 433440

KAMBAMPATI, R., LAUHON, C.T. (1999): IscS is a Sulfurtransferase for the in Vitro Biosynthesis of 4-Thiouridine in Escherichia coli tRNA. Biochem. 38, $16561-16568$

KAMBAMPATI, R., LAUHON, C.T. (2000): Evidence for the Transfer of Sulfane Sulfur from IscS to Thil during in Vitro Biosynthesis of 4-Thiouridine in Escherichia coli tRNA. J. Biol. Chem. 275, 10727-10730

KARRING, H., BJÖRNSSON, A., THIRUP, S., CLARK, B.F.C., KNUDSEN, C.R. (2003): Functional effects of deleting the coiled-coil motif in Escherichia coli elongation factor Ts. Eur. J. Biochem. 270, 4294-4305 
KAWAMURA, K., NAGAHAMA, M., KURANOUE, K. (2005): Chemical evolution of RNA under hydrothermal conditions and the role of amino acids for the prebiotic degradation and formation of RNA. Adv. Space Res., 35, 1226-1233

KIEFERSAUER, R., THAN, M.E., DOBBEK, H., GREMER, L., MELERO, M., STROBL, S., DIAS, J.M., SOULIMANE, T., HUBER, R. (2000): A novel free-mounting system for protein crystals: transformation and improvement of diffraction power by accurately controlled humidity changes. J. Appl. Cryst. 33, $1223-1230$

KIFUSA, M., FUKUHARA, H., HAYASHI, T., KIMURA, M. (2005): ProteinProtein Interactions in the Subunits of Ribonuclease $P$ in the Hyperthermophilic Archaeon Pyrococcus horikoshi OT3. Biosci. Biotechnol. Biochem. 69, 1209-1212

KIM, S.H., QUIGLEY, G.J., SUDDATH, F.L., MCPHERSON, A., SNEDEN, D., KIM, J.J., WEINZIERL, J., RICH, A. (1973): Three-dimensional structure of yeast phenylalanine transfer RNA: folding of the polynucleotide chain. Science, 179, 285-288

KIM, S.H., SUDDATH, F.L., QUIGLEY, G.J., MCPHERSON, A., SUSSMANN, J.L., WANG, A.H., SEEMAN, N.C., RICH, A. (1974): Threedimensional tertiary structure of yeast phenylalanine transfer RNA. Science $185,435-440$

KLUSKENS, L.D., VAN ALEBEEK, G.W.M., WALTHER, J., VORAGEN, A.G.J., DE VOOS, W.M., VAN DER OOST, J. (2005): Characterization and mode of action of an exopolygalacturonase from the hyperthermophilic bacterium Thermotoga maritima. FEBS J., 272, 5464-5473 
KLUSKENS, L.D., VAN ALEBEEK, G.W.M., VORAGEN, A.G.J., DE VOS, W.M., VAN DER OOST, J. (2003): Molecular and biochemical characterisation of the thermo-active family I pectase lyase from the hyperthermophilic bacterium Thermotoga maritima. Biochem. J. 370, 651659

KOOLMAN. J., RÖHM, K.H., (1998): Taschenatlas der Biochemie, (2. Aufl.). Thieme Verlag, Stuttgart, New York

KRUGER, M., PEDERSON, S., HAGERVALL, T. (1998): The modification of the wobble base of tRNA ${ }^{\text {Glu }}$ modulates the translation rate of glutamic acid codons in vivo. J. Mol. Biol. 284, 621-631

KRZYWDA, S., BRZOZOWSKI, A.M., KARATA, K., OGURA, T., WILKINSON, A.J. (2002): Crystallization of the AAA domain of the ATPdependent protease FtsH of Escherichia coli. Acta Cryst. D58, 1066-1067

KUMAR, S., NUSSINOV, R. (2001): How do thermophilic proteins deal with heat? Cell Mol. Life Sci. 58, 1216-1233

LAEMMLI, U.K., (1970): Cleavage of structural proteins during the assembly of the head of bacteriophage T4. Nature 227, 680-685

LAUHON, C.T., (2002): Requirement for IscS in Biosynthesis of All Thionucleosides in Escherichia coli. J. Bacteriol. 184, 6820-6829

LAUHON, C.T., ERWIN, W.M., TON, G.N. (2004): Substrate Specifity for 4Thiouridine Modification in Escherichia coli. J. Biol. Chem. 279, 23022-23029

LAUHON, C.T., KAMBAMPATI, R. (2000): The iscS Gene in Escherichia coli Is Required for the Biosynthesis of 4-Thiouridine, Thiamin, and NAD. J. Biol. Chem. 275, 20096-20103 
LAUHON, C.T., SKOVRAN, E., URBINA, H.G., DOWNS, D.M., VICKERY, L.E. (2004): Substitutions in an Active Site Loop of Escherichia coli IscS Result in Specific Defects in Fe-S Cluster and Thionucleoside Biosynthesis in Vivo. J. Biol. Chem. 279, 19551-19558

LEHMANN, C. (2000): Röntgenstrukturuntersuchungen an GlycopeptidAntibiotika und ihren Komplexen mit Zellwandpeptiden Gram-positiver Bakterien. Dissertation, Georg-August-Universität Göttingen

LEIPUVIENE, R., QUIAN, Q., BJÖRK, G.R. (2004): Formation of Thiolated Nucleosides Present in tRNA from Salmonella enterica serovar Typhimurium Occurs in Two Principally Distinct Pathways. J. Bacteriol. 186, 758-766

LEONARDI, R., ROACH, P.L. (2004): Thiamine Biosynthesis in Escherichia coli: In vitro Reconstitution of the Thiazole Synthase Activity. J. Biol. Chem. 279, 17054-17062

MADORE, E., FLORENTZ, C., GIEGE, R., SEKINE, S., YOKOYAMA, S., LAPOINTE, J. (1999): Effect of modified nucleotides on Escherichia coli tRNA ${ }^{\text {Glu }}$ structure and on its aminoacylation by glutamyl-tRNA synthetase. Eur. J. Biochem. 266, 1128-1135

MAGNUSSON, L.U., FAREWELL, A., NYSTRÖM, T. (2005): ppGpp: a global regulator in Escherichia coli. TRENDS Microbiol. 13, 236-242

MARQUEZ, V., WILSON, D.N., NIERHAUS, K.H. (2002): RNA-Protein Machines. Biochem. Soc. Transact. 30, 133-140

MCPHERSON, A. (2003): Introduction to Macromolecular Crystallography. Wiley-Liss Inc, New Yersey

MIHARA, H., ESAKI, N. (2002): Bacterial cysteine desulfurases: their function and mechanisms. Appl. Microbiol. Biotechnol. 60, 12-23 
MIHARA, H., KATO, S., LACOURCIERE, G.M., STADTMAN, T.C., KENNEDY, R.A.J.D., KURIHARA, T., TOKUMOTO, U., TAKAHASHI, Y., ESAKI, N. (2002): The iscS gene is essential for the biosynthesis of 2selenouridine in tRNA and the selenocysteine containing formate dehydrogenase H. PNAS. 99, 6679-6683

MUELLER, E.G., BUCK, C.J., PALENCHAR, P.M., BARNHART, L.E., PAULSON, J.L. (1998): Identification of a gene involved in the generation of 4-thiouridine in tRNA. Nucleic Acids Res. 26, 2606-2610

MUELLER, E.G., PALENCHAR, P.M., BUCK, C.J. (2001): The Role of the Cysteine Residues of Thil in the Generation of 4-Thiouridine in tRNA. J. Biol. Chem. 276, 33588-33595

NAKANISHI, K., NUREKI, O. (2005): Recent Progress of Structural Biology of tRNA Processing and Modification. Molls. Cells 19, 157-166

NELSON, K.E., CLAYTON, R.A., GILL, S.R., GWINN, M.L., DODSON, R.J., HAFT, D.H., HICKEY, E.K., PETERSON, J.D., NELSON, W.C., KETCHUM, K.A., MCDONALD, L., UTTERBACK, T.R., MALEK, J.A., LINHER, K.D., GARRETT, M.M., STEWART, A.M., COTTON, M.D., PRATT, M.S., PHILLIPS, C.A., RICHARDSON, D., HEIDELBERG, J., SUTTON, G.G., FLEISCHMANN, R.D., EISEN, J.A., WHITE, O., SALZBERG, S.L., SMITH, H.O., VENTER, J.C., FRASER, C.M. (1999): Evidence for the lateral gene transfer between Archaea and Bacteria from genome sequence of Thermotoga maritima. Nature, 399, 323-329

NELSON, K.E., LEVY, M., MILLER, S.L. (2000): Peptide nucleic acids rather than RNA may have been the first genetic molecule. PNAS 97, 3868-3871 
NILSSON, K., LUNDGREN, H.K., HAGERVALL, T.G., BJÖRK, G.R. (2002): The Cysteine Desulfurase IscS Is Required for Synthesis of All Five Thiolated Nucleosides Present in tRNA from Salmonella enterica Serovar Typhimurium. J. Bacteriol. 184, 6830-6835

OPPEZZO, O.J., PIZARRO, R.A. (2003): Inhibition of sulfur incorporation to transfer RNA by ultraviolet-A radiation in Escherichia coli. J. Photochem. Photobiol. B. 71, 69-75

PALENCHAR, P.M., BUCK, C.J., CHENG, H., LARSON, T.J., MUELLER, E.G. (2000): Evidence that Thil an enzyme shared between thiamin and 4thiouridine biosynthesis, may be a sulfurtransferase that proceeds through a persulfide intermediate. J. Biol. Chem. 275, 8283-8286

PIERREL, F., BJÖRK, G.R., FONTECAVE, M., ATTA, M. (2002): Enzymatic Modification in tRNAs, MiaB is an Iron-Sulfur Protein. J. Biol. Chem. 277, 13367-13370

RAMABHADRAN, T.V. (1976): Method for the Isolation of Escherichia coli Relaxed Mutants, utilizing Near-Ultraviolet Irradiation. J. Bacteriol., 3, 15871589

RAMABHADRAN, T.V., FOSSUM, T., JAGGER, J. (1976): Escherichia coli Mutant Lacking 4-Thiouridine in Its Transfer Ribonucleic Acid. J. Bacteriol. 2, 671-672

RAMABHADRAN, T.V., JAGGER, J. (1976): Mechanism of growth delay induced in Escherichia coli by near ultraviolet radiation. Proc. Nat. Acad. Sci. 73, 59-63

REUTER, K., FICNER, R. (1999): Overproduction, purification, crystallization and preliminary $\mathrm{X}$-ray diffraction studies of the human spliceosomal protein U5-15kD. Acta Cryst. D 55, 888-890 
RHODES, G. (2000): Crystallographie Made Crystal Clear. $2^{\text {nd }}$ Edition, Academic press, San Diego

RISSE, B., STEMPFER, G., RUDOLPH, R., MÖLLERING, H., JAENICKE, R. (1992): Stability and reconstitution of pyruvat oxidase from Lactobacillus plantarum: Dissection of the stabilizing effects of coenzyme binding and subunit interaction. Protein Science, 1, 1699-1709

RODNINA, M.V., BERINGER, M., BIELING, P. (2005): Ten remarks on peptide bond formation on the ribosome. Biochem. Soc. Trans., 33, 493-498

RÖHM, K.H., KOOLMANN, J.: Taschenatlas der Biochemie. Thieme Verlag Stuttgart New York, 1998

ROMBY, P., CARBON, P., WESTHOF, E., EHRESMANN, C., EBEL, J.P., EHRESMANN, B., CIEGE, R. (1987): Importance of conserved residues for the conformation of the T-loop in tRNAs. J. Biomol. Struct. Dyn. 5, 669-687

RUAN, B., AHEL, I., AMBROGELLY, A., BECKER, H.D., BUNJUN, S., FENG, L., TUMBULA-HANSEN, D., IBBA, M., KORENCIC, D., KOBAYASHI, H., JACQUIN-BECKER, C., MEJLHEDE, N., MIN, B., RACNIAK, G., RINEHART, J., STATHOPOULOS, C., LI, T., SÖLL, D. (2001): Genomics and the evolution of aminoacyl-tRNA synthesis. Acta Biochim. Pol. 48, 313-321

RYALS, J., HSU, R.Y., LIPSETT, M.N., BREMER, H. (1982): Isolation of Single-Site Escherichia coli Mutants Deficient in Thiamine and 4-Thiouridine Syntheses: Identification of a nuvC Mutant. J. Bacteriol. 151, 899-904

SAKURAI, M., OHTSUKI, T., SUZUKI, T., WATANABE, K. (2005): Unusual usage of wobble modifications in mitochondrial tRNAs of the nematode Ascaris suum. FEBS Letters 579, 2767-2772 
SAMBROOK, J., FRITSCH, E. F., MANIATIS, T. (1989): Molecular cloning: A laboratory manual (2. Aufl.). Cold Spring Harbor Laboratory Press, Cold Spring Harbor, New York, USA

SCHLEGEL, H.G. (1992): Allgemeine Mikrobiologie. 7. überarbeitete Auflage, Thieme Verlag, Stuttgart, New York

SCHRIMPF, G. (2002): Gentechnische Methoden, Eine Sammlung von Arbeitsanleitungen für das molekularbiologische Institut. (3. Aufl.). Spektrum Akademischer Verlag, Heidelberg, Berlin

SCHUMANN, J., BOHM, G., SCHUMACHER, G., RUDOLPH, R., JAENICKE, R. (1993): Stabilization of creatinase from Pseudomonas putida by random mutagenesis. Protein Sci. 2, 1612-1620

SEKOWSKA, A., KUNG, H., DANCHIN, A. (2000): Sulfur Metabolism in Escherichia coli and Related Bacteria: Facts and Fiction. J. Mol. Microbiol. Biotechnol. 2, 145-177

SHIGI, N., SUZUKI, T., TERADA, T., SHIROUZU, M., YOKOYAMA, S., WATANABE, K. (2005): Temperature dependent biosynthesis of 2thioribothymidine. JBC-Paper in Press. Nov. 2005

SKOVRAN, E., DOWNS, D.M. (2000): Metabolic Defects Caused by Mutations in the isc Gene Cluster in Salmonella enterica Serovar Typhimurium: Implications for Thiamine synthesis. J. Bact. 182, 3896-3903

SPRINZL, M., STEEGBORN, C., HÜBEL, F., STEINBERG, S. (1996): Compilation of tRNA sequences and sequences of tRNA genes. Nucleic Acids Res. 24, 68-72

STRYER, L.: Biochemie, Spektrum Akademischer Verlag GmbH, Heidelberg, Berlin. 1999 
TANAKA, T., NAGAI, Y., KIKUCHI, Y. (2005): Substrate Shape Preference of Escherichia coli Ribonuclease $\mathrm{P}$ Ribozyme and Holo Enzyme Using Bottom-Half Part-Shifting Variants of Pre-tRNA. Biosci. Biotechnol. Biochem. 69, 1992-1994

TAYLOR, S.V., KELLEHER, N.L., KINSLAND, C., CHIU, H.J, COSTELLO, C.A., BACKSTROM, A.D., MCLAFFERTY, F.W., BEGLEY, T.P. (1998): Thiamin Biosynthesis in Escherichia coli. Identification of ThiS Thiocarboxylate as the Immediate Sulfur Donor in the Thiazole Formation. J. Biol. Chem. 26, 16555-16560

TERPE, K. (2003): Overview of tag protein fusions: from molecular and biochemical fundamentals to commercial systems. Appl. Microbiol. Biotechnol. 60, 523-533

THOMA, R., SCHWANDER, M., LIEBL, W., KIRSCHNER, K., STERNER, R. (1998): A histidine gene cluster of the hyperthermophile Thermotoga maritima: sequence analysis and evolutionary significance. Extremophiles, 2, 379-389

THOMPSON, M.J., EISENBERG, D. (1999): Transproteomic evidence of a loop-deletion mechanism for enhancing protein thermostability. J. Mol. Biol. 290, 595-604

TUMBULA, D., VOTHKNECHT, U.C., KIM, H., IBBA, M., MIN, B., Li, T., PELASCHIER, J., STATHOPOULOS, C., BECKER, H., SÖLL, D. (1999): Archaeal Aminoacyl-tRNA Synthesis: Diversity Replaces Dogma. Genetics. 152, 1269-1276

URBINA, H.G., CUPP-VICKERY, J.R., VICKERY, L.E. (2002): Preliminary crystallographic analysis of the cysteine desulfurase IscS from Escherichia coli. Acta Cryst. D 58, 1224-1225 
URBONAVICIUS, J., QIAN, Q., DURAND, J.M.B., HAGERVALL, T.G., BJÖRK, G.R. (2001): Improvement of reading frame maintenance is a common function for several tRNA modifications. EMBO J. 20, 4863-4873

VANDER HORN, P.B., BACKSTROM, A.D., STEWART, V., BEGLEY, T.P. (1993): Structural genes for thiamine biosynthetic enzymes (thiCEFGH) in Escherichia coli K-12. J. Bacteriol. 175, 982-992

VETRIANI, C., MAEDER, D.L., TOLLIDAY, N., YIP, K.S., STILLMAN, T.J., BRITTON, K.L., RICE, D.W., KLUMP, H.H., ROBB, F.T. (1998): Protein thermostability above 100degreesC: a key role for ionic interactions. Proc. Natl. Acad. Sci. 95, 12300-12305

WAAS, W.F., CRECY-LAGARD, V., SCHIMMEL, P. (2005): Discovery of a gene family critical to wyosine base formation in a subset of phenylalaninespecific transfer RNAs. J. Biol. Chem. In Press

WANG, L., RUFFNER, D.E. (1997): An ultraviolet crosslink in the hammerhead ribozyme dependent on 2-thiocytidine or 4-thiouridine substitution. Nucleic Acids Res. 25, 4355-4361

WEBB, E., CLAAS, K., DOWNS, D.M. (1997): Characterization of thil, a Gene Involved in Thiazole Biosynthesis in Salmonella typhimurium. J. Bacteriol. 179, 4399-4402

WILKINSON, S.R., BEEN, M.D. (2005): A pseudoknot in the 3'-core region of the glmS ribozyme enhances self-cleavage activity. RNA. 11, 1788-1794

WINKLER, W.C., NAHVI, A., ROTH, A., COLLINS, J.A., BREAKER, R.R. (2004): Control of gene expression by a natural metabolite-responsive ribozyme. Nature. 428, 281-288 
XI, J., KINSLAND, C., MCLAFFERTY, F.W., BEGLEY, T.P. (2001): Biosynthesis of the thiazole moiety of thiamin in Escherichia coli: Identification of an acyldisulfide-linked protein-protein conjugate that is functionally analogous to the ubiquitin/E1 complex. PNAS. 98, 8513-8518

YARIAN, C., MARSZALEK, M., SOCHAKA, E., MALKIEWICZ, A., AGRIS, P.F. (2000): Modified nucleoside dependent Watson-Crick and wobble-codon binding by tRNA ${ }^{\text {Lys }}$ UUU species. Biochemistry. 39, 13390-13395

YARIAN, C., TOWNSEND, H., CZESTKOWSKI, W., SOCHAKA, E., MALKIEWICZ, A.J., GUENTHER, R., MISKIEWICZ, A., AGRIS, P.F. (2002): Accurate Translation of the Genetic Code Depends on tRNA Modified Nucleosides. J. Biol. Chem. 277, 16391-16395

YASUKAWA, T., SUZUKI, T., ISHII, N., OHTA, S., WATANABE, K. (2001): Wobble modification defect in tRNA disturbs codon-anticodon interaction in a mitochondrial disease. EMBO J. 20, 4794-4802 


\section{Publikationen}

Teile der Ergebnisse dieser Arbeit werden bzw. wurden veröffentlicht in:

\section{a.) Fachzeitschriften:}

NAUMANN, P.T., LAUHON, C.T., FICNER, R.: Expression, Purification, Crystallization and Preliminary Crystallographic Studies of the tRNAmodifying sulfurtransferase Thil from Thermotoga maritima bound to a truncated tRNA. In Vorbereitung

NAUMANN, P.T., FICNER, R.: Crystallographic studies on the tRNAmodifying enzyme Thil. Jahresbericht HASYLAB, 2004

NAUMANN, P.T., LAUHON, C.T., FICNER, R.: Thil from Thermotoga maritima: preliminary crystallographic studies of a complex with a truncated tRNA. Jahresbericht HASYLAB 2005, in Vorbereitung

b.) Posterpräsentation:

NAUMANN, P.T., LAUHON, C.T., FICNER, R.: Thil from Thermotoga maritima - Cloning, Expression, Purification and Preliminary Crystallographic studies of a Thil-tRNA-complex.

Posterpräsentation anlässlich der Jahrestagung des VAAM, 2005 


\section{Danksagung}

Herrn Prof. Dr. Ficner danke ich für die Überlassung des interessanten Themas, seinem Interesse am Fortgang der Arbeiten und für die Möglichkeit des freien Arbeitens. Zusätzlich möchte ich mich noch für die Einführung in die Welt der kristallographischen Computerprogramme bedanken.

Herrn PD. Dr. Hoppert danke ich für die Übernahme des Korreferats

Herrn Dr. Dickmanns danke ich für die hilfreichen Tipps bezüglich des experimentellen Arbeitens

Für das nette Arbeitsklima möchte ich mich bei allen ehemaligen und jetzigen Mitarbeitern des MSB bedanken, wobei ich natürlich den Leuten aus „meinem“ Labor: Hr. Dr. Christos Gouloudis, Fr. Dr. Carmen Steinke, Fr. Christina Kiecke, Hr. Winfried Lendeckel und Fr. Annette Berndt (der auch ein Dankeschön für die ersten Aufreinigungen der coli Proteine zusteht) besonders danken möchte.

Ein weiteres Dankeschön geht an Fr. Angela Kopp und Fr. Christina Greulich

Ein besonderer Dank auch für meinen persönlichen Computerbeauftragten $\mathrm{Hr}$. Michael Böhme

Für das Korrekturlesen dieser Arbeit bedanke ich mich bei Hr. Dr. E.A. Dickmanns, Hr. Dr. C. Gouloudis, Fr. Stefanie Nathow und Fr. Dr. C. Steinke.

Und ein Extra-Danke für die vielen nervenaufreibenden Kicker-Schlachten in den letzten 3 Jahren geht an Hr. Dr. Christos Gouloudis

Zu guter Letzt möchte ich auch meiner Familie für die in jeder Hinsicht gewährte Unterstützung während des Studiums und der Promotion danken!

Und natürlich ein Dankeschön an Alle, die ich vergessen habe zu erwähnen war keine Absicht! 


\section{Lebenslauf:}

20. März 1975

August 1981- Juni 1985

August 1985- Juni 1995

Juni 1995

Juli 1995 - April 1996

Oktober 1996

Oktober 1998

Juli 2001

Juli 2001- April 2002

Juli 2002 geboren in Trier

Katholische Grundschule St. Paulin, Trier

Staatliches Gymnasium, Konz

Abitur

Bundeswehr, Fernmelder Daun (Eifel)

Immatrikulation an der Georg-August-Universität Göttingen im Studiengang Biologie

Diplomvorprüfung in den Fächern Mikrobiologie, Botanik, Anorganische Chemie und Physikalische Chemie

Diplomhauptprüfung in den Fächern Mikrobiologie (Hauptfach), Biochemie und Organische Chemie

Experimentelle Diplomarbeit unter Leitung von Prof. Dr. F. Mayer am Institut für Mikrobiologie und Genetik zum Thema: „Optimierung von Methoden zur Immobilisierung von Enzymen an künstlichen Membransystemen“

Beginn der experimentellen Arbeiten zur vorliegenden Dissertation 